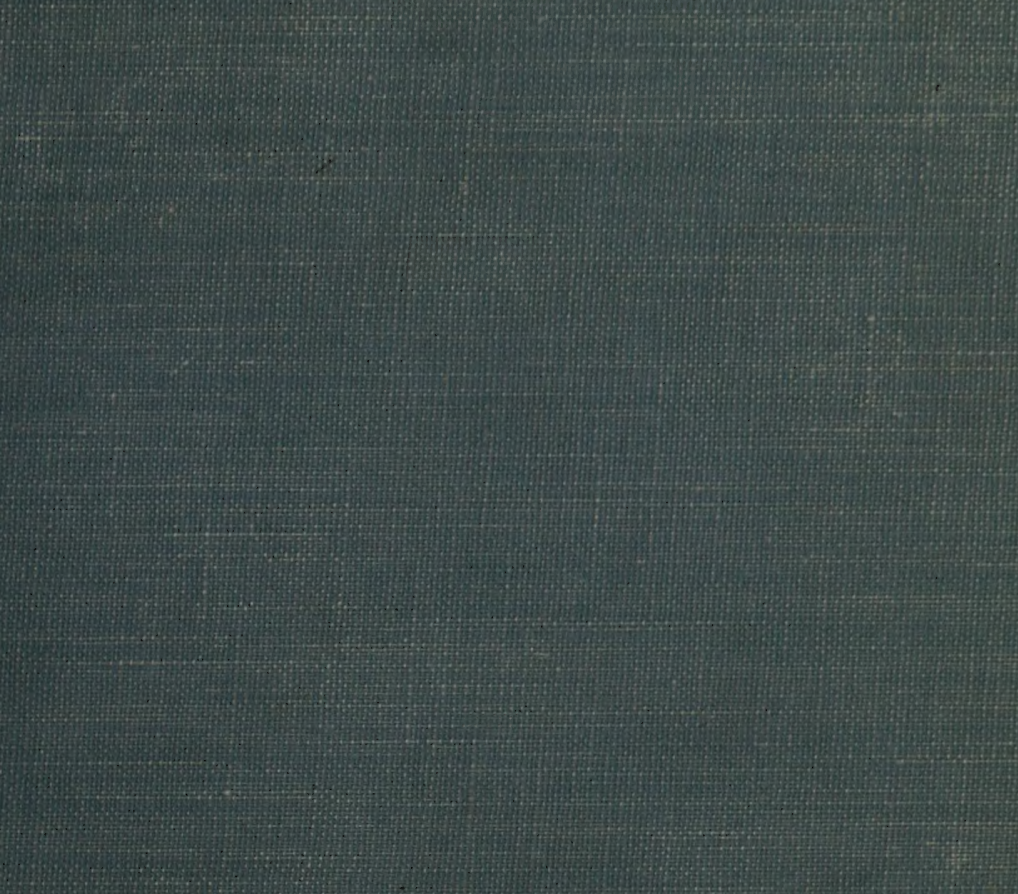





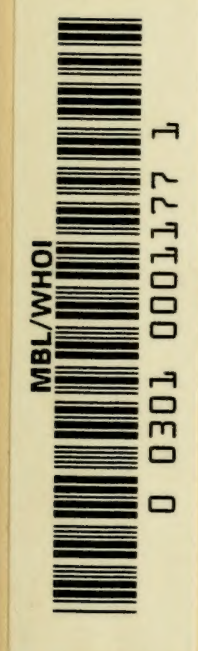



The Page-Barbour Lectures at the University of Virginia (A Complete List for 1907-4I is given on pages 159-6r.)

\section{THE FLOOR OF THE OCEAN}





\section{The}

Floor of the Ocean

New Light on Old Mysteries

\section{BY REGINALD ALDWORTH DALY}

Sturgis Hooper Professor of Geology, Harvard University

THE PAGE-BARBOUR LECTURES AT THE

UNIVERSITY OF VIRGINIA, I94I

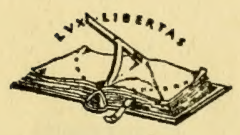

Chapel Hill

THE UNIVERSITY OF NORTH CAROLINA PRESS

I 942 
COPYRIGHT, I942, BY

THE UNIVERSITY OF NORTH CAROLINA PRESS

First printing, November, 1942

Second printing, February, 1945

PRINTED IN THE UNITED STATES OF AMERICA BY

THE SEEMAN PRINTERY, INC., DURHAM, N. C. 


\section{GONTENTS}

CHAPTER I

FOUNDATIONS OF THE GREAT DEEP

PAGE

INTRODUCTION

3

DIMENSIONS OF THE OCEAN

RELIEF OF THE SEA BOTTOM

CONTINENTAL TERRACES

THE GENERAL FLOOR

Bottom Deposits

II

Detection with the Seismograph

I3

Testimony of the Plumb-bob and Gravimeter

23

Some Relevant Facts from Geology

CONCLUSIONS

CHAPTER II

\section{SUBMARINE MOUNTAINS}

INTRODUCTION

THE VOLCANIC MOUNTAINS

Catastrophic Changes of Island Topography

Origin of the Volcanic Heat

The Volcanic Mountain a Test of Crustal Strength 
$\mathrm{Vi}$

CONTENTS

THE MOUNTAIN RANGES

PAGE

East Indian Chain

West Indian Chain

82

CONCLUSIONS

CHAPTER III

CONTINENTAL TERRACES AND SUBMARINE VALLEYS

INTRODUCTION

THE TERRACES

Special Topographic Features

IOI

Condition of the Terrace Sediments

I06

VALLEY SYSTEMS OF THE CONTINENTAL SLOPE

III

Facts of Topography

Origin of the Submarine Valleys

NOTES

INDEX 


\section{LIST OF TABLES}

TABLE

I. Dimensions of Sea, Land, and Earth

PAGE

II. Muray's Classifcation of

III. Average Velocities of Types of Surface Waves 20

IV. Velocities of a Surface-shear Wave along Different Paths 22

V. Dimensions of the Canyons off the Middle Atlantic States 122

VI. Average Longitudinal Gradients of Submarine

Canyons, by Groups

VII. Thickness of Silty Layer, Measured at Four Stations along the Length of Lake Mead (Feet)

\section{LIST OF FIGURES}

FIGURE

I. Map of the Mid-Atlantic Swell

2. Diagrammatic Cross-section of a Continental Terrace

facing 8

3. Photograph of the Piggot "gun"

4. Sliced Cores Brought Up from the Atlantic Floor

5. Diagrammatic Seismogram, Showing Onset of Push, Shake, and Long Waves

6. Seismogram for the Earthquake in Turkey in December, I939 15

7. Diagrammatic Cross-section of the Continental Part of the Earth's Crust

8. Map of the Hawaiian Islands

9. Map Showing Paths of Seismic Waves from a South Atlantic Center of Shock

Io. Map of the Seychelles Plateau

Ir. Admiralty Chart of Ascension Island

12. Diagrammatic Section Illustrating Departure of the Geoid from the Standard Spheroid under Two Circumstances 
I3. Diagram Illustrating the Assumptions on which Calculation of the Bouguer Anomaly of Gravity Is Based

I. . Bouguer and Isostatic Anomalies of Gravity in Certain Regions 30

15. Limits of the Last Ice-cap on Fennoscandia

I6. Outflow of the Fennoscandian Ice from the Center of Accumulation

17. Map Showing Crustal Recoil in Region of Fennoscandia

r8. Lines of Equal Rates of Current Upheaval in Fennoscandia

19. Map of Southern Finland, Illustrating Current Upwarping and also Isobases for a Late-glacial Sea Beach

20. Amount of Upwarp Still Needed to Bring the Earth's Crust of the

Fennoscandian Region into Balance with the Crust Elsewhere $4 \mathrm{I}$

21. Mean Anomalies of Gravity in Three Belts of Finnish Territory 43

22. Stereogram to Illustrate the Earth-shells 46

23. Map of Niaufou Island facing 50

24. Map of Upolu Island, Samoa facing 50

25. Stages in the Reduction of a Volcanic Island to a Shoal at Wave-base

26. Stages in the History of Krakatoa 54

27. Map of Ofu and Olosega Islands, Samoa

28. Night View of Kilauea Lava-lake facing 56

29. A River of Incandescent Hawaiian Lava facing 56

30. Inferred Character of the Earth's Outer Shells at an Older Geological Epoch

3r. The Relation of Substratum to Volcanism 60

32. Free-air Anomalies of Gravity in Oahu Island 63

33. Anomalies of Gravity in Hawaii Island 64

34. Map of Bermuda Island and Surrounding Bank 66

35. Sections Summarizing Logs of Bore-holes in Bermuda Island, Michaelmas Cay, and Heron Island

36. Map of Barrier Reef Around the Truk Islands 68

37. Map of Atolls in the Caroline Group 69

38. Map of Mille or Mulgrave Atoll 70

39. Map of Suva Diva Atoll 7 I

40. Sections Illustrating Flatness of the Floors of Reef Lagoons $\quad 72$ 
4I. Sections Illustrating the Glacial-control Theory of the

PAGE

Living Coral Reefs

42. Long Lagoon inside the Great Barrier Reef of Australia, with

Location of Michaelmas Cay and Heron Island

43. "Drowned" Atolls of the Philippine Archipelago

74

44. Map of the Nero Deep

45. Gravity Anomalies Over and Near the Nero Deep

46. The East Indian "Negative Strip"

47. The West Indian "Negative Strip"

83

48. Section Illustrating the Root Theory of the Strips of

Negative Gravity Anomaly

49. Limestone Beds, Originally Horizontal but Now Upturned and Intensely Crumpled

50. Six Stages in Progressive Deformation of Originally Flat-lying Beds of Rock

5I. Axes of the Asiatic Mountain Chains

52. Axis of the East Indian "Negative Strip"

53. The Java Deep and the Trough inside the Curve of the East Indian "Negative Strip"

54. Present Course of the Lower Mississippi River

55. The Mediterranean Delta of the Rhone River

104

56. Diagrammatic Map to Illustrate Abbe's Theory of the Carolina Cusps

57. Paths of Seismic Waves for the Refraction Method

58. Map Showing Location of Ewing's Southern Section across the Continental Shelf, Eastern United States

59. Ewing's Sections of the Continental Shelf, Eastern United States 109

6o. North-south Section across Louisiana, Showing Location of

Deep Bore-holes

II I

6r. Relation of the Hudson (Shelf) "Channel" to the Hudson (Slope) "Canyon"

62. Location of Canyons and Principal Furrows off the Mid-Atlantic States

63. Hudson Canyon and Vicinity

64. Wilmington Canyon and Vicinity

II 8

65. Washington Canyon and Vicinity 
66. Norfolk Canyon and Vicinity

68. Gullied Slope in California, about 75 feet in height

69. Gullied Slope in California, about 300 feet in height

facing 124

70. Distribution of Submarine Canyons of the World facing 124

7r. Cliff-and-talus Topography of the Grand Canyon

of Arizona

facing 125

72. Sandstorm in Nubia

facing 125

73. Rhone Delta in Lake Geneva

74. Map of Lake Mead

75. Diagram Illustrating the Kuenen Experiment on Silty Currents 149 76. Photograph of the Tank Used in the Kuenen Experiment facing 148 77. Suspension-current Seen from Above: Kuenen Experiment

facing 148

78. Turbulence in Silty Underflow Developed in Kuenen Tank

facing 150

79. Side Views of Density Current in Kuenen Tank facing 150

8o. Closer View of Density Current in Kuenen Tank facing $15 \mathrm{I}$

8r. Georges Bank, Showing Location of Glacial Till and Submarine Canyons

82. Submarine Canyons off California 
THE FLOOR OF THE OCEAN 



\section{FOUNDATIONS OF THE \\ GREAT DEEP}

\section{Introduction}

Whatever his remote ancestors may have been, man is now a land animal. Because he lives off the land, he needs to learn all he can about the rock formations under his feet. Knowledge of this kind guides him to raw materials on which his necessities and comforts largely depend. With living secured, he has time and surplus energy to think-to think more and more intensely about his planetary home. Thus from the demands of practical life and from the philosophical urge has come one of the youngest of the sciences, geology, which in anything like a systematic development did not exist before the nineteenth century.

As a result of regional surveys in detail, supplemented by more rapid studies all across continents, many principles of earth science have been established, even though, as the work goes on, new discoveries are keeping geological philosophy in a state of flux. It is also true that many fundamental questions, including those that must occur to every intelligent traveler, are still elusive for the specialist in geology. For example, a century of research has still left wide gaps in our knowledge about the ultimate cause of mountain-building; about the origin of continents; about the structure and history of the Basement Complex, the oldest and most important visible part 
of each continent; about the reasons why Dead Sea, Caspian Sea, and Death Valley of California are below sealevel, and why mediterranean seas have replaced broad regions of dry land. All these and many other facts may be grouped under a single formula: the earth's body is plastic.

Whence comes this plasticity? The accessible rocks are in general brittle, not plastic. The relative weakness of the terrestrial materials must be, then, at depth; at what depth? To answer this question we must have more and more information about the structure of the earth's body in oceanic areas as well as under the land surfaces. The major mysteries of land geology itself are planetary, and to a large extent their secrets lie hidden under the ocean.

The learning of those secrets will mean a wide extension of the field of knowledge and therewith a new call on human courage. The tax on the will of man is growing as knowledge grows. When the ascertained facts of Nature were comparatively few, even Aristotle had to add boldness to genius in drawing a picture of the universe. Nearly two thousand years later, men were still not disheartened by floods of new discoveries, but wrote "natural philosophies," syntheses of known facts, old and new. Since Newton's time the field of knowledge has spread like an exploding rocket, and perforce science has become compartmented. Yet this involves danger of profound error, because Nature, reality, is not compartmented. In final analysis, the "flower in the crannied wall" is the problem of the universe. This principle of mutual dependence among the sciences is particularly clear to the geologist, whose job is to deduce the structure and history of a whole planet, with due regard to the steadily revised principles of a dozen other sciences. And the geologist has found that in his own field he must cover ground three times more extensive than that where hammer, compass, and foot-work are his traditional 
tools; he must probe the rocky layers on which the ocean rests. His interpretation of the dry lands has taxed his will and skill; all the greater should be courage and technical efficiency as he continues to explore his earth under water.

Only thirty years ago geologists were baffled in the effort to demonstrate the mechanical conditions below the salt-water cover. Since then, however, special methods of diagnosis have been invented and applied. Some of the results are described in the following pages, which attempt to tell the complex story in words perhaps not unbearably technical. First, the composition and thickness of the earth's "crust" under the veiling ocean will be considered. The second chapter will deal with mountain structures now known to feature the sea floor. The third and final chapter will specialize on the sloping, submerged flanks of the plateau-like continents, and on the systems of great valleys shown to make those "continental slopes" rugged in marvellous degree. The investigation of the ocean's bed is still in its initial stage; yet already the gains for science are so spectacular and so full of meaning that even a report of progress can have value. That report will illustrate the dramatic quality of ocean geology, and also the genius of the men who have been using the new methods in a scientific reconnaissance of two thirds of the globe.

A summary of the detective methods and results may well begin with the problem of the rocky structure on which the open, truly deep, ocean rests. Logically that underpinning extends down 4,000 miles, all the way to the earth's center, but we shall see that in general our geological inquiry need reach down no more than 100 miles from the surface. After learning some figures about the size of the watery envelope, we shall review the recent studies on the sub-oceanic part of the solid skin of the earth. A composition in decided contrast with that of the remaining, continental, part will be indicated. 
This difference explains why there is dry land, why human life is possible.

\section{Dimensions of the Ocean}

Man has inherited the earth and he has made good progress in picturing his inheritance. The nineteenth century began adequate charting of ocean depths, and here again the initial stimulus was commercial, practical. The dangers of the deep led national governments, particularly the British, to spend millions in sounding the sea with lead and line. Within the last twenty years instruments ensuring greater accuracy and incomparably greater economy in operation have come into use. Now the true shape of the sea bottom is being disclosed at a rate undreamed of as late as the year 1920.

The improved way of measuring depth is by echo-sounding or sonic sounding. ${ }^{1}$ A resonant blow is struck on the hull of a ship at an accurately determined moment of time. The resulting sound wave speeds to the sea bottom, is there reflected back to the ship. The times of departure and arrival are registered to the hundredth of a second. Knowing the velocity of sound in the water, it is an easy matter to calculate the length of the double journey and ultimately the depth of water. The sonic sounder can be used in a properly equipped steamship, even while plowing its way from port to port. Thus thousands of good readings of depth at as many different points are possible during a single voyage.

No less essential is the fixing of latitude and longitude for each echo-sounding. In deep water, far from land, the older methods of the navigator-observation of sun or star and deadreckoning by $\log$ or revolutions of propeller-are still necessary. In shallower water and to distances up to 200 miles from shore, location of the sounding ship is now being determined by one or more of three methods, bearing the respective names, 
buoy control, taut-wire control, and radio-acoustic ranging. Their description will not be undertaken.

Echo-soundings have shown that, while the older charts of water depth need some corrections, yet these will not greatly change figures for the average depths of the different oceans, already and so expensively obtained by lead and line. See Table I, which gives also mean heights for the continents. It is seen that the mean depth of the ocean is five times the mean height of the continents; and that, in average, the land surface stands nearly three miles above the bottom of the deep sea.

TABLE I

DIMENSIONS OF SEA, LAND, AND EARTH

\begin{tabular}{|c|c|c|c|c|}
\hline & 1 & 2 & 3 & 4 \\
\hline & $\begin{array}{c}\text { Area } \\
\text { (square } \\
\text { miles) }\end{array}$ & $\begin{array}{l}\text { Average } \\
\text { depth } \\
\text { (feet) }\end{array}$ & $\begin{array}{l}\text { Average depth } \\
\text { outside the } \\
\text { continental } \\
\text { terraces (feet) }\end{array}$ & $\begin{array}{c}\text { Average } \\
\text { height } \\
\text { (feet) }\end{array}$ \\
\hline 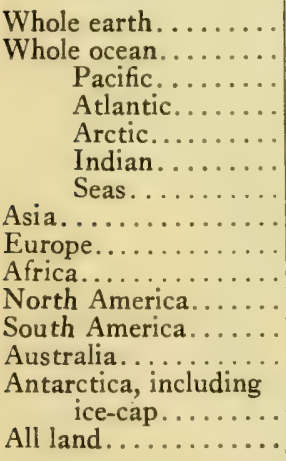 & $\begin{array}{r}197,000,000 \\
140,000,000 \\
64,000,000 \\
32,000,000 \\
5,500,000 \\
28,500,000 \\
10,000,000 \\
17,000,000 \\
3,800,000 \\
11,000,000 \\
9,000,000 \\
6,900,000 \\
4,000,000 \\
5,000,000 \\
57,000,000\end{array}$ & $\begin{array}{r}12,000 \\
14,000 \\
12,900 \\
4,100 \\
12,900 \\
\ldots \ldots \\
\ldots \ldots \\
\ldots \ldots \\
\ldots \ldots \\
\ldots \ldots \\
\ldots \ldots\end{array}$ & $\begin{array}{l}12,500 \\
14,200 \\
13,100 \\
10,000 \\
13,100 \\
\ldots \ldots \\
\cdots \cdots \\
\cdots \cdots \\
\cdots \cdots \\
\cdots \cdots \\
\cdots \cdots\end{array}$ & $\begin{array}{l}\cdots \cdots \\
\cdots \cdots \\
\cdots \cdots \\
\cdots \cdots \\
\cdots \cdots \\
3,150 \\
1,115 \\
2,460 \\
2,360 \\
1,935 \\
1,115 \\
6,000 \\
2,500\end{array}$ \\
\hline
\end{tabular}

Among the greatest depths of water yet found are those at the "deeps" of the western Pacific, with soundings as follows: Nero Deep off Guam Island, at 5269 fathoms or $31,6 \mathrm{r}_{4}$ feet; deep off Mindanao Island, at 5348 fathoms or 32,088 feet; and deep off Japan, at 544I fathoms or 32,646 feet. 
The depths stated in column 2 of Table $I$ are averages for all of each basin, including the areas covered by the submerged flanks of the continents. Such shallow floodings of the continental plateaus are exemplified by Bering Sea, Hudson Bay, North Sea, Baltic Sea, China Sea, the extensive shelf areas of the East Indies, and those off the eastern United States, Yucatan, Brazil, eastern Patagonia, South Africa, and the British Isles. When these and other regions of shallow water are excluded, we get for the average depths of the open oceans the values of column 3 , Table $I$.

Clearly the geologist's contact with the sub-oceanic tables of stone which record earth history must be mental rather than physical. Here controlled imagination must be supreme. Before the beginning of the twentieth century there was plenty of imagination, but there were comparatively few facts of observation to control it. Since that time a good start in the establishment of compelling data has been made. The new discoveries have come from study of the submarine morphology, from sampling of the floor of the ocean, from the geology of islands and continents, and from geophysics.

\section{Relief of the Sea Bottom}

The floor of the ocean is far from being a monotonous, level plain. Oceanographers are impressed with the variety of topographic forms. Thousands of major and minor features have already been charted, and the end is not yet. Here, then, is a long-hidden world, new to science. How to describe it in trenchant, unequivocal words is a problem, analogous to that represented by the map of the Moon. Neither geographer nor selenographer has completed his list of common nouns, names of topographic species; and his list of proper nouns, names of individual reliefs. However, in our oceanic study we shall not 




FIGURE I. MAP OF THE MID-ATLANTIC SIVELL (RÜCKEN), SEPARATING BASINS (BECKEN) TO EAST AND WEST. AFTER G. WÜST. 

need a complete classification of the forms. Those features that are essential to our thinking include, besides the major basins themselves: ( $\mathrm{I}$ ) the continental terrace that flanks each of the larger masses of land; (2) the deep-sea or thalassic island with its great submerged pedestal; (3) the shoal or "bank"; (4) the broad "plateau," rising Iooo fathoms to I500 fathoms above the general sea floor, though in average still rooo fathoms or more below sealevel; (5) the "swell," with the same order of upward projection but arch-shaped and elongated in ground-plan, as illustrated by the Mid-Atlantic Swell (Figure I); (6) the "deep," a long, relatively narrow trough with water depth rooo to 3000 fathoms greater than the ruling depth of the open ocean.

After a rapid flight from the land across the continental terrace, we shall range far and wide over deep water, in the effort to find the nature of the substructure supporting the ocean outside the terrace and between the island pedestals.

\section{Continental Terraces}

Each continent may be regarded as itself a more or less rugged table-land, projecting nearly three miles above the floor of the open ocean. As a rule the surface of the table-land does not fall at a constant rate to this considerable depth. From the shoreline out to distances of Io to I50 miles the descent is gentle. At the oceanward limit of this nearly flat belt, the water has a depth averaging between 300 and 600 feet; to use a technical term, that outer limit lies between the 300 -foot or 50-fathom isobath and the 6oo-foot or roo-fathom isobath. The gently sloping plain is called the continental shelf. See Figure 2. From the outer limit, which is a break of slope, the sea bottom drops more rapidly and all the way to the flatter floor of the deep sea, with gradients reaching as much as $I$ in Io and 


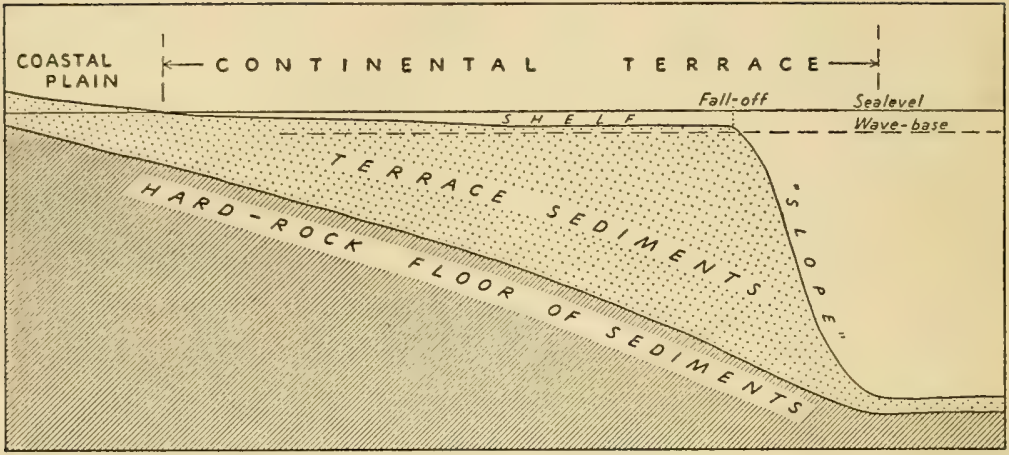

FIGURE 2. DIAGRAMMATIC CROSS-SECTION OF A CONTINENTAL TERRACE.

averaging about $\mathbf{I}$ in $\mathbf{I}$. This second belt, now recognized as the flank of the continent, is called the continental slope. Shelf and slope together make the composite surface of a great threedimensional bench which is conveniently named the continental terrace. Each continent is bordered by its terrace, varying in width along the shores but essentially continuous. The total length of the terraces, the world over, is at least 60,000 miles; their average breadth, measured from shoreline to foot of the continental slope, is roughly roo miles.

Observation shows that the continental terrace is composed of two kinds of material-underlying hard rock and an overlying soft formation. The former represents an offshore belt of the continent where drowned to moderate depth by downwarping or by collapse along steeply inclined fractures or socalled faults. At the seashore one can actually see the surface of the hard-rock continent dip gently under the sandy beach and wave-tossed water. In many cases nubbles or considerable masses of the continental rock reappear in the form of islands or skerries, many miles from shore. Typical examples interrupt the flat floor of the Australian shelf, whose seaward limit is near the line of the Great Barrier Reef, made by corals growing up on the shelf. Here many islands of granite and 
other rock types characteristic of the continent project out of the sand and mud of the wide lagoon inside the Reef.

The cause of the drowning of the hard-rock coastal belt may be obscure, but there is no mystery about the essential origin of the overlying blanket of soft material. All superficial rock of the lands is subject to weathering with disintegration. The resulting solid detritus is washed down by rain and river and ultimately reaches the sea, where waves and currents drag the gravel, sand, and mud outward, far from land. Other such detritus is manufactured by the surf attacking the sea-cliffs, and these other products of erosion, along with countless organic shells and skeletal fragments, are also swept oceanward. The double process has been at work along most of the existing shorelines for millions of years. The result has been the development of huge embankments of sediment. Proof that these deposits are in general unconsolidated or semi-consolidated will be stated in the third chapter.

\section{The General Floor}

We come now to the chief subject of the present chapter -the nature of the terrestrial crust beyond the foot of the continental slope. Its investigation has been advanced by the invention of three new tools: improved sampler of the sea bottom; the so-called seismogram; and a specially designed gravimeter, an instrument that measures the force of gravity from point to point on the surface of the sea.

Bottom Deposits.-Before noting the results of the recent researches, it is worth while to summarize a set of facts won by an older method, using the deep-sea dredge. A large number of oceanographic expeditions, outfitted with the dredge, have disclosed the nature of the first few feet of the bottom sediment. The most comprehensive exploration of the kind was 
made by the British ship "Challenger." Sir John Murray, member of the expedition and editor of the report in many royal-quarto volumes, classified the different kinds of sediment and published a map of their distribution over the world. Murray defined deep-sea deposits as those dredged from depths greater than roo fathoms or 600 feet, and forming two groups. The one group he named "terrigenous," since these represent detritus from lands which are respectively not far distant. The other group, named "pelagic," represents slowly accumulated deposits in deep water, far from any land. Table II gives the subdivisions. ${ }^{2}$

\section{TABLE II}

MURRAY'S CLASSIFICATION OF DEEP-SEA DEPOSITS

Terrigenous Group:

Blue Mud

Red Mud

Green Mud

Volcanic Mud

Coral Mud
Pelagic Group:

Globigerina Ooze

Pteropod Ooze

Diatom Ooze

Red Clay

Radiolarian Ooze

The deep-sea dredge gets its load while being dragged along the bottom. It gives little information as to how the character of the soft deposit varies with depth. To find the nature of this variation we need an instrument based on the principle of the cheese-sampler. If a long steel tube, lowered and kept vertical all the way to the bottom, be forcefully driven into the deposit, a sample, with the original layering intact, can be trapped in the tube and brought to the surface for study. Penetration of the loose sediment is accomplished in either of two ways: by the automatic release of a heavy weight, dropping on the head of the tube like a pile-driver; or by the automatic firing of a "gun" charged with high explosive, the hollow tube being the "bullet." Both methods give valuable results, but here only the "gun" apparatus, invented by Dr. C. S. Piggot, will be illustrated. ${ }^{3}$ 


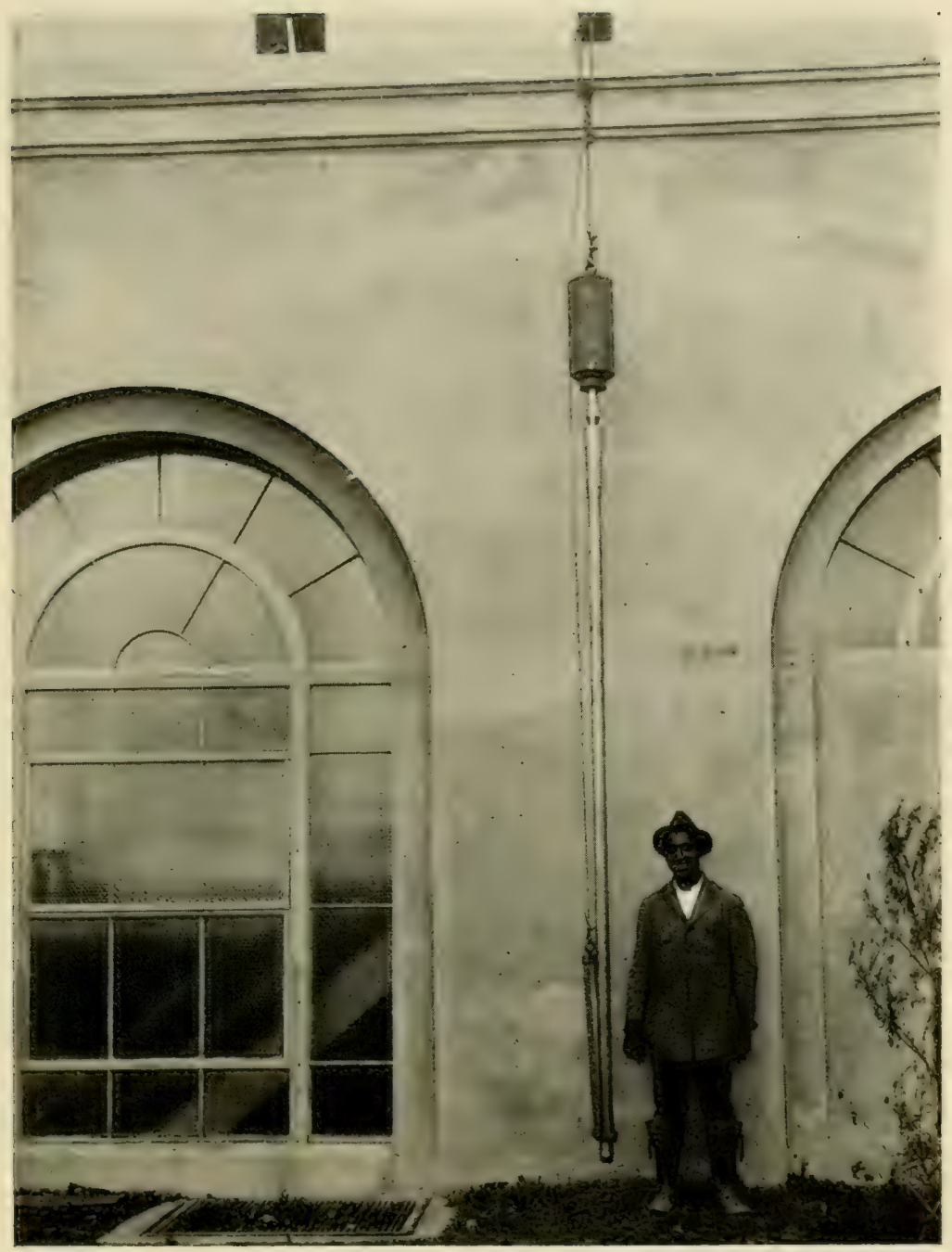

FIGURE 3. PHOTOGRAPH OF THE PIgGot "GUN." 


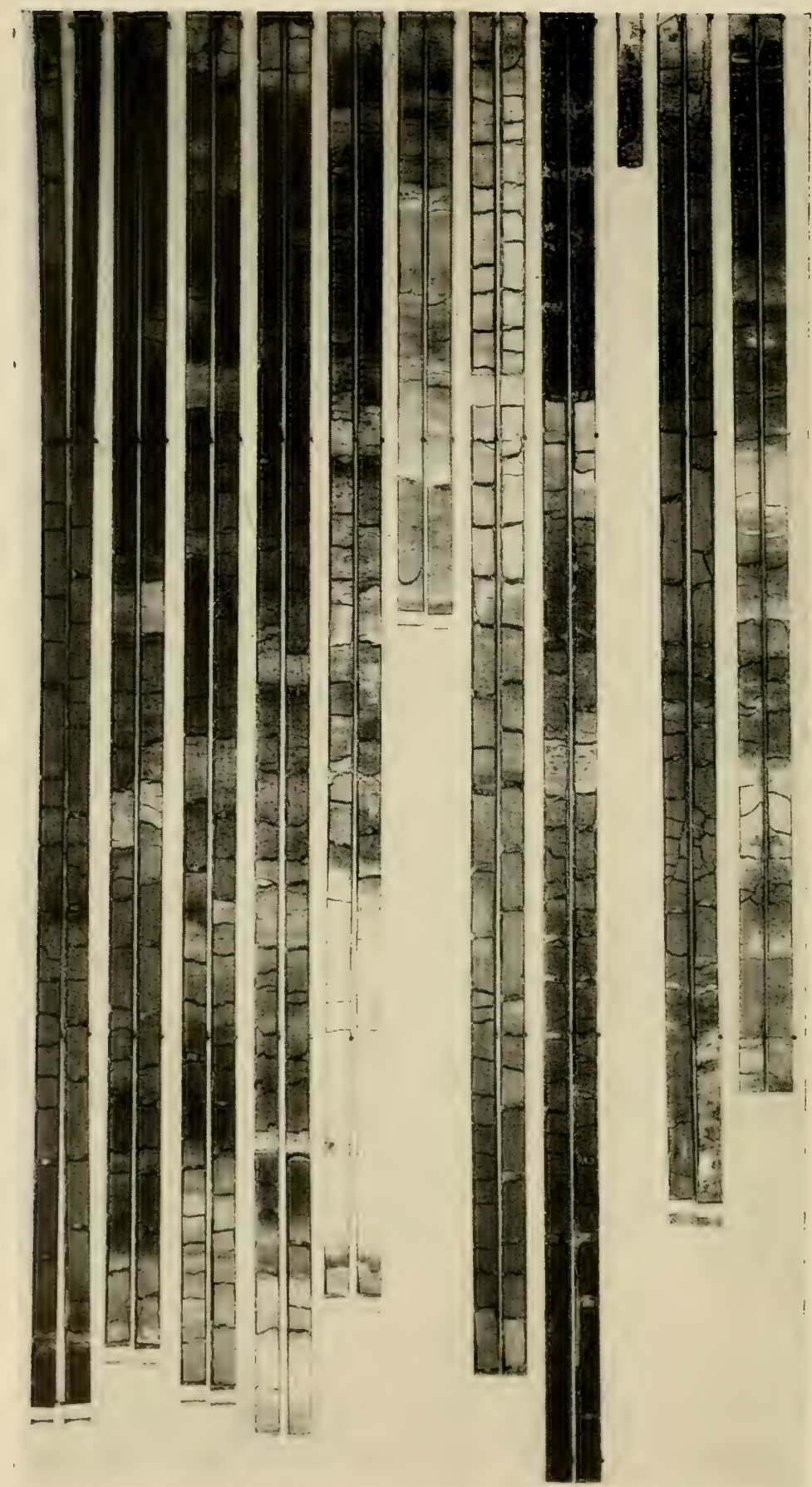

FIGURE 4. SLICED CORES BROUGHT UP FROM THE ATLANTIC FLOOR BY THE PIGGOT SAMPLING APPARATUS. 
Figure 3 is a photograph of the tube with the thicker "gun" at the top. In 1936 Dr. Piggot thus secured samples at points along a complete traverse across the Atlantic, from Newfoundland to Ireland. These core samples were sliced longitudinally and photographed, with the result shown in Figure 4. Careful study of the cores, inch by inch, has already demonstrated that the deep-sea sampler is henceforth to be regarded as a valuable aid in correlating the physical events on the continents with the evolutionary changes of the open ocean.

If the layer of deep-sea ooze and mud could be sampled from top to bottom, it would undoubtedly add much to the historical record of a billion years. It is therefore probable that men of science will not rest until they have penetrated as far as possible into the slowly accumulating sediments. Much more difficult must be a sampling of the hard rock beneath that sedimentary veneer. For information about the deeper material geologists are indebted to geophysical methods of investigation.

Detection with the Seismograph.-The first of two methods to be described depends on a sensitive instrument, the seismograph, which, at hundreds of stations distributed on all continents and some islands, registers the arrival of earthquake waves. The timing of arrival is relative to the "instant" of shock at the center of disturbance. Every world-shaking earthquake sends out different kinds of elastic waves, each with its own time of arrival at any one of the observing stations. From such travel-times valuable data concerning the character of the rocky material all the way to the earth's center have been already secured.

In order to understand this way of detecting that which must remain forever hidden, we shall make a quick analysis of the seismogram, the writing by a seismograph. ${ }^{4}$ For our purpose the essential characteristics of the writing are represented in Figure 5. A seismograph has what may be called a 


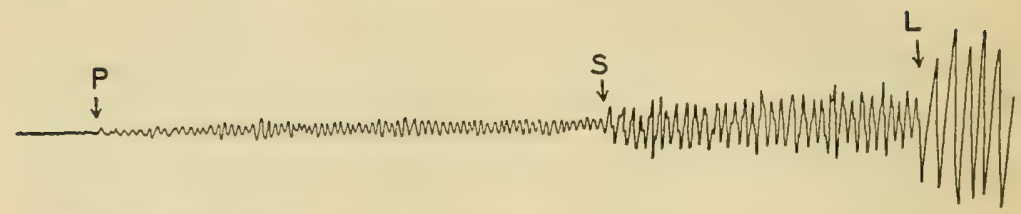

FIGURE 5. DIAGRAMMATIC SEISMOGRAM, SHOWING ONSET OF PUSH (P), SHAKE (s), AND LONG (L) WAVES.

"finger" that traces on paper wavy lines from which the motions of the ground under the recording station can be deduced. These motions indicate the successive passages of several kinds of elastic waves.

The first wave to arrive at a station is a Compressional wave, analogous to that of sound in air. Here the motion of a rock particle is to and fro, in the direction of wave propagation or the wave-ray. Because the displacement of the myriads of particles is in the to-and-fro sense, the first wave is called also the Longitudinal wave. Being propagated by successive compression and dilatation of the rock, it bears still a third name, Push wave. In the diagram of Figure 5 the instant of arrival of the Push wave is marked at the point $P$.

Some time later a second wave makes its appearance; its onset is marked at the point $S$. Now the motion of each rock particle is across the wave-ray or direction of propagation. This wave is accordingly named the Transverse or Shear wave. It is analogous to the wave set up in a carpet when you shake it from one end; hence a third name, Shake wave.

After another delay the seismographic "finger" writes the beginning of yet another kind of motion, caused by the socalled Main waves which occasion the widest swings of the rock particles. The Main waves have periods of swing much longer than the periods of $\mathrm{P}$ and $\mathrm{S}$ waves and are therefore also called Long waves. Their beginning is marked on the diagram at the letter $\mathrm{L}$. As in the case of the other waves, the 
initial Main wave is followed by a train of waves, and these may keep coming to the station for hours, until the planet ceases to tremble.

Figure 6 represents an actual seismogram traced at the Harvard University station when the waves arrived from the

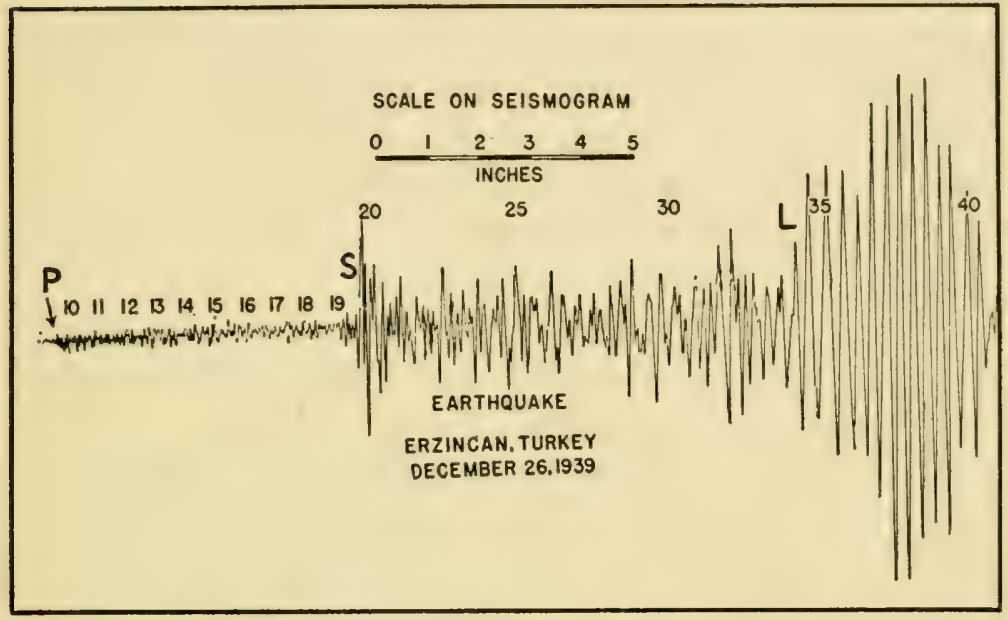

FIGURE 6. SEISMOGRAM OBTAINED BY L. D. LEET FOR THE DESTRUCTIVE EARTHQUAKE IN TURKEY IN DECEMBER, I939.

center of the terribly destructive shock of 1939 in Turkey. The onset of the Push wave is represented by the point P; that of the Shake wave by the point $S$; and that of the Long or Main waves, with large maximum of swinging, by the point $\mathrm{L}$.

The Push and Shake waves, starting at the center of shock, spread out in all directions through the depths of the earth; they are therefore often referred to as Body waves. In contrast, the Main waves are propagated along the rocky surface of the globe and bear another appropriate name, Surface waves. While they are running, the oscillation of rock particles is unimportant at and below a level only a few scores of miles down. 
The Push waves race through every part of the earth and emerge even at the antipodes. On the other hand, the Shake waves are greatly or entirely damped out when they enter the earth's so-called Iron Core, which begins at the depth of about 2900 kilometers or 1800 miles and continues to the center, 4000 miles below sealevel. Incidentally, this apparent failure of the Shake waves to pass entirely through the Iron Core suggests that the Core is fluid, at least in part-fluid in spite of the inconceivable pressure on the material, ranging from $I, 300,000$ atmospheres at its top to more than 3,000,000 atmospheres, or $45,000,000$ pounds to the square inch, at the center of the globe. See Figure 22.

The late Lord Rayleigh showed that, if the earth were everywhere uniform in density and elastic properties, there would be only one kind of Surface wave. Its passage would be accompanied by motion of the rock particles in paths that are partly in the vertical direction and partly horizontal in the direction of propagation. Seismologists have named such a theoretically deduced wave a Rayleigh wave. The earth is not homogeneous, but it has been found that some of the oscillations registered in seismograms are much like those forecast by Rayleigh's mathematical analysis, and are accordingly called pseudo-Rayleigh waves.

And there is a second kind of Surface wave, expected because of proof that the earth is layered and vertically heterogeneous, each layer being in general more incompressible and more rigid than the layer above it. Professor A. E. H. Love of Oxford University asked himself the question: what kind of Surface wave should be set up in such a planet when vibrating under Nature's hammer-blow? His mathematical treatment of the problem showed that, in addition to the pseudo-Rayleigh wave, there must be another type, characterized by motion of the rock particles in the horizontal direction and at right 
angles to the wave-path or direction of propagation. Rhythmical motions of the kind have been demonstrated in the seismograms, so that a class of Love waves or Surface-shear waves is recognized.

For a given earthquake the Push wave, Shake wave, pseudoRayleigh wave, and Love wave have each its own particular velocity, and each of the corresponding travel-times can tell us something about the nature of the sub-oceanic crust of the earth.

Study of the travel-times for Push and Shake waves has already shown that the first fifty miles of the continental part of the crust is in a general way made up of three layers, as shown in the cross-section of Figure 7. The top layer, about io

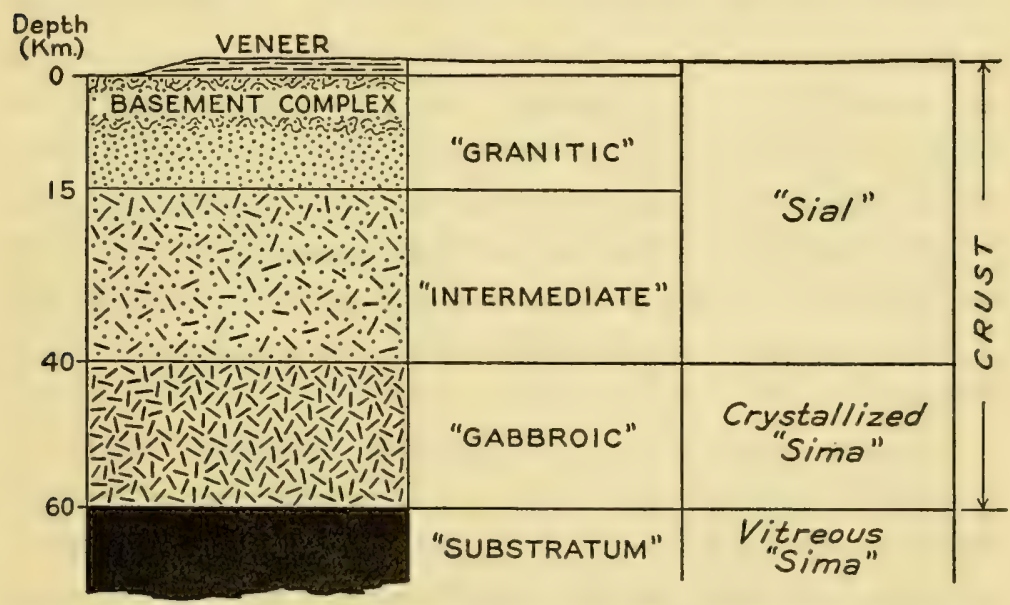

FIGURE 7. DIAGRAMMATIC CROSS-SECTION OF THE CONTINENTAL PART OF THE EARTH'S CRUST, AS INFERRED FROM THE FACTS OF SEISMOLOGY AND GEOLOGY.

miles in thickness, carries the waves at speeds indicating an average composition like that of common granite, and seismologists have adopted the name "granitic layer." Below it a layer, about 15 miles thick, has wave-velocities and elastic 
properties appropriate to rock denser than granite and less dense than solidified basalt, the most fashionable of the world's lavas. A third layer, beginning at the depth of about 25 miles and, according to one estimate, 20 miles or thereabouts in thickness, has wave-velocities and elastic properties appropriate to basalt itself, when solidified under the conditions of high pressure at the depth described. The technical name for thoroughly crystallized, deep-seated basalt is "gabbro," and the third layer may be called the "gabbroic" layer. The second layer, more elastic than granite and less elastic than the gabbroic layer, is generally called the "intermediate" layer of the continental crust.

It is convenient to add to our vocabulary two other technical words. Rocks dominating in the granitic and intermediate layers would yield the chemist relatively large proportions of two oxides, silica and alumina. Hence for such material has come the mnemonic name "sial," with adjectival form "sialic." On the other hand, basalt, whether molten or crystallized, and the gabbroic layer as a whole, and also material still deeper in the earth are all rich in silica and magnesia; all are grouped together as the "sima" of the earth, with adjectival form "simatic."

Proof of the layering under the continents has been made possible by the establishment of seismographic stations at many points on the land. As yet a similar adequate network of stations has not been placed in any oceanic area. Particularly valuable would be chains of stations, located on rows of islands like the Hawaiian group and so strung out for a distance of at least a thousand miles (Figure 8). Without such establishment a satisfying diagnosis of the sea floor through study of the Push and Shake waves is impossible. Yet it is significant that a single station, situated at Apia on Upolu Island of Samoa (Figure 24), has already furnished a clue. There Dr. G. Angenheister 


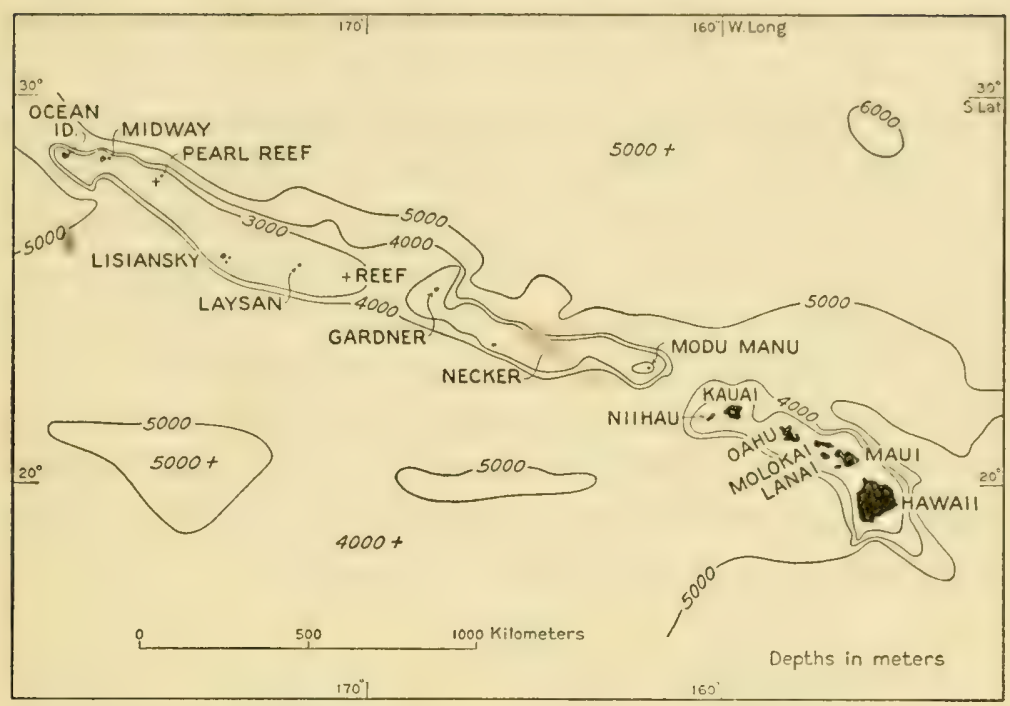

FIGURE 8. MAP OF THE HAWAIIAN ISLANDS. DEPTHS IN METERS.

concluded, from the travel-times of Push waves, that the upper part of the sub-Pacific crust, surrounding the lofty volcanic pile on which his seismograph rested, has the elastic properties of gabbro or solidified basalt. The granitic layer is thought to be entirely absent, and the reported wave-velocities seem too high to permit us to assume that even the intermediate layer of the continents is represented.

Much more comprehensive study of the Surface or Long waves has demonstrated strong contrast between the suboceanic and continental segments of the earth's crust. In this alternative mode of detection both pseudo-Rayleigh and Love waves are employed. Each of the two kinds is propagated at a velocity depending on the elastic properties of the relatively superficial rock of the earth's body. The result of the double investigation is proof that the sub-oceanic part of the crust is more elastic than the continental part, as if the average rock between the bottom mud and depth of fifty miles is crystallized 
basalt or gabbro. A glance at some details of the investigation is warranted.

From a large number of seismograms Dr. B. Gutenberg and Dr. C. F. Richter measured the velocities of Love or Surfaceshear waves with periods of 22 to 25 seconds. ${ }^{5}$ The average velocities for different kinds of wave-paths are given in the second vertical column of figures in Table III. The same two seismologists made a similar set of measurements for the pseudo-Rayleigh waves, with periods ranging from $\mathrm{I} 7$ to 23 seconds. The average velocities for these waves, as they rush along differing kinds of wave-paths are given in the last column of the table, as so many kilometers per second.

\section{TABLE III}

AVERAGE VELOCITIES OF TYPES OF SURFACE WAVES

\begin{tabular}{|c|c|c|c|c|}
\hline \multirow[b]{2}{*}{ Region traversed } & \multicolumn{2}{|c|}{$\begin{array}{l}\text { Surface-shear waves } \\
\text { (periods } 22-25 \text { secs) }\end{array}$} & \multicolumn{2}{|c|}{$\begin{array}{l}\text { Pseudo-Rayleigh waves } \\
\text { (periods } 17-23 \text { secs) }\end{array}$} \\
\hline & $\begin{array}{c}1 \\
\text { Number of } \\
\text { traverses }\end{array}$ & $\begin{array}{c}2 \\
\text { Velocity } \\
(\mathrm{km} / \mathrm{sec})\end{array}$ & $\begin{array}{c}3 \\
\text { Number of } \\
\text { traverses }\end{array}$ & $\begin{array}{c}4 \\
\text { Velocity } \\
(\mathrm{km} / \mathrm{sec})\end{array}$ \\
\hline $\begin{array}{l}\text { Atlantic Ocean......... } \\
\text { Indian Ocean......... } \\
\text { Pacific Ocean except }\end{array}$ & $\begin{array}{l}4 \\
2\end{array}$ & $\begin{array}{l}4.25 \\
4.20\end{array}$ & $\begin{array}{l}3 \\
3\end{array}$ & $\begin{array}{l}3.60 \\
3.97\end{array}$ \\
\hline $\begin{array}{r}\text { western part ........ } \\
\text { Western part of Pacific }\end{array}$ & 19 & 4.32 & 11 & 3.77 \\
\hline 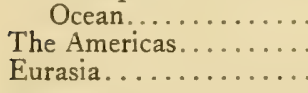 & $\begin{array}{r}5 \\
32 \\
10\end{array}$ & $\begin{array}{l}3.57 \\
3.63 \\
3.33\end{array}$ & $\begin{array}{l}4 \\
5 \\
5\end{array}$ & $\begin{array}{l}3.45 \\
3.24 \\
2.92\end{array}$ \\
\hline Continents. . . . . . . & 42 & 3.55 & 10 & 3.08 \\
\hline Pacific................ & 25 & 4.30 & 17 & 3.78 \\
\hline
\end{tabular}

It will be observed: first, that each type of surface wave runs faster across the ocean-covered sectors of the earth than across the continental sectors; second, that each type runs somewhat more slowly across the southwestern Pacific than across the rest of the Pacific region; and, third, that the pseudo-Rayleigh 
waves run somewhat more slowly across the Atlantic than across the other two oceans.

Now the velocities of each type of wave depend largely on the nature of the rock constituting the outer fifty miles of the solid earth. The table of values shows, therefore, that the suboceanic crust is more elastic than the continental part of the crust. The actual velocities suggest, in fact, that the granitic layer and perhaps also the intermediate layer of the continents are lacking under most of the Pacific and Indian oceans. It looks as if there the crust has the properties of solidified basalt. On the other hand, the slightly smaller velocities of the waves traversing the Atlantic indicate the existence of some lighter and less elastic rock just beneath the Atlantic ooze, though there is no proof that such rock forms a continuous layer all across that oceanic region.

Recently Mr. J. T. Wilson analyzed the seismograms made at seventeen stations for a world-shaking earthquake that centered at the small circle drawn in the southern part of the map of Figure 9. ${ }^{6}$ From that center of shock a Love wave with a period of 32 seconds ran along great circles around the globe, these paths being indicated by smooth, curved lines that terminate at the corresponding named stations. The velocities of the wave, deduced by Wilson, are stated in the first six rows of the last column of Table IV. The first three paths were purely oceanic; the other three paths were "mixed," that is, partly (6o per cent) across ocean basin and partly (40 per cent) across continent. For comparison Gutenberg's velocities of the same type of Love wave, where traversing continent alone, are given in two rows at the bottom of the last column. We see this Surface wave to be faster under the ocean than in the continental traverse. Accordingly we are not surprised to find intermediate values for the velocities along the "mixed" paths. The conclusions to be drawn regarding crustal composition are 


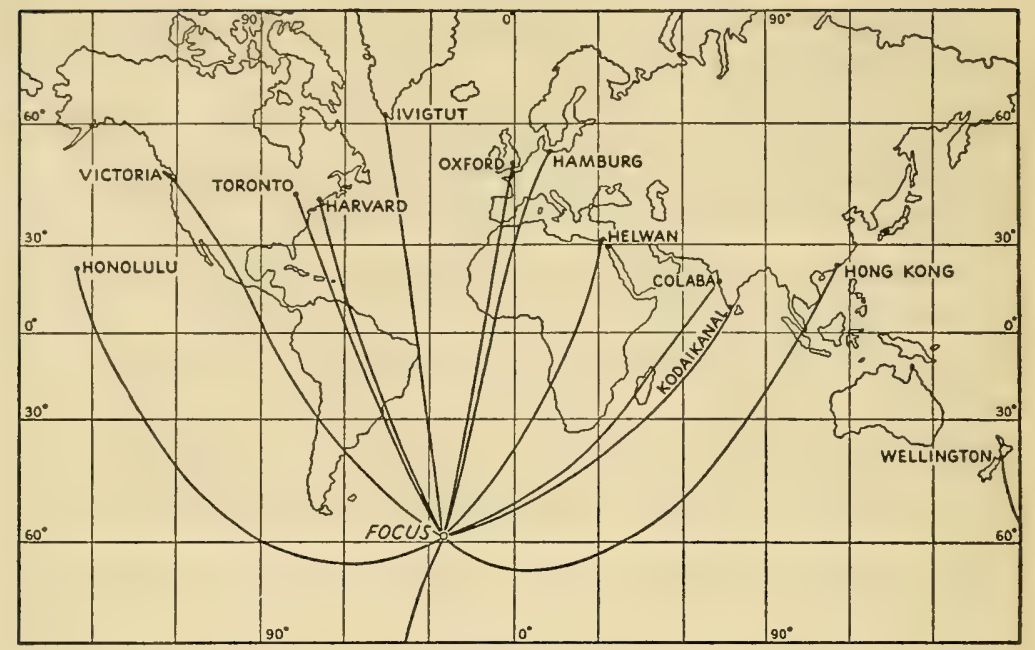

FIGURE 9. WORLD MAP ON MERCATOR PROJECTION, SHOWING PATHS OF SEISMIC WAVES FROM A SOUTH ATLANTIC CENTER OF SHOCK. AFTER J. T. WILSON.

like those derived from the work of Gutenberg and Richter, with the exception that Wilson found no evidence of any great difference between the average rock under the Pacific ooze and the average rock beneath the Atlantic ooze. There is also confirmation of the opinion that granitic rock of notable thickness

TABLE IV

VELOCITIES OF A SURFACE-SHEAR WAVE ALONG DIFFERENT PATHS

\begin{tabular}{|c|c|c|c|}
\hline & $\begin{array}{l}\text { Per cent of } \\
\text { path con- } \\
\text { tinental }\end{array}$ & $\begin{array}{l}\text { Recording } \\
\text { station }\end{array}$ & $\begin{array}{l}\text { Velocity } \\
(\mathrm{km} / \mathrm{sec})\end{array}$ \\
\hline 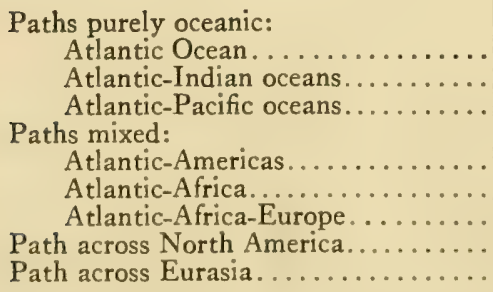 & $\begin{array}{r}0 \\
0 \\
0 \\
40 \\
40 \\
40 \\
100 \\
100\end{array}$ & $\begin{array}{l}\text { Ivigtut } \\
\text { Colaba } \\
\text { Honolulu } \\
\text { Toronto } \\
\text { Helwan } \\
\text { Stonyhurst } \\
\ldots \ldots \\
\ldots \ldots\end{array}$ & $\begin{array}{l}4.35 \\
4.25 \\
4.40 \\
\\
4.05 \\
4.05 \\
4.00 \\
3.70 \\
3.53\end{array}$ \\
\hline
\end{tabular}


cannot be continuous under the Atlantic. Further, the wavevelocity in the oceanic sectors of the earth is so high that one may well question the existence there of a continuous layer of the rock type that makes up the "intermediate" layer of the continental crust.

Nevertheless, it is clear from geological observations that granite and other sorts of continental rock do constitute patches on the Atlantic floor as well as on the floor of the northwestern part of the Indian Ocean and on the floor of the southwest Pacific. In each of these three regions small islands are seen to include typical continental rocks, and each emergent mass must be continued out on the ocean floor for some distance. Examples are: the Azores of the Atlantic; Fiji, Tonga, and many other islands of the southwest Pacific; and the Seychelles Islands on the Seychelles Plateau of the Indian basin (Figure I0). Additional evidence is furnished by the granitic fragments ejected from explosive volcanoes that rise from the MidAtlantic Swell. One of these is Ascension Island. Its map, copied from an Admiralty chart, is given in Figure II. It was the youthful Charles Darwin who first collected the granitic bombs on the huge basaltic cone of Ascension and so proved the surprising fact that rock of the continental type underlies the deep Atlantic, halfway between Africa and South America. It is, indeed, probable that the 7000-mile Mid-Atlantic Swell projects somewhat above the general floor of this ocean because the Swell is a greatly elongated patch of continental rock resting on a basaltic crust.

In the next chapter, dealing with the oceanic islands, we shall find another reason for thinking that the crust under the greater part of the deep sea is essentially of basaltic composition.

Testimony of the Plumb-bob and Gravimeter.-Having seen how the rushing earthquake waves furnish data about the 


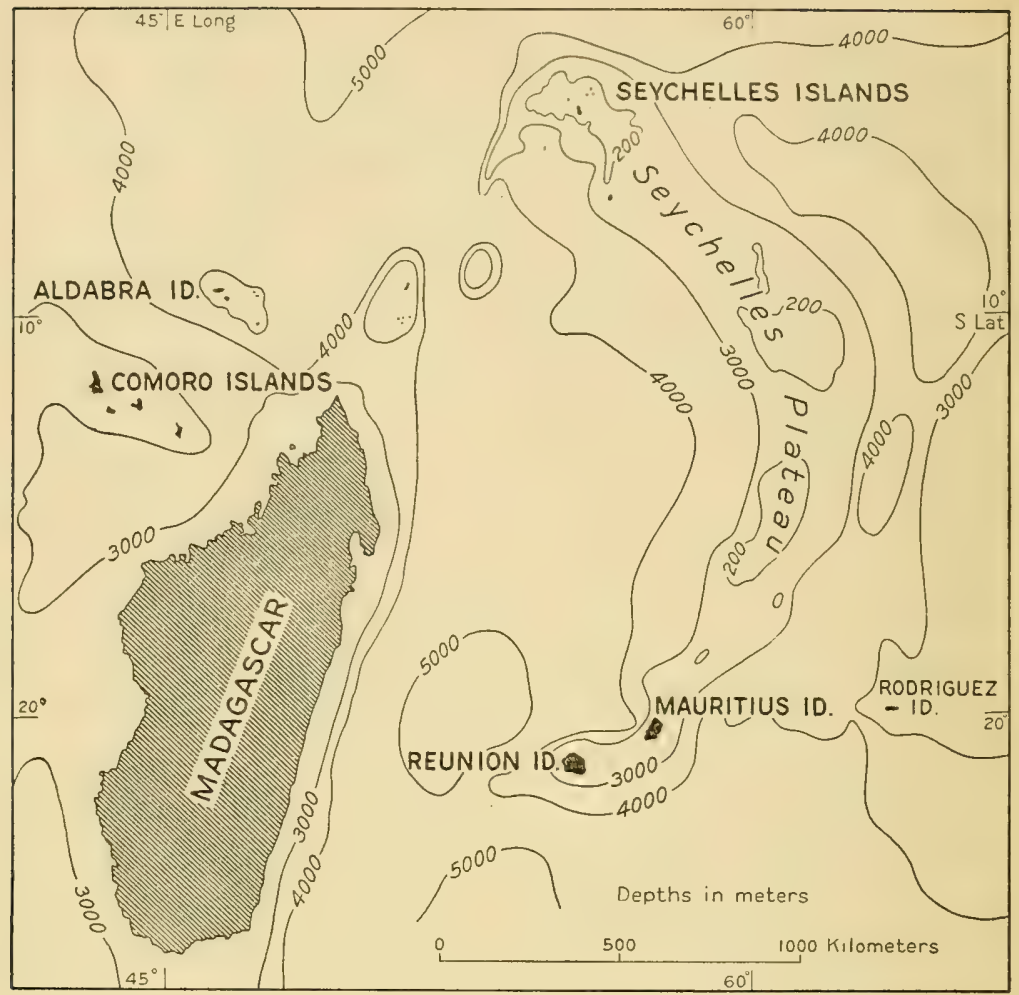

FIGURE IO. MAP OF THE SEYCHELLES PLATEAU. DEPTHS IN METERS.

hidden sub-oceanic crust, let us next consider the other geophysical line of investigation. Here too we are to deal with facts which for the most part were unknown before the beginning of the present century. Their discovery has been made by experts in geodesy, a science originating among the ancient Greeks, but until recently not developed far enough for the needs of our problem. ${ }^{7}$

The chief aim of the geodesist is to determine the true figure or shape of the earth and thus make possible an accurate mapping of lands and seas. By "figure of the earth" is meant either of two things. On the one hand, the phrase signifies the shape 




FIGURE II. ADMIRALTY CHART OF ASCENSION ISLAND. 

represented by perfectly still water, whether the water be that of the ocean or that of a narrow canal supposed to be cut in any direction through continent or island and continuous with mean sealevel. Such a sealevel figure of the earth bears the technical name geoid. It is a wavy, highly complicated figure. On the other hand, "figure of the earth" is often used to mean a shape that can be defined in comparatively simple terms and yet gives a close approximation to the geoid. A century of intensive study by government and privately interested geodesists has proved that one figure satisfying the requirement is an ellipsoid, which is the three-dimensional shape made by the complete revolution of a perfect ellipse on its minor axis. Actually the minor axis of the ellipse is taken to be identical with the polar axis of the earth, while the end of the major axis of the generating ellipse traces in imagined space a circle that closely corresponds with mean sealevel at the equator. In principle we recognize the "oblate spheroid" of our schooldays. As a matter of fact, however, the gravitational field of the earth is such that a still more exact mathematical figure must differ slightly from a perfect ellipsoid; hence the geodesists have devised another formula to represent more accurately the "figure of fluid equilibrium" or "standard spheroid." The standard spheroid expresses, then, the best approximation to the actually wavy surface of the geoid or world-circling sealevel.

Now, while working out the geoidal figure, geodesists have discovered some fundamental facts about the earth's outer shells, including the sub-oceanic crust, and have confirmed the discoveries by measurement of the force of gravity at many points in the geoidal level.

The first of two ways of thus adding to knowledge depends on measurement of the degree of waviness for the geoidal surface. With exquisitely accurate instruments it is proving pos- 
sible to see how far the wavy geoid departs from the standard ellipsoid or standard spheroid. We may think of the geoid as made of humps above and hollows below the standard surface. The hump-and-hollow waviness is clearly caused by irregularities in the distribution of matter in the earth's body. Under or near each geodetic station located on a geoidal hump there is excess of attracting matter; under or near each station located on a geoidal hollow there is defect of attracting matter.

In average the continents project a half-mile above sealevel and in average the bottom of the deep sea is 2.5 miles below sealevel. If the ocean water, with its density of r.03, were converted into continental rock, with density of 2.7 , the mean continental surface would stand about two miles above the surface of that condensed ocean. Each of the projecting continental masses, covering millions of square miles in area and two miles in thickness must exert a strong horizontal pull on the plumbline. If that continent represented an excess of matter in the corresponding sector of the earth, plumb-bobs suspended on all sides of the continent would be pulled sideways, toward the central part of the land, and pulled so much that the angles of the pull could be easily measured. The inward deflection of the plumb-line would mean a continent-wide hump on the geoid, for at any point in the geoid this surface must be rigorously at right angles to the local plumb-line. The geoidal hump should culminate near the center of the continent. See Figure I2, in which the broken line represents this arching of the geoid over the continent.

Moreover, the theory of gravitational attraction shows that the mean level of an ocean between two such continental bodies of excess matter would have to be decidedly hollowed below the standard spheroid. For example, if the Americas and the lands of the Old World were extra masses, there should be an easily demonstrable hollow in the geoid over the Atlantic 


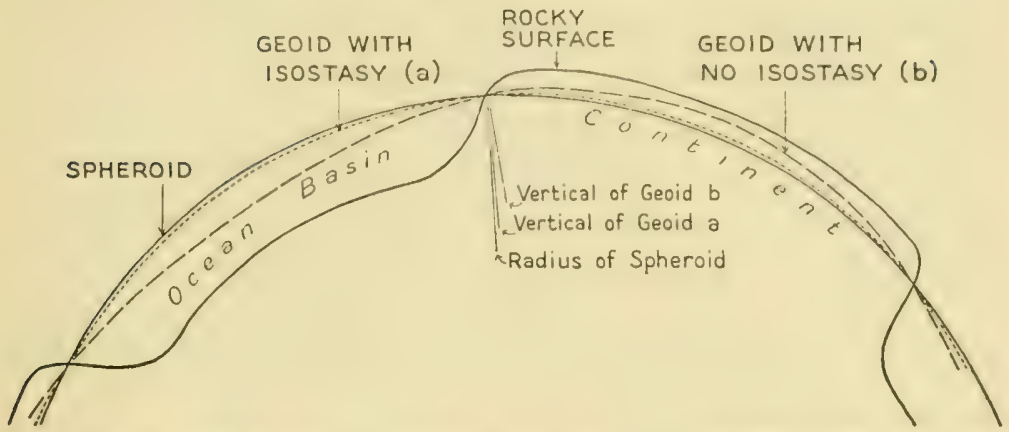

FIGURE 12. DIAGRAMMATIC SECTION TO ILLUSTRATE DEPARTURE OF THE GEOID FROM THE STANDARD SPHEROID, WHEN: (a) CONTINENTAL CRUST IS IN BALANCE WITH THE SUB-OCEANIC CRUST (CONDITION CALLED ISOSTASY); AND (b) CONTINENT REPRESENTS EXCESS MATTER ON THE EARTH'S BODY (NO ISOSTASY).

region. But it has been proved beyond doubt that the actual geoid shows no large-scale warping of the kind described. There is only one possible explanation: the relative lack of attracting matter in the ocean water must be compensated for by relative excess of attracting matter in the rock under the ocean; in other words, the density of the sub-oceanic rock must be greater than the density of the rock under the continental surfaces.

That conclusion comes clearly and even more directly from the second method of diagnosis, based on measurements of the intensity of gravity at many land and sea stations. The instruments used are called gravimeters, and the method is called the gravimetric. Most of the measurements have been made with special pendulums, one type designed for land stations and another type for use at sea. In each case the pendulum's period of swing gives, after proper precautions and calculations, the intensity of gravity. Manifestly the sea-going pendulum must operate in the absence of strong disturbance of the instrument by the waves. The requirement is met by setting up the pendulum in a submarine vessel, capable of submergence to the 
depth of 200 or 300 feet, where the effects of wave oscillation are generally small. The remarkable gravimeter for work at sea was invented by Dr. F. A. Vening Meinesz of the Netherlands Geodetic Commission, who with the instrument has circumnavigated the earth and has occupied more than 500 stations at sea. His feat of invention and his physical and moral endurance in securing highly accurate measurements where, twenty years ago, these seemed humanly impossible, are among the wonders of science.

To compare the intensities of gravity on lands and seas, it is necessary to reduce the value found at each station to a common level. The level chosen is naturally the geoid or sealevel. The reductions of immediate interest are of two principal kinds.

The first kind is called the Bouguer reduction, because suggested by Pierre Bouguer, a staff member of the famous French party which, in the latter part of the eighteenth century, spent ten years in measuring the length of a degree of latitude in Peru. Bouguer's line of thought may be followed. Let it be assumed, first, that all the rock of a continent above sealevel represents excess of matter over that required to keep the continental region in hydrostatic balance with a plain having its surface at sealevel. Let us measure gravity on the high land of the continent and reduce the observed value to sealevel, on the assumption that the rock above sealevel is replaced by air, of negligible mass, as suggested by the section of Figure 13. If this last value is much smaller than that expected from the standard spheroid, and if the same result accrues at many other observing stations, then we can be sure that much or all of the continental rock above sealevel is not in excess. In other words, we shall have found that the initial assumption was false and that the projection of the continent must be explained in some other way. As a matter of fact, the reduced value of gravity at 
every high station turns out to be much smaller than the theoretical value given for the same point by the standard spheroid. That relation may be otherwise expressed: for continental stations well above sealevel the "Bouguer anomaly" is characteristically and strongly negative.

There is analogous procedure for using measurements of gravity at sea. In this case let us assume that the ocean, only about 40 per cent as dense as continental rock, represents deficiency of attracting matter as compared with that under a rocky plain with surface at sealevel. We imagine such rock to replace the water and calculate the gravitational attraction at each station after the replacement. See Figure 13. The differ-

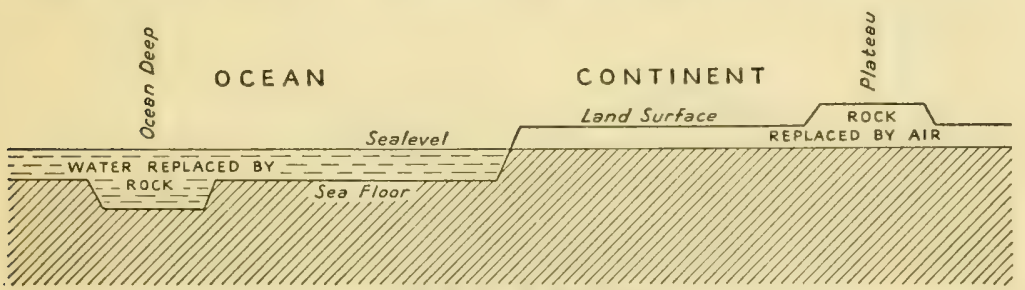

TOPOGRAPHY

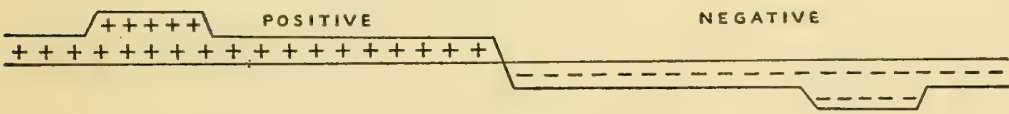

\section{BOUGUER ANOMALY}

FIGURE 13. DIAGRAM ILLUSTRATING THE ASSUMPTIONS ON WHICH CALCULATION OF THE BOUGUER ANOMALY OF GRAVITY IS BASED.

ence between the calculated value of gravity and the theoretical or standard-spheroid value is the Bouguer anomaly for the sea station. If the former is much larger than the latter, then we can be sure that our initial assumption is false; that we must seek elsewhere for explanation of the depth of the ocean.

Professor Vening Meinesz measured gravity at series of stations across both Atlantic and Pacific stations and then 
computed the Bouguer anomalies. In both instances he found these anomalies to be strongly positive. He used the ordinary unit, the milligal, which is very close to being one millionth of normal gravity. His values for the anomalies are given by the underlined numbers in the top and bottom maps in Figure I4. The values are positive to such a degree that there cannot
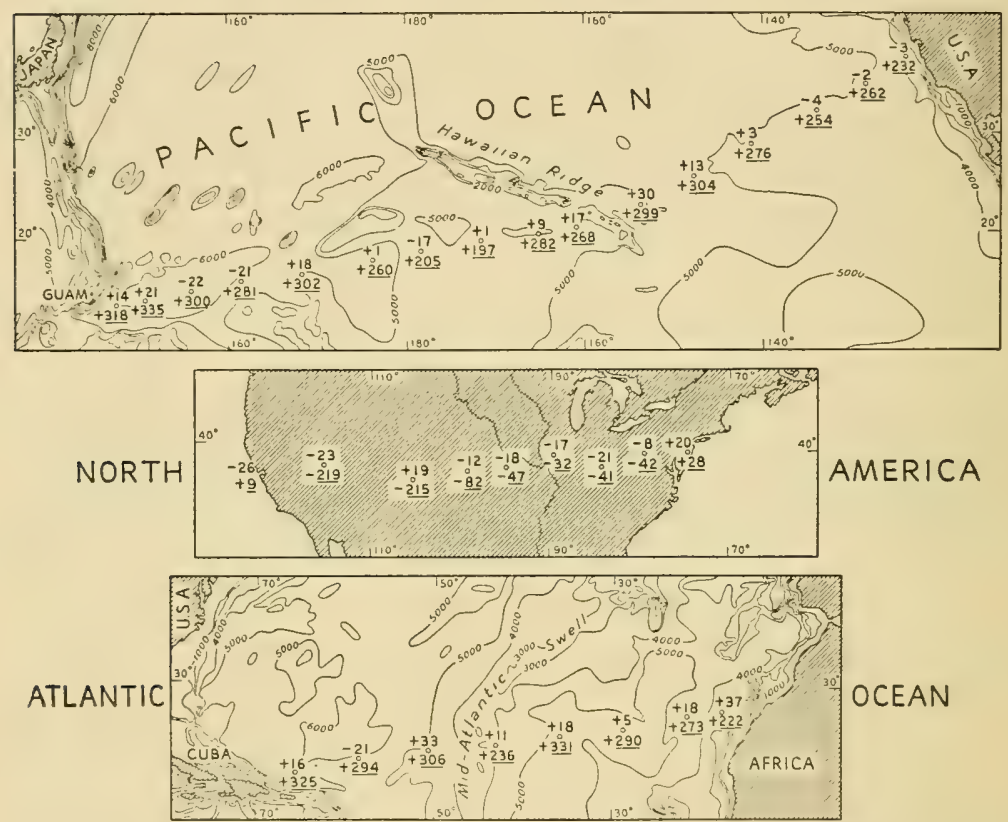

FIGURE I4. MAPS SHOWING BOUGUER AND ISOSTATIC ANOMALIES OF GRAVITY ALONG TRAVERSES OF PACIFIC OCEAN, NORTH AMERICA, AND ATLANTIC OCEAN.

be any deficiency of matter under the ocean. This means that the density of the rock below the oceanic ooze is considerably higher than the density of average continental rock. The conclusion is all the more certain in view of the fact that the Bouguer anomalies on high ground of the United States are strongly negative. To see this, note the underlined figures in 
the middle map, specially observing those over the high western Cordillera.

Evidently, then, the greatest of the earth's reliefs, the projection of continent above sea floor, is compensated for by a difference of density, and therefore weight, for the rock underlying the two regional types. In effect we can say: the continents are floating high on the earth's body.

Further, the geodesists have been able to show that the difference of density between sub-continental and sub-oceanic rock is almost entirely confined to the fifty-mile layer at the surface of the earth. At its bottom there begins a thick, worldcircling layer or earth-shell, which in the horizontal direction is nearly constant in density and composition. This shell is in an almost perfect hydrostatic state, so that the weight of the 50.5 miles of continental crust is essentially counterbalanced by the weight of 47.5 miles of sub-oceanic crust plus the weight of 2.5 miles of overlying sea water. The level at which rocky matter is assumed to begin is called the depth of compensation.

Proof of the mutual balancing, with the direct implication that the major reliefs of our planet are compensated for by systematic variation of density in the horizontal direction, is too technical and lengthy for present description. The principle involved has been given the name "isostasy," meaning "equipoise" (of vertical column against vertical column) in free translation from the Greek roots. Many different hypotheses have been proposed to cover laws for the variation of density. For each "isostatic" hypothesis, necessary corrections are made to the measured value of gravity at each land and sea station, to find the value at sealevel. The result may be called the reduced "observed" value. It is then compared with the intensity of gravity expected at the same point of latitude and longitude on the standard spheroid. The difference of intensity is called the "isostatic anomaly." For a given station the iso- 
static anomalies differ according to the underlying hypotheses. These have been proposed by as many geodesists, whose names have been attached to the corresponding anomalies of gravity; hence we have Hayford anomalies, Airy anomalies, Heiskanen anomalies, and still other types. Now, with any of the hypotheses it is found that the depth where the earth-shell in an approximately hydrostatic state begins is only a few scores of miles below the surface of the globe. One of the good evidences that this is true is the prevailingly small size of the isostatic anomaly when computed according to a good assumption as to the depth of compensation. Examples are given in the three maps of Figure I4, where the numbers without underlining represent the isostatic anomalies, here too expressed in milligals. Thus the isostatic data from two oceans and a continent tell the same story as the Bouguer anomalies: the thickness of the strong superficial shell of the earth is of the order of 50 miles, though somewhat greater under the deep sea than elsewhere.

Some Relevant Facts from Geology.-The geologist has his own independent grounds for belief in an extremely weak earth-shell at moderate depth. He has shown that thousands of feet of rock have been eroded off the continents and that a large part of the resulting detritus is now weighing on the suboceanic sectors of the earth. To restore the balance so disturbed, material in depth has been flowing from oceanic region to continental region. The stress causing the flow has at no time been great; hence the flowing material must have a minimum of strength or no strength at all. For this there is only one explanation, namely, high temperature. How high must it be?

Some students of the problem believe that the necessary temperature may be far below that where the rock would melt. Others assume a temperature close to that of melting-a view implying an incredibly delicate relation of temperature to the 
earth's internal supply of heat. Neither assumption assures sufficient weakness for the deep layer. According to a third hypothesis, the rock at depth is too hot to crystallize and is therefore in the glassy or vitreous state. In the writer's opinion, founded on a multitude of facts, this hypothesis is the best of the three, even though it is as yet not clearly supported by seismological evidence. If the reasoning is correct, the earth has a true, solid crust resting on a vitreous substratum, which, however stiffened by the high pressure upon it, is not actually solid and endowed with notable strength. Most of the grounds for that opinion are technical and not to be described here, but one of them, combining facts won from geological and geodetic studies, will be outlined. Beforehand, a related consideration may be mentioned.

According to geophysical theory the earth's crust must be thicker under the ocean than under a continent. All rock species yet tested are somewhat radioactive, the radioactivity being accompanied by the evolution of heat. Because granite and other rocks characteristic of the continents are richer in radioactive elements than the denser rocks of the sea floor, the radioactive furnace is specially efficient under the continental surfaces. We therefore expect the crust, as just defined, to have maximum thickness under the ocean. Such excess of thickness is indicated in the section of Figure 30. On the left is the ocean with its gabbroic or simatic crust; on the right, the continent with its thinner crust; partly sialic and partly simatic. One reason for picturing the substratum in two sub-layers will be given in the next chapter.

Now, in spite of the somewhat greater thickness of the suboceanic crust, any special evidence for a weak, deep layer under the continent can also be regarded as good evidence for a similar layer under the ocean. There is such special evidence, recently shown to be more than ever trustworthy. To under- 
stand this indirect method of diagnosing the foundations of the deep sea, we shall have to go ashore.

We go ashore to watch powerful Nature test the idea of true crust and quasi-liquid substratum by the most trusted criterion of science, namely experiment. Any convincing experiment has to be on a scale far beyond human contrivance.

During the last Glacial Period enormous volumes of water were evaporated from the ocean and, in the form of a dozen thick ice-caps, piled on the continents. Because of their wide spans, these great weights bent down the earth's crust and naturally bent it down most where the ice was thickest. In other words, the crust was basined under each of the broad ice-caps. With their melting and consequent removal of load, the crust began to bend up again. In two cases this recoil of the crust is still going on, and there we find new proof of extreme weakness for the subcrustal material. ${ }^{8}$

The most complete evidence comes from the part of northwestern Europe that was overwhelmed by the last of the icecaps that waxed and waned during the Pleistocene Period. The limits of this glaciated tract are shown in Figure 15. The ice was thickest over the western shore of the Gulf of Bothnia, the northern branch of the Baltic Sea. From that center the ice flowed out and spread over Finland and Scandinavia, as indicated in Figure 16 . An appropriate name for the piled-up mass is, therefore, the Fennoscandian ice-cap. It covered nearly one and a half million square miles, had central thickness not far from three miles, and had average thickness of about one mile.

Forty thousand years ago the Fennoscandian ice began to melt. With occasional short pauses in the melting, the mass grew thinner and lost area, leaving moraines at intervals from northern Germany and northwestern Russia to the Gulf of Bothnia. Eighty-seven hundred years ago the melting was so 


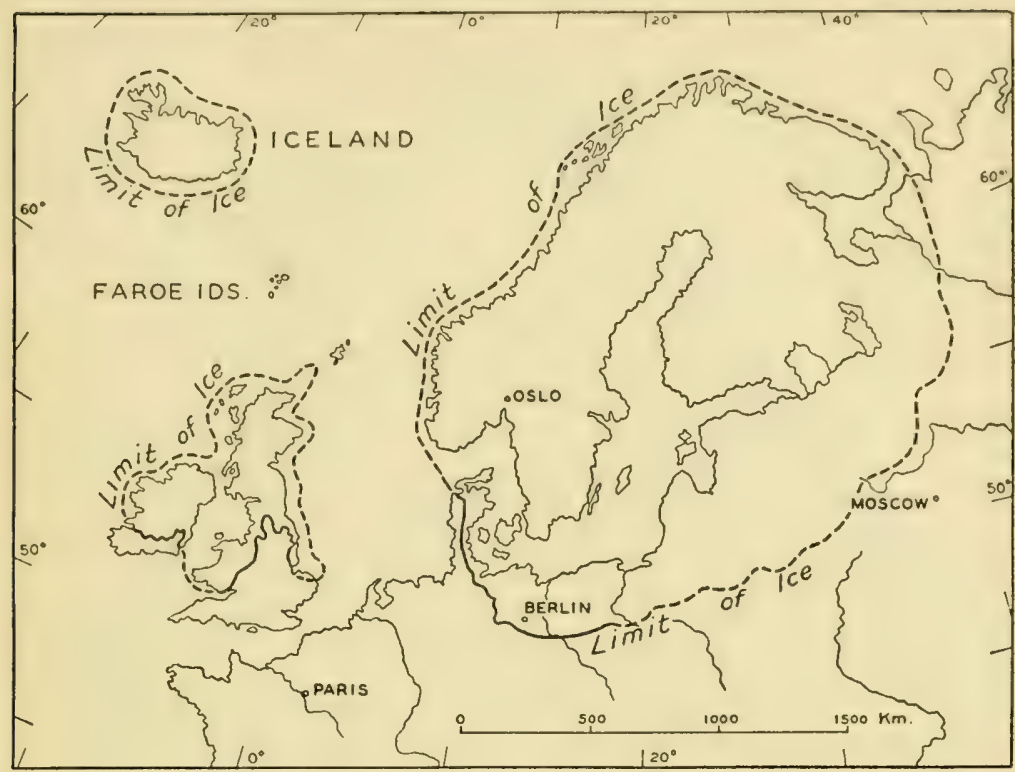

FIGURE I5. MAP SHOWING LIMITS OF THE LAST ICE-CAP ON FENNOSCANDIA.

far advanced that the Fennoscandian geologists make that epochal date the beginning of post-Glacial time.

At the Bothnian center the mighty load had depressed the earth's crust about half a mile, but less and less along the radii out to the edge of the glaciated tract. During the slow melting and transfer of water back to the ocean, and ever since, most of the glaciated region has been slowly rising. In leisurely but unmistakable fashion the earth's crust has been recoiling from its temporarily basined condition. Where the ice had been thickest and heaviest the crust has risen most; where thinner, it has risen less; and near the outermost moraine, not at all.

The upwarp of the crust has been proved by the tilting of sea-beaches and of beaches made by extensive, temporary lakes which, during the retreat of the ice-front, were shored by the ice-cap itself and by the rocky hills of the basined tract. The 


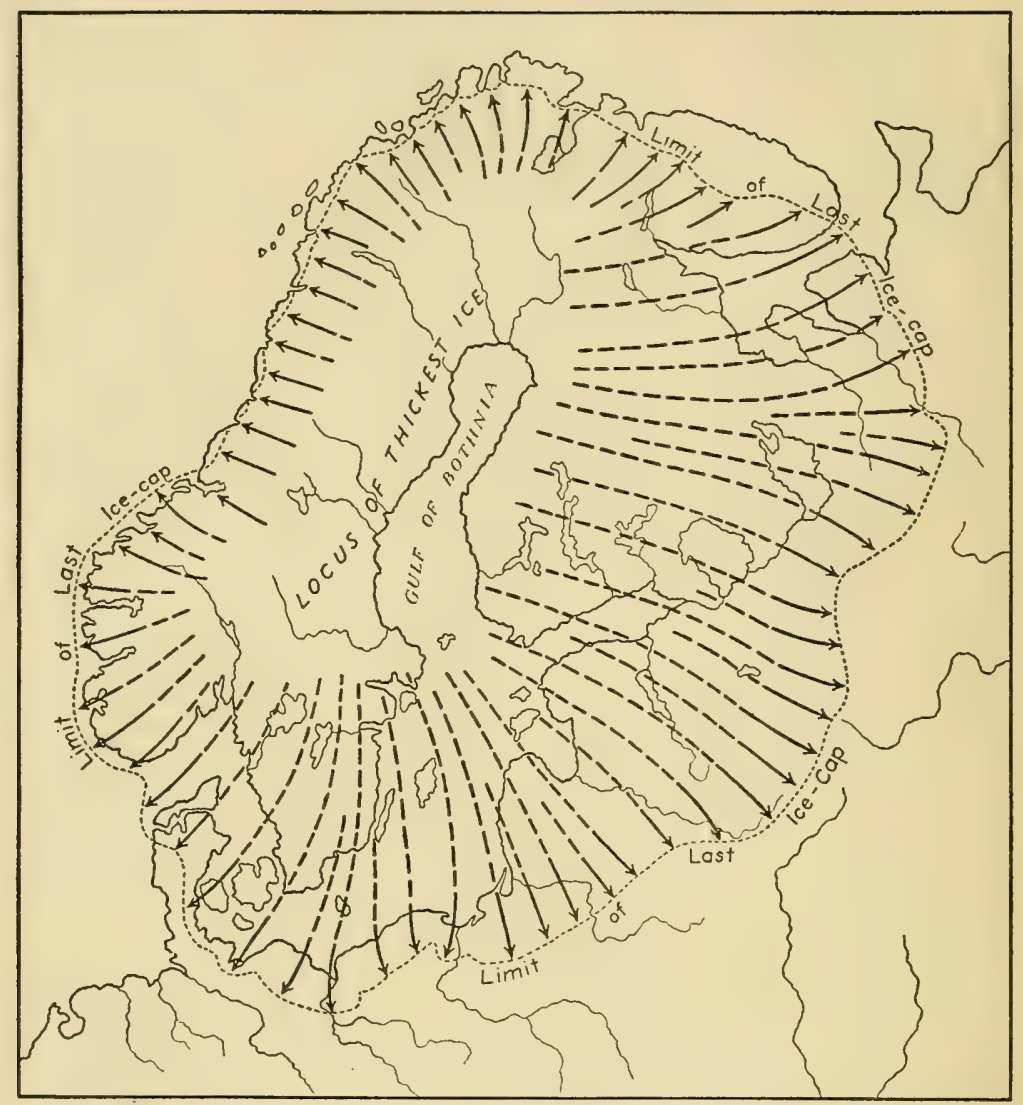

FIGURE I6. MAP ILLUSTRATING WITH ARROWS THE OUTFLOW OF THE FENNOSCANDIAN ICE FROM THE CENTER OF ACCUMULATION.

field observations on which the proof is based are abundant and satisfying. Their gathering and interpretation by the Fennoscandian geologists represent one of the most masterly achievements in earth science. Stage by stage this upheaval of the crust, with truly dramatic effects on geography and biology, has been pictured in rigorous scientific terms. The story is too long for present retelling, but the reality of the crustal recoil can be made clear by the map of Figure 17. It shows the exist- 




FIGURE I7. MAP SHOWING (A) THE AREA INVADED BY THE ATLANTIC SINCE, BY MELTING OF THE FENNOSCANDIAN ICE, ITS FRONT BEGAN TO RETREAT ACROSS THE BALTIC REGION; AND (B) THE ISOBASES (LINES OF EQUAL UPLIFT) OF THE HIGHEST SEA BEACHES OF THE REGION. HEIGHTS IN METERS.

ing outline of the Baltic Sea and, by the stipple pattern, the much greater area which, at some time or other since the icecap began to melt, was invaded by the salt water of the Atlantic. The curved lines indicate in meters ( 3.2 feet to one meter) the heights to which the beaches made by this invading Atlantic have been upheaved. We see the uplift to have been 
greatest-more than 275 meters or about 900 feet-where the ice had been thickest and heaviest.

The recoil of the earth's crust is still going on. The map of Figure 18 gives approximately the present rates of uplift as

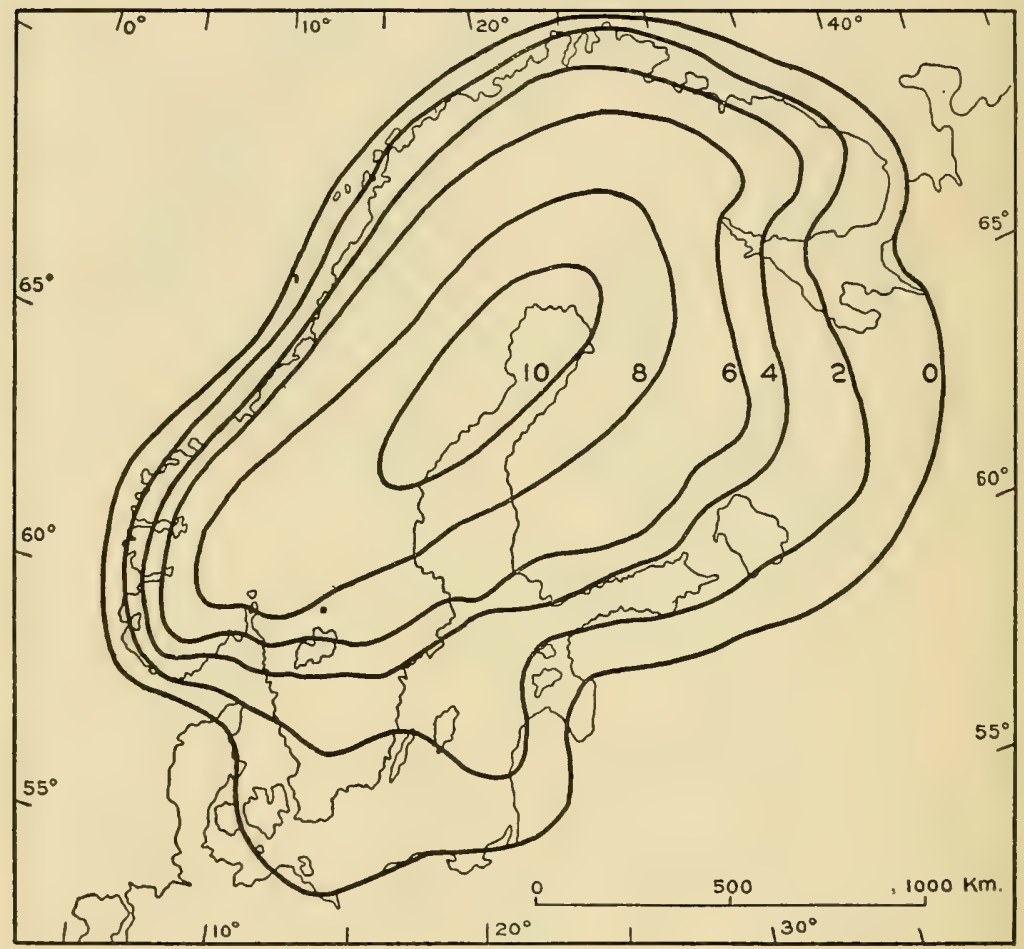

FIGURE I8. MAP SHOWING APPROXIMATELY THE LINES OF EQUAL RATES OF CURRENT UPHEAVAL IN FENNOSCANDIA. THE NUMBERS REPRESENT MILLIMETERS PER ANNUM. AFTER A. PENCK.

determined by tide-gages; here the numbers on the different contour-lines indicate in millimeters the annual amount of upheaval along the respective lines. According to the map the rate of vertical uplift at the Bothnian center is now about one meter per century. If the movement continues long enough, 
the floor of the Gulf of Bothnia will become dry land, bearing some lakes of fresh water.

Within the last three years the testimony of the tide-gage has been strikingly corroborated by a quite different instrument, the spirit-level. ${ }^{9}$ In 1938 geodetic stations of southern Finland, where levels had been accurately established forty years before, were re-occupied. The new levels at once showed that a long belt of ground had been differentially upheaved, in direction and amount matching well with those expected by the old method measuring the crustal warping.

To illustrate this fact Figure ig has been prepared. We recognize the Gulf of Finland and Helsingfors or Helsinki,

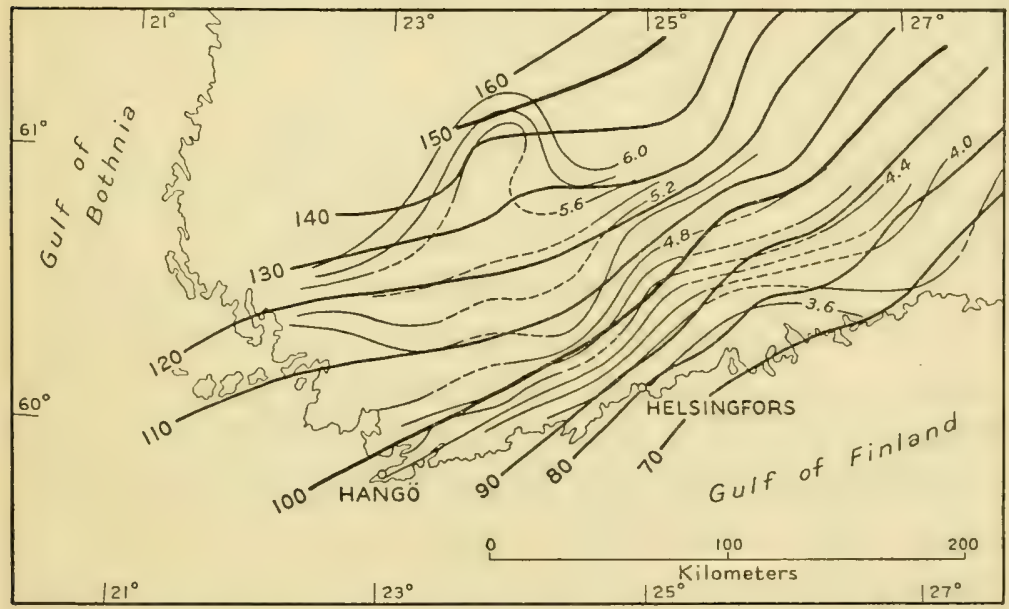

FIGURE I9. MAP OF SOUTHERN FINLAND, ILLUSTRATING CURRENT UPWARPING IN MILLIMETERS PER ANNUM, AND ALSO ISOBASES FOR A LATE-GLACIAL SEA BEACH (YOLDIA SEA). AFTER T. J. KUKKAMÄKI.

now of immortal fame for its heroism. Each of the thicker, continuous lines joins points of equal upwarping since one of the old sea-beaches was built by the invading Atlantic. The amounts of uplifting are indicated in meters. In a similar way the thinner, partly broken lines of the map represent the 
present rates of uplifting of the same region as determined by precise leveling. Here the figures mean the numbers of millimeters of rise during one year. We see that the one set of lines roughly parallels the other. Moreover, in this region the rates of tilting as determined by tide-gage and spirit-level are almost identical with each other and also comparable with the rate of tilting of a sea-beach that was built 7000 years ago.

We wish to know the amount and distribution of the stress - unbalanced, inward pressure-now felt by the subcrustal material of the Fennoscandian region. Both desiderata are obtained as soon as we learn the dimensions of the negative load still remaining in the glaciated tract. The maximum stress must be centered near the Gulf of Bothnia, the place of thickest ice at maximum glaciation. To find that stress we need a good estimate of the weight of rock matter that will be restored to the central sector when, in the distant future, the upheaval ceases and the earth's crust comes to equilibrium. Such an estimate has been reached in two different ways.

The first way was followed by Dr. E. Niskanen of Finland. The rate of upheaval since the beginning of post-Glacial time, nearly 9000 years ago, has been decreasing, and a reasonably definite law of the decrease established. With the help of this law Niskanen has been able to estimate the amount of uplift still to come. He has also prepared the map of Figure 20, showing the amounts of future uplift to be expected along the radii of the glaciated tract, from the central area out to the Russian territory on the southeast. The amounts of the uplift during the millennia to come are indicated in meters. The lines of equal displacement, needed to correct for the negative load on the Finnish sector of the earth, are closely parallel to those of equal displacement in the tide-gage map covering Finland. See Figure I8.

To effect the future uplift, subcrustal material must flow in 


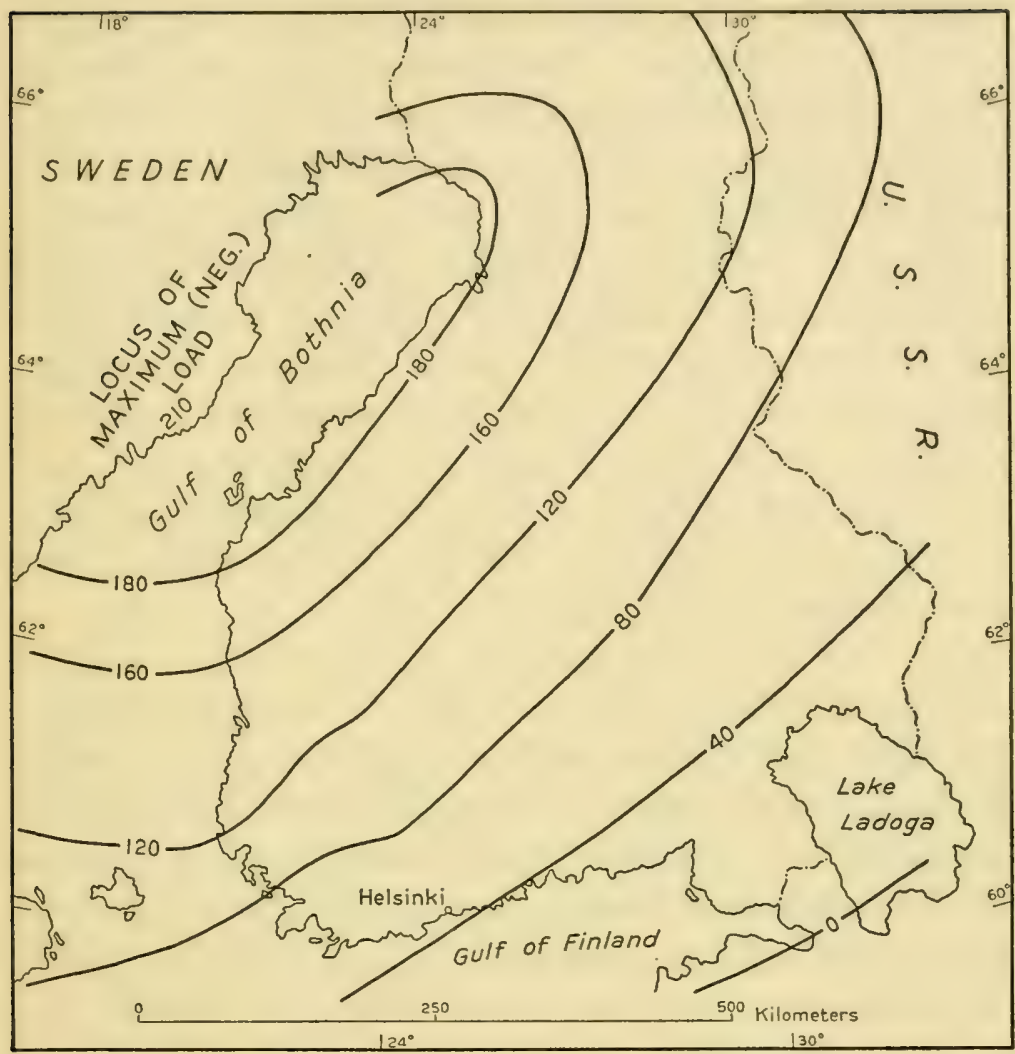

FIGURE 20. MAP SHOWING IN METERS THE AMOUNT OF UPWARP STILL NEEDED TO BRING THE EARTH'S CRUST OF THE FENNOSCANDIAN REGION INTO BALANCE WITH THE CRUST ELSEWHERE. AFTER E. NISKANEN.

from the periphery of the glaciated tract. When the inflow is completed, a vertical column of this material under the central point of the glaciated land will have the same mass as that of a column of granite a little over 700 feet in height.

The other way of estimating the mass still to be thrust into the central region and so bring the earth's crust into stable balance, is based on measurements of gravity at many points in 
Finland. The measurements have just recently been reported, by Dr. R. A. Hirvonen. The observed values were "reduced" to the geoid or sealevel, and these new values were subtracted from those respectively given by the best available figure of the earth. The differences are called technically "free-air anomalies of gravity." To show their meaning here, in a comparatively simple way, their averages for three different belts, each about 250 kilometers wide, were computed. The resulting averages, expressed in milligals, are stated in Figure 2r. Belt I, adjoining the center of the glaciated tract, has 22 stations; their mean anomaly is -28 milligals. Belt II, with 62 stations, has a mean anomaly of $-\mathrm{I} 7$ milligals. Belt III, with 77 stations, has a mean anomaly of $-\mathrm{I} 2$ milligals.

Thus all three belts have, in average, negative anomaly, showing that there is deficiency of mass throughout Finland. It is highly probable that, when the rest of the glaciated region has been similarly studied, it also will show net deficiency. We are particularly interested in the central area. If there the mean anomaly is as much as -28 milligals, we can conclude that the defect of mass at the center is equal to that of a column of granite about 250 meters or nearly 800 feet in height.

We have arrived at two different estimates of the amount of matter that is still lacking in the central area before Fennoscandia can come to equilibrium. Admittedly the data need to be supplemented by more field-work; yet one may feel some confidence in the belief that our results are not wildly wrong. The fact that the two estimates of the defect of mass under the Gulf of Bothnia rather closely agree is significant. Let us accept their mutual corroboration and ask: what must be the order of stress under this central area, at the depth of, say, 50 miles? An engineer's analysis gives the answer. By this analysis the maximum stress at a depth of 50 miles is only a few atmospheres. The stress will grow less and less as the centuries roll 


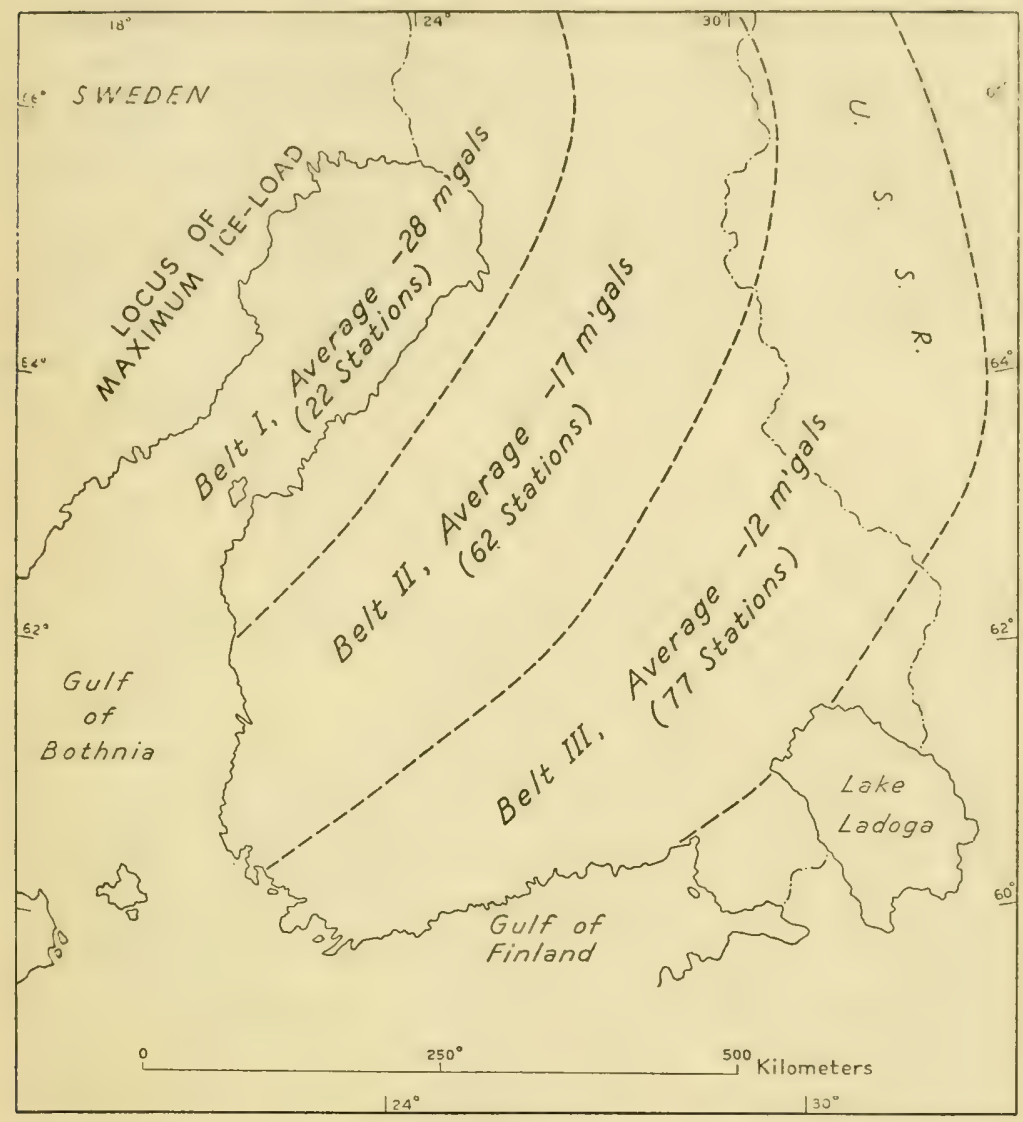

FIGURE 2I. MAP SHOWING MEAN ANOMALIES OF GRAVITY IN THREE BELTS OF FINNISH TERRITORY, CONCENTRIC WITH THE CENTER OF FORMER GLACIATION.

on and the negative load decreases correspondingly. When we note that the shearing strength of ordinary rock is measurable in many hundreds of atmospheres, and that the strength of the outer half of the earth's crust is still greater, we see that the subcrustal layer has comparatively little power of resistance to shearing pressure. In fact, the test with the ice-cap leaves one in doubt that this material has any strength whatever. 
Apparently contemporaneous with the last Fennoscandian ice-cap was a much more extensive and probably thicker icecap in North America. Here too there was deep basining of the earth's crust under the load of ice, followed by recoil which still continues, as shown by water-gages at harbors of the Great Lakes. Here too the recoil occurs in an area of deficient mass. An illustration of this last fact is furnished by the latest gravity observations in a part of southern Canada. The region concerned, 700 miles long from east to west and in average about 200 miles wide, lies between $75^{\circ}$ West Longitude and $90^{\circ}$ West Longitude. It is well inside the southern limit of the glaciated tract, though everywhere more than 600 miles from the point where the ice was thickest. In this region, the average isostatic anomaly for 26 stations, reported by Mr. A. H. Miller of the Dominion Observatory, is $-\mathrm{r} 7$ milligals, a quantity identical with the average anomaly in Belt II of Finland. ${ }^{10}$ Near the center of glaciation, in Hudson Bay, the tide-gage is said to have shown current uplift even faster than at the Fennoscandian center. Thus, in spite of the difficulties of travel and the making of adequate observations in Labrador, northern Ontario, and the Northwest Territories of Canada, it seems safe to assume that the negative load at the Hudson Bay area is comparable with that at the analogous center near the Gulf of Bothnia. If this is true, we have a second proof of the extremely small strength of a layer beginning at the depth of not more than 50 miles below a continental surface.

Manifestly ice-caps cannot grow on the floor of the deep sea; here, then, we cannot use Nature's experiments with icecaps for judging the distribution of strength below the ocean. Yet the indirect testimony of Fennoscandia and eastern Canada is seen to have value when we remember that the cause of subcrustal weakness is high temperature, and that, in spite of difference of radioactivity, a continental sector of the earth is 
only a little hotter than an oceanic sector. Failing accurate knowledge of the distribution of radioactive elements, and also in view of uncertainty about other sources of underground heat, including that inherited from the earth's infancy, it is not possible to calculate exactly the depth where the sub-oceanic rock begins to show extreme weakness. However, with reasonable assumptions it appears that the strong superficial layer is probably between ten and twenty miles thicker under the ocean than under the continental surface.

\section{Conclusions}

The next chapter will be concerned with the deep-sea islands, from which we shall also seek information about the earth-shells. Before thus adding to the store of relevant facts, it is expedient to list the principal results so far obtained.

I. The instrumental records of earthquake waves suggest that under the central Pacific, the Arctic Ocean, and much of the Indian and Atlantic oceans the solid rock, down to the depth of 50 miles or so, has the elastic properties of crystallized basalt. However, the velocities of the waves traversing the middle of the Atlantic and the southwest Pacific indicate the presence of broad veneering patches of rocks like those outcropping on the continents.

2. Those suggestions gain support from studies of the figure of the earth and variation of gravity along the surfaces of lands and seas.

3. All three geophysical methods of diagnosis, like the geological evidence from glaciated regions, make it necessary to postulate a thick layer of exceedingly weak rock, that begins at a depth of about 50 miles.

4. The weakness of this deep layer implies high temperature. Its actual temperature is unknown, but we have con- 
sidered a good working hypothesis-that the deep layer is so hot as to be actually vitreous. This hypothesis seems to be the only one that is well grounded on geological and geophysical observations.

5. A red-hot to white-hot, glassy layer would react to earthquake waves as if it were solid, and yet to stresses of much longer duration it would react like a viscous liquid. If we do assume the existence of a glassy layer just beneath the crust, we have gone far toward answering an early principal ques-

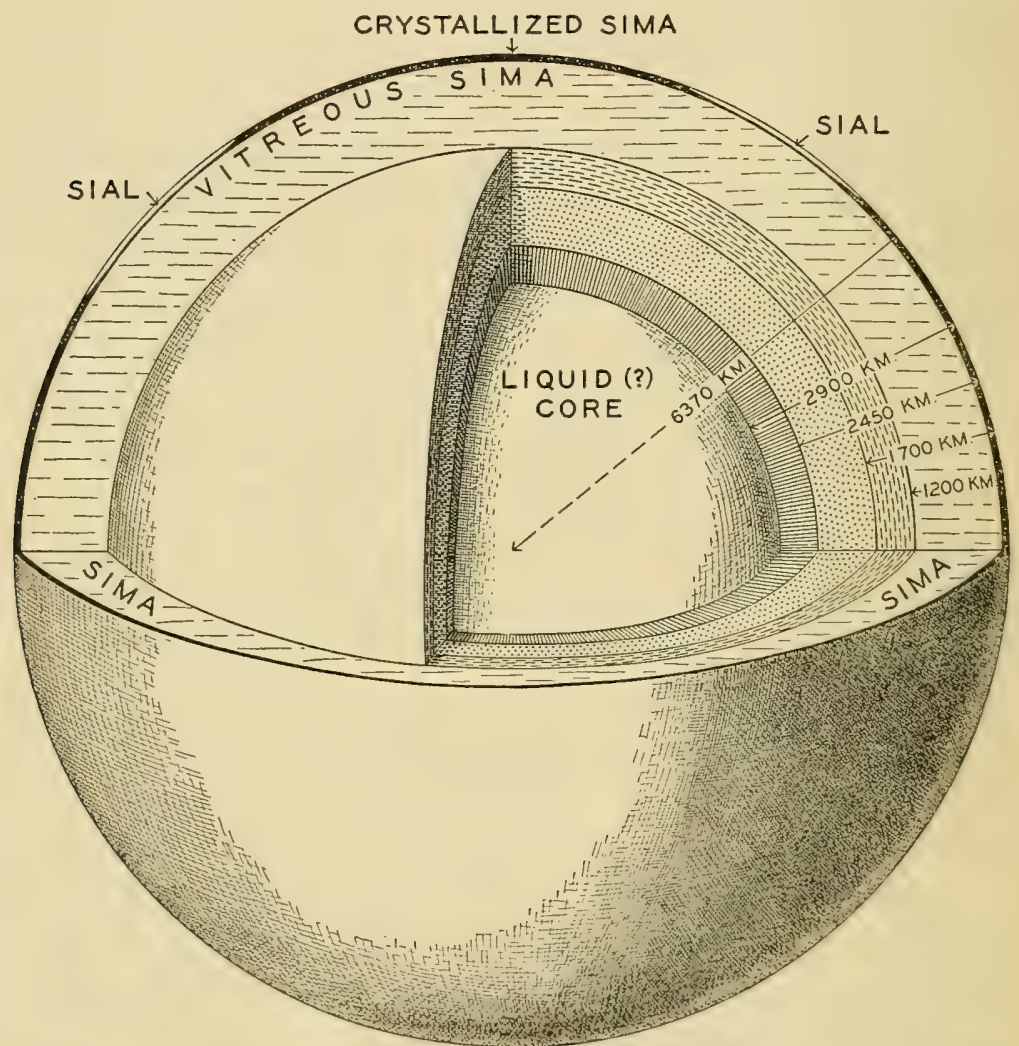

FIGURE 22. STEREOGRAM TO ILLUSTRATE THE EARTH-SHELLS AS DEDUCED FROM DATA SUPPLIED BY SOME SEISMOLOGISTS AND BY OBSERVATIONS IN GENERAL GEOLOGY. 
tion: how can the earth have the plasticity demonstrated by the changes which, during the ages, have produced her rugged relief and visible, complex structure? Flow has taken place in the solid crust, but, according to clear deduction by geologists, that more superficial flow has depended on vastly greater plasticity of the subcrustal layer. Indeed, it appears that the mountain chains of the lands are by-products of the horizontal displacement of whole continents over the earth's body, and that this horizontal motion of the crust is possible only because the subcrustal layer is nearly or quite as weak as water. Furthermore, as will be emphasized in the next chapter, the weak substratum is world-circling, beneath ocean as well as continent. Perhaps, too, this conclusion may yet give a basis for solving a supreme puzzle, namely, the concentration of the sial, the earth's lighter rock, in the continental sectors, leaving the oceanic sectors without any continuous cover of sialic rock.

The stereogram of Figure 22 represents an attempt to portray the earth-shells in a succession which is favored by some, though not all, seismologists. In the section the sial of the continents is indicated by thin, unshaded segments of the crystalline surface layer; the crystalline sima of the sea floor, by a thin line in solid black. Just beneath that heterogeneous crust is the vitreous sima of the substratum. The nature of deeper shells and the state of the Iron Core, labelled as possibly a true liquid, thought to be too mobile to transmit earthquake waves of the Shake variety, are problems for the future. 


\section{SUBMARINE MOUNTAINS}

\section{Introduction}

The traveler at sea, whether lighthearted tourist or seasoned sailor of the crew, knows the thrill of the landfall, and the emotion is perhaps most lively when one of the deep-sea islands looms out of the mist. Sharing this human feeling, compounded of curiosity and the nostalgia of a land animal, the geologist on board looks at the growing profile with special excitement. More than others he senses challenging mystery. He has the divine stimulus of wonder. How did this island originate? Why does it lift its head above a sea floor which, through hundreds or thousands of miles of traverse, has been I0,000 to 20,000 feet below the ship? What can this island add to knowledge of the earth's crust as a whole? The first chapter sketched the results of instrumental study of the general floor of the ocean. We shall now seek further light among the thalassic islands and the related shoals far out from the continents.

Hundreds of invisible shoals, like the island masses, begin their rise above the flat plain of bottom ooze and mud, at depths ranging from two to four miles below sealevel. Both shoal and island are therefore lofty mountain masses. Wherever visible, the lava is basalt or, in far smaller proportion, a chemical derivative of basaltic liquid, either pure or contaminated by absorbed crust-rock or water. We recall that basalt is the 
most abundant among all the types of lava, whether on land or at sea.

A host of other islands are in contrast. They are neither basaltic nor essentially of volcanic origin at all; they are made of rock species that are staple only in the continents and large islands. The "continental" species carry high proportions of the compounds called silica and alumina. From these names, as we learned in the first chapter, the mnemonic word "sial" has been coined, to cover "continental" rocks in general. Islands composed of the sial we shall describe as "sialic." The basalt of the volcanic islands, being rich in silica and magnesia, may in a corresponding way be described as "simatic."

Let us search the two classes of islands, in succession, for clues concerning the properties of the earth-shells beneath the wide ocean.

The clues already discovered would have been better and more numerous if the most economical program for wresting the secrets of the oceanic islands had been adopted. This involves prolonged co-operation of specialists, covering group after group and thereby gaining in mastery of the island technique. The geologist needs detailed information from the topographer, who maps the relief of land and adjacent sea bottom; from the biologist and the paleontologist, who find in the distribution of organic species, living and extinct, the evidences for or against former land connections; from the anthropologist, who may be able to show how much migratory man may have changed the original conditions of organic distribution; and from the geophysicist, who tells whether each island-studded region is in gravitative balance with the rest of the earth. The naturalists of the Netherlands have had the wisdom to explore their East Indian domain along all of these lines, and have remarkably illustrated the power of co-operation. Twenty-five years ago there was a possibility that, in the 
course of a decade or two and at relatively small cost, the geology and natural history of all the islands of the open Pacific could be worked out by a single group of explorers. ${ }^{1}$ If this were done, we should have in hand the essential geology of all the dry land appearing in more than one quarter of the whole earth. At present such a program is hardly possible: first, because war and its aftermath, together with the damage wrought by the current world revolution, have apparently ruled out private endowment of the enterprise; and again because the jealous "owning" and "mandate-holding" nations, seeking airplane fields and naval harbors, have raised political barriers against the free, comprehensive accumulation of facts about the islands. Yet, in spite of the political bosses, private studies have been made during the last twenty-five years, for instance: in Hawaii, Samoa, Society group, Easter Island-of the Pacific; in the Canary Islands, Cape Verde Islands, Ascension Island, and Saint Helena Island-of the Atlantic; and in the Maldive archipelago and Kerguelen Island of the Indian Ocean. Also important has been the recent geophysical examination of some deep-sea islands and their immediate surroundings.

\section{The Volcanic Mountains}

In the darkened stalls of the theater, millions, seeking romance, have discovered the volcanic island, but never a picture of its dramatic evolution. No "producer" has dared to film the mighty conflict that resulted in the towering mass of lava itself. Each volcanic island has meant a struggle between Pluto and Neptune, with Pluto the winner. In spite of the pressure of two or three miles of sea water, and in spite of water-cooling of the glowing, liquid lava, the infant cone, adding flow on flow, fights its way up. It becomes a shoal and then a new 


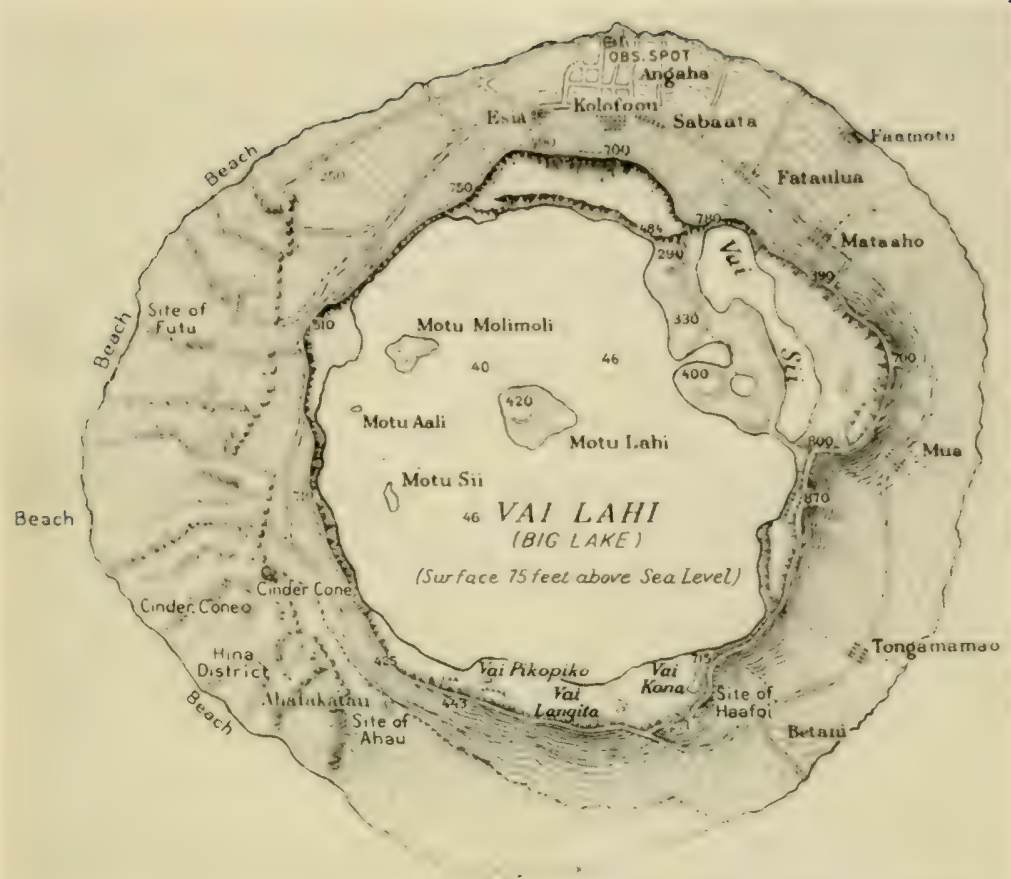

FIGURE 23. MAP OF NIAUFOU ISLAND. AFTER T. A. JAGGAR.

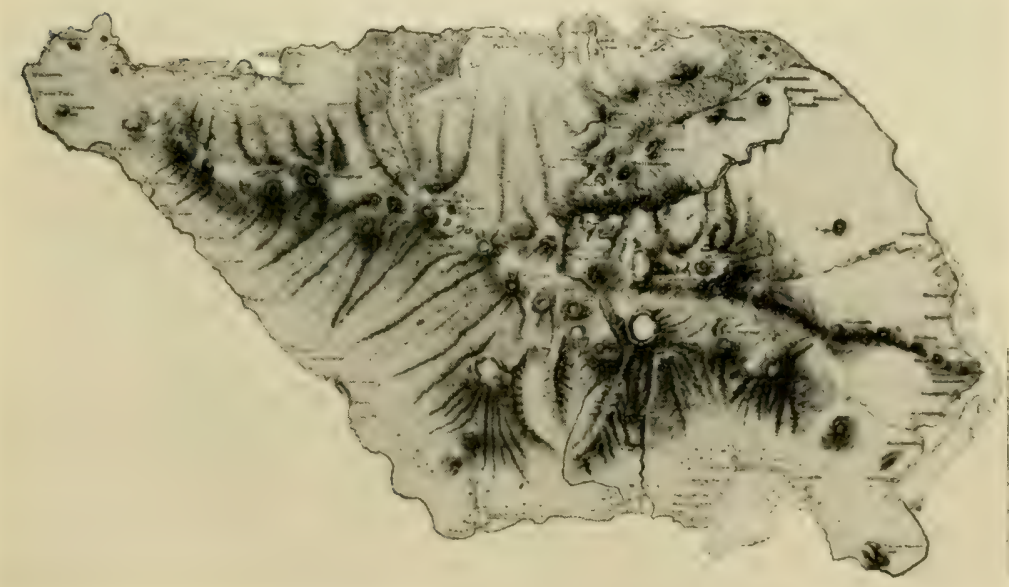

FIGURE 24. MAP OF UPOLU ISLAND, SAMOA. 

island. No human eye can witness the whole titanic battle, but there is no reason to doubt that the process of upbuilding below sea is like that above sea.

Above sea we can see that explosions periodically reshape the pile. The hoisting power is supplied by the tension of water vapor imprisoned in old lava or of original gases imprisoned in the new, hot lava. The ash and so-called tuff made by the explosions are characteristically weak materials, subject to rapidly effective attack by the ocean breakers. For a period of time, therefore, the top of the slowly growing volcanic mountain is kept reduced to a shoal.

Ultimately, however, a more stable cone with crater or socalled caldera, now defended against the surf by interbedded flows of solidified lava, is developed. Niaufou Island of the central Pacific (Figure 23) represents this stage. Still later, eruptions at new fissures and pipes, opened through the submarine mass, ornament the island with many craters, as in the case of the Samoan Upolu, where Robert Louis Stevenson spent his last years (Figure 24).

The essential structure of the submarine part of each island can be reasonably inferred from that exposed in the subaerial part, where valley-wall and sea-cliff show scores of superposed lava flows with occasional thin beds of volcanic "ash."

Long after the emerged part of the volcanic mass has been deeply dissected by streams, it is reduced to a state of low relief, and finally, by the unceasing wave-attack, reduced to a shoal. The changes are summarized by the cross-sections of Figure 25. The top section is that of the relatively young, full-grown island; the other three sections portray successive stages of the destruction. The detritus made by torrent and crashing wave is built out to form growing shelves, as at $\mathrm{XY}$ and $\mathrm{XZ}$. The bottom cross-section shows the ultimate stage, where the island is completely replaced by a shoal. The erosive attack on hard 
1

2

3

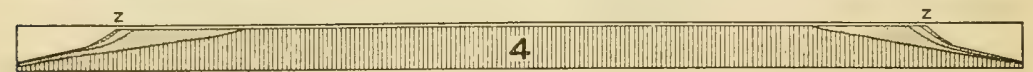

$2 \quad 1 \quad 2 \quad 3 \quad 4 \quad 5 \quad 10 \mathrm{Km}$.

FIGURE 25. SECTIONS TO ILLUSTRATE STAGES IN THE REDUCTION OF A VOLCANIC ISLAND TO A SHOAL AT WAVE-BASE.

rock by waves of the open ocean becomes almost negligible at a depth no greater than about 300 feet. The level at this depth is called technically the "wave-base," a term we shall find convenient for use later on.

At the present time hundreds of island-crowned volcanic piles are dotted over the ocean. Their study has to be superficial in the literal sense of the word. The geologist can learn something by direct inspection, but in every case only about the top, a relatively minute fraction, of the whole volcanic structure. Even Hawaii, the most extensive, as well as the highest, of the volcanic islands, rests on a submarine pedestal with a volume about 20 times that of the visible island. In general the ratio of island to submarine pedestal is much less than I to Ioo.

Catastrophic Changes of Island Topography.-Both upgrowth of the structure and its erosion after emergence above sealevel are long-enduring processes. Both are liable to be interrupted by catastrophes. Sporadic, revolutionary alteration of the form and extent of an island may be brought about by two different causes, major explosion and landsliding on a big scale.

Toward the close of the eruptive stage, volcanic gas is col- 
lected under a tight cover made by the superficial beds of frozen lava. As this gas accumulates, its tension may increase to the point of overcoming the combined weight and strength of the imprisoning cover. Normally the tension is relieved by escape of the gas through cracks, causing moderate explosions but no great change in the island topography. On the other hand, the famous evisceration of Krakatoa Island of the East Indies illustrates the fact that with terrifying suddenness a deep-sea volcano may be modified on a grand scale. Dr. B. G. Escher has drawn the multiple diagram of Figure 26, showing how the original and broad Krakatoa Island (at top of the series of stereograms) was long ago reduced by evisceration, perhaps accompanied by subsidence, to three small islands. The successive stereograms below are intended to illustrate how eruptional additions were made to the dry land, and how in 1883 the main island was once more torn out by what was probably the most violent explosion recorded in human history. Fortunately for colonizing man, such murderous episodes, eviscerations of islands, are rare, though doubtless in prehistoric time, through the geological ages, a good many high islands have been so transformed into "basal wrecks" or even great pits in the sea floor.

Special conditions favor landsliding on a large scale, the second kind of sudden change interrupting the normal evolution of island topography. The constructional slopes of the volcanic mountains are comparatively steep, and gravity is always at work on the slopes. And, secondly, beneath those slopes there are outward-dipping, weak beds along which the slipping may take place. Lubricants of the kind include water-soaked tuffs and volcanic ash. We know, too, that the older layers of lava and ash of a great cone are subject to invasion by outwardly inclined sheets of younger, liquid lava, serving as a different kind of lubricant. Perhaps in some instances violent 


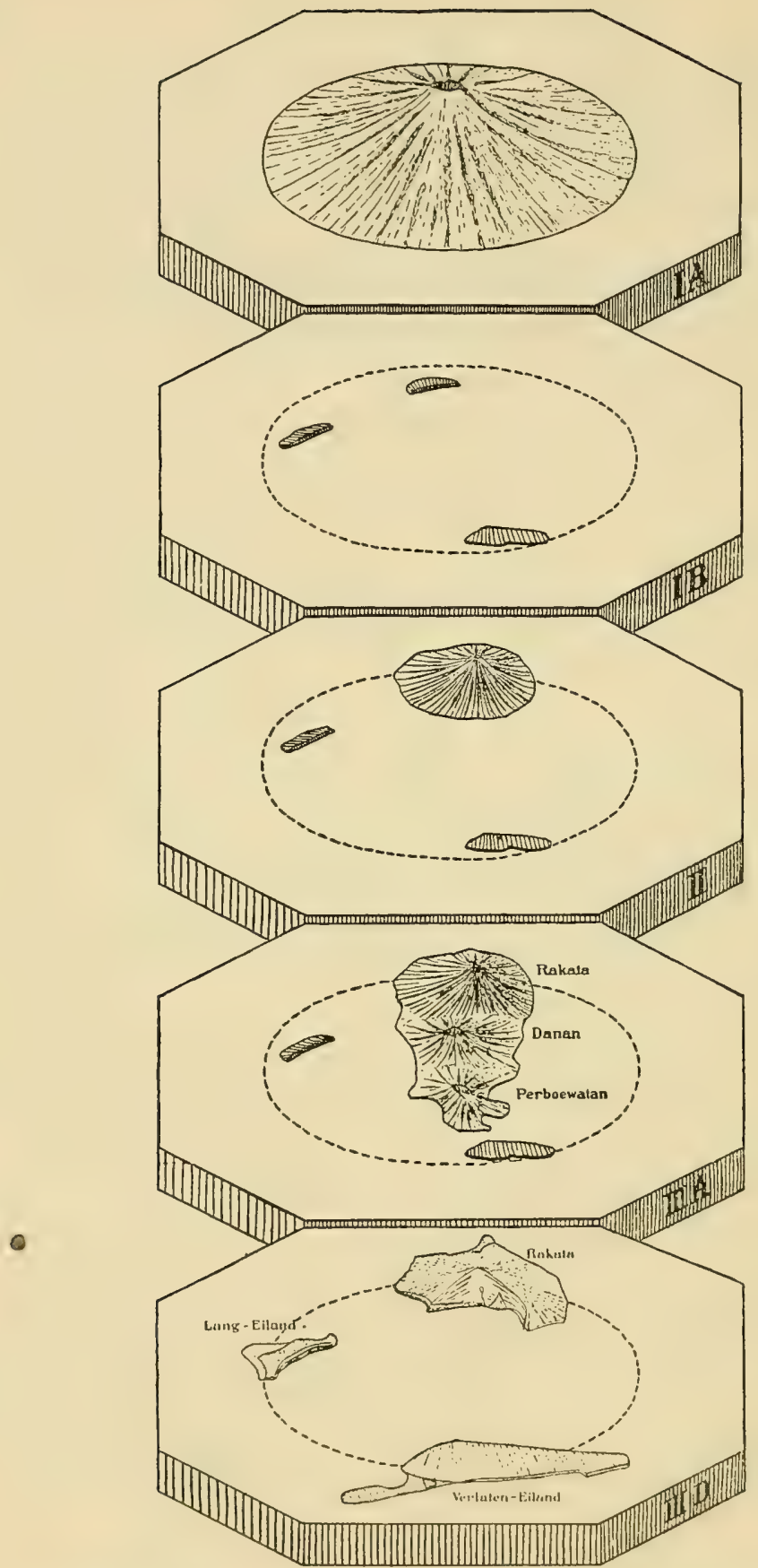

FIGURE 26. STAGES IN THE HISTORY OF KRAKATOA. AFTER B. G. ESCHER. 
earthquake shocks have pulled the trigger and so given the final impulse to catastrophic collapse. The reality of the sliding process was impressed on the writer while mapping volcanic islands in both Atlantic and Pacific oceans.

For one illustration we visit eastern Samoa of the southwest Pacific. There Ofu and Olosega, twin basaltic islands, rise precipitously out of the water, with shapes that immediately suggest a geological drama. See Figure 27. The two islands are

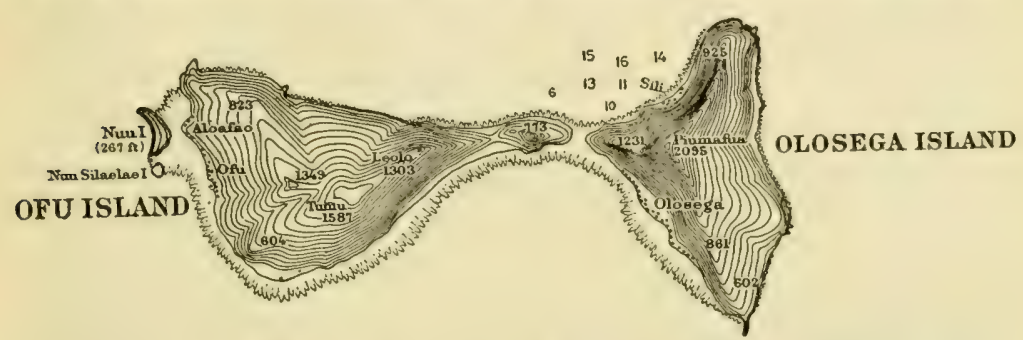

FIGURE 27. MAP OF OFU AND OLOSEGA ISLANDS, SAMOA. FRINGING CORAL REEFS HAVE GROWN OUT SINCE THE COLLAPSE OF THE ORIGINAL VOLCANO.

separated by only a few hundreds of feet of water. Magnificent exposures of the constituent, layered lavas, outcropping in the high cliffs, make it clear that the twin islands are residuals of a single island whose area was much larger than the combined areas of Ofu and Olosega. The chart shows the ground-plan of the existing cliffs composed into two great curves, one concave to the north and the other concave to the south. Field observations, which need not here be detailed, led to the conclusion that this peculiar topography resulted from two geologically recent slides on opposite sides of the original island, and that the displaced masses of rock are now buried under the ocean. Accordingly the high, arcuate cliffs are the inner limits of gigantic scars left by the landslides. In principle the curved crest-lines are like those seen at the heads of scars made by the slipping of rock masses on the continents. In the Ofu-Olosega case the scars only can be seen. The stated theory of origin 
therefore needs checking by adequate sounding of the adjacent sea floor; for it is probable that the foundered débris must have contours unlike those normal to the submarine slopes of a basaltic mountain.

Origin of the Volcanic Heat.-The visible volcanic island, no matter how high, is but the attic story of a building with vastly greater bulk. About this building as well as about its dry-land fraction, we ask two fundamental questions: what is the source of the volcanic heat?; and where does the lava itself originate? In turn the two questions are to be briefly discussed.

The most accurate measurements of temperature for the live lava in the islands have been made at Kilauea of Hawaii. Figure 28 shows the lake of highly fluent lava, which on a night of I934 occupied this famous vent. Over most of the lake a thin, opaque film of glass had been developed because of the tremendously rapid radiation of heat to the sky, but near the shore cliff of the lake the boiling liquid burst its way in high, ever-changing fountains. On the left side of the photograph the gas-charged liquid rock cascades from a wall fissure 400 feet above the lake level.

A few volcanologists attribute the high temperature chiefly to heat-producing, chemical reactions among the primitive gases originally dissolved in the liquid rock. When this composite mass is forced up to levels of low pressure, the gases are not in chemical equilibrium; they make new combinations and this with the evolution of heat. Here, then, we have a true furnace-effect, which is most intense at or near the surface. Yet this kind of "combustion" supplies only a partial solution to the heat problem. Still remaining is the fundamental question as to the temperature of the primitive gas before it began to rise from the depths. During the ascent to levels of lower pressure the gas must expand and thereby tend to grow cooler. As yet no way has been found to calculate the amount by which the 


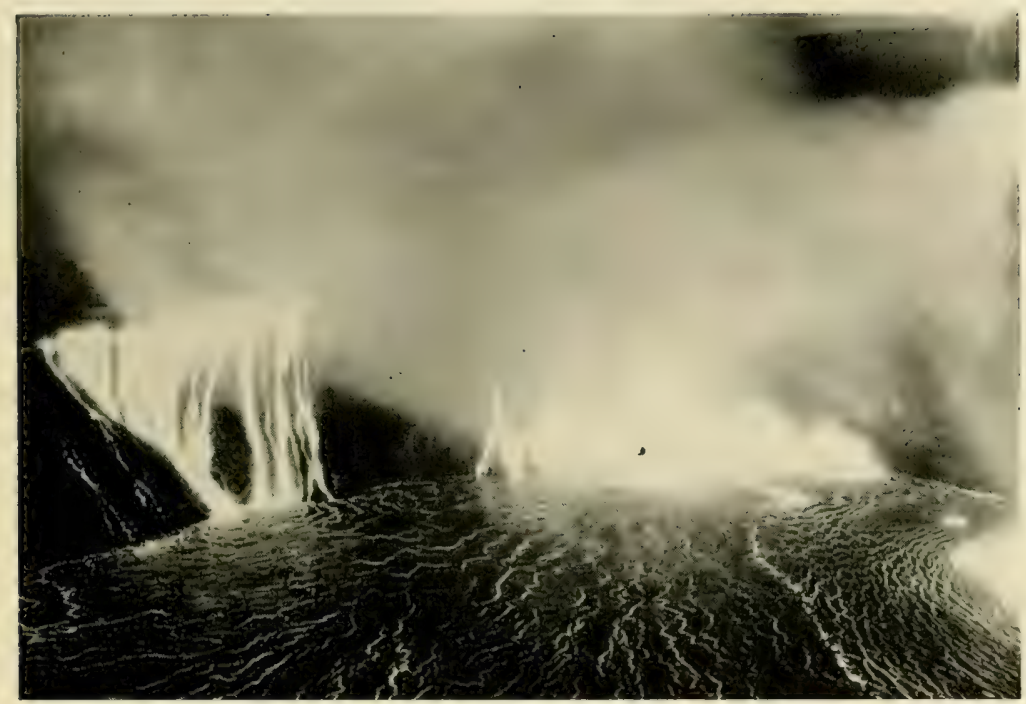

FIGURE 28. NIGHT VIEW OF KILAL'EA LAVA-LAKE. PHOTOGRAPH COPYRIGHTED BY K. MAEHARA.

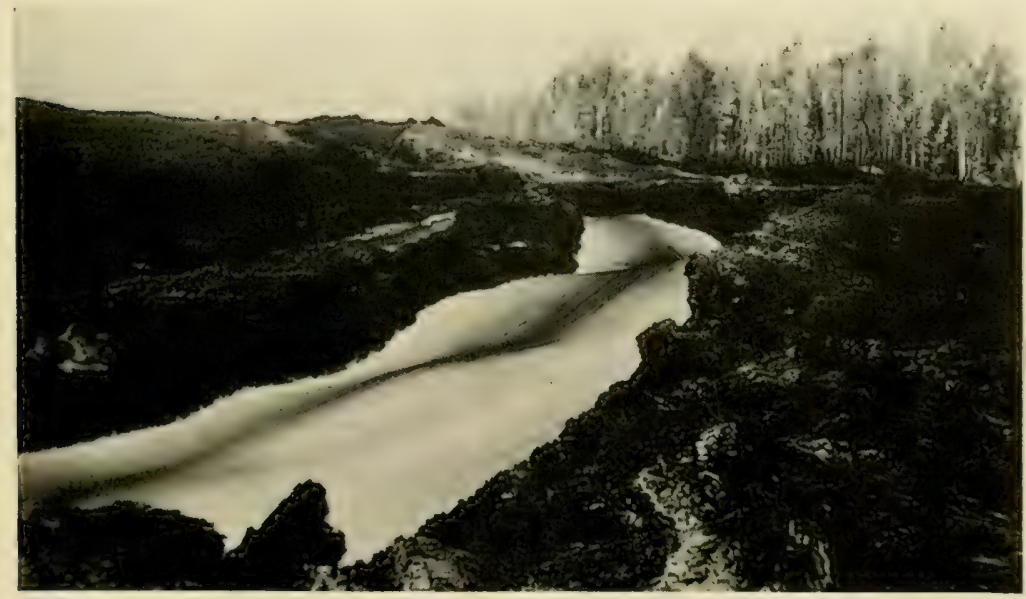

FIGURE 29. A RIVER OF INCANDESCENT HAWAIIAN LAVA, FLOIVING ABOUT IO MILES AN HOUR. PHOTOGRAPH BY T. A. JAGGAR. 

cooling is affected by the furnace-heat of chemical reactions. It is, indeed, uncertain that the initial temperature of the emanating gas was below that of white heat. If it were so high, the rock at the deep level of origin could not be truly solid, that is, crystallized; it would have been largely or wholly in the glassy state.

Other volcanologists favor the view that the source of the live lava at any volcanic center is a local reservoir of molten, gas-charged rock in the otherwise crystallized earth. This second hypothesis has been proposed to account for the distribution of the various chemical species represented by volcanic rocks, and also to reconcile the presence of liquid rock in a planet which, in average, is more "rigid" than steel. Neither of these arguments for assuming that all lava emanates from localized subterranean reservoirs is valid, and the hypothesis suffers from the lack of any adequate cause for the localization of melting in depth.

Less troublesome is a third suggestion-that, during most of geological time, both land and ocean volcanoes were fed from a continuous, world-circling layer of red-hot to white-hot material, beginning at a depth no greater than about 50 miles. It is now assumed that the temperature of this level was high enough to produce a glassy, vitreous state, even at the high pressure ruling at and below the depth of 50 miles. This third explanation for the elevated temperature of erupted matter is based on the study of volcanology in the broadest sense. The reader will note that the general conception of strong crust and hot, glassy, weak substratum was reached when, in Chapter I, the physics of the general sea floor was studied.

A principal fact from which the preferred hypothesis has been derived is the dominance of the dark-colored, relatively dense lava bearing the familiar name of basalt. On land and sea floor alike, in overwhelming floods, this primary molten 
material has been poured out on a scale not rivalled by any other of the hundreds of known chemical species of lava. Its true liquidity during actual eruption is illustrated by the photograph of Figure 29.

Moreover, the eruption of the non-basaltic kinds of lava has been preceded, in many regions, by flows of basalt; and, as already remarked, it appears from observations in field and laboratory that the non-basaltic species are themselves derivatives of liquid basalt or of liquid basalt which had been contaminated with material from the solid rocks through which the molten basalt was forced during its upward journey.

The great individual volumes and enormous total bulk of the visible basaltic piles, the high temperature of their flows, the world-wide distribution of basaltic eruptives, and the genetic relation of basalt to other types of volcanic rock-all these are interrelated problems. All seem to find solution if we assume that both the material and the elevated temperature of the basaltic flows have come, in general, from a subcrustal layer which is too hot to crystallize.

Until a comparatively recent geological epoch this basaltic layer seems to have been continuous all around the globe, thus forming a complete earth-shell. See Figure 30. Judging from new observations on the elasticity of basaltic glass at high pressures and temperatures, it appears probable that glassy basalt cannot now be world-wide and continuous: that here and there, within broad segments, the ancient, energy-charged layer has crystallized because of the slow cooling of our planet.

The velocities of the earthquake waves at depth suggest that at most only a few miles below the crystallized basalt of the crust there now exists a thick, world-circling layer of vitreous, non-crystallized, material which is rich in the constituents of the mineral olivine or peridot, and is therefore named peridotite. 


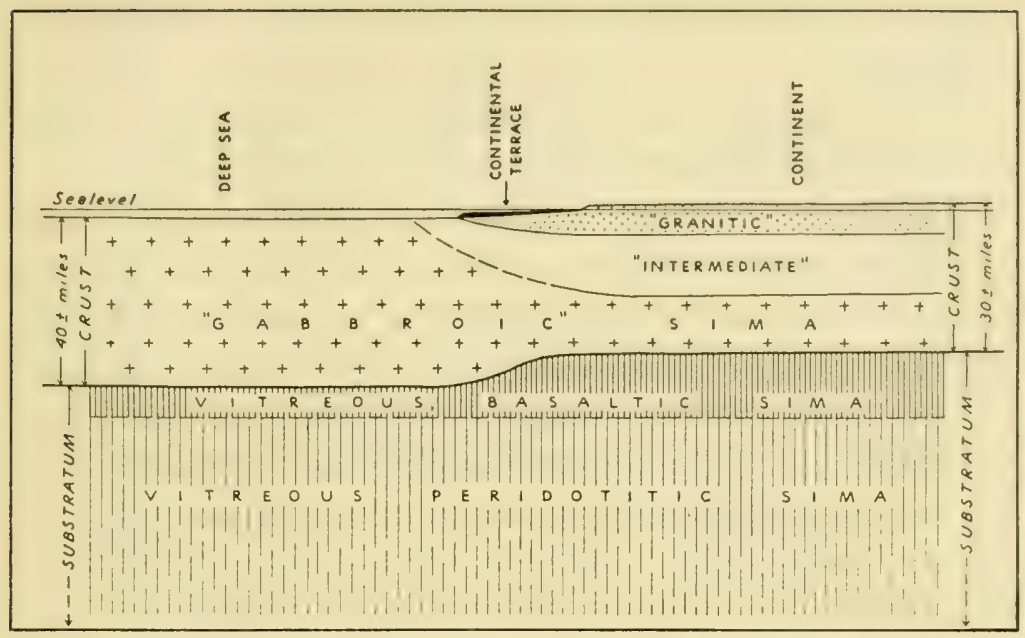

FIGURE 30. DIAGRAMMIATIC SECTION ILLUSTRATING INFERRED CHARACTER OF THE EARTH'S OUTER SHELLS AT AN OLDER GEOLOGICAL EPOCH, WHEN THE CRUST WAS THINNER THAN NOW AND THE VITREOUS BASALT WAS WORLDCIRCLING.

Because the temperature of the vitreous rock approaches or actually reaches that of white heat, the lowest of the earthshells described is extremely weak; the great hydrostatic pressure on it keeps it highly viscous, but its material will flow if subjected to small unbalanced pressure.

In summarizing this story of the underground we recall once more the two technical nouns, "sial" and "sima," with corresponding adjectives, "sialic" and "simatic." The oceanic sectors of the earth are characteristically simatic; that is, their accessible rocks are characteristically rich in the metals silicon and magnesium. Under the ooze and mud of the sea bottom there begins a true crust of frozen, crystallized, basalt. Also simatic is any vitreous basalt which may form "pockets" in the crust. Simatic, too, is the still deeper peridotite. The continental sectors differ by including two sub-layers, both of which are "sialic," that is, relatively rich in the metals silicon and 
aluminum, and the underlying simatic sub-layers, basaltic and peridotitic.

This crust-substratum hypothesis has bearing on almost every phase of physical geology. Its broader implications have been analyzed in several books. ${ }^{2}$ On the present occasion only two aspects of the subject will be considered; each deserves attention because of the recent discovery of relevant, vital facts. The marine volcanic mountains are localized masses of erupted lava resting on the general sea floor. Can the crust-substratum hypothesis tell us how lava can be lifted high above sealevel? Are the great loads of lava being stably supported? If they are, their support must come from the crust alone, for the substratum is assumed to have negligible strength.

It is to the advantage of the hypothesis that it almost automatically answers the first question. If the substratum is glassy because hot, it is eruptible. If some force opens a fissure extending from bottom to top of the crust, the essentially liquid glass, under an initial pressure of the order of 200 tons to the square inch, is shot upward into the fissure. On the left side of each section in Figure $3 \mathrm{I}$ (drawn on the assumption that

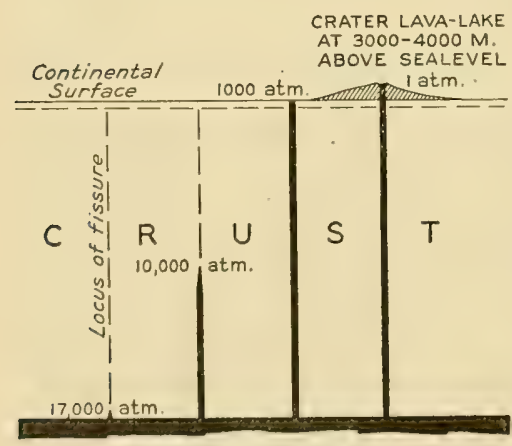

SUBSTRATUM
CRATER LAVA-LAKE AT $3000-4000 \mathrm{M}$. ABOVE SEALEVEL



SUBSTRATUM

FIGURE 3 I. SECTION ILLUSTRATING THE RELATION OF SÜBSTRATUM TO VOLCANISM. 
the substratum is topped by basalt) is the trace of such a vertical fissure through the crust. To right of it are shown other fissures, along which the molten basalt from the substratum (solid black) rises in successive stages. At the top is a built-up cone, through which the liquid column passes, all the way to the open crater. The two sections respectively picture the conditions for basaltic eruption on continent and sea floor, at a geological epoch when the glassy basalt formed a world-circling layer. For the reason stated in the first chapter, the sub-oceanic crust is shown as somewhat thicker than the sub-continental crust.

As the surface cone grows higher by the piling of frozen lava and ash-beds around the vent, the active liquid column becomes longer and exerts increasing pressure on the substratum. Evidently this back-pressure puts a limit to the height to which the liquid column or the surface crater can reach. That limit is reached when the weight of the crust, plus the weight of air and water on the crust, becomes equal to the weight of the liquid column.

The highest liquid column of the oceanic volcanoes is that of Mauna Loa, Hawaii, when its crater is occupied by a "lake" of boiling, basaltic lava, about 13,000 feet above sealevel. The ro,ooo-foot Mount Etna in full activity seems to contain the highest column of liquid basalt on the continents. Let us suppose that Mauna Loa and Mount Etna have both completed their growth. If we can estimate the average densities of these two liquid columns, and also estimate the respective average densities of the sub-oceanic and continental segments of the crust, we can calculate the approximate thicknesses of the crust in the two segments. With the stated assumptions, the crust under Sicily is found to be not far from 40 miles; the crust under the mid-Pacific, not far from 50 miles. Both estimates are crude but seem to give a reasonable order of magnitude. 
The comparison seems significant even if glassy basalt does not now constitute a complete earth-shell.

The Volcanic Mountain a Test of Crustal Strength.-Compared to the width of an ocean basin, a thickness of 50 miles for the crust is small, and the crust must be regarded as relatively thin. On that skin of the earth the volcanic piles have been built. Their constituent rock is between two and three times as dense as the displaced water. The roughly conical pile is two to six miles thick (high) and at base has a minimum width of roo to 200 miles. Each mountain is an enormous mass resting on the original floor of the ocean, and the way in which it is supported is at once seen to be of prime importance in connection with the crust-substratum hypothesis. We now face the second fundamental question: can the membrane-like crust continue to bear these great superficial loads of rock, if the substratum has little or no strength? The answer depends: first, on the degree to which the crust is stressed by the loads; second, on the degree of stability actually characterizing the volcanic mountain; third, on the degree of strength possessed by crystalline rock when, under the controlled conditions of the laboratory, it is subjected to the same conditions of pressure and temperature as those affecting the assumed crust. We shall briefly review recent researches bearing on all three topics, which manifestly have vital relation to earth physics in general.

That the volcanic cones rising from deep water represent great loads on the earth's crust has been proved by the gravity pendulum. The first chapter contains a brief account of the so-called "reductions" of observed values of gravity to the corresponding sealevel values. We learned, too, that at each occupied station the difference between the reduced value and that expected from the general figure of the earth, or the standard spheroid, is called a gravity anomaly. Of the different 
classes of anomaly we shall now be interested in only two-the free-air anomaly and the isostatic anomaly.

Actual measurements of the intensity of gravity have been made on Bermuda, Ascension Island, and Saint Helena Island of the Atlantic, and on Oahu Island and Hawaii Island of the Pacific. In every instance gravity is much above normal. The same is true at the submarine stations occupied by Professor Vening Meinesz off Oahu, Madeira, and Sao Miguel islands. ${ }^{3}$ Figure 32, a map of Oahu, illustrates one of the cases (land stations only). Gravity stations are indicated by dots, beside which are the corresponding free-air anomalies. Much greater free-air anomalies are found in Hawaii. See Figure 33, where numbers in brackets represent isostatic anomalies. All the

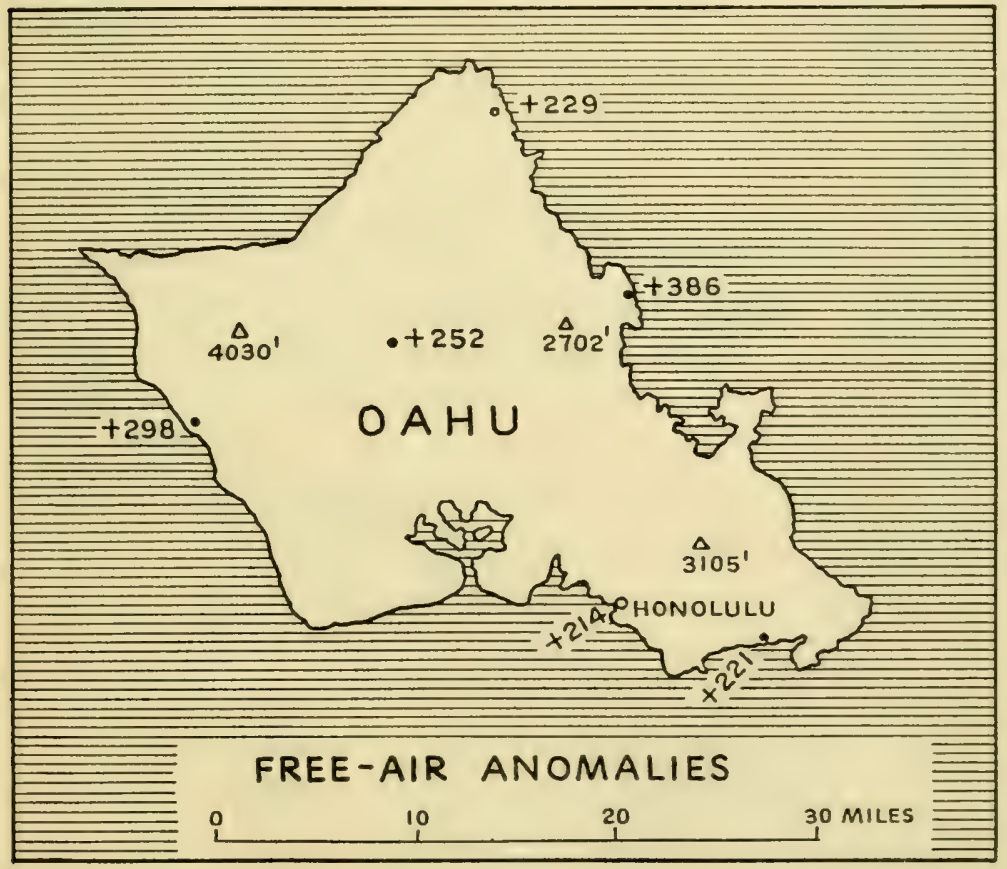

FIGURE 32. FREE-AIR ANOMALIES OF GRAVITY IN OAHU ISLAND. HEIGHTS IN FEET. 
numbers are expressed in milligals, a milligal being again defined as practically one millionth of average gravity at the earth's surface.

On grounds too technical for present description, it appears that at each volcanic mountain a free-air anomaly somewhat exaggerates the implied excess of attracting rock, but in general by less than 50 per cent. A milligal means a force equal to the

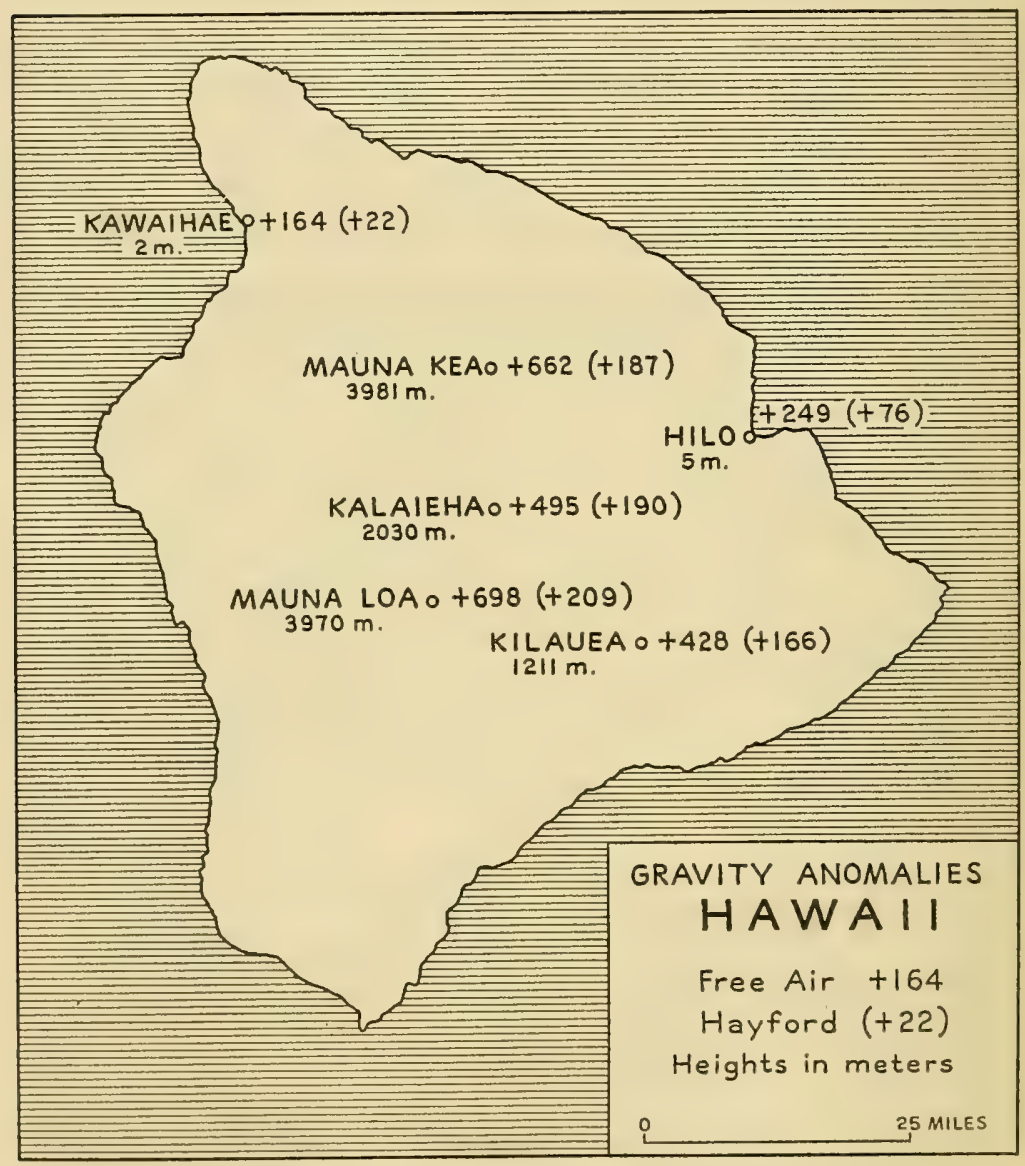

FIGURE 33. ANOMALIES OF GRAVITY IN HAWAII ISLAND. 
attraction of an indefinitely extended, uniform plate of granite about 30 feet in thickness. Hence from the anomaly maps it is a fairly conservative conclusion that each Hawaiian island presses on the general sea floor with a weight like that of a cylinder of granite a mile thick and having a horizontal diameter as great as 200 miles, the width of one of these volcanic buildings. The excess loads at the Atlantic islands are somewhat smaller, and yet they too must severely tax the strength of the earth's crust, if this is no more than 50 miles in thickness.

Naturally the foregoing estimates of load cannot be used for computing the strength of the crust until another step is taken. We need to know whether the great volcanic loads can be stably borne. There is, in fact, no reason to believe that the sub-oceanic crust is yielding to the loads. Let us call to the witness stand Bermuda; then some analogous islands of the Pacific; and, finally, the large number of volcanoes capped by living coral reefs that belong to the atoll and barrier types.

A vertical bore-hole was sunk through the shell (-coral) sand of Bermuda (Figure 34) to a depth of about 240 feet below sealevel. There the bit of the boring machine entered the wave-eroded surface of a volcano of basaltic habit. See Figure 35. The penetrated lava was largely fragmental, as if the material had been exploded out of an ancient vent. Interspersed among the fragments are small shells of marine animals that lived and became extinct in Tertiary time, at least ten million years ago. Already at that time Bermuda, a volcanic pile, had been truncated by the Atlantic waves and reduced to a shoal. Ever since, the beveled cone, roo miles across at its base and more than I2,000 feet high, has been pressing on its floor, and yet apparently the sub-Atlantic crust has not yielded to the load.

Similar paleontological proof of crustal stability, in the 


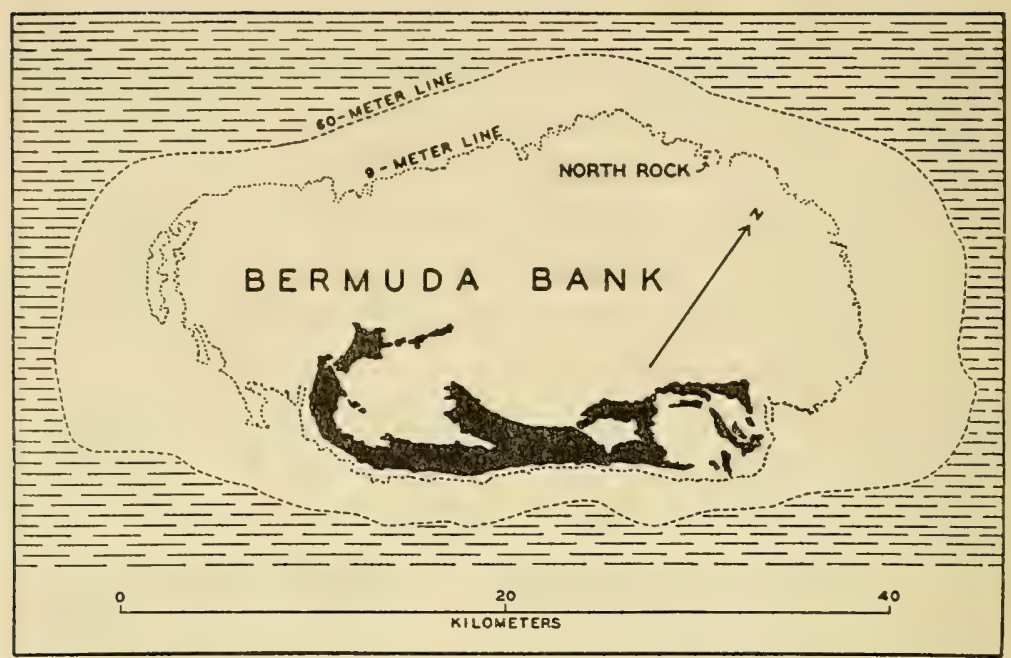

FIGURE 34. MAP OF BERMUDA ISLAND (SOLID BLACK) AND SURROUNDING BANK.

Pacific region, has come from limestone-veneered, volcanic cones represented by Mango Island of the Fiji group, Mangaia Island of the Cook group, Uvea of the Loyalty group, and Jaluit Atoll of the Marshall group. Several of the Hawaiian islands show plain evidence of repeated risings and sinkings in slow rhythm, but as yet no evidence that these greatest of all

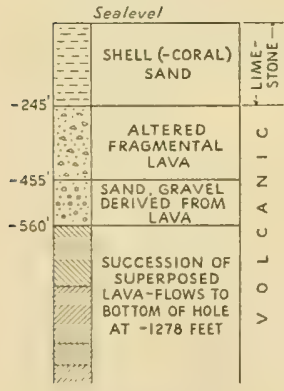

BERMUDA

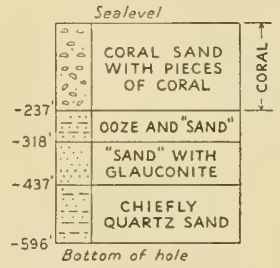

MICHAELMAS CAY

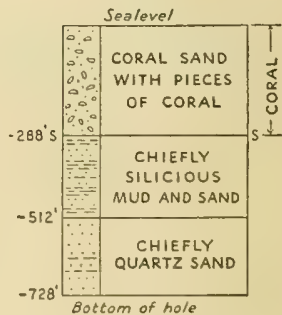

HERON ISLAND

FIGURE 35. SECTIONS SUMMIARIZING LOGS OF BORE-HOLES IN BERMUDA ISLAND, MICHAELMAS CAY, AND HERON ISLAND. 
volcanic loads on the Pacific floor are breaking the crust and therefore in net subsidence.

Soundings show the foundations of many barriers and atoll reefs to have shapes essentially like those of the truncated volcanoes on which the gravity pendulum has been swung. Moreover, in a large number of cases the visible island surrounded by barrier reef is clearly the emerged top of a volcano of dominantly basaltic composition. It seems highly probable, therefore, that the reef-veneered volcanic piles also are excess masses weighing heavily on the crust. Nevertheless, the submarine topography spells stability for these weighted areas during hundreds of thousands of years and even millions of years.

The topographic evidence for that stability is easily stated. ${ }^{4}$ The lagoons inclosed by barrier or atoll reef are wide, and except for occasional knolls of upgrowing corals, the bottom of each lagoon is almost perfectly horizontal. A few examples will be cited.

First, we study the barrier lagoon of the Truk Islands, Caroline group (Figure 36). Note its considerable width, given by the scale, and the small variation in the number of fathoms of lagoon depth.

Similar characteristics are found in the Nomwin and Murilo atolls, also of the Carolines (Figure 37); the Mille or Mulgrave atoll (Figure 38); the magnificent atoll of Suva Diva in the Indian Ocean (Figure 39), whose cross-section helps the map to emphasize the flatness of the lagoon floor.

The cross-sections of Figure 40 still further illustrate the case. The water is shown in solid black; depths in fathoms; respective horizontal scales in nautical miles, each equal to I00o fathoms. The first two sections represent the Seychelles Bank of the Indian Ocean and the Macclesfield Bank of the China Sea. The next two sections were made across banks in the Indian Ocean, bearing reef patches in their central parts 


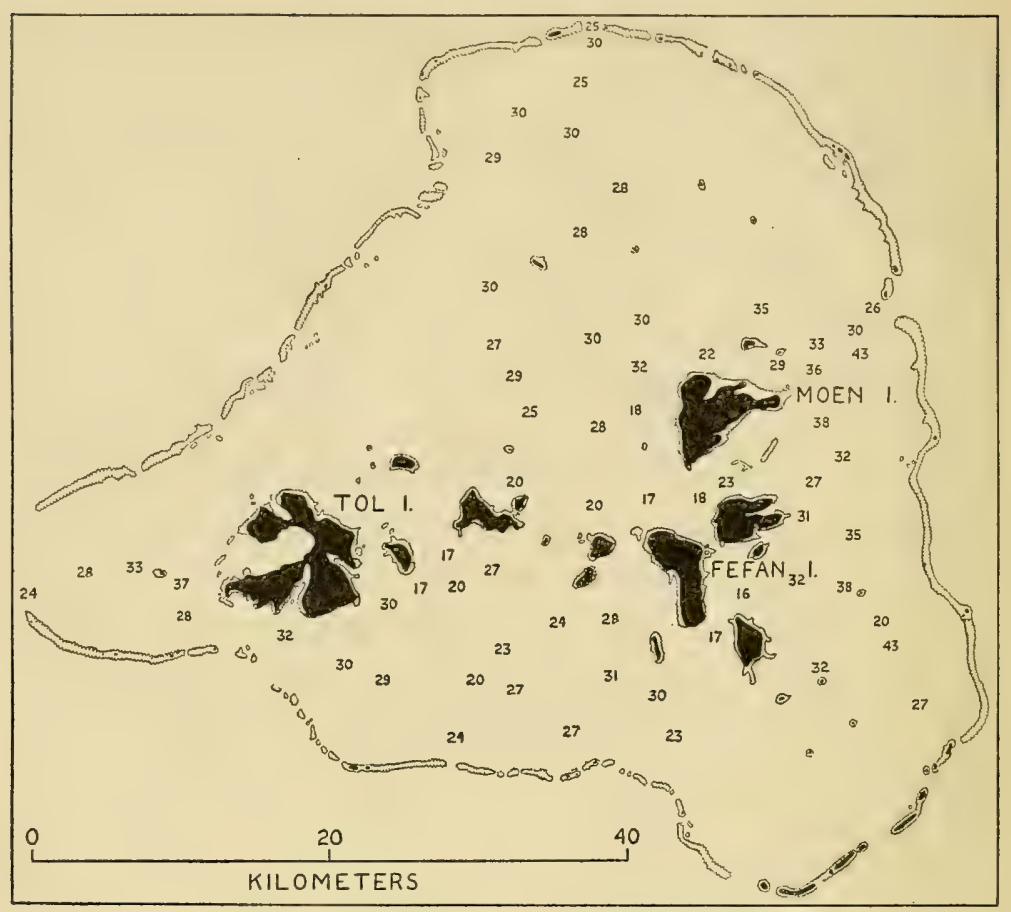

FIGURE 36. MAP OF BARRIER REEF AROUND THE TRUK ISLANDS. DEPTHS IN FATHOMS.

(reef-insets). The third pair, which are sections across Tagula Island of the Pacific Louisiade archipelago, and Truk Islands of the Pacific Caroline group, exemplify typical barrier reefs. The last three sections refer to Peros Banhos of the Indian Ocean, Funafuti of the Pacific Marshall group, and Kolumadulu of the Indian Ocean-all typical atolls.

Maps and sections alike point to a conclusion which is extremely hard to avoid: the living reefs are veneers, grown up on old banks that had been smoothed by wave and current before the banks were colonized by the coral larvae. In all of the cited cases, and at hundreds of other atolls and barriers of the tropical belt, the lagoon depths never reach 50 fathoms or 


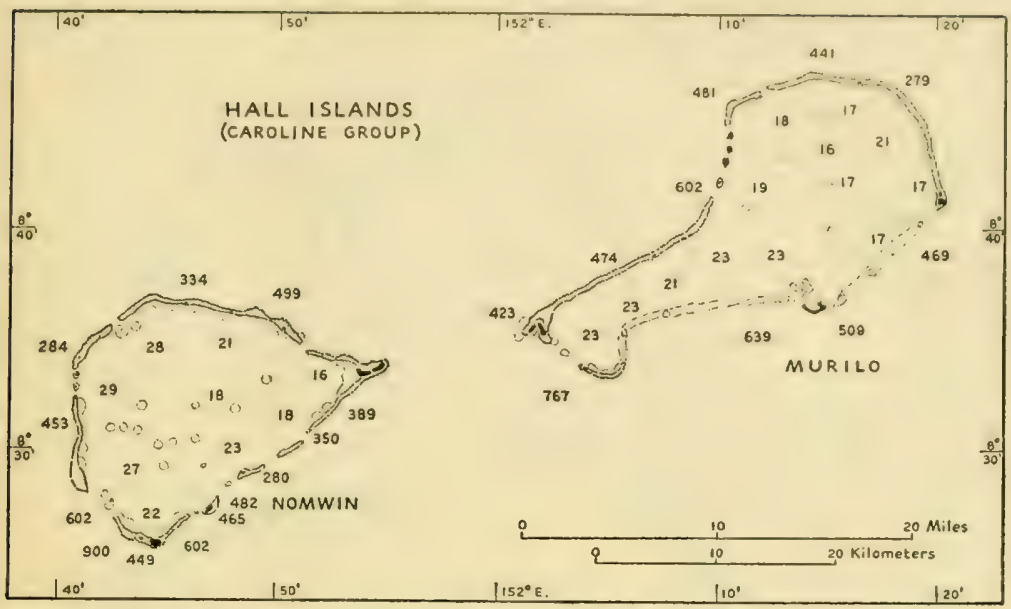

FIGURE 37. MAP OF ATOLLS IN THE CAROLINE GROUP. LAND IN SOLID BLACK. DEPTHS IN FATHOMS.

300 feet, which is practically the depth of wave-base. The billiard-table flatness of the lagoon floors is the product of cutand-fill by the waves, and the excess of 50 fathoms over the lagoon depth can be reasonably ascribed in large part to incipient filling of the lagoon by shells and skeletal fragments derived from the organisms that thrive on reef and over lagoon floor.

Yet clearer is the fact that the actual flatness of floor can have been developed only during prolonged stillstand of the volcanic foundation, that is, during a long period of crustal stability, including the present time.

The main living reefs stand wall-like on the borders of the lagoons, and 200 to 250 feet above the lagoon floors. From their classic studies, Charles Darwin and James Dwight Dana concluded that the living reefs project upward in this way because the reef foundations slowly sank and continue to sink slowly. Their theory, made before adequate soundings had been made in the tropical belt, has serious defects. There is a 


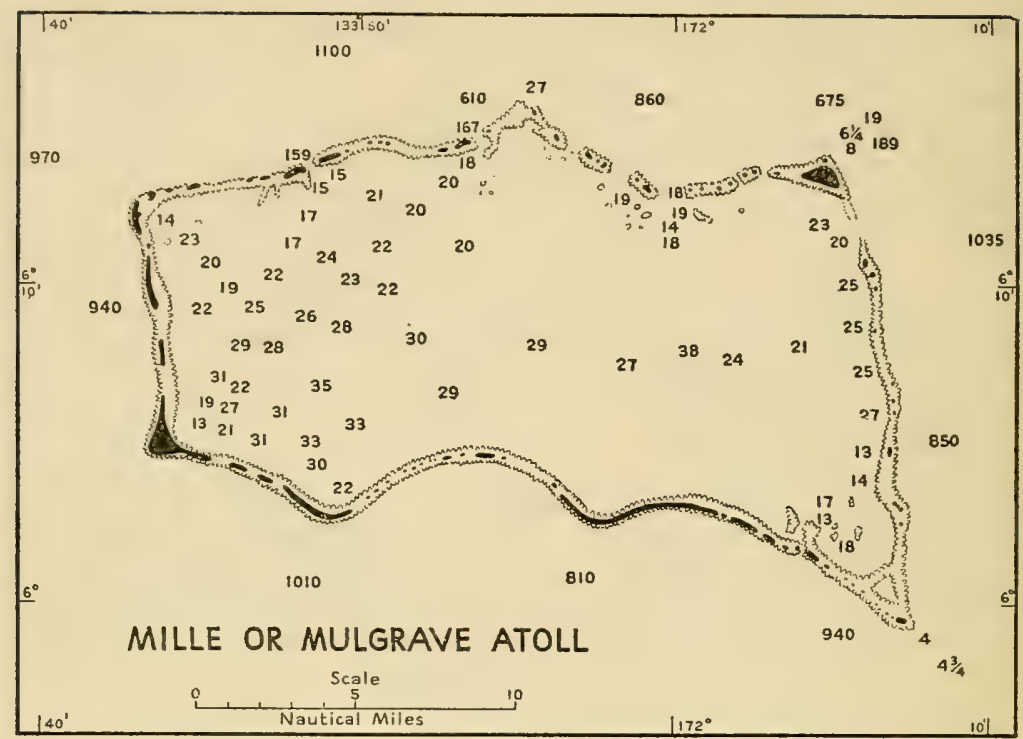

FIGURE 38. MAP OF MILLE OR MULGRAVE ATOLL. LAND IN SOLID BLACK. DEPTHS IN FATHOMS.

much more appealing explanation of the break of slope between lagoon floor and reef. According to the better reasoning, the living reefs have grown up from banks, shoals, during a slow, late-Glacial and post-Glacial rise of sealevel all over the world.

The Glacial Period contained four long successive stages during which major ice-caps were formed on the continents. The Glacial stages were separated by three inter-Glacial stages, times of ameliorated climate. The water of the ice-caps had been evaporated out of the ocean, so that, whenever the ice lay thick on the land, sealevel was lowered everywhere-in maximum about 300 feet. During each Glacial stage, coral growth was greatly inhibited by the relative coolness of the sea and probably still more by the muddiness of the shore waters, muddiness being the deadly enemy of the reef-building corals. Lacking defense by living reefs, the old, soft-rock shoals and 


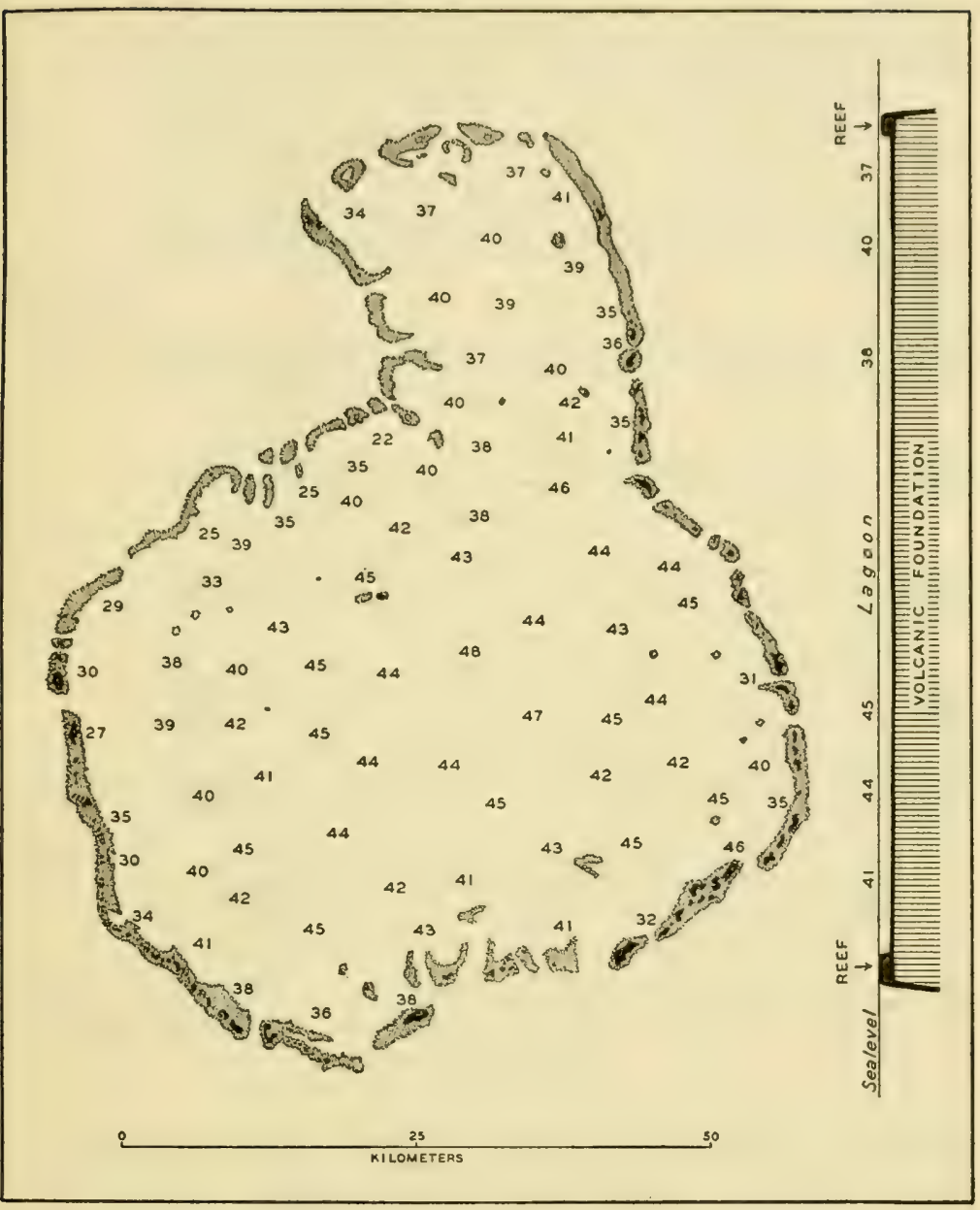

FIGURE 39. MAP OF SUVA DIVA ATOLL. LAND IN SOLID BLACK. DEPTHS IN FATHOMS.

shelves of the tropical belt were then eroded to flatness. With the next melting of ice-caps and consequent rise of general sealevel, coral larvae, emerging from places of asylum and distributed by currents, colonized the smoothed flats, took root, and with the slow rise of sealevel, throve particularly well 


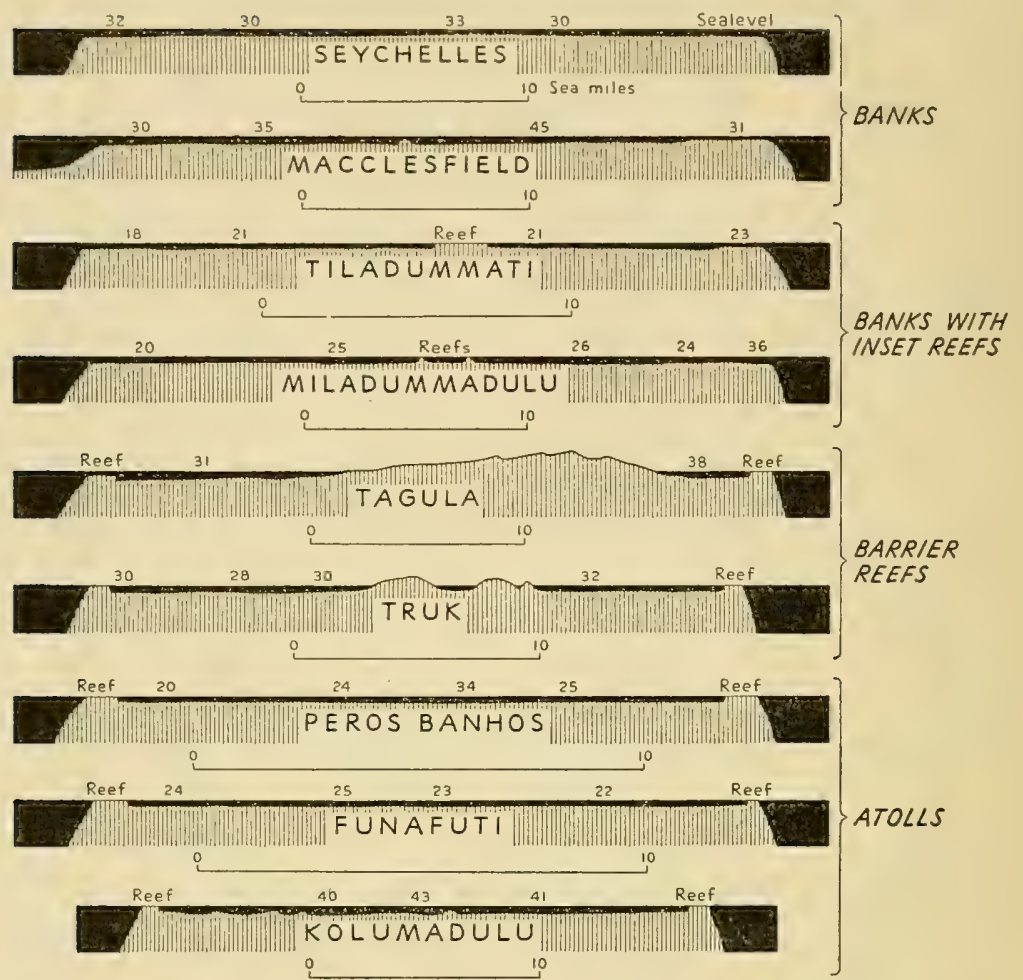

FIGURE 40. SECTIONS ILLUSTRATING FLATNESS OF THE FLOORS OF REEF LAGOONS AND THE CLOSE SIMILARITY OF WATER DEPTHS WITH THE DEPTH ON OLD BANKS.

along the edges of those flats. There they grew up as walls, to be destroyed during the next Glacial stage.

The sections of Figure 4I illustrate the postulated history, so far as it relates to the time since the last inter-Glacial stage. The last world-wide rise of sealevel permitted the colonizing corals to build the wall-like reefs living in the tropical belt.

Space cannot be taken for a full statement of this Glacialcontrol theory, but two tests of its validity may be mentioned.

First, we note that the 300 -foot upward shift of sealevel is 

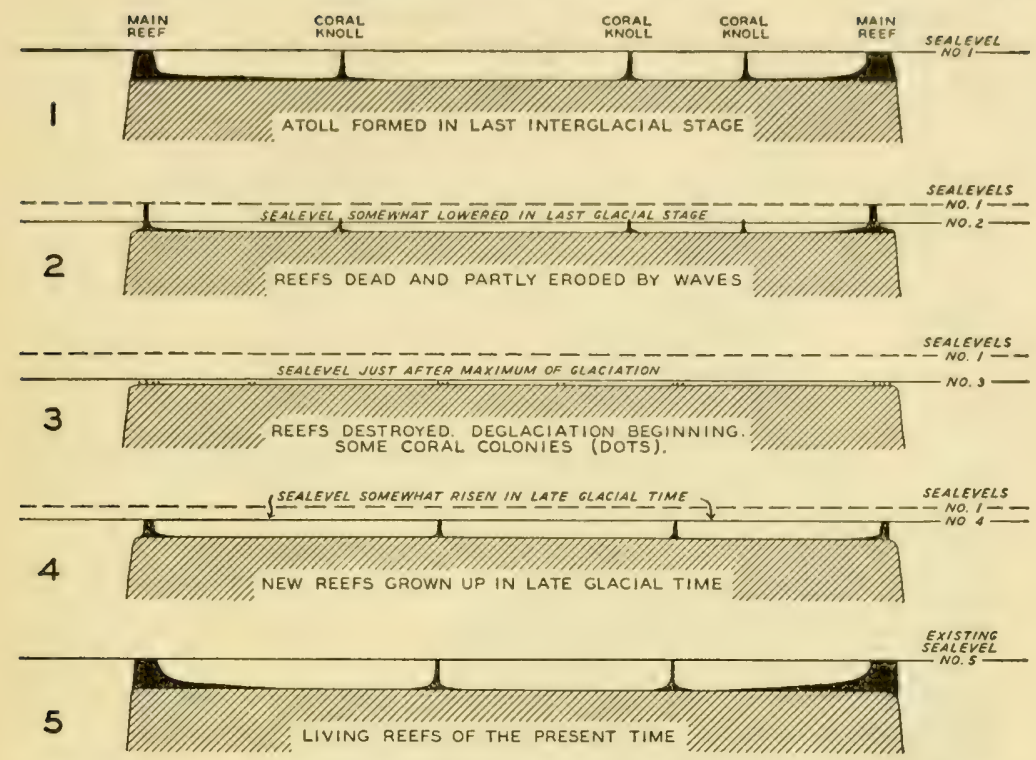

FIGURE 4I. SECTIONS ILLUSTRATING THE GLACIAL-CONTROL THEORY OF THE LIVING CORAL REEFS. REEF IN SOLID BLACK; PLATFORM IN DIAGONAL SHADING.

just right to match the height of the wall-like reefs above the lagoon floors.

Second, the relative merits of the two theories can be tested by the logs of bore-holes sunk in appropriate places. Darwin and Dana regarded the Great Barrier Reef of Australia and associated lagoon, each I200 miles long, as furnishing the grandest example of subsidence. Now, two borings have been made through coral rock situated well inside the Barrier and also far from the main shore of Australia. See Figure 42. According to the subsidence theory, coral rock should have been found in each hole at depths far exceeding that of 300 feet below sealevel. Figure 35 gives, in summary, the logs of the two borings. At Michaelmas Cay the coral continues down to the depth of 237 feet; at Heron Island, to the 288 -foot level, where a bed of pure quartz sand was found. Neither depth 


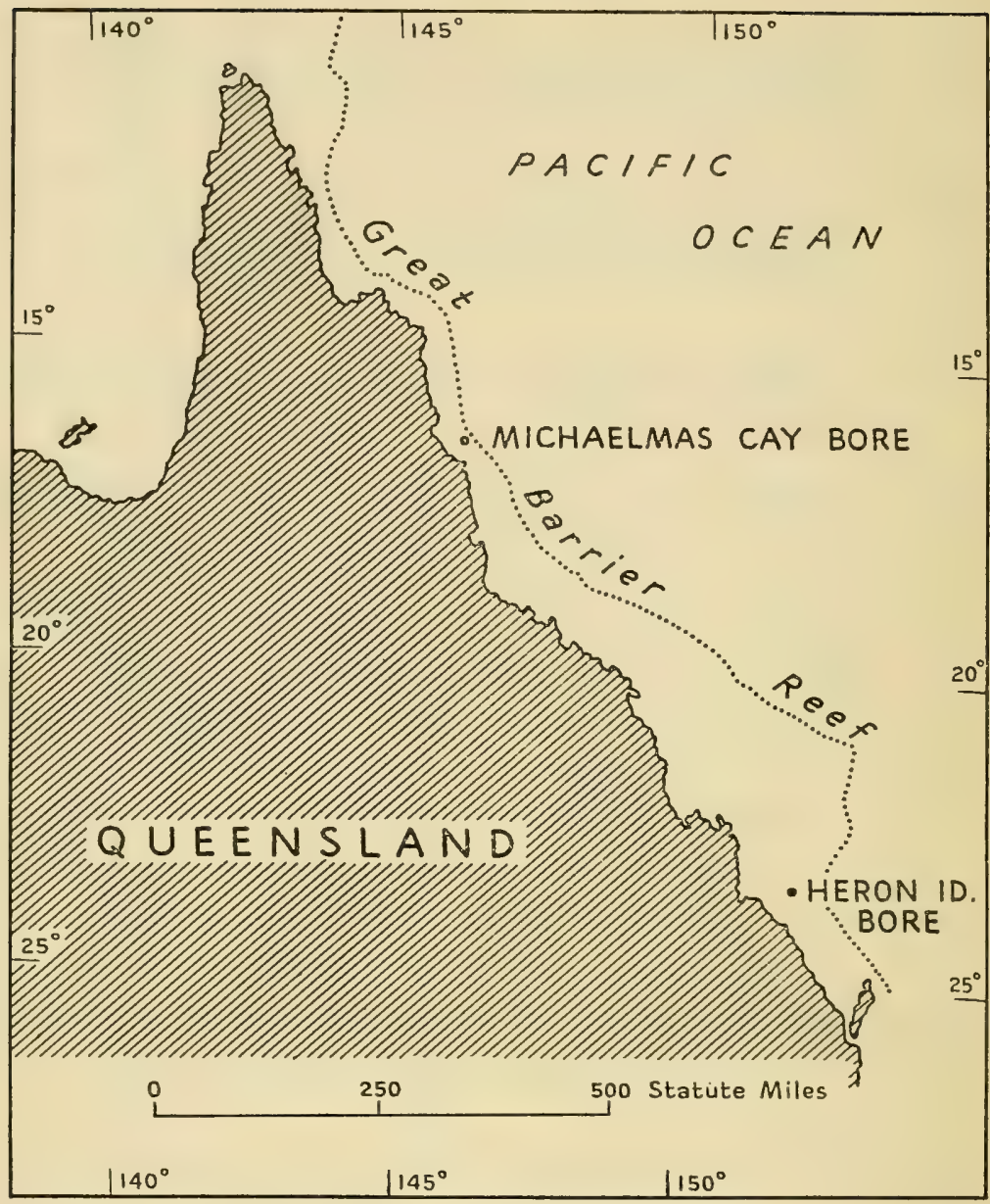

FIGURE 42. MAP SHOWING LONG LAGOON INSIDE THE GREAT BARRIER REEF OF AUSTRALIA, WITH LOCATION OF MICHAELMAS CAY AND HERON ISLAND.

reaches 300 feet. Each is of the same order of distance below sealevel as that reached by the bottom of the shell-coral sand in Bermuda. Thus it seems clear that the association of broad lagoon with peripheral reef, whether atoll or barrier, does not demonstrate subsidence of the earth's crust or give a measure of the strength of the sub-oceanic crust. 
On the contrary, it is reasonable to find in the prolonged stability of a Bermuda, Truk, Suva Diva, or Funafuti a measure of the strength of the sub-oceanic crust.

Of course, proof that the sub-oceanic crust, though heavily burdened with piles of lava, has not sunk during the last million years or so by no means implies stillstand in earlier times. In fact, the sea floor had to keep sinking while each volcanic mountain was slowly growing up, flow on flow, ash-bed on ash-bed. The mere transfer of the huge total mass of lava to the surface meant removal of the underpinning of the rocky floor of the ocean round about, and therefore subsidence in the same region. Moreover, any older volcanic mountain that had been built on the outlying part of the belt of subsidence had also to go down. It is a case of action at a distance-true subsidence compelled by the elastic strength of the earth's crust. A possible example may be represented by the moderately drowned Bora Bora Island of the Society group; here the drowning is conceivably the result of the eruption of the voluminous lavas constituting the younger volcanic mountain of Tahiti, not far away.

For still other reasons, quite unconnected with volcanism, an atoll or reef-rimmed island, which had been stable long enough for the development of a broad lagoon, may have been forced to subside. Examples may be sought where an oceanic region has been disturbed by the forces of mountain-building. Such may be the case with the "drowned" atolls of the China Sea and the atolls of the Philippine region (Figure 43).

On the other hand, the "drowning" of these same atolls may be only apparent, not real. They lie in the broad belt tormented by typhoons, storms capable of beheading the reefs to depths of five to ten fathoms below sealevel. According, then, to an alternative hypothesis there is no need to assume any departure from that stability of reef foundations which is 


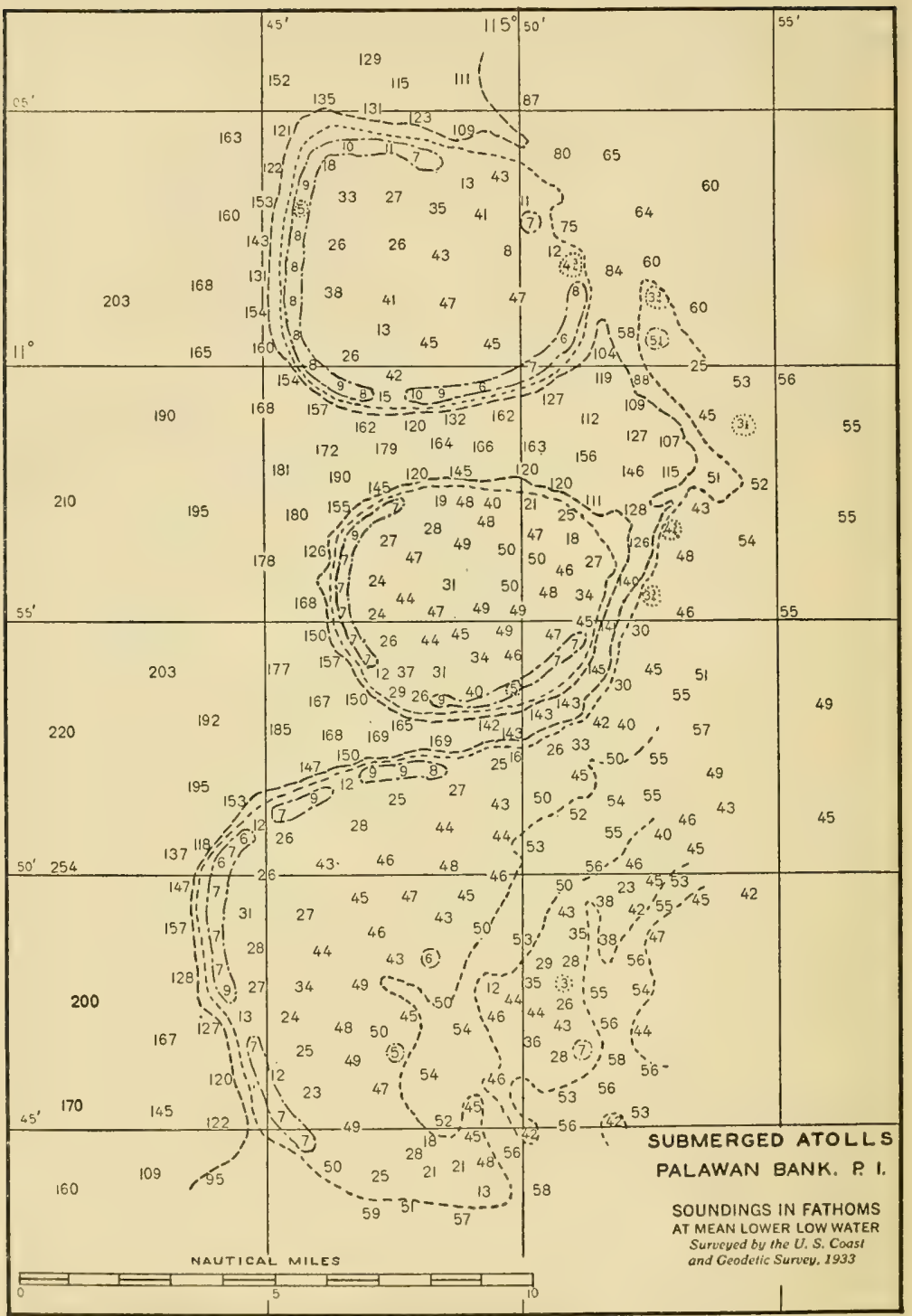

FIGURE 43. "DROWNED" ATOLLS OF THE PHILIPPINE ARCHIPELAGO. FROM MANUSCRIPT MAP PRESENTED BY H. W. MURRAY OF THE UNITED STATES COAST AND GEODETIC SURVEY. 
so clearly indicated by the flatness of the lagoon floors. A proper choice between the two explanations of the "drowning" remains an open problem, which illustrates the difficulty of telling where "submergence" means "subsidence."

In summary, it looks as if the sub-oceanic crust preserves its elastic strength even under the heavy volcanic loads. If this is true, we should expect that similar support should be given to what may be conveniently called negative loads. Just such loads are represented at the ocean "deeps," mentioned in the first chapter. (See page 9.) The long troughs seem to have been formed where the sub-oceanic crust has been bent down by the powerful force of mountain-building: specifically under the horizontal pressure of overriding, continental blocks. Beneath each resulting trough the material of the substratum was forced away laterally, and sea water was accumulated in the trough itself. Manifestly the outflow of heavy rock-matter and inflow of the much less dense water involved a net deficiency of matter under the trough. Here the upward pressure of the quasi-liquid substratum has been increased, but its tendency to push up the crust toward the original level is resisted by the strength of the crust. So long as this resistance is unimpaired, the crust under the deep carries a negative load.

The amount of the load can be approximated by measuring gravity at a sufficient number of stations within the region of deformation. This Professor Vening Meinesz has done at the Nero Deep off Guam Island, a map of which appears in Figure 44. The maximum sounding in the deep is nearly ro,000 meters or 33,000 feet. The submarine of Vening Meinesz followed the course marked by the broken line. The corresponding cross-section (Figure 45) represents the solid crust by shading, and sealevel by the middle horizontal line that bears the designating numbers of the observing stations. The broken-line and dotted curves picture the variations of four different kinds 


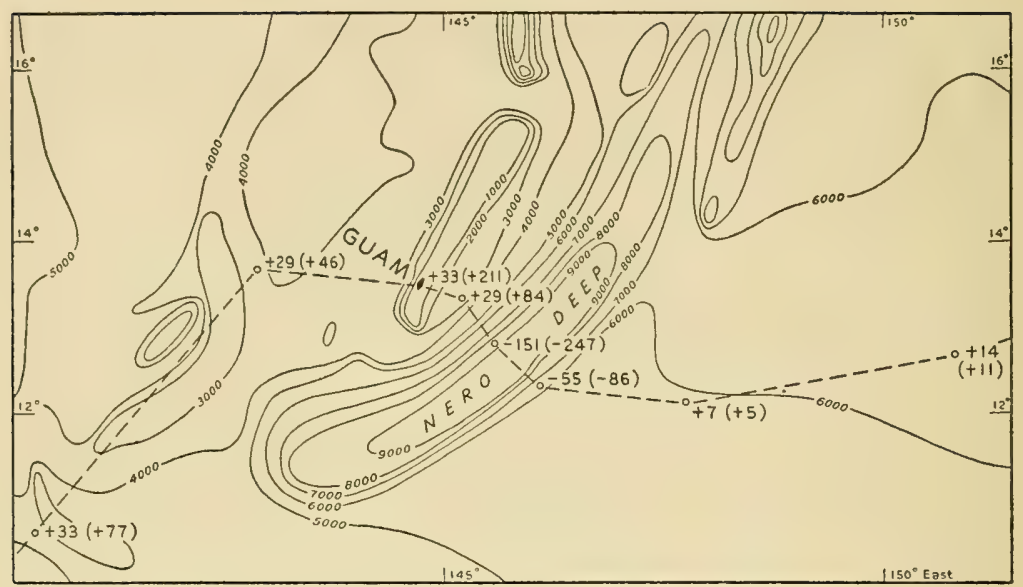

FIGURE 44. MAP OF THE NERO DEEP. DEPTHS IN METERS.

of gravity anomalies. The scale for the anomalies, in milligals, is on the left; the scale for depth of water, in meters, on the right. The strong downward deflection of all the curves is proof of abnormally low intensity of gravity over the deep, and this can mean only local deficiency of attracting matter. The study of other deeps has given essentially similar results.

The new data suggest that the negative loads rival the positive loads in stressing the sub-Pacific crust. From both sets of observations geologists have been led to assume for the crust an average strength about twice that of granite.

Here we meet our third principal question: can a 50-mile crust, although red hot at its base, have such a high degree of strength? Manifestly the strength of rock decreases with rise of temperature, and mines and bore-holes amply prove rise of temperature with increase of depth. On the other hand, well controlled experiments, including the best of all, those of Mr. David Griggs at Harvard University, show cool rock to grow much stronger when subjected to an all-sided pressure of a few thousands of atmospheres. Because of the time element 


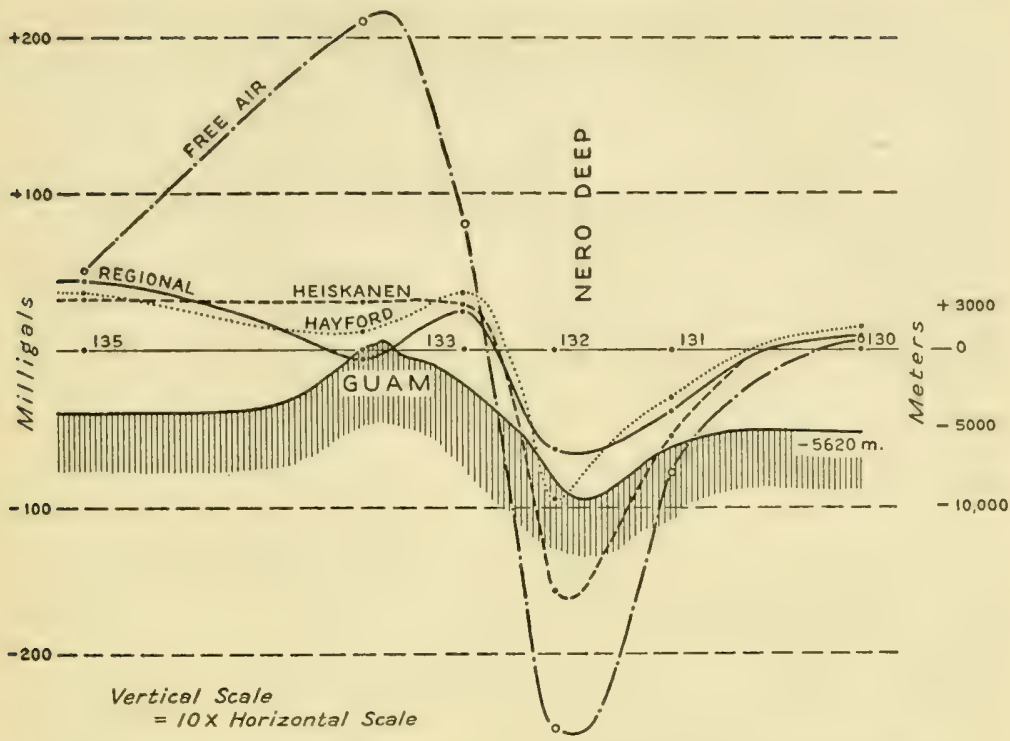

FIGURE 45. GRAVITY ANOMALIES OVER AND NEAR THE NERO DEEP. AFTER F. A. VENING MEINESZ.

involved, experiments of this kind are not easily conclusive, but already they have made it highly probable that a true crust 40 or 50 miles thick would be at least twice as strong as rock in the quarry, whether granite or thoroughly crystallized basalt. Accordingly there seems to be good warrant for assuming the actual crust to be competent to carry the loads indicated by the volcanic islands and by the ocean deeps. The substratum need not be called upon to take any part in the support. If this be true, we find in the weak substratum the primary condition for the earth's plasticity, crustal complexity, and ruggedness of surface.

\section{The Mountain Ranges}

Some principal facts and conclusions have been gathered from the simatic, volcanic islands. What, in their turn, have 
the sialic islands to say about the nature of the earth-shells? From Chapter I we recall that the islands of the second kind are partly or wholly made of granite or other rock characteristic of the continents. These relatively small bits of dry land appear as (I) lonely individuals, or (2) in the form of wide archipelagoes, or (3) arranged in long, distinct lines or belts. Each of these three classes has its own problems, now under discussion by geologists. Because of limited space we shall concentrate attention on two sets of the islands and shoals belonging to the third category-islands in linear arrangement. One set can be traced more than 2500 miles through the East Indian archipelago; the other for about the same distance through the West Indian archipelago. The significance of these two belts for the student of planetary mechanics was not guessed until, within the last dozen years, Professor Vening Meinesz and other investigators inspired by him reported on measurements of gravity in the two regions.

Information is most abundant about the East Indian case, to which our chief attention will be given. The dry lands of this extensive region make a complex map, and an unusually dense network of soundings has proved the relief of the sea floor to vary in comparable degree. Probably no equal area of the globe is so "accidented." It is natural that geodesists, seeking the best figure of the earth, should wish to know how the shape of sealevel is affected by the positive gravitational attraction of the island masses and also by the negative attraction of deep, water-filled hollows. Examples of these hollows are the Banda, Celebes, and other "mediterranean" sea-basins. Professor Vening Meinesz undertook the gigantic task of measuring the intensity of gravity in a submarine, successively located at hundreds of selected points in the East Indian waters.

From each measured value of gravity at the depth of the submarine there was computed the value at sealevel, imme- 
diately above the vessel. In general this sealevel value was found to differ from that expected from the standard spheroid. This difference we recognize as the free-air anomaly of gravity; it may be a positive quantity or a negative quantity. Geodetic work in continental regions shows that a positive free-air anomaly at a given station does not necessarily mean excess of attracting matter under the station; nor does a negative freeair anomaly mean deficiency of mass. In order to detect excess or deficiency under a station its free-air anomaly must be "corrected" in accordance with the principle of isostasy, briefly described in the first chapter.

According to that principle, high parts of the earth's surface are, in general, underlain by crust-rock which is less dense than the average superficial rock of the crust; on the other hand, low parts of the solid surface are in general underlain by crustrock which is more dense than the average superficial rock. In technical language, the earth's relief is "compensated" by the horizontal variation of density. As already noted, this variation in an area as large as the United States is largely confined to a layer extending from the surface down to the depth of about 50 miles. At about this level is the "depth of compensation." At the depth of compensation the columns of rock or rock plus water, under the surfaces of wide mountain range, low plain, and sea-basin have nearly equal weights.

The exact mode of horizontal variation of density is not easily determined. While searching for it geodesists have tested different working hypotheses. Besides those bearing the names of Hayford, Airy, and Heiskanen-referred to in Chapter IVening Meinesz tried a fourth hypothesis, based on what is called "regional-isostatic compensation." He computed the anomalies derived from all four hypotheses. As a rule he found no great differences in the respective values. Further, it became clear to him that a strongly positive free-air anomaly means 
in general a strongly positive isostatic anomaly; and that a strongly negative free-air anomaly means a strongly negative isostatic anomaly.

East Indian Chain.-When the isostatic anomalies were plotted on the map, there appeared a most remarkable "strip" of negative anomaly-that is, deficient mass-all across the region and keeping a fairly constant width of about roo miles. The actual length of the strip exceeds 3000 miles, for it goes far beyond the limits of the East Indies. The scale of the phenomenon is appreciated when we reflect that the archipelago has an over-all area greater than half that of the United States. The map of Figure 46 represents the serpentine strip by shading, the intensity of which is proportional to the size of the negative anomaly. Along the axis of the strip the anomalies commonly exceed roo milligals. To bring this axial belt, with negative anomaly greater than Ioo milligals, into balance with the rest of the earth's crust, about 3000 feet of granite or equivalent matter would have to be added to the belt.

The astonishing discovery of the negative strip led automatically to the question of origin, which became still more intriguing when another was found in the West Indies. A sketch map of it is given in Figure 47. In scale and other essentials it is the twin of the East Indian strip. Note the broken line, representing the axis of the strip, winding its way through the complex of islands, shoals, sea troughs and sea-basins.*

Aided by the geologists of the Netherlands, Professor Ven-

* It is reasonable to suspect that a third negative strip, also thousands of miles long, would be demonstrated if measurements of gravity were made in the South Atlantic region stretching from Patagonia through South Georgia to the South Sandwich Islands and across to Graham Land of Antarctica. Here there is strong curvature of an island-crowned structure with a pronounced "fore-deep," analogous to the Porto Rico deep of the West Indies and the Java deep of the East Indies. The South Atlantic region further resembles the other two by being subject to heavy earthquake shocks. One of these originated at the center indicated in Figure 9, a point near the South Sandwich fore-deep. Such disturbances are to be expected if, here too, the earth's crust is not in equilibrium. 







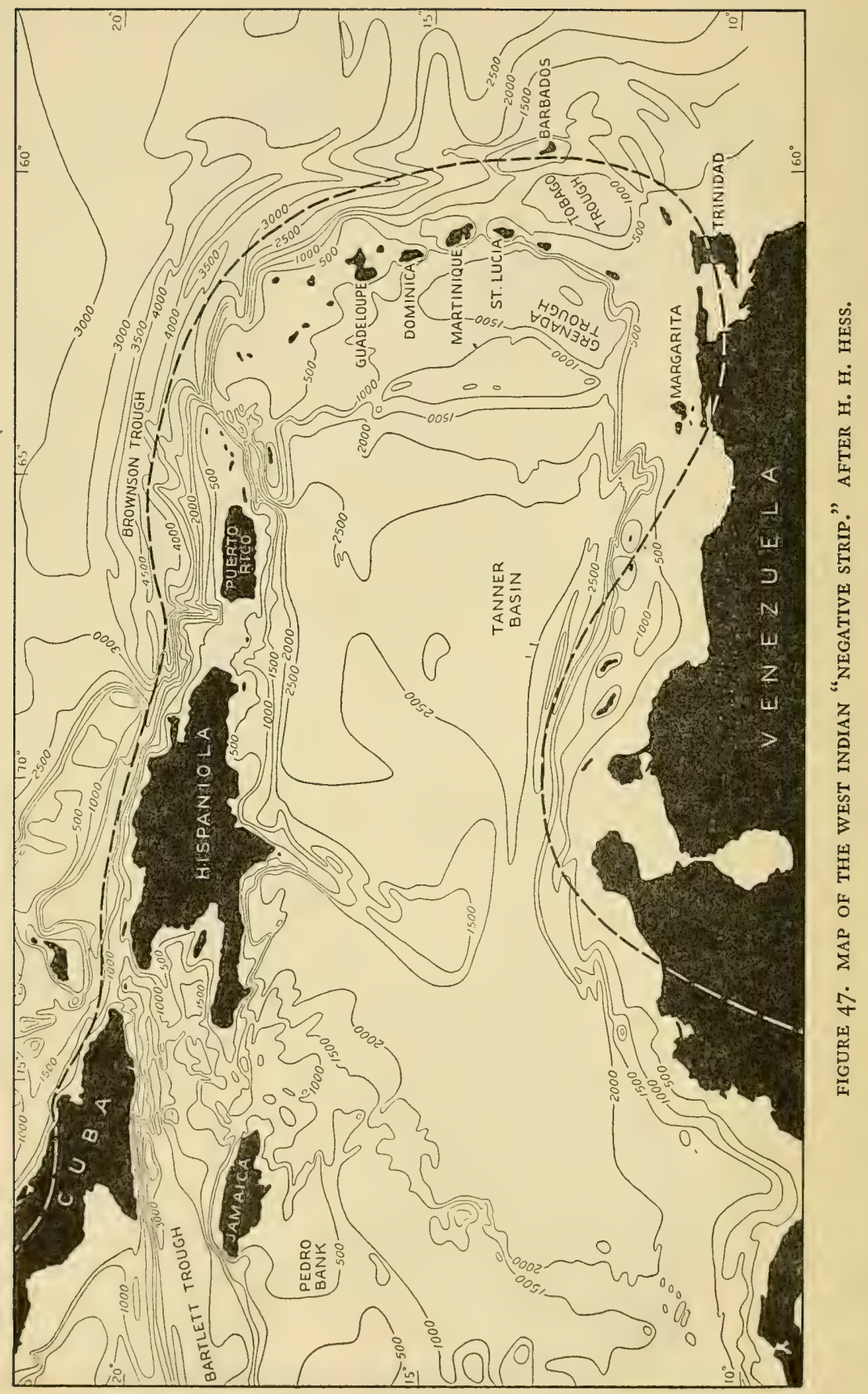


ing Meinesz developed a theory of the East Indian strip, which has appealed to many geologists, and a special study by Professor $\mathrm{H}$. H. Hess shows this theory to apply well also to the West Indian strip. According to the theory, each strip represents a young, largely submarine mountain chain of the first rank. This idea is so new that it is still missing in most geological textbooks and is not yet fully appreciated by men of science in general.

Figure 48 is a diagrammatic cross-section copied from the memoir by Professor Vening Meinesz. It illustrates his theory



WhWWh

FIGURE 48. SECTION ILLUSTRATING THE ROOT THEORY OF THE STRIPS OF NEGATIVE GRAVITY ANOMALY.

of the negative "strip." The stippled band at the top represents a thin, superficial, sialic layer of the earth's crust. The shaded band beneath represents the rest of the crust, its stronger part, with density taken to be 2.7 times that of water. The third layer, with assumed density of $3 \cdot 3$, extends indefinitely downward, and represents the weak earth-shell corresponding to our vitreous substratum (which, however, should have, at top, a density no greater than 3.I). The continental land of Asia is situated to the left of the section; the deep ocean, whether Indian or Pacific, is situated to the right, at and beyond the depression marked "Deep." Professor Vening Meinesz supposes that the crust under the surface of Asia was pushed or pulled bodily toward the ocean. He further supposes that, as Asia slowly traveled toward the ocean, the middle layer of the 
crust was bent down, displacing the material of the third, weak layer; and that the top, sialic, layer was, as it were, scraped off the rest of the crust and accumulated as a crumpled and sliced, overthrust mass under the region marked "Strip." Toward its bottom the sial has attained a so-called "root." A root of just this kind has been demonstrated under the Swiss Alps, where, in an analogous way, the superficial rock formations were set writhing and piled on one another when Europe and Africa were pushed together. In both belts the extra thickness of the relatively light sial gives buoyant support to the deformed masses.

While the Vening Meinesz theory is the best in sight, it is well to note that to a considerable extent it is founded on indirect evidence. Where the thing to be explained is so largely veiled by the ocean, it is well to consider the grounds for approval of the theory. We are to find that the evidence is in part geological and in other part geographical, and that much of the reasoning is from the analogy of the "negative strip" with the visible, accessible mountain chains of the continents. For reasons more or less obvious, the analogy is not perfect, but in this very imperfection we shall find food for thought about the mountain-making process-one of the most baffling problems of earth science.

Let us run through a list of characteristics for the visible cordilleras of the world. Detailed study of each of the mountain-structures shows it to be the product of localized folding, crushing, and slicing of sialic rock, the deforming pressure having been essentially horizontal. The folding is illustrated in Figure 49. The series of vertical cross-sections of Figure 50 may serve to show how, under intense and continuing horizontal pressure, thick sheets of rock of the sialic or continental type are sliced apart and driven over one another. 




FIGURE 49. LIMIESTONE BEDS ORIGINALLY HORIZONTAL BUT NOW UPTURNED AND INTENSELY CRUMPLED. PHOTOGRAPH SUPPLIED BY THE GEOLOGICAL SURVEY OF SCOTLAND. 


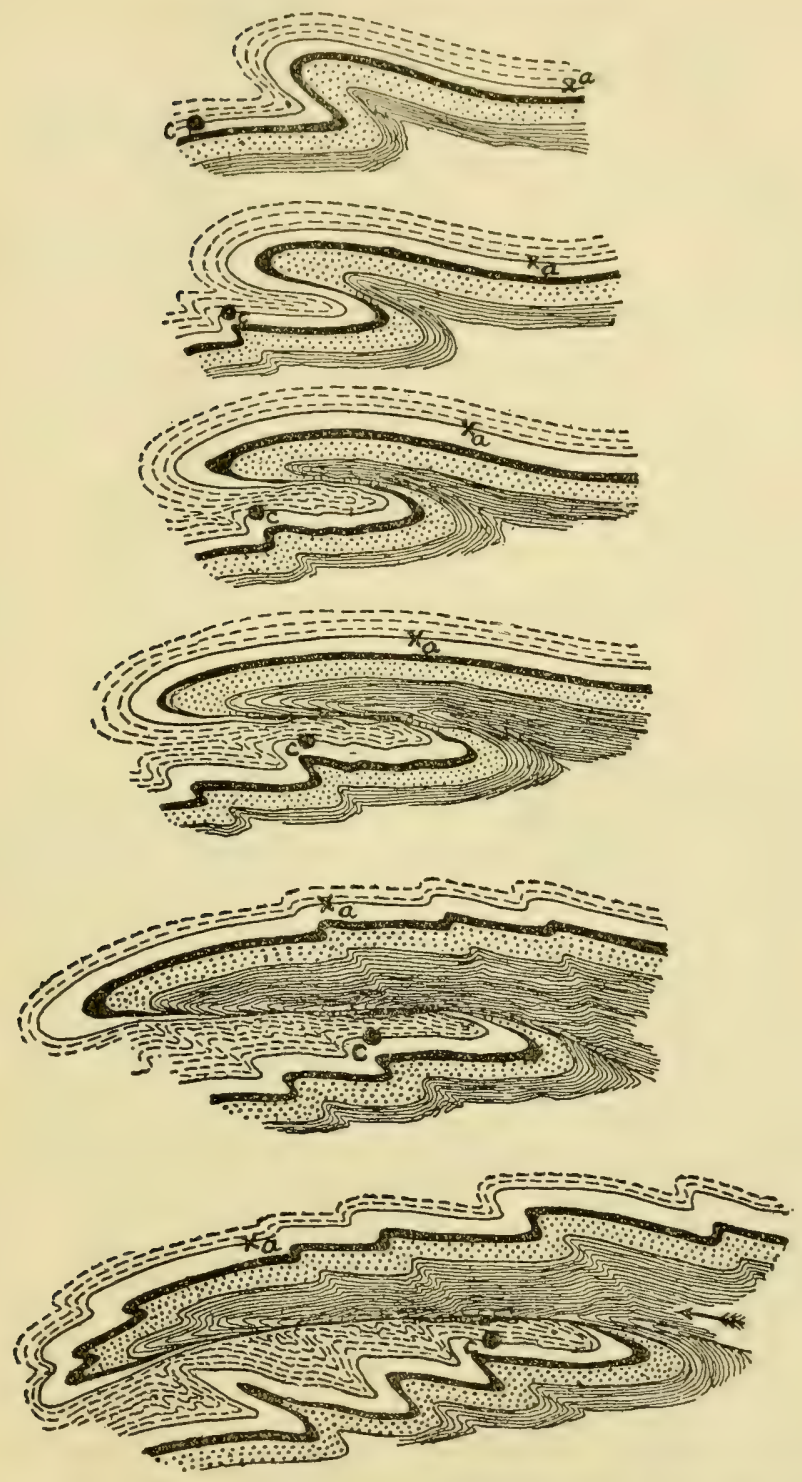

FIGURE 50. SIX STAGES IN PROGRESSIVE DEFORMATION OF ORIGINALLY FLATLYING BEDS OF ROCK, WITH ULTIMATE SLICING AND OVERTHRUSTING OF SLICE ON SLICE. 
A second generalization: Each structure forms a long, comparatively narrow belt.

Third: The more conspicuous chains were developed during the Cenozoic or Tertiary Era, the latest principal division of geological time.

Fourth: The folding and piling of slice on slice thickened the sial in the belt of deformation.

Fifth: The deformed belts are characteristically curved, arcuate, in ground-plan, and the arcs in coastal regions are convex toward the ocean. Figure 5I, showing with curved lines the axes of the Asiatic chains, supplies examples.

Sixth: In many instances the mountain-built belts are fronted by so-called "fore-deeps," that is, long, water-filled

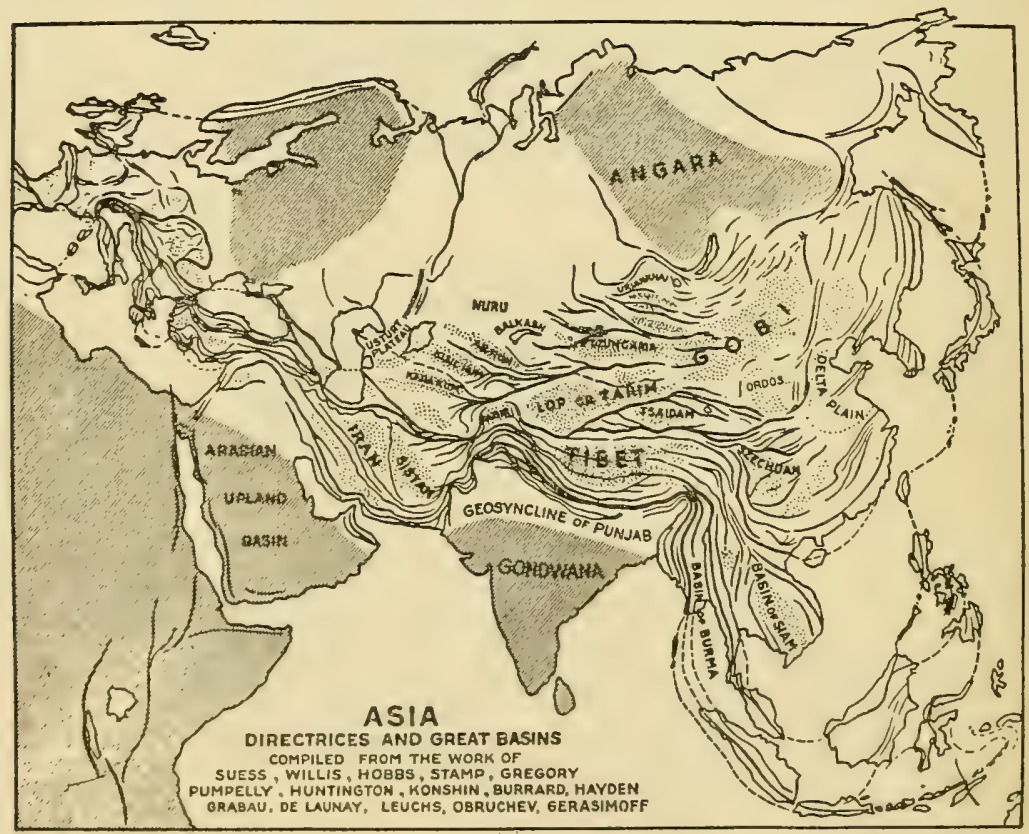

FIGURE 5I. MAP OF AXES OF THE ASIATIC MOUNTAIN CHAINS, WITH ILLUSTRATION OF THE EARTH'S NECESSARY PLASTICITY. AFTER C. P. BERKEY AND F. K. MORRIS. 
troughs roughly paralleling the respective axes of the chains; while inside the arc there may be a "back-deep," namely, a basin occupied by a "mediterranean" sea.

Seventh: The dry-land cordilleras show signs of having been vertically upwarped after the paroxysms of folding and crushing were ended.

Now for comparison with the structure indicated by the East Indian "strip of negative anomalies of gravity." The map of Figure 52 bears a thick curved line indicating the axis of the "strip," whose tremendous scale may be appreciated by the width of the area covered by the map, namely 3500 miles. Clearly any direct evidence of intense deformation within the "strip" is to be sought only in the accessible parts, the islands located within the belt. In total length these represent no more than a small fraction of the "strip," but they do give affirmative testimony. Beginning with Siberoet and Sipoera islands off Sumatra, we have, in succession, Timor, Saumlaki, Tanimbar, Kei, Ceram, and Banggai islands, and the eastern part of sprawling Celebes. The rocks of all those visible parts of the "strip" are strongly deformed. On the other hand, the larger islands, Sumatra, Java, Soembawa, and Flores, though also elongated and aligned, were not seriously deformed by the pressure that crushed the "strip" islands.

Geologists can date the epoch of intense folding and crushing; it falls in the latter part of the Tertiary Era. They have also proved that in the deformed belt the more superficial rocks, of sialic composition, were thrust, one over another, so as to increase greatly the original thickness of the sial under the belt. It became clear, too, that the composite mass, so thickened, sank under its own weight and therewith displaced, pushed away, more plastic material below the earth's crust.

From the map we see that the Vening Meinesz theory satisfies also the fifth criterion: the "negative strip" is like the dry- 


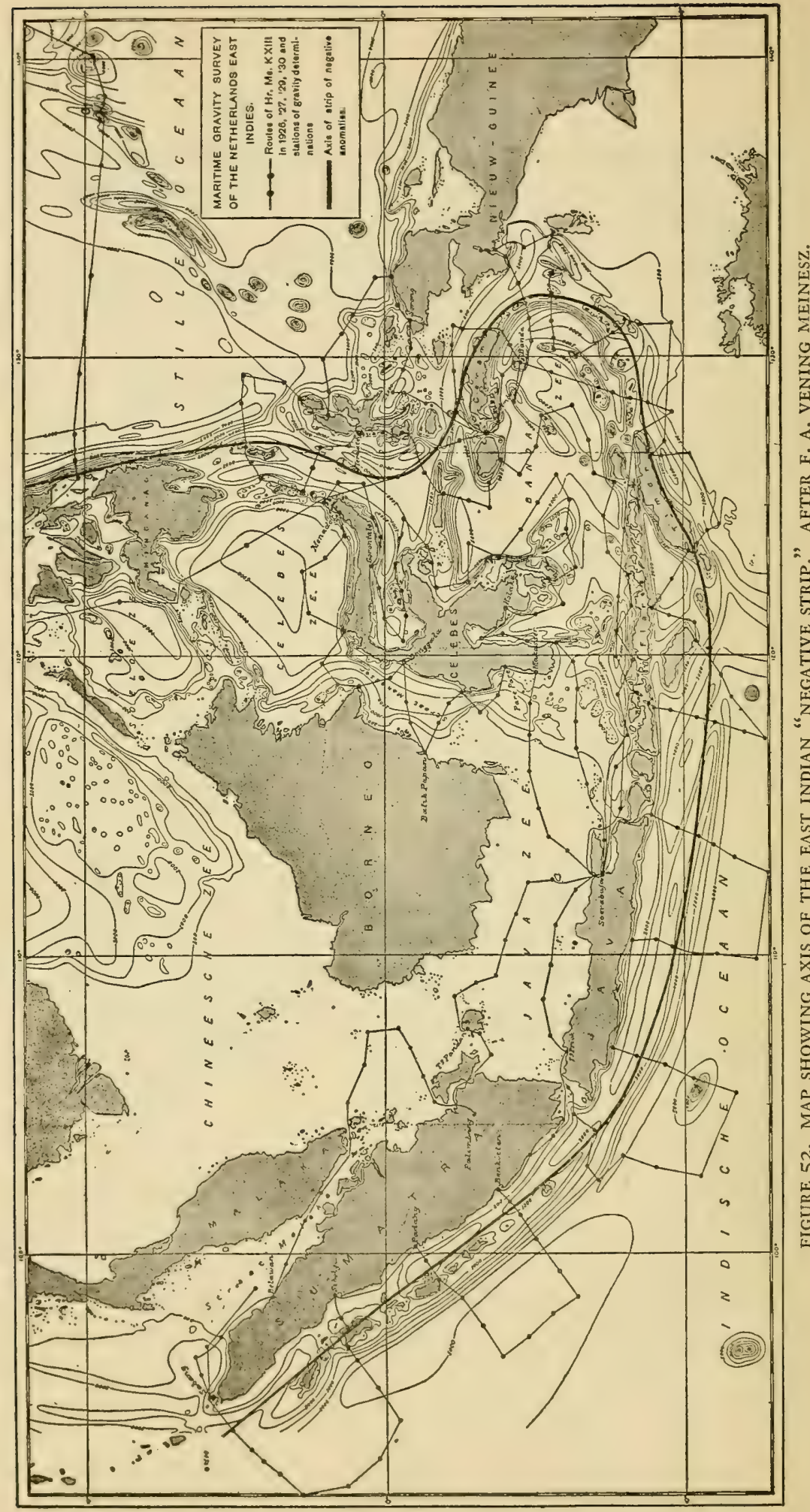


land cordilleras in being arcuate. Like each of them it has a ground-plan convex toward the ocean. Again, like them, it has a "fore-deep," part of which is shown with submarine contours or isobaths drawn on the map in Figure 53. The contour

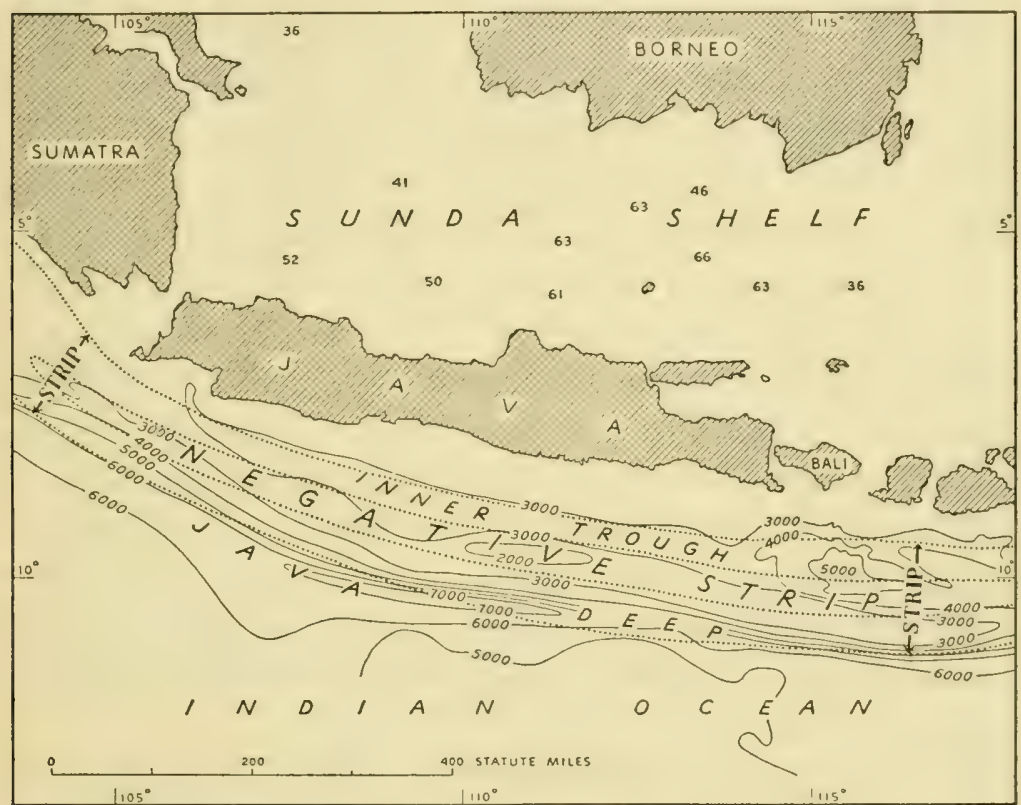

FIGURE 53. MAP OF THE JAVA DEEP AND THE TROUGH INSIDE THE CURVE OF THE EAST INDIAN "NEGATIVE STRIP."

intervals are stated in meters. South of Java the "negative strip" follows a continuous submarine ridge, inside of which is a trough that bears deeper water and lies between that ridge and Java itself. In principle the trough seems to correspond well with the basin occupied by the Banda Sea farther east, as well as with the "back-deeps" represented by the Sea of Japan inside the Japanese arc, and by the analogous sea inside the Loo Choo arc farther south.

At first sight it might look as if the seventh test for the 
Vening Meinesz theory gives an unfavorable result. The Swiss Alps not only include heaven-piercing Matterhorns and Jungfraus but, in average, stand about 4000 feet above sealevel. Another dry-land range, the Himalaya, supreme in majesty, has a mean elevation not far from three miles and has five-mile pinnacles. Each of the famed mountain-structures was built during a comparatively early part of the Tertiary Era, and, after the crustal turmoil came practically to an end, each of the deformed belts has been uplifted thousands of feet. If the East Indian "strip" really covers a structure of the alpine type, we might expect to find evidence of recent uplift of its visible peaks, the islands within the "strip." In a measure this expectation is matched by fact. Several of the islands are veneered with young coral reefs and other shore formations that are now hundreds of feet above sealevel. It has thus been proved that Timor Island has risen more than 2000 feet. But the average uplift along the "strip" is much smaller than the average uplift of Alps or Himalaya; why? The contrast calls for explanation, which in the present state of our knowledge has to be largely speculative.

Professor Vening Meinesz offered a partial explanation. He attributes the negative character of the "strip" in part to the enforced depression of the belt, whereby it had initially, and still has, defect of mass beneath it. He assumes the intense deformation of the belt to have been so recent that the earth's crust has not had time to regain equilibrium. He also thinks that even now the deforming horizontal pressure is not fully relaxed.

But there is a second reason why here uplift has been much less pronounced than that registered in Alps or Himalaya. The reason is implicit in the root theory of Vening Meinesz, according to which the root was made of superficial, comparatively cool rocks. When these were downfolded and thickened by 
overthrust of slice on slice, each composite mass sank under its own weight, down to levels in the earth's body where higher temperatures prevail. Hence heat has been conducted into the root, which is therefore slowly expanding-expanding vertically, with uplift of the surface of the thickened sial. If the sialic root or the depressed simatic rock beneath it is actually melted by the heat, there is additional expansion and uplift of the surface. It is the opinion of the present writer, based on a century of study of mountain chains by the geological profession, that under all of the chains there has been re-melting of sialic rock on a grand scale. Since much of the earth's sialic layer is made of ancient granite, the re-melting gives new, liquid granite, and this hot, mobile material cannot fail to invade its own roof. Moreover, because of its relatively low density, the new melt must tend to push up that roof. Out of a world of actual illustrations only one will be cited.

There is reason to think that the peerless height of the Himalaya is in part due to the former invasion of its solid root by a mass of comparatively light, molten rock. The top part of Mount Everest, its celebrated culminating peak, is nearly six miles above sealevel, but is made of limestone which was originally deposited below that level. The intense Himalayan deformation of the earth's crust was most pronounced during the early part of the Tertiary Era. The upheaval of the tortured mass was much later. With the gravimeter and plumb-line geodesists have proved the lofty range to be in balance with the low ground of peninsular India, Siberia, and other broad regions in Asia. The stable arrangement finds explanation if we postulate not only a thick root of sialic rock under the range but also a huge body of underlying, intrusive granite which is still hot and expanded, if not partially molten. This possibility is not purely speculative, for in the deeper valleys 
of the range geologists have found big tongues of once-molten, now solidified granite, which rose from depth and penetrated the upper rock formations of the range. The intrusion of the molten granite took place while, and immediately after, the mountain rocks were crushed, and it is probable that the deeper part of the bulky granitic mass is still expanded by heat.

The bearing of these different considerations on our immediate problem appears when we remember: first, that the strong folding and crushing along the East Indian strip occurred a good many millions of years after the main Alpine and Himalayan paroxyms; and, secondly, that on account of the slowness with which heat is conducted through rock, it takes millions of years for the wave of heat from the earth's deep interior to cause much expansion of the root rocks. For this reason the amount of uplift should have been much less along the East Indian strip than in the Himalayan belt.

However, there is reason to doubt that the strip rocks will ever be pushed up to heights comparable with Alps or Himalaya. Each of these latter structures, now so lofty, was made inside the limits of the old Eurasia-Africa continent. Before the epoch of mountain-making, the sial there had normal continental thickness and therefore floated relatively high on the earth's body. There also, the mountain-making meant piling of sialic slices and overturned folds on sial of normal thickness. In two respects the conditions in the East Indies may have been different. It is possible that here the sial was originally thinner than the sial under undisturbed Eurasia. And the second condition: from the topographic map and known rock structures it seems clear that along the East Indian strip the sial was thrust over, and thickened on top of, the sub-oceanic simatic crust, which has density about ro per cent greater than the density of the sial. See Figure 30. When, therefore, the crust shall here have come to equilibrium in both 
material and thermal content, the mountain chain along the negative strip will in all probability never rival even the Swiss Alps in height.

West Indian Chain.-The number of gravity stations in the West Indies is comparatively small, but there can be little doubt as to the general continuity of the negative strip in the region. The broken line of Figure 47 represents the trend of its axis. With average width of about roo miles, the belt is strongly curved, and here also with convexity toward the ocean. Few islands are found within the limits of the strip, and therefore evidence of violent disturbance of the rocks in the belt is meager. However, strong deformation is clear in Trinidad, Barbados, and Cuba, and, as in the East Indies, is of Tertiary age. Just as Timor, Roti, and other islands of the Asiatic strip show upheaval after the crushing of their rocks, so Barbados and Cuba at least have recently been uplifted hundreds of feet. And one more similarity: both strips are located in archipelagoes elsewhere unrivalled.

In view of so many like features, Professor Hess was already prepared to accept the conclusion of Vening Meinesz that both had the same type of origin, and added another argument. ${ }^{5}$ At intervals along the course of a mountain chain geologists often find large bodies of rock which, in the molten state, was thrust into the mountain roots during, or soon after, the time of greatest crushing. These huge melts have crystallized into rock typified by the species called peridotite. (See page 58 .) Such masses, now cool and crystallized, are particularly abundant along the arcuate, dry-land ranges of the western Pacific. Now, after study of the Asiatic and American strips, Professor Hess has been able to show that similar large bodies of these otherwise rare rocks appear in the islands along each strip. This generalization leads to one more suggestion of essential identity between strip and mountain chain of the dry land. 
Why have peridotite and closely allied kinds of rock been thrust into the mountain roots? No geologist has yet offered an answer free from speculative elements. According to the theory outlined in the first chapter, the layer immediately underlying the earth's solid skin, a true crust, formerly consisted of a thin basaltic shell in the glassy state. This vitreous shell in its turn rested on a thicker peridotitic shell, also in the glassy state. See Figure 30. Let us assume that this kind of stratification really characterized the East Indian sector at the time of this mountain-making, and then apply the main principle of the Vening Meinesz theory. If, accordingly, the mountain root was formed while the crust was bent down, it is not difficult to imagine that the down-warped crust pushed aside the basaltic material and made contact with the lower vitreous layer. Any deeply penetrating crack in the depressed crust would be a channel for the upward injection of the peridotitic melt. If, simultaneously, the depressed crust was broken into blocks, forced away from one another, the rising melt would come to occupy large chambers within the broken crust, there to solidify as crystalline peridotite or its derivatives. Just such fracturing of the crust is implied by a mechanically sound version of the Vening Meinesz theory-as Professor Hess also seems to have assumed in his discussion.

\section{Conclusions}

The principal conclusions of this chapter may now be reviewed and thereby made easier of comparison with those of the first chapter, which outlined a theory of the earth-shells under both land and sea. Incomplete as the survey of the deepsea mountains has been, it has broadened the field of observed facts on which that theory has been based. Let us run through the list of these facts. 
I. The chemical composition, structure, and magnitude of the volcanic islands, as well as the initial temperature of their lavas seem to find best explanation if the corresponding vents are assumed to have been fed from a simatic substratum, world-circling and so hot that it is necessarily in the glassy state.

2. The volcanic islands, like many shoals, represent extra masses of rock, built up on the floor of the ocean in the form of high, bulky mountains, whose relief is only partly, if at all, "compensated" by abnormal density for the rock beneath the upstanding masses.

3. Although many of the volcanic loads are great and have been weighing on the old sea floor for millions of years, they are to all appearances stably borne; they seem not to be now bending down or breaking down the earth's crust.

4. Computation, founded on laboratory experiments on the strength of rock at high, all-sided pressure, makes it highly probable that the volcanic loads can be stably carried by a true crust with thickness of about 50 miles.

5. The ocean deeps represent negative loads of the same order numerically as that of the positive, volcanic loads, and here again the crust unaided seems competent to give full support.

6. Because the crust is so sturdy, neither kind of loading gives a valid argument against extreme weakness for the substratum.

7. Such weakness appears to be an inescapable condition for the development of mountain chains of the Alpine type. The mountain structure and the characteristically arcuate groundplan of a chain prove that crust-blocks of continental dimensions have moved horizontally over the earth's body, through distances of scores of miles, if not hundreds of miles. The horizontal displacements defy understanding unless there be 
a subcrustal layer which must yield even under minute shearing stress.

8. We have found cause to adopt in principle the view of Vening Meinesz and Hess, that the negative strips of East and West Indies are long mountain chains of Alpine complexity of structure.

9. The submarine character of these two chains, in contrast with the proud loftiness of Alps, Andes, or Himalaya finds explanation if the sub-oceanic part of the earth's crust differs from the continental part in the way that has been suggested. 


\section{GONTINENTAL TERRAGES AND SUBMARINE VALLEYS}

\section{Introduction}

Men of science, like fishermen and navigators, have long had lively interest in the continental terrace, but its scientific appeal has recently become more than ever eloquent. For it has been discovered that the long outer slope of the terrace is wonderfully dissected into a maze of deep valleys, separated by high ridges. The cause of this systematic ruggedness, quite unsuspected ten years ago, when echo-sounding was not yet applied in the delineation of the continental slope, is the principal theme of this chapter. Before entering on its discussion, note will be taken of a few instances where the dry-land topography of the continents reflects the process of terrace-building. Then account will be given of a new method for detecting the nature of the invisible mass composing the terrace. Already it has been proved that the normal thickness of the terrace deposits is measurable in thousands of feet; also that, in general, the deposits are but loosely consolidated, if at all. With these two facts in mind, we shall be prepared to discuss the valley systems sunk in the deeply submerged flanks of the continents.

\section{The Terraces}

From the first chapter we recall some facts and definitions. The widths of the terraces vary from a few miles to 200 miles. 
From the beach out to the line where the depth of water measures 50 to roo fathoms (300 to 600 feet), the broad top of each terrace is inclined gently toward the deep ocean. This nearly horizontal part of the surface of the terrace is called the continental shelf. At its outer limit, given by the depth just stated, begins the fall-off, or break-of-slope, at the beginning of the continental slope, which extends to the foot of the terrace, 2000 to 2500 fathoms below sealevel. See Figure 2.

Most of each continental shelf lies some fathoms deeper than it would lie if the land-derived sediments were now being moved in a continuous sheet of detritus all the way from the beach to the continental slope. By actual dredging Dr. H. C. Stetson has found that the seaward limit of even the fine muds which are now being added in clearly observable quantity to the Atlantic terrace off Massachusetts is tens of miles inside the fall-off. Out to the limit of these muds the shelf is being raised by sedimentation. As the slow shallowing continues, the waves and currents will be able to push that outer limit for the continuous layer of sediment farther and farther to seaward. When the new layer shall have been extended to the fall-off, the surface of the shelf will be something like io fathoms or 60 feet higher than it is at present. It will then have reached a profile of equilibrium. Then the level of the fall-off will be at wave-base, to use the technical term meaning the level down to which the ocean waves can effectively stir and transport detritus. At the present time, then, it appears that the outer half of each broad continental shelf is too deep to represent a profile in equilibrium with the forces responsible for the building of the continental terrace. The observation of Dr. Stetson suggests that in comparatively recent time a top layer had been removed from the terrace, and that an equivalent amount of sediment is being slowly restored to the broad continental shelf. Why the original profile of equilibrium, which had 
been established during millions of years of terrace-building, was so modified is a question to be answered when we consider the origin of valleys sunk in the continental slopes.

The oceanward gradient of the whole continental slope down to the I500-fathom level averages about $\mathrm{x}$ in 15 or 350 feet to the statute mile. It is steeper at the top; between the roo-fathom and 500-fathom levels the average gradient for the belt off the eastern United States is nearly I in 10 or, say, 500 feet to the mile.

Special Topographic Features.-Whether brought by rushing river or eroded by waves from sea-cliffs, the terrace sediment is carried seaward by an endlessly complex system of tidal and wind-driven currents in the ocean. Undertow of waves and offshore motion of other currents co-operate. A vast job has been done and is now under way, without pause, in all the oceans. In general we land dwellers have no direct evidence of the submarine construction, but there are two instances where the dry-land topography of our own continent has been spectacularly molded during the growth of the continental terrace.

The first example is found in the remarkable asymmetry of the Mississippi Delta. At a point near Baton Rouge the Mississippi turns sharply from a north-south direction to run southeastwardly for the remaining two hundred miles of its course. The whole stretch of two hundred miles lies on the more recently formed part of the delta. Professor R. J. Russell of the State University of Louisiana has summarized the results of studies by himself and colleagues regarding the evolution of the delta during the last 50,000 years. ${ }^{1}$ The Mississippi has changed its course over the delta several times; the last major change brought the river into its present course, from Donaldsonville through New Orleans. Since then the delta has grown steadily toward the southeast. Thus, the river has been turning 
systematically to the left, as it forges its way gulfward over its own great deposit of sediment, including the bird-foot fraction of the delta represented in Figure 54.

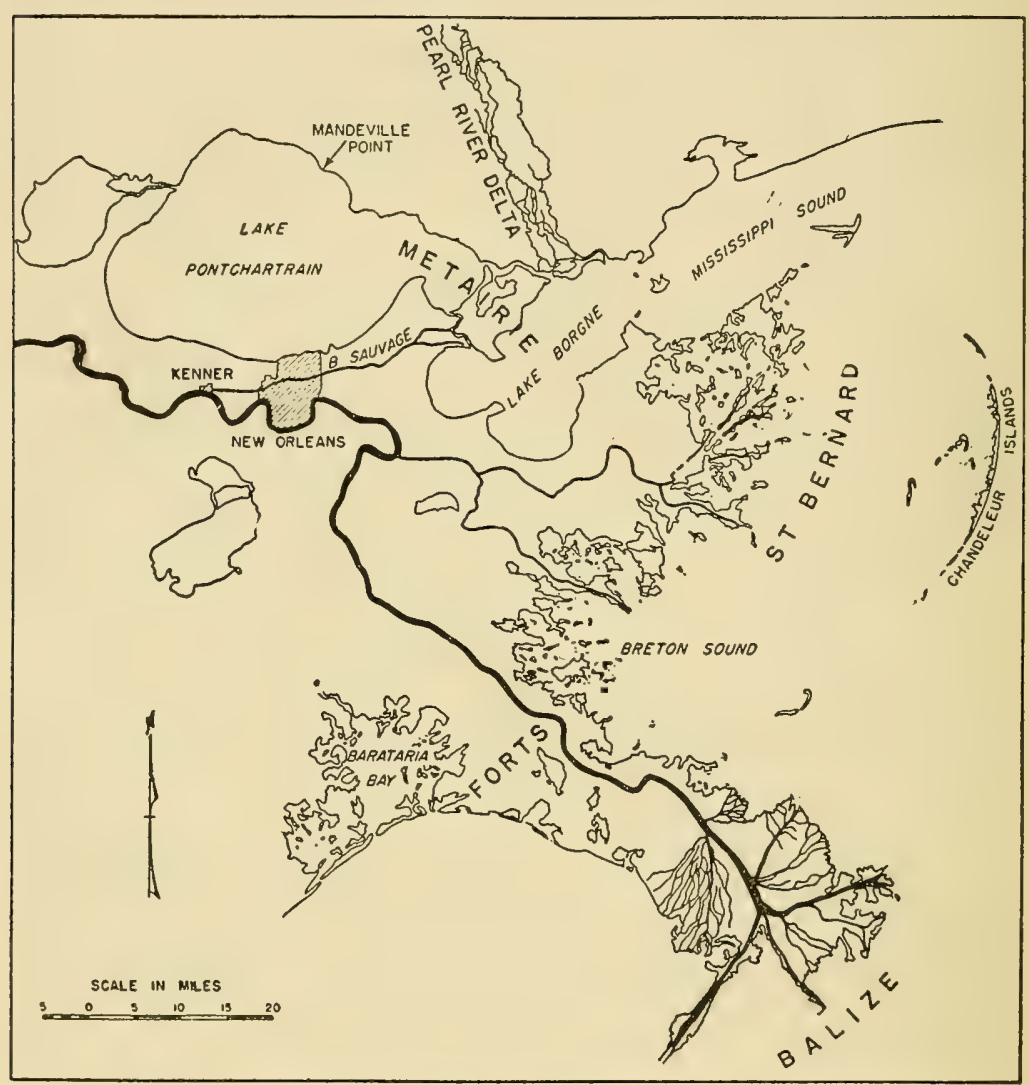

FIGURE 54. PRESENT COURSE OF THE LOWER MISSISSIPPI RIVER. AFTER R. J. RUSSELL.

The more recent diversion toward the east seems best explained by the influence of a dominant marine current that runs past the delta from east to west. Every year, during the flood season, the river builds a sand bar just in front of each mouth, the annual advance of the most important bar being 
about 200 feet. After the flood season the 'longshore current erodes the bar and especially at its eastern end. At that end the depth of water on the bar is correspondingly increased. With the rush of the next flood of the river, the following year, the Mississippi finds its way least obstructed at the eastern end of the bar and therefore extends the channel to the left of the river's axis. Through thousands of years the step-by-step diversion has proceeded, the river more or less steadily turning eastward, that is, toward the direction from which the marine current comes.

Deflection of the river's axis by the marine current is possible because the Gulf of Mexico is not affected by strong tides. Manifestly the complex, reversing currents of the tidal sort would tend to annul the systematic effect of the wind-driven current on the ground-plan of the delta. For this reason strong asymmetry for outgrowing deltas should not be expected in the case of rivers that empty directly into the open ocean, where tidal disturbances are great. However, we should look for parallels to the Mississippi deflection in other nearly tideless seas. The Mediterranean of Europe furnishes examples. There the Ebro delta, like that of the Rhone River, has grown toward the river's left because a dominant marine current runs from left to right. See the arrows in Figure 55.

As shown by soundings, the asymmetry of the dry-land part of each of the three deltas matches an asymmetry in the rivermade embankment covered by the sea. The forward growth of the continental terraces is correspondingly uneven.

And there is a second way in which the shore contour of a continent reflects the hidden process of shelf-building. Its principle is illustrated along our eastern coast, from Virginia to Florida. Since school-days we have been familiar with the exquisitely molded shapes of the sandy forelands at Cape Hatteras, Cape Lookout, Cape Fear, and Cape Canaveral. Each of 


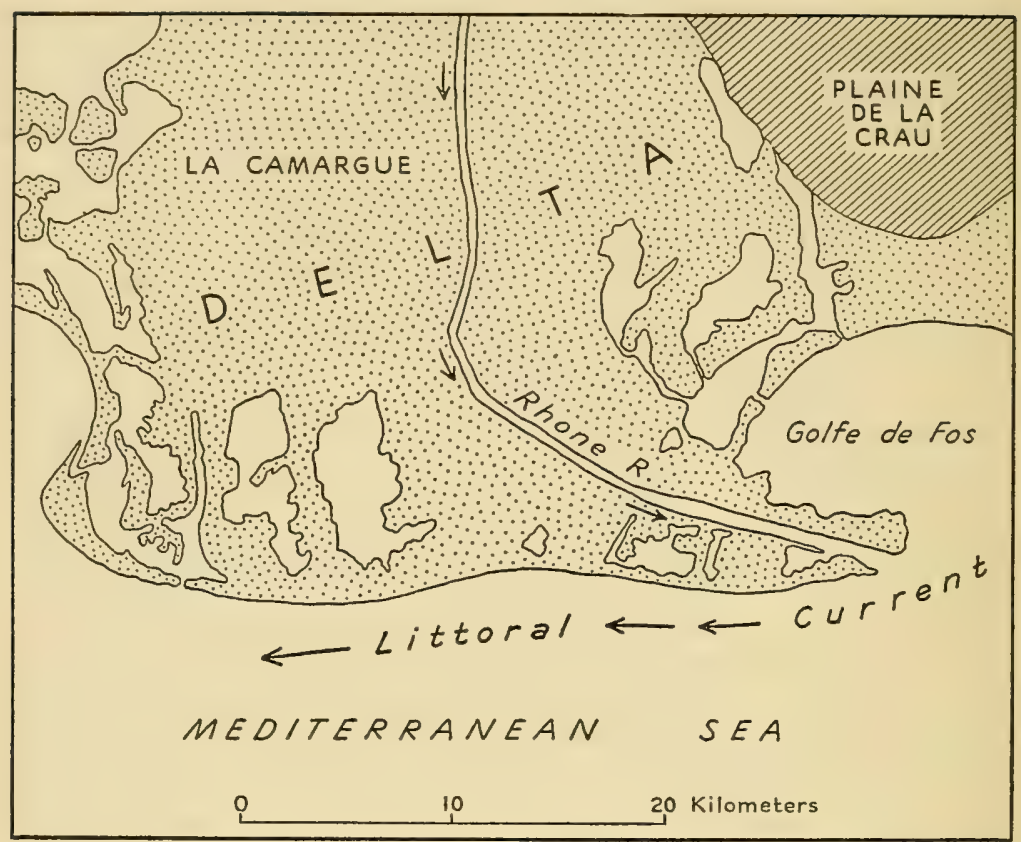

FIGURE 55. MAP OF THE MEDITERRANEAN DELTA OF THE RHONE RIVER. THE ARROWS INDICATE THE DIRECTION OF THE LOCAL DOMINANT CURRENT IN THE SEA.

the capes is a cusp, projecting oceanward, as it were in the teeth of the breakers. Between the cusps are the long, bay-like re-entrants with their own beach lines and graceful curves. The whole assemblage of topographic forms is unique in both scale and rhythm, and it is natural to attribute them to a common cause. Forty-five years ago Cleveland Abbe, Jr., suggested the cause-the Gulf Stream, the speediest of the major sea currents that pass continental shores. ${ }^{2}$

Figure 56 illustrates Abbe's reasoning about the remarkable phenomenon.

From southern Florida to the latitude of Cape Hatteras the Stream has an axial velocity of three to five miles an hour, 


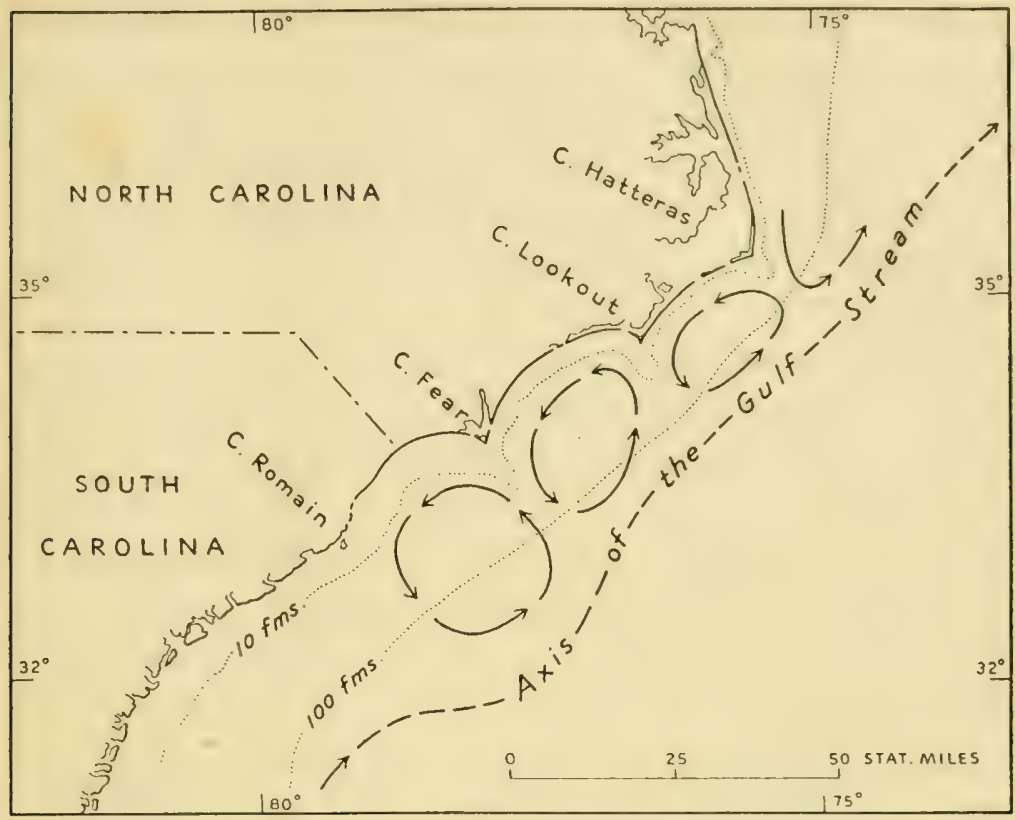

FIGURE 56. DIAGRAMMATIC MAP TO ILLUSTRATE ABBE'S THEORY OF THE CAROLINA CUSPS.

maximum thickness of half a mile, and width measurable in scores of miles. Such a masterful "river" of salt water, continually on the run through the Atlantic basin, could not fail to produce eddy-like motions in the water of its "banks." Abbe suggested that the water between the Stream and the continent is thus compelled to move in great eddies which have emplacement and dimensions just right to explain the building of the four sandy cusps out into the Atlantic. Figure 56 shows how the deduced whirls might well gear into one another and with the Gulf Stream itself, so as to bring about the result described. The eddy responsible for Cape Canaveral is not shown, since the map does not extend far enough to the southward. As shown by the arrows, the outbound part of an eddy, on the north side of each cusp, tends to carry the sand toward mid- 
Atlantic; the inbound part of the eddy just to the south tends to drag the sand to the westward. This conflict of currents accounts for the asymmetry of the cusps. Possibly Cape Romain may yet be ornamented by a similar cusp. The seaward bends of the ten-fathom line on the map show that, as expected, the outgrowth of the sedimentary terrace is most rapid opposite the cusps.

Condition of the Terrace Sediments.-The thickness of gravel, sand, and mud composing the continental terraces is important in connection with the origin of the valley systems that fret the outer slopes. It is known that the cover of detritus on the hard-rock floor is highly variable. Wide areas of the shallow shelf off California are practically free from any detrital cover. In general, however, the shelves are surfaced by unconsolidated sediment almost continuously from the beach to the submarine contour at depth of 2000 fathoms. The detrital cover tends regularly to grow thicker in the seaward direction, out to where the flat shelf meets the top of the continental slope. Measurement of thickness for the terrace deposits is now possible through the use of specially designed seismographs and other instruments.

Pioneer studies of the kind have been made by M. Ewing, A. P. Crary, and H. M. Rutherford, ${ }^{3}$ and by E. C. Bullard and T. F. Gaskell. ${ }^{4}$ They used the seismic method, which has some analogy with the $\mathrm{X}$-ray technique of surgeon and physician, who also need to know the shapes of structures hidden from human eyes. In our present problem the elastic waves registered by the seismograph are generated by explosive charges placed on the sea floor at known points of latitude and longitude. Each explosion sends sound waves through both sediment and hard-rock floor. The times of arrival of these waves at strung-out observing stations are accurately recorded by sensitive instruments called geophones, also placed on the sea 

floor. The interval between the instant of explosion and instant of arrival at the geophone station is called the travel-time of the wave. The length of the travel-time depends on the elastic properties of the material traversed-its compressibility and rigidity - and on the path followed by the wave. The path may be of two kinds, that of reflection or that of refraction.

Reflection occurs if at any deep level there is a sharp change in the elastic properties of the rock. In this case the seismologist can use the travel-time to measure with fair accuracy the depth of the "discontinuity" or change of character of the deep-lying rock.

The alternative, refraction, method may be illustrated by Figure 57, where "shot point" is the place of explosion and

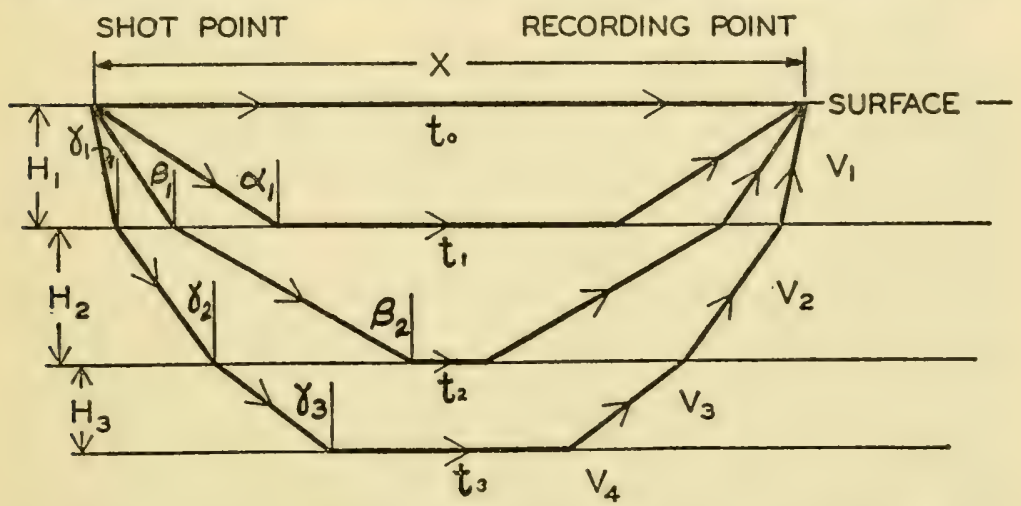

FIGURE 57. PATHS OF SEISMIC WAVES FOR THE REFRACTION METHOD.

"recording point" is the location of the geophone. The diagram represents four layers of material, these chosen according to the general rule that the elasticity of rock matter increases with depth below the surface of the earth. The paths of four different waves are marked with arrows. One follows the surface. A second plunges to the first break of material, to be refracted at this discontinuity, then to run some distance in the top part of the second layer, and finally to be refracted 
upward and have its arrival time clocked at the recording point. Multiple refractions characterize the more complicated paths of the third and fourth layers. With suitable precautions the wave-velocities in all four layers can be computed with considerable accuracy. From these velocities, and from independent experiments giving the relation of wave-velocity to the nature of the rocky materials of all the common sorts, it becomes possible to name the respective kinds of rock represented in layers one to four.

The Ewing party used the reflection method and the refraction method along two lines running at right angles to the shore of the eastern United States. One of these sections was lined out from Cape Henry, Virginia; the other, from Woods Hole, Massachusetts. See Figure $5^{8}$.

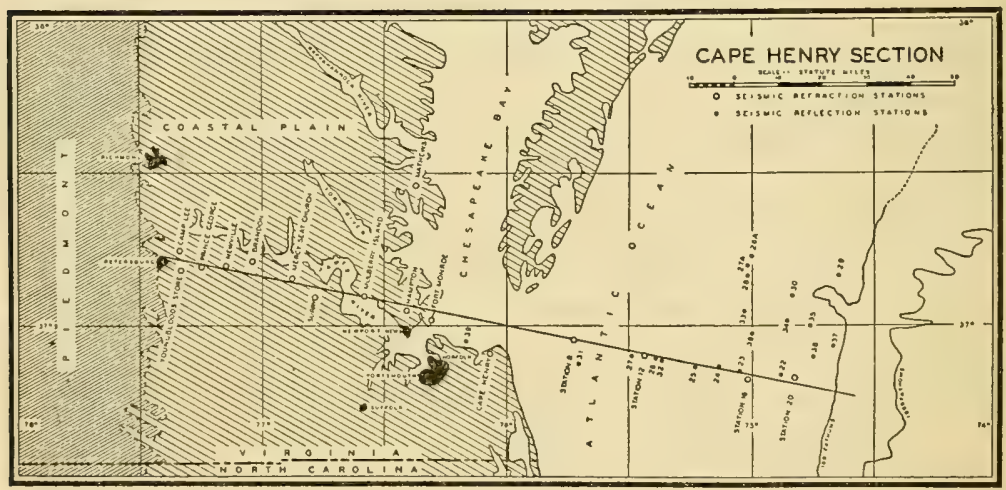

FIGURE 58. MAP SHOWING LOCATION OF EWING'S SOUTHERN SECTION ACROSS THE CONTINENTAL SHELF, EASTERN UNITED STATES.

The coastal plain of Virginia represents an emerged part of the continental terrace, a part where the results of seismological location of hidden discontinuities can be checked by the logs of deep wells. Partly for this reason the Virginia section was begun at a point 75 miles inland from the shore at Fort Monroe. From there the line was run straight out 90 more miles, 
CONTINENTAL TERRACES AND SUBMARINE VALLEYS IOG across the continental shelf almost to the fall-off where the continental slope begins.

The results of the investigation are summarized in the lower cross-section in Figure 59. Here the top horizontal line

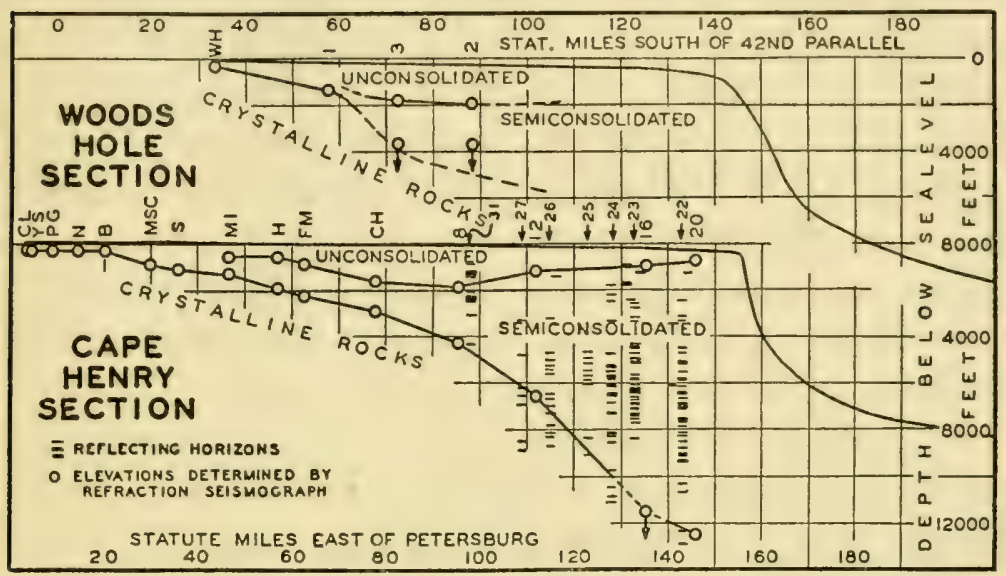

FIGURE 59. EWING'S SECTIONS OF THE CONTINENTAL SHELF, EASTERN UNITED STATES.

represents sealevel and the uppermost heavy line represents the surface profile of coastal plain and terrace; Fort Monroe is situated at the point marked FM.

The refraction method demonstrated a discontinuity which is indicated by the upper chain of small circles. Above the line joining these points in depth, the wave-velocities were those expected in loose sand, mud, and gravel. A second, much more pronounced break of material was found at depths shown by the lower chain of circles. Between those two discontinuities the wave-velocities were those expected if the elastic waves had been propagated in more compacted, perhaps semi-consolidated, sediments of the same detrital kinds, though thin layers or lenses of hard limestone may be interbedded. The diagra 11 shows a thickening of the terrace sediments from 3000 feet at 
Fort Monroe to about 12,000 feet at the edge of the flat, submerged shelf.

In principle the reflection method corroborated the conclusions won by the refraction method, regarding thicknesses for the unconsolidated and semi-consolidated or more compacted piles of sediment, and also showed that the lower, thicker pile is interrupted by many thin, presumably more consolidated layers or lenses. These minor discontinuities are represented at their appropriate depths by the short horizontal lines of the diagram.

Below the composite mass of sediments is "crystalline rock" -hard rock-carrying elastic waves at a speed much greater than that found in the overlying detrital mass.

The shorter Woods Hole section, shown in the upper crosssection of Figure 59, gave a thickness of about 4000 feet for the terrace sediments, where measured at the outermost recording point, which was 60 miles from the beach and 50 miles inside the top contour of the continental slope.

With the seismic method, Bullard and Gaskell deduced the thickness of the "relatively unconsolidated" sediments constituting the European continental terrace off the British Isles. Twenty miles and eighty miles off the Lizard they found respective thicknesses of 500 feet and rooo feet; II5 and I75 miles west-southwest of the Lizard, respective thicknesses of at least 2000 feet and at least 4000 feet (probably a considerable underestimate).

The technical difficulties of a research of this kind are notable, and there is need of further testing of the seismic methods as well as occupation of many other cross-sections of the continental terraces. But already we can be reasonably sure that the soft sediments of the terraces do greatly thicken out to, or nearly to, the seaward limit of the continental shelf. In accord with this conclusion is the proof by actual borings along the 
Louisiana and Texas coast that unconsolidated sediments rule down to the depth of at least 10,000 feet. See Figure 60.



FIGURE 6O. NORTH-SOUTH SECTION ACROSS LOUISIANA, SHOWING LOCATION OF DEEP BORE-HOLES. GREAT EXAGGERATION OF THE VERTICAL SCALE MUCH OVER-STEEPENS THE INCLINATION OF THE BEDS OF SEDIMENTARY ROCK.

\section{Valley Systems of the Continental Slope}

The scientific imagination must be stretched as we plunge into the black dark under the waves, to see what the continental slopes are really like.

Before the development of echo-sounding, geologists assumed that in general the continental slope is essentially as smooth and monotonous as the shelf. The smoothness was thought to be a necessary result of the mode of upbuilding of the continental terrace as a whole. Great was the astonishment of geologist and oceanographer at the discovery of the closely set series of valleys and ridges. Further, it already appears highly probable that the submerged flanks of the continents are so trenched, dissected, through a total length of 50,000 miles or twice the circumference of the earth. The phenomenon is 
world-wide. Its explanation, when made clear beyond peradventure, is certain to establish new, fundamental principles of earth science and to engage the attention of all those interested in the grander processes of Nature. Let us look more closely at the facts and then at the different hypotheses so far offered to account for the submerged relief.

The essential facts, won even by preliminary exploration in regions so unfamiliar, are numerous and not easily held in full memory during the attempt to picture the mysterious furrowing of the continental slopes. Perhaps this difficulty will be eased if the writer baldly states what seems to be the best among the various explanations for valley and ridge, so that this explanation will be in mind from the start.

According to the preferred theory, the continental slopes were originally unfurrowed and comparatively smooth. Their present ruggedness is due to erosion, down-cutting, by underflows of heavy water that used to rush down the continental slopes, much as gushes of rain-water gully hillsides on the land. The water of these bottom currents was heavy because laden with mud and sand in suspension, the mud and sand being made of rock particles which are two to three times as dense as clean sea water. The mud and sand were brought into suspension during the tumult of storm waves that broke on the shallows of the continental shelf, and during the run of the turbulent tides across the shelf. The water thus made denser, heavier per unit of volume, than the clean water of the ocean, crept slowly down the gently inclined continental shelf and then rushed down the much steeper continental slope. The velocity of these underflows was so great that deep canyons and furrows were cut in the original sediments of the continental slope, and as many ridges were left between the new valleys.

Such submarine cutting of trenches may be possible at the present time, especially where the zone of intense wave-action 
is only a short distance from the fall-off to the continental slope, but, according to the theory, the intense furrowing of the flanks of the continents was due to the special conditions of the Glacial Period, when there were drastic, world-wide migrations of the zone of breakers out to the edge of the continental shelf and back again.

Facts of Topography.-Proof that offshore waters hide long and deep valleys came originally from fishermen, who, in search of fishing banks, extended their soundings over the continental shelves of the world; from systematic soundings of coastal belts as aids to navigation; and from soundings of cable-laying companies, who needed to know the relief of the sea bottom, especially where their cables were to come ashore. The hydrographic surveys under government auspices were naturally the most extensive. Early in the latter half of the nineteenth century it became clear that the generally smooth surfaces of the continental shelves flanking North America, Europe, and Africa are interrupted by trenches or "channels," each of which begins a few miles from the beach line and continues in a fairly straight line across the shelf, all the way to the fall-off where the continental slope begins.

In several cases those shelf "channels," slowly deepening to the fall-off, about 300 feet below sealevel, are continued into the continental slopes. Here the widths of the valley-like trenches are measurable in miles, while the floors lie thousands of feet below the general surface of the continental slope. Thus, within the belt of the continental slope, the comparatively narrow and shallowly incised "channel" of the shelf passes into an intaglio trough with dimensions of the same order as the Grand Canyon of Arizona. For the outer, deeper, and wider part of each of these submarine troughs the name "canyon" has been borrowed. Even by the older methods of sounding it was shown that some of the "canyons" head far 
inside the line marking the top of the continental slope. Figure 6 I gives an example, the Hudson Canyon, continuing the




Hudson "Channel" which crosses the shelf and is itself en axe with the Hudson River at New York City.

A few years of sonic sounding increased the number of known submarine canyons from a half dozen to more than one hundred. This is already a large number, though less than one per cent of the total length of shelf or slope off continental land has been adequately sounded.

Off a 400-mile stretch of the coast of eastern United States, more than a score of canyons, or one for an average 'longshore interval of 15 to 20 miles, have been mapped. But the wonder of their disclosure grew with the simultaneous discovery of deep and general trenching of the areas separated by the canyons. There the trenches, greatly outnumbering the canyons, differ from these by heading at or below the fall-off at the head of the continental slope. To distinguish these many shorter valleys, we shall call them "slope furrows" or simply "furrows." Figure 62 shows the canyons and principal furrows of the long belt. Barbed arrows indicate their axial extent down to the rooo-fathom level; they reach down much farther than that. Between each pair of adjacent furrows there is a long strip of higher ground; each strip may be called an "interfurrow ridge" or simply "ridge." Like the furrows and canyons, the ridges run in the general direction of the continental slope, that is, approximately at right angles to the line of falloff or break of slope of the continental terrace.

The first maps to illustrate well the association of canyon, furrow, and ridge were made by the United States Coast and Geodetic Survey. Its exploring vessels have sounded in great detail the inshore waters from Georges Bank off Maine to Cape Henry of Virginia. From the soundings of 1930 to 1932 the region of Georges Bank was mapped by Lieutenant P. A. Smith. He indicated the submarine topography with isobathic lines, an isobath being one that joins points of equal depth of 


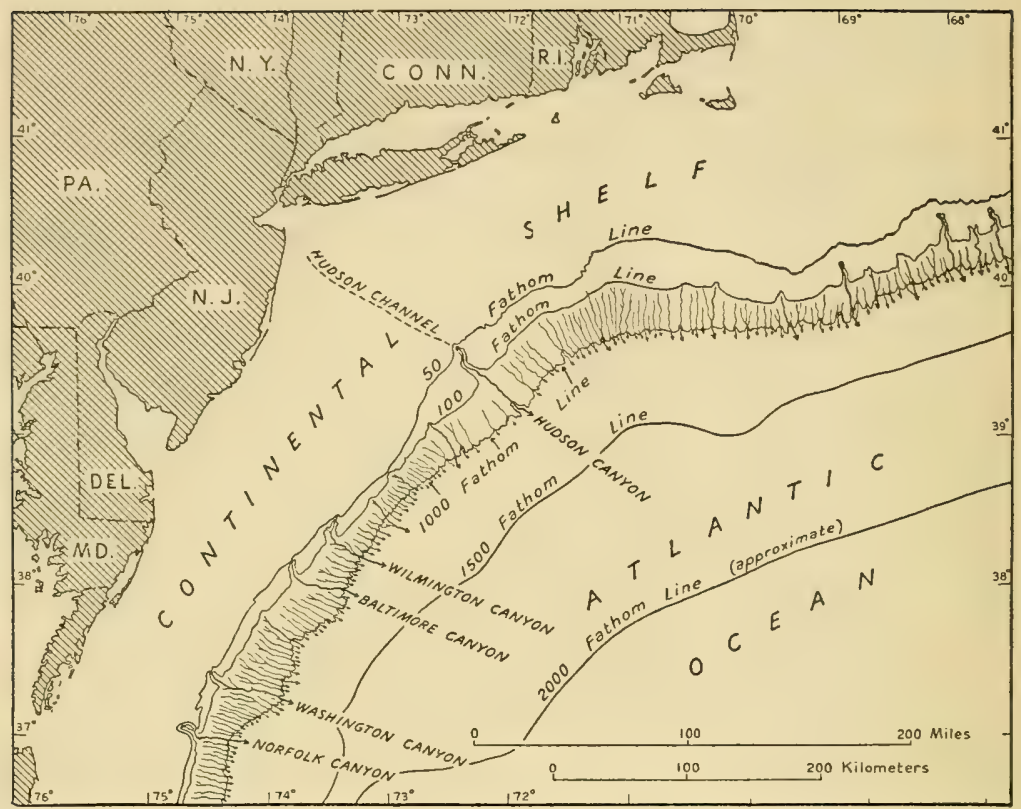

FIGURE 62. MAP SHOWING LOCATION OF CANYONS AND PRINCIPAL FURROWS OFF THE MID-ATLANTIC STATES; ALSO EXTENT OF THE CONTINENTAL SHELF AND LOCATION OF THE CONTINENTAL SLOPE.

sea floor below sealevel. Within the roo-mile belt covered by Lieutenant Smith fourteen canyons were given names. Only five of them head more than two or three miles inside the fall-off.

The next four seasons of exploration covered in large part the continental shelf and slope along a belt from Long Island to a point off Norfolk, Virginia. From the soundings three isobathic maps were drawn by the late A. C. Veatch. ${ }^{5}$ This belt, 250 miles long, portrayed five principal canyons, all heading far back in the continental shelf. To suggest their relative positions, they have been named, in order from north-northeast to south-southwest, the Hudson, Wilmington, Baltimore, Washington, and Norfolk canyons. 
The original large-scale maps are not easily reproduced as book illustrations, but excerpts serve well to suggest the impressive ruggedness of the 400 -mile belt. Figure 63 is such a

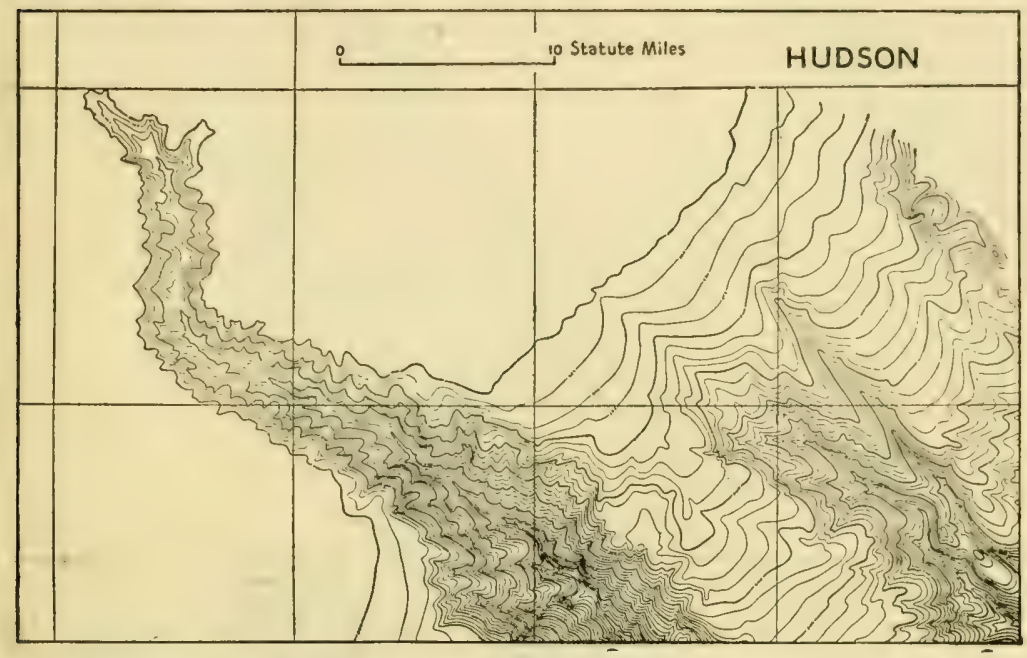

FIGURE 63. MAP OF THE HUDSON CANYON AND VICINITY. CONTOURINTERVAL 25 FATHOMS (I5O FEET).

reduced copy of a small part of one of the maps, the part covering merely the head of the Hudson Canyon and vicinity. Note the scale. This canyon heads I7 miles inside the hundredfathom line. Its over-all charted length is 50 miles; the actual length is at least 20 miles greater. The vertical interval (contourinterval) between successive isobaths below that of roo fathoms is 25 fathoms, or 150 feet. From the crowding of the contours, with the large contour-interval chosen, one can see how magnificent is the Hudson Canyon.

Excerpt maps, again much reduced in scale, represent the local areas covered by the Wilmington, Washington, and Norfolk canyons, and appear as Figures 64,65 , and 66 respectively. For comparison a principal canyon in Georges Bank is shown in Figure 67. 


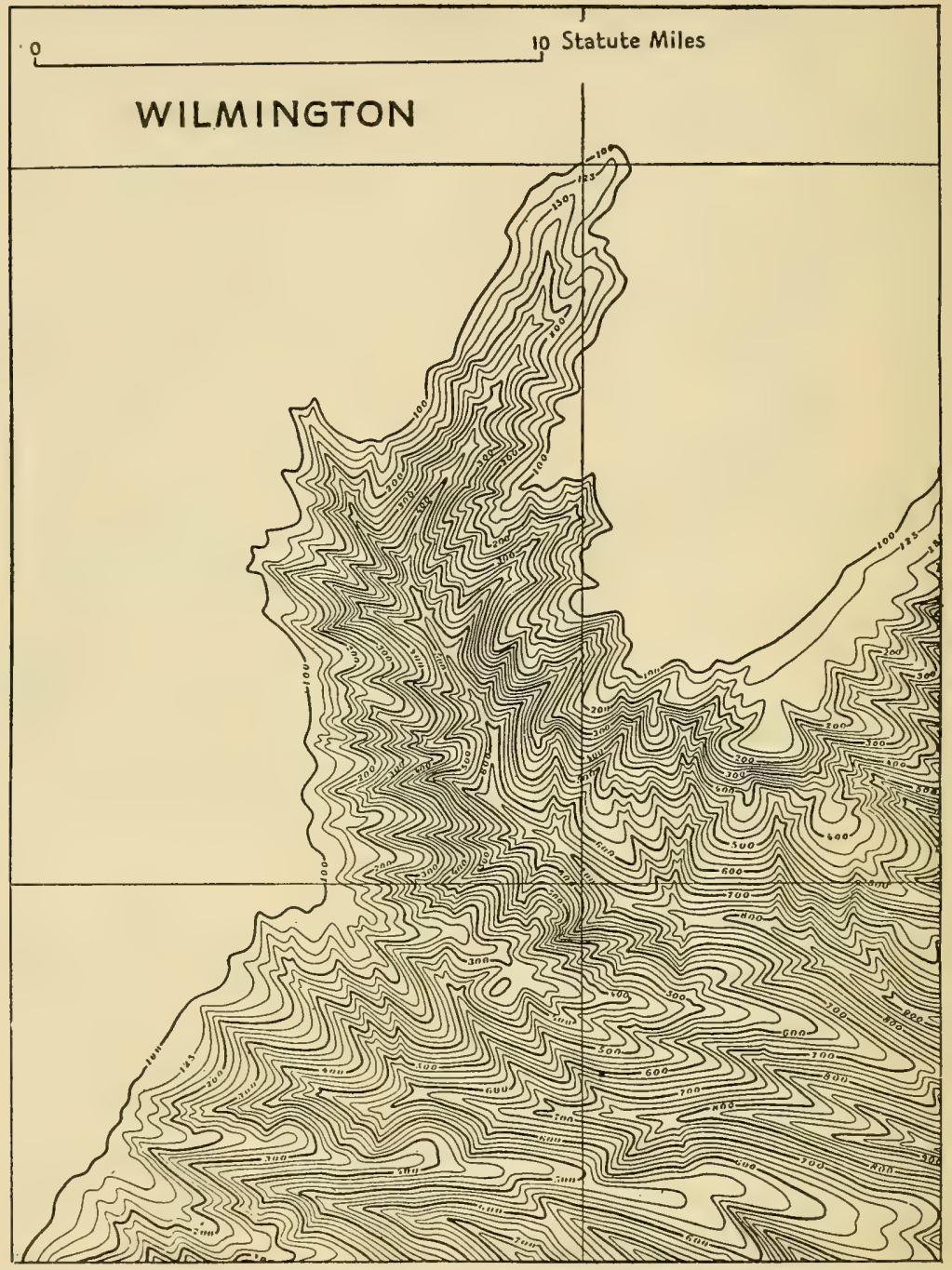

FIGURE 64. MAP OF THE WILMINGTON CANYON AND VICINITY. CONTOURINTERVAL 25 FATHOMS.

The Hudson Canyon is continuous with the Hudson Channel across the shelf. There is no similarly clear relation of any other of the principal canyons with shelf channel, though 


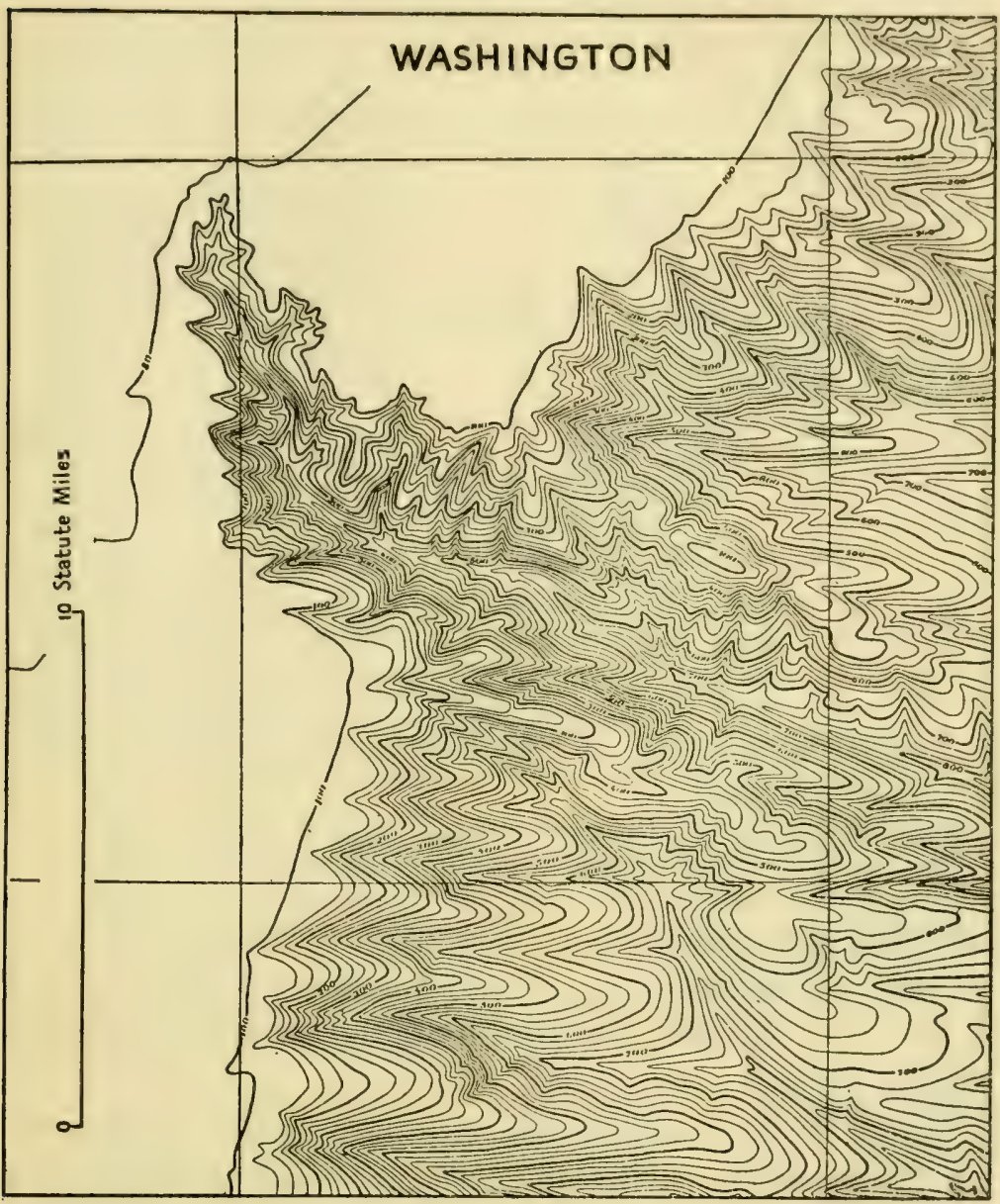

FIGURE 65. MAP OF THE WASHINGTON CANYON AND VICINITY. OUTSIDE THE IOO-FATHOM ISOBATH THE CONTOUR-INTERVAL IS 25 FATHOMS.

traces of what may be true shelf channels appear to east and west of Cape May. Nevertheless, it is possible that some of the more southerly canyons are genetically connected with the Delaware and Susquehanna river systems, thus recalling the more direct correlation of the Hudson River, Hudson Channel, and Hudson Canyon. On the other hand, it is worth noting at once 


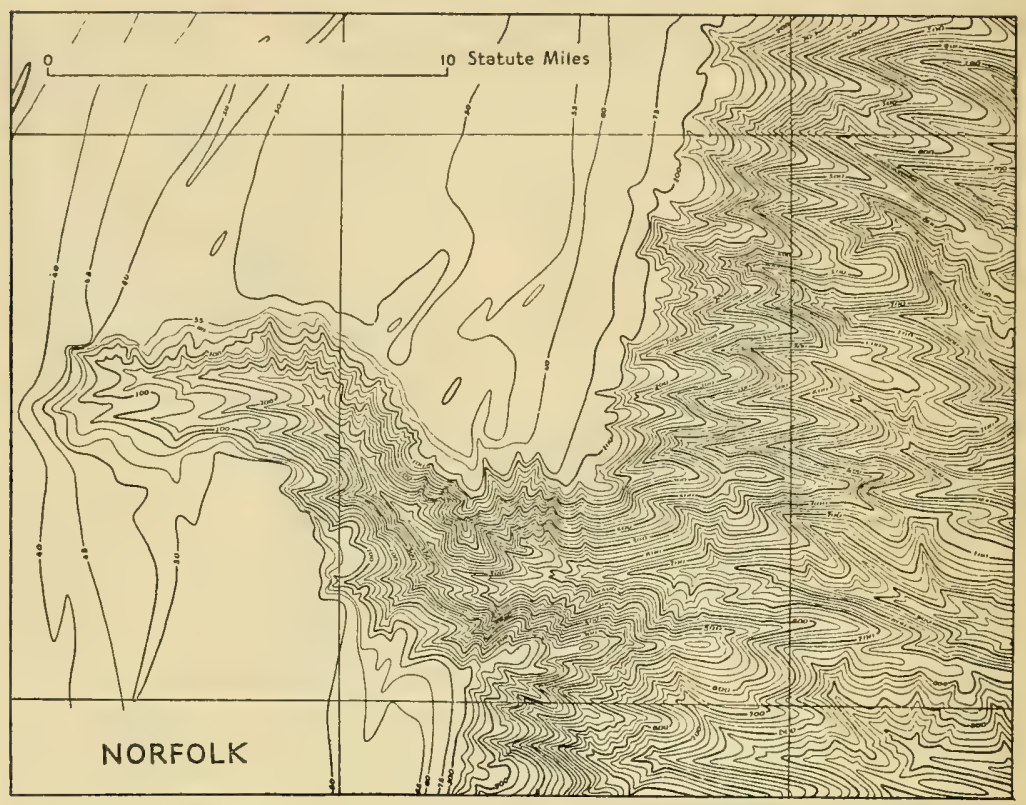

FIGURE 66. MAP OF THE NORFOLK CANYON AND VICINITY. OUTSIDE THE IOO-FATHOM ISOBATH THE CONTOUR-INTERVAL IS 25 FATHOMS.

that none of the canyons of Georges Bank has any obvious or probable relation to rivers of the continent-a fact to be emphasized when we consider the origin of all this submerged topography.

Table $\mathrm{V}$ gives some of the significant data regarding the five canyons mapped by Dr. Veatch. The unit of length is the statute mile. For comparison some dimensions are stated for two major land canyons of our Far West. Note particularly the enormous difference in the longitudinal gradients for subaerial and submarine canyons.

That contrast is even more striking when the mean slopes of the groups of submarine canyons in different parts of the world are compared with the mean slopes of the Colorado and Snake River valleys. In Table VI the averages are expressed in 


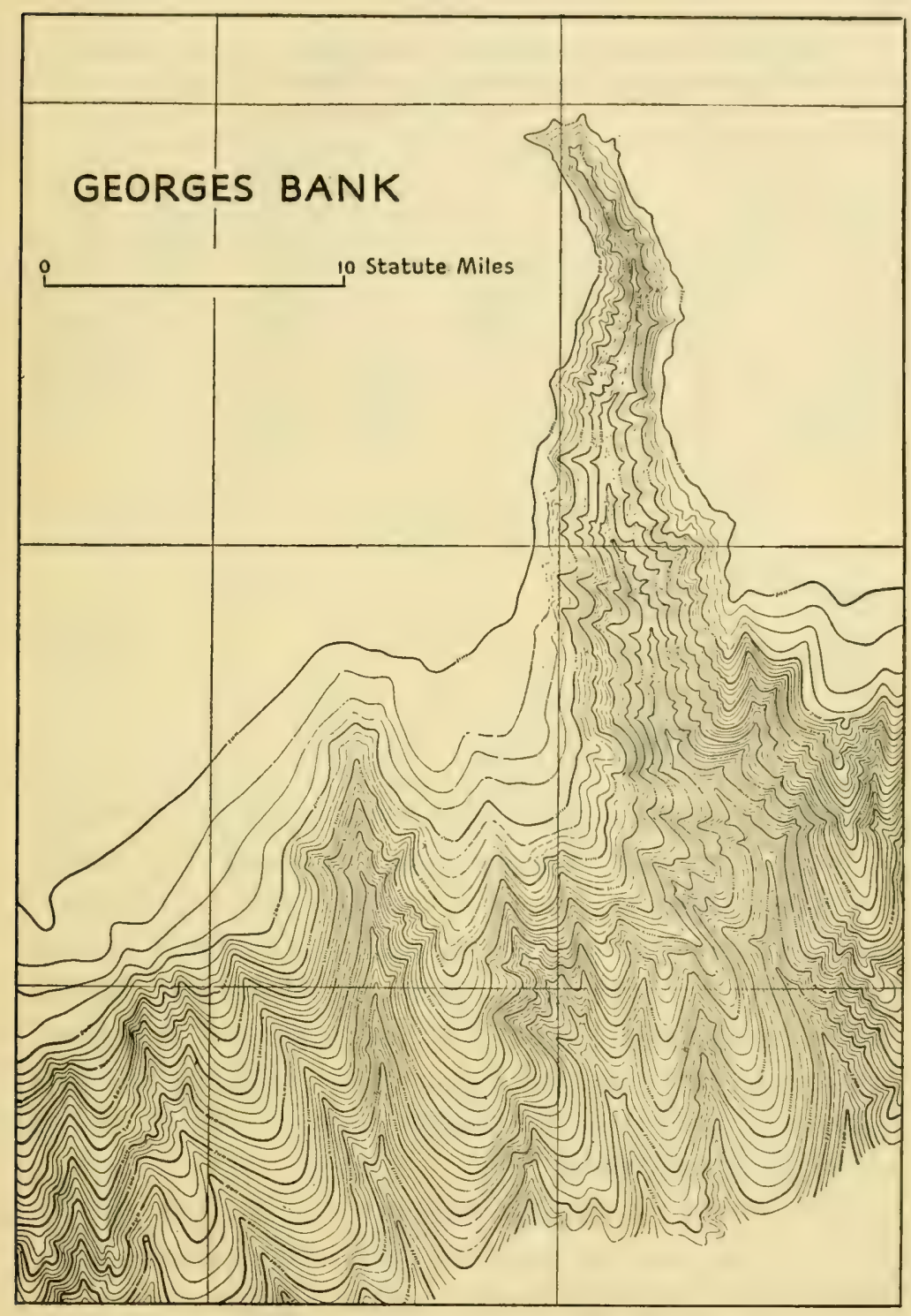

FIGURE 67. MAP OF THE LONGEST CANYON IN GEORGES BANK. CONTOURINTERVAL IS 25 FATHOMS, 


\section{TABLE V}

DIMENSIONS OF THE CANYONS OFF THE MIDDLE ATLANTIC STATES

\begin{tabular}{|c|c|c|c|c|c|c|c|}
\hline & 1 & 2 & 3 & 4 & 5 & 6 & 7 \\
\hline Canyon & $\begin{array}{c}\text { Mapped } \\
\text { total } \\
\text { length } \\
\text { (miles) }^{*}\end{array}$ & $\begin{array}{l}\text { Length } \\
\text { of part } \\
\text { invading } \\
\text { the shelf } \\
\text { (miles) }\end{array}$ & $\begin{array}{c}\text { Maximum } \\
\text { width } \\
\text { (miles) }\end{array}$ & $\begin{array}{c}\text { Maximum } \\
\text { depth } \\
\text { below } \\
\text { adjacent } \\
\text { ridges } \\
\text { (feet) }\end{array}$ & $\begin{array}{c}\text { Greatest } \\
\text { mapped } \\
\text { depth of } \\
\text { floor } \\
\text { below } \\
\text { sealevel } \\
\text { (feet)* }\end{array}$ & $\begin{array}{l}\text { Mean } \\
\text { longitu- } \\
\text { dinal } \\
\text { gradient } \\
\text { in shelf } \\
\text { area }\end{array}$ & $\begin{array}{l}\text { Mean } \\
\text { longitu- } \\
\text { dinal } \\
\text { gradient } \\
\text { in belt of } \\
\text { continen- } \\
\text { tal slope }\end{array}$ \\
\hline $\begin{array}{l}\text { Hudson.... } \\
\text { Wilmington } \\
\text { Baltimore... } \\
\text { Washington } \\
\text { Norfolk.... }\end{array}$ & $\begin{array}{l}50 \\
65 \\
85 \\
65 \\
60\end{array}$ & $\begin{array}{r}17 \\
10 \\
10 \\
7 \\
11\end{array}$ & $\begin{array}{l}8 \\
7 \\
6 \\
4 \\
4\end{array}$ & $\begin{array}{l}4,000 \\
3,600 \\
2,700 \\
2,400 \\
3,000\end{array}$ & $\begin{array}{r}7,400 \\
9,400 \\
10,000 \\
8,200 \\
9,000\end{array}$ & $\begin{array}{l}1: 33 \\
1: 18 \\
1: 18 \\
1: 20 \\
1: 19\end{array}$ & $\begin{array}{l}1: 40 \\
1: 53 \\
1: 66 \\
1: 53 \\
1: 48\end{array}$ \\
\hline
\end{tabular}

FOR COMPARISON

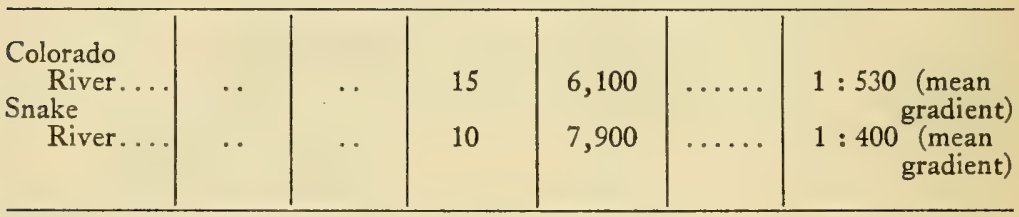

*In each case the actual dimension is greater.

percentages as well as in feet per mile. Again the mean slope is seen to be less steep than the slope at the head of the canyon. A similar relation is characteristic of subaerial river valleys.

The side slopes of submarine canyons are variable but comparatively steep. Along the upper and deeper parts of these valleys, as mapped by Smith and Veatch, the side slopes range from $I$ in 3 to $I$ in 6 and average about $I_{5}$ degrees from the horizontal. Such gradients suggest angles of rest for the soft sediments of the terrace.*

The whole topographic pattern is on a scale nowhere

* The contour-lines of the maps under discussion are generalizations from a limited number of soundings, and therefore cannot represent the submarine relief with exactitude. Departure from the reality is doubtless most serious where the depth of water exceeds 6000 feet. Evidently many more soundings over the continental slope are desirable, but it seems already clear that ultimate correction of the contouring will not in principle change the canyon-furrow-ridge pattern. 
TABLE VI

AVERAGE LONGITUDINAL GRADIENTS OF SUBMARINE CANYONS, BY GROUPS

\begin{tabular}{|c|c|c|c|c|c|}
\hline Regional group & $\begin{array}{c}\text { Number of } \\
\text { canyons } \\
\text { averaged }\end{array}$ & $\begin{array}{r}\text { Gradient } \\
\text { as a }\end{array}$ & $\begin{array}{l}\text { f canyon } \\
\text { hole }\end{array}$ & $\begin{array}{c}\text { Gradie } \\
\text { of }\end{array}$ & $\begin{array}{l}\text { at head } \\
\text { nyon }\end{array}$ \\
\hline $\begin{array}{l}\text { Eastern United States } \\
\text { Western United States } \\
\text { Eastern Asia......... } \\
\text { Indian Ocean...... } \\
\text { Mediterranean Sea.. } \\
\text { Oceanic islands...... } \\
\text { Off large rivers..... }\end{array}$ & $\begin{array}{r}14 \\
29 \\
28 \\
5 \\
12 \\
4 \\
9\end{array}$ & $\begin{array}{c}\text { Per cent } \\
5.5 \\
4.83 \\
7.0 \\
9.8 \\
10.9 \\
13.8 \\
1.7\end{array}$ & $\begin{array}{c}\text { Feet/mile } \\
290 \\
255 \\
370 \\
517 \\
575 \\
729 \\
90\end{array}$ & $\begin{array}{c}\text { Per cent } \\
7.3 \\
9.96 \\
14.4 \\
20.0 \\
15.2 \\
21.0 \\
3.24\end{array}$ & $\begin{array}{r}\text { Feet/mile } \\
385 \\
525 \\
760 \\
1,075 \\
800 \\
1,125 \\
170\end{array}$ \\
\hline
\end{tabular}

For Comparison

\begin{tabular}{|c|c|c|c|}
\hline $\begin{array}{l}\text { Colorado River...... } \\
\text { Snake River........ }\end{array}$ & . & $\begin{array}{l}0.2 \\
0.25\end{array}$ & $\begin{array}{l}10 \\
13\end{array}$ \\
\hline
\end{tabular}

matched on the lands, where, however, there are small-scale analogies. Among these are the gullied slopes of many railway cuts. Illustrations are found where the initially smooth sides of the cuttings have exposed weak material, and that so long ago that gushes of rain-water have had time to gully the artificial slopes. Particularly fine examples are to be seen along hundreds of miles of railway traversing the southern Appalachians. Another analogy, with more generous dimensions, is the system of rain gullies eroded out of the soft Californian formations shown in Figures 68 and 69. At the railway cut an occasional gully is more deeply incised than the average gully, and also heads far back of the break of slope at the limit of higher ground alongside the cutting. Such an exceptional gully corresponds to the typical submarine canyon.

As yet, soundings in belts other than those around the United States have not been detailed enough to show how general is the furrowing of continental flanks the world over. On the other hand, the more easily discovered canyons are 
reported off six continents and in the three principal oceans, and it is highly probable that each canyoned region is also intensely furrowed. The map of Figure 70, drawn by Professor Shepard, indicates with IOI short lines an equal number of canyons already discovered, though adequate sounding of the continental slopes has only just begun. ${ }^{6}$ We see that the distribution of the canyons is world-wide-a fact of great importance for any theory of origin for the great valleys.

Some of the foreign canyons are approximately en axe with master rivers of the respective continents. Examples are those of the Congo, Ganges, and Indus regions. However, in most cases there is no manifest relation of the kind.

The floors of the canyons have been dredged and also sampled from cores trapped in steel tubes which were driven vertically into the floors. From his pioneer work with these methods, Dr. H. C. Stetson has been able to show that the canyons off the east coast of the United States are being slowly filled with fine mud. The mud contains the minute shells of foraminifera belonging to species now living in the overlying water. Some inches below the surface of that mud, shells of foraminifera now living farther north, in much colder water, were found. It has been reasonably suggested that this deeper mud was deposited during the last cold stage of the Glacial Period, 20,000 to 40,000 years ago. If such be the fact, Stetson's investigation would lead to two other conclusions: first, that the principal furrowing was accomplished before the last icecap began to melt away because of a permanent amelioration of climate; secondly, that under present conditions, the waves and currents of the Atlantic are tending to fill canyons and furrows with sediment. Although the rate of filling is small, its continuation through millions of years would much reduce the ruggedness of the continental slope. Hence it appears that the furrowing was either initiated or accentuated in recent 


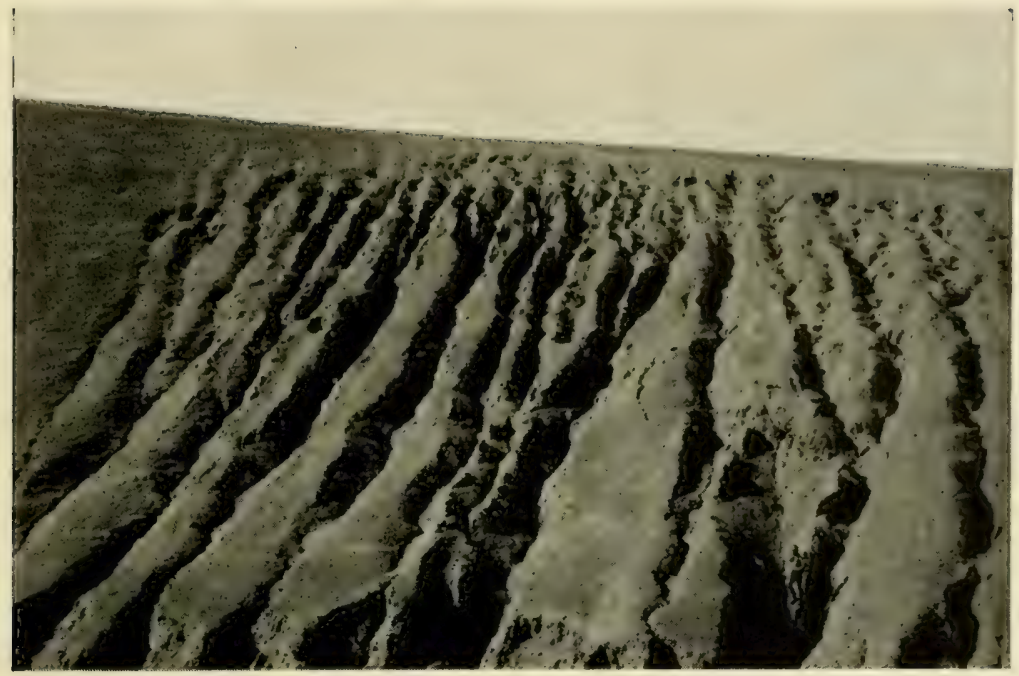

FIGURE 68. GULLIED SLOPE IN CALIFORNIA, APPROXIMATELY 75 FEET IN HEIGHT. PHOTOGRAPH BY F. G. RENNER.

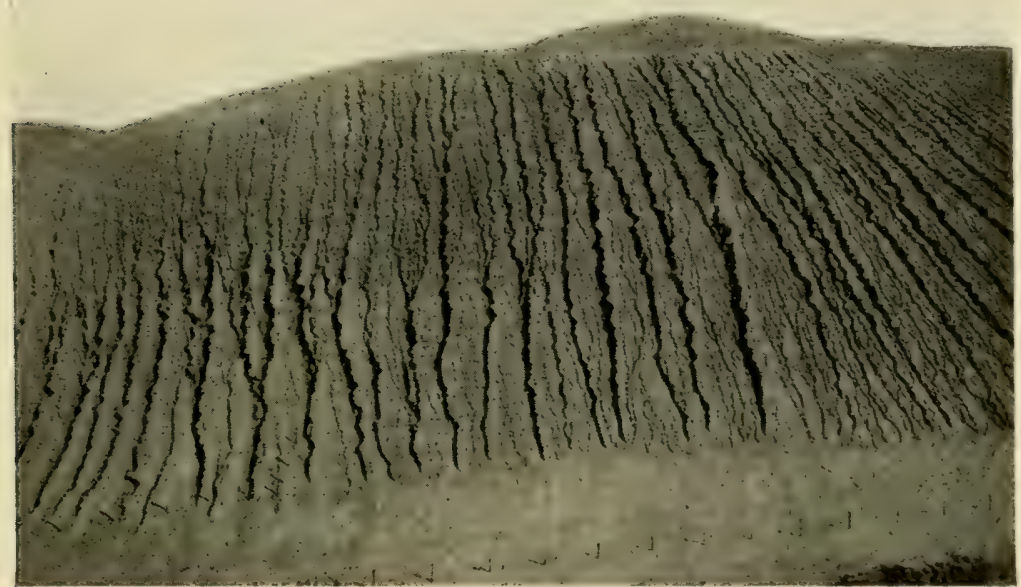

figure 69. GUllied Slope in CAlifornia, About 300 FEet in Height. PHOTOGRAPH BY F. G. RENNER. 


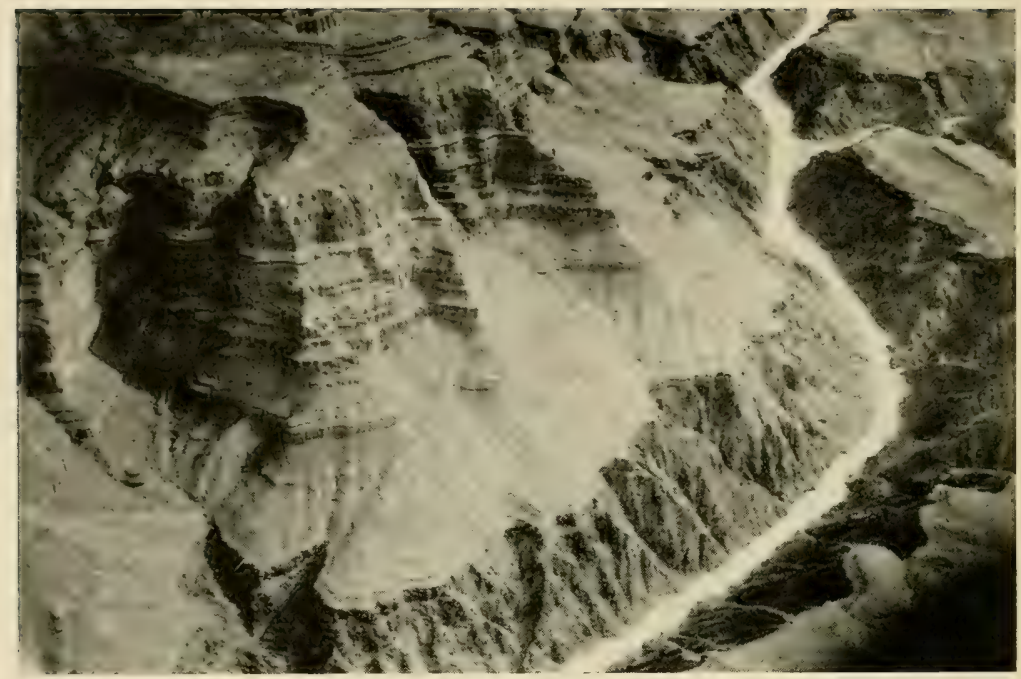

FIGURE 7I, CLIFF-AND-TALUS TOPOGRAPHY OF THE GRAND CANYON OF ARIZONA. AERIAL PHOTOGRAPH BY D. H. MCLAUGHLIN.

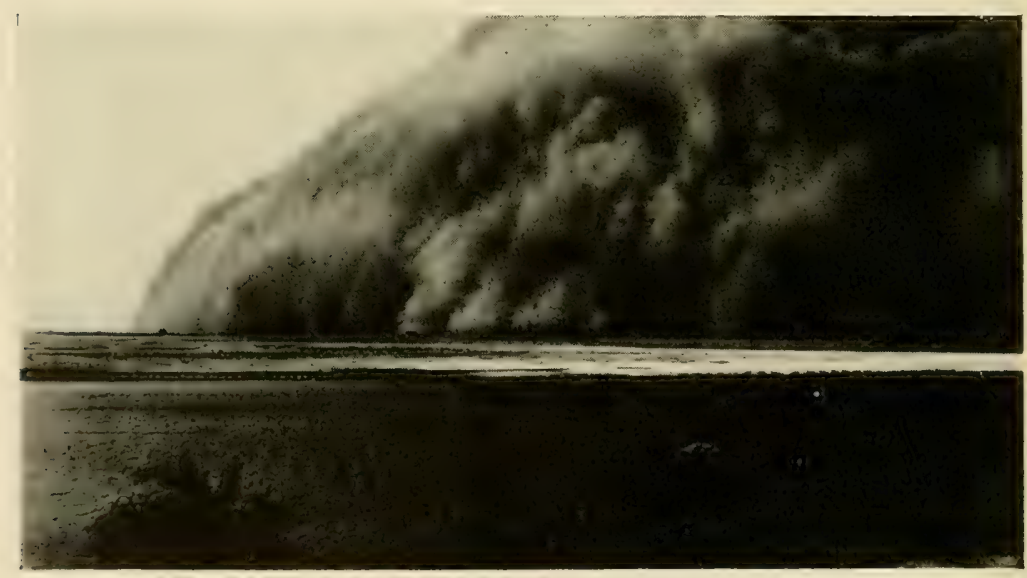

FIGURE 72. SANDSTORM IN NUBIA, ILLUSTRATING THE PRINCIPLE OF BOTTOM-SUSPENSION CURRENTS. 


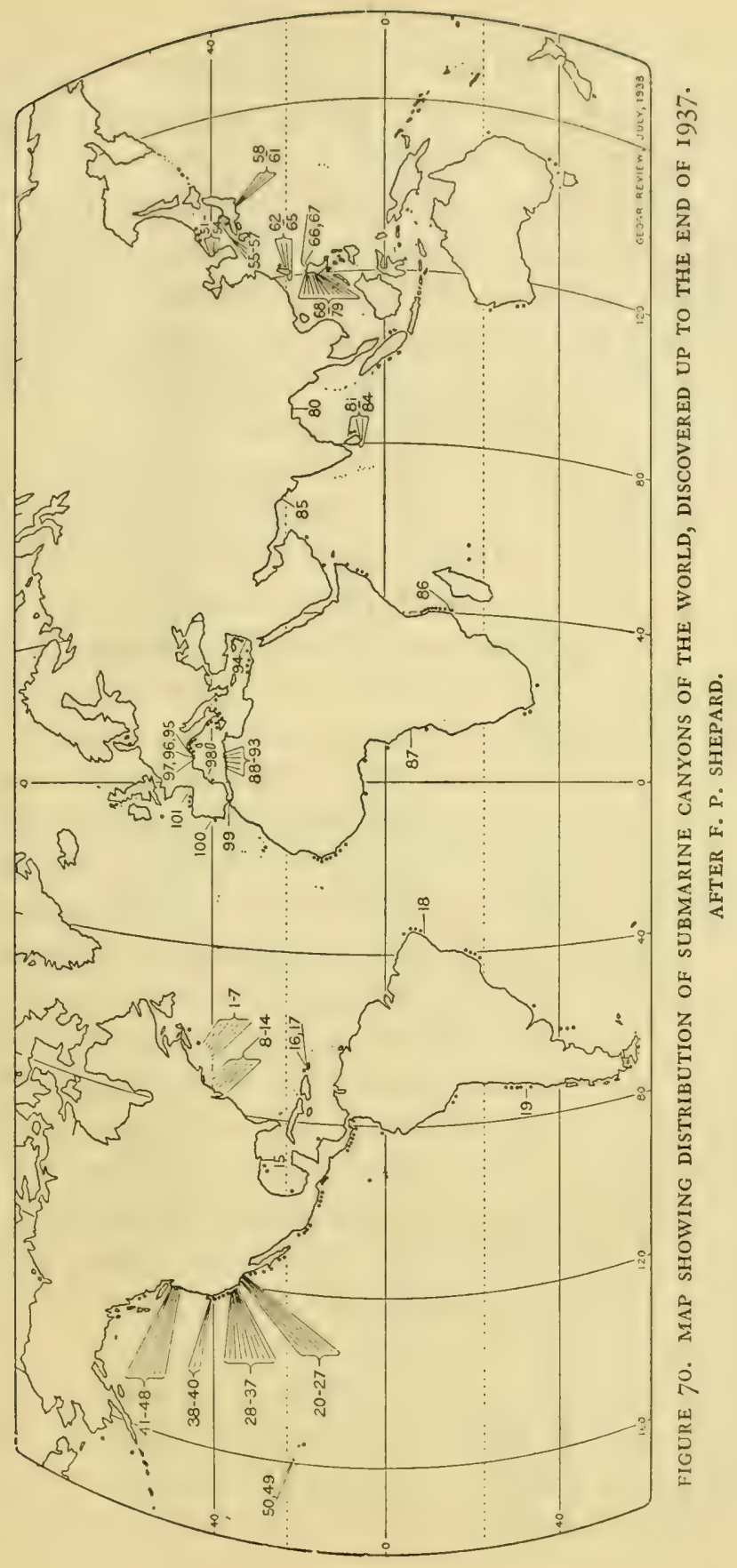


geological time, and then, during post-Glacial time, was stopped more or less completely.

In general the canyons off other coasts have form and dimensions like those characterizing the canyons of the American continental terrace. From these similarities we may well assume that at least the majority of the canyons, the world over, were simultaneously developed, as well as representing youthful features of the submarine topography.

Where mapped in detail, the submarine valleys seem to differ significantly from the Grand Canyon of Arizona and similarly walled, subaerial valleys exemplified in Figure 7 I. The eroding river responsible for each of these land valleys has cut down through rock layers of differing strength. Where the hardest layers crop out in the valley walls, there are cliffs; where softer layers crop out, there are much gentler slopes made on aprons of fallen débris. More technically expressed, the walls present cliff-and-talus topography. But, though individual cases of similar variation of side slopes may be ultimately found in the submarine valleys, no systematic alternation of cliff and talus is shown by any of the isobathic maps now published. These maps suggest that the layered rocks composing the great continental terraces are, with respect to strength, relatively homogeneous. It is true that Dr. Stetson has dredged occasional slabs of hard rock from the canyon walls, while most of his samples from the walls were clays and sandy clays, but there is no evidence that the harder beds surpass a few feet in individual thicknesses or that their total thickness represents an important fraction of the continental terrace as a whole.

Some of the canyons off California have walls of abnormal steepness, even to approximate verticality. Near the heads of these canyons Professor Shepard has dredged up pieces of granite, torn from the walls, which he believes to be largely 
composed of such strong rock and therefore capable of being precipitous. Besides having canyon walls of unusual steepness and composition, the California terrace is exceptional in three other respects. It is much narrower than most of the other continental terraces, is surfaced by hard rock in extraordinary degree, and is situated in a region of recent dislocation of the earth's crust on a large scale. Taking into account all available information, it seems probable that at least some of the canyons off California were excavated above sealevel by ordinary rivers and then submerged by sinking of the land. The preservation of each in the form of an open trench, in spite of the tendency of offshore sediment to fill it, can be explained by the same kind of mechanism as that later suggested for the digging of submarine canyons and furrows elsewhere. In any case the nature and history of the continental terrace off California seem to differ essentially from those of the terraces off the eastern United States and other coasts.

Origin of the Submarine Valleys.-Now for the genetic problem. To guide us toward its solution let us review some of the principal facts. First: The furrowing of the continental slope is clearly the work of running water. Second: This slope is steep, averaging about $\mathbf{I}$ in $\mathbf{1 5}$ and scores of times greater than the channel of any long river on land. Third: Seismograph and boring machine have proved the continental terrace to be largely composed of water-soaked, poorly consolidated clay and sand, offering little resistance to stream erosion. The side slopes of most canyons and furrows are those expected if they are underlain by this weak material. Fourth: The general similarity of the canyons suggests simultaneous formation for at least the majority. Fifth: Their distribution is world-wide, planetary. Sixth: Judging by analogy with subaerial valleys, nearly all of our canyons and furrows are to be rated as youthful features of the earth's topography. The canyons off the 
eastern United States were excavated in post-Miocene time, as proved by Dr. Stetson's discovery of fossiliferous Miocene sediment outcropping on the canyon walls. ${ }^{7}$ Since these canyons were dug, their floors have been raised a few feet or inches by the recent deposition of fine muds, whose fossils denote a decided warming of the Atlantic during this limited sedimentation. Beneath that muddy layer are sediments containing shells of cold-water animals, which are reasonably believed to have lived during the last (so-called Wisconsin) stage of Pleistocene glaciation on the lands. This assumption implies that some of the canyoning of the continental slopes is to be referred to pre-Wisconsin time, though not necessarily to pre-Glacial time.

The likeness of the furrowed submarine slopes to raingullied slopes on the lands early prompted the idea that subaerial streams excavated also the submarine canyon. This hypothesis was first elaborated by James D. Dana, following A. Lindenkohl. It was argued that the continental terraces were uplifted, so as to be for a short time 5000 to I0,000 feet above sealevel; that during this high stand the canyons were cut by rain-fed rivers; and that, after the deep trenching, each continental slope sank bodily, with drowning of the new canyons. A few students of the problem still prefer that hypothesis, and also extend it to cover the intense furrowing of the continental slopes-a feature not known to Dana and Lindenkohl.

Several weighty objections of the conception led Professor Shepard, long after, to assume subaerial excavation of canyon and furrow, not because of temporary uplift of the continental terraces but because of temporary, world-wide sinking of sealevel, the continents suffering no distortion. To describe such a general withdrawal of the ocean we have the technical word, eustatic. If the supposed eustatic shift were great enough and long enough continued, canyon and furrow could be the- 
oretically ascribed to subaerial erosion, that is, to ordinary river-cutting.

Fifty-five years ago F. A. Forel, the eminent Swiss hydrologist, considered an explanation that demands no temporary emergence of the continental terraces, but assumes the canyons to have been dug by bottom currents in the ocean itself. ${ }^{8}$ Although Forel had little faith in his own idea, this in various forms is now growing in favor among both geologists and hydrologists. Among the reasons for the preference are the weaknesses of all the alternative explanations yet published. It will therefore be profitable to study the alternatives in order and in some detail.

r. The principle of local or regional uplift of the earth's crust was already well established when Dana and Lindenkohl wrote, and the idea of temporary super-elevation of the continental terraces came easily to mind. But there are ample grounds for doubting that this process has had anything to do with the ruggedness of the continental slope.

In the first place, geologists know of no case where regional uplift of a mile or more has been soon followed by subsidence of the same region and of the same order. In the present case this kind of oscillation of the earth's crust is particularly incredible. The original formation of each continental terrace and the grading of the continental shelf at its surface took millions of years. During that long time, the crust was disturbed so little that the outer limit of the continental shelf was, in average, only 40 or 50 fathoms below sealevel. We know also that at the present time the shelf is covered with water which in average is not more than about ten fathoms deeper than the water that lay on the shelf before the canyoning. In other words, the uplift hypothesis demands that enormous upheaval was soon followed by a sinking of almost exactly the same amount. Such practically perfect reversal of movement 
seems quite beyond possibility. Geologists know full well the stubbornness of the earth's crust in resisting forces of deformation, especially where the deformed region has a span of only a few scores of miles. In this case any distortion of the strong crust would have to be to a high degree irreversible.

Second, we note that, to account for the world-wide distribution of the canyons, the double movement of the crust would have been assumed to affect the borders of every continent (except Antarctica, off which canyons have not been reported), and that contemporaneously or nearly so. No experienced geologist could credit crustal displacement defined by so delicate conditions of time as well as of space.

Third, the hypothesis lacks support because no reason for either uplift or later subsidence has ever been proposed. Until this question is properly answered, the imagined up-and-down swinging of the crust will remain a matter of pure conjecture.

Fourth, the idea can be tested in still another way. If temporary emergence of the continental slope permitted rain-made furrowing, master rivers that head far within the original shoreline should have dug comparable furrows in their own delta deposits and other weak formations of the coastal belt. Yet no river of the eastern United States, though flowing long distances across weak sediments, has done that. They, like the Mississippi, have trenched themselves in their lower courses as much as 300 feet, but this limit is precisely the depth expected on a sounder theory of the furrowing. As we shall see, this theory is based on the assumption of moderate swings of sealevel up and down, the earth's crust remaining undisturbed.

Without further elaboration it seems clear that the attempt to account for the submarine valleys by assuming a mighty, vertical oscillation of each continental terrace is a failure. If Dana had been acquainted with the wealth of data secured by 
sonic sounding, he would hardly have regarded his idea as even a good working hypothesis.

2. We now turn to Professor Shepard's explanation. According to him, canyon and furrow represent drowned valleys which had been cut by rivers of the ordinary type, during an interval of time when the continental slopes were temporarily emerged because of a world-wide or eustatic lowering of sealevel. ${ }^{9} \mathrm{He}$ ascribed the negative shift of sealevel to the withdrawal of water from the ocean in quantity sufficient to build the ice-caps of the Glacial Period. Many glacialists have computed the maximum for the negative shift so occasioned and agree on a value of about 100 meters or little more than 300 feet. Shepard has tried to show that the shift was approximately 3000 feet or nine times as much. However, the large value comes out after making impossible assumptions regarding both areas and thicknesses of the ice-caps. A lowering of Ioo meters well accounts for the "channels" cut across the continental shelves where the Hudson and other master rivers were extended out to the new, lower shorelines ruling at the peak of glaciation. But manifestly the actual eustatic shift would not cause emergence of the continental slopes, whose rugged topography is the problem at issue. In any case, the furrowing between the isobathic lines of 3000 and 10,000 feet are left unexplained, even if Shepard's estimate of the worldwide lowering of sealevel could be admitted.

3. Since neither crustal displacement nor eustatic shift of sealevel are adequate conditions, we are left with the remaining suggestion-that the dissection of the continental slopes was the work of currents at the bottom of the ocean. Based on this idea, three contrasted explanations of canyon and furrow have been proposed.

We note first that given by Professor D. W. Johnson in a recent book. He supposed that canyon and furrow are homo- 
logues of a special class of land valleys, namely, those that have originated in, as well as deepened by, "spring-sapping."10 Illustrations of these are found among the high plateaus of the southwestern United States. The plateaus are underlain by alternating beds of porous and tight, permeable and impermeable, rock. The rain-water fallen on the high parts of one of the plateaus sinks to one of the continuous, permeable beds, along which the water creeps, down to a lower level where the bed crops out at the surface. Such a porous, continuous bed may be conveniently referred to under the technical name "aquifer."

At the lower, outcropping end of the aquifer the subterranean stream issues with kinetic energy and also with power to dissolve rock matter. There the relatively weak, porous rock is eroded away, whereby the overlying, stronger beds of rock are undermined. Ultimately the undermined rock is torn apart, with sliding of great blocks into the new gulch. The débris of the slides is further broken up by frost and other weathering agents, and, both in solution and by mechanical washing, is carried away. Thus the new valley is gradually lengthened by "spring-sapping." Because the valley has been formed by slumping at its upper end, its head is blunt in ground-plan; it belongs in the class of "box-head" canyons or gorges.

The speculation that spring-sapping is the chief mode of formation of the submarine valleys was based on a number of assumptions: (a) each continental terrace includes an adequate number of continuous, porous beds or aquifers; $(b)$ the aquifers crop out on the continental slope at the appropriate levels; and $(c)$ there has been sufficent flow of ground-water (downcreeping rain-water) along the aquifers to produce trenches of great length and of great depth below their respective rims. All three assumptions may well be doubted.

While here and there permeable beds have been demon- 
strated in the continental terraces, we have no evidence that they are abundant enough or continuous enough to match the number of submarine valleys already discovered. Then, too, it is highly improbable that there can be aquifers outcropping near the fall-off to the continental slope, in number sufficient to explain the heading of so many furrows at the line of falloff. In the third place, the published maps do not represent the valleys as of the box-head kind; their heads are more sharply bitten into the continental terrace. A fourth objection is still more cogent. By hypothesis the fresh underground water must continue to flow oceanward, though opposed by the pressure of the denser sea water. Professor Johnson recognizes this difficulty and tries to meet it by supposing that the aquifers have been fed from rain-gathering surfaces many hundreds of feet above sealevel. In this way the subterranean streams are thought to have been supplied with pressure sufficient to displace the heavier sea water at the submarine outcrop of the aquifer. In the case of the Atlantic terrace between Long Island and Cape May, a fraction of the required "hydraulic head" might be conceived as given, if the landward limit of each aquifer were located on the coastal plain, well above sealevel. Compare Figure 2. However, the amount of such counteracting pressure is far from enough, even under the most favorable conditions, in the existing coastal plain. Professor Johnson therefore adds an additional speculative premise: the needed hydraulic head was supplied when the coastal plain of the mid-Atlantic States extended far beyond its present limit and to a height far greater than its present maximum height. This ad hoc hypothesis has no definite backing from geological observations; it increases the number of unverifiable premises; and it leads to new troubles. Among these a few may be noted. As fully developed, the spring-sapping hypothesis implies that the submarine valleys off the eastern United States were exca- 
vated tens of millions of years ago, whereas the valley pattern has the marks of extreme youth. Again, the postulate of a high-level coastal plain as feeder for the underground drainage is still more doubtful in the case of the hundred-mile stretch of canyons and furrows along Georges Bank; for this bank is isolated, out to sea, and not backed by any coastal plain. Perhaps even clearer is the absence of rock structure and topography that could give the required head to spring-sapping streams off the canyoned shore-belts of India, California, and the west coast of Africa.

There is a fifth difficulty. The development of a subaerial box-head valley depends on the removal of rock fallen from the walls, as these undergo spring-sapping. We saw that the removal is by solution and by transportation downstream by running water. Now, Professor Johnson expressly excludes the possibility of adequate bottom currents of the kind, and is therefore forced to rely on solution as the one essential for furrowing the continental slope. Yet, if the submarine spring be capable of dissolving rock, its water must be relatively fresh, and, because of its lower density, must rise in the heavier sea water and so lose contact with any rock. The spring water could not wash away or dissolve away the detritus fallen from the valley wall at the point of emergence of the spring.

A final and likewise telling objection: the spring-sapping hypothesis postulates important solution of one of the least soluble materials known to geology-clay. With that premise, neither geologist nor geochemist is likely to be satisfied.

In summary, it seems clear that the spring-sapping explanation of the submarine valleys cannot be retained.

4. Professor W. H. Bucher, also preferring submarine erosion to subaerial erosion, attributes canyon and furrow primarily to cutting by the reflux currents associated with powerful earthquake waves in the ocean ${ }^{11}$ Like wind wave and true 
tidal wave, an earthquake wave in the sea is compounded of alternating, forward and backward motions of the water. The displacement of water in both onset and reflux has a maximum velocity increasing with the height of the wave. Hence a firstclass seismic wave, with several times the height of even great storm waves, is characterized by to-and-fro currents of extraordinary power. Professor Bucher supposed that the reflux currents so generated run along the continental slopes, with sufficient friction along the sea bottom to tear up the clay and sand and ultimately excavate canyon and furrow. But here too there are troubles.

That part of the energy that belongs to the reflux current is largely concentrated near the surface of the ocean, the velocity of the motion decreasing with great rapidity as the depth of water increases. The laws of hydraulics demand that even the mightiest seismic wave cannot give a reflux current rapid enough to erode the lower half of the continental slope, down which, nevertheless, the submarine valleys continue for many miles.

And for another reason the ultimate effectiveness of the reflux may be questioned. The earthquake waves run in packs or so-called trains, but any such train of importance attacks a coast for only an hour or so, and that only once in a stretch of time measurable in decades or centuries. In fact, no major earthquake wave has ever been recorded in the North Atlantic, where submarine valleys are in full development. The possibility that during pre-historic time this ocean was long shocked much more vigorously than at present is emphasized by Bucher, but only in a purely speculative way and without proof. Similarly there is no direct evidence that the reflux currents have been powerful and numerous enough to account for the valleys sunk in the continental terraces of the Indian Ocean. The western Pacific is the home of seismic 
waves on the grand scale, but we have no record of their vigorous onslaught along the continental terrace between Vancouver and southern California-another belt with many canyons and furrows.

Thus the adequacy of earthquake waves is doubted; first, because their reflux currents lack sufficient erosional energy in the lower half of the continental slope; second, because these catastrophic waves are too rare in both time and space.

5. We come now to what seems to be the best hypothesis on which to base explanation of the submarine valleys. The essential idea may be summarized as follows: The trenching is referred to bottom streams of sea water containing mud in suspension and therefore temporarily endowed with density greater than that normal to the clean water overlying the respective continental terraces. It is further supposed that the conditions for the formation of such bottom currents were specially developed at certain stages of the Glacial Period, though they may now be intermittently operating in a few regions where the offshore terraces are narrow. ${ }^{12}$

About 40,000 years ago, the last set of Pleistocene ice-caps of North America and Europe were of maximum total volume, but were just beginning to melt away. With the exception of a few small patches, the last remnants of these gigantic masses of ice had disappeared by the year 7000 B.c. Since the water represented in the ice-caps was evaporated from the ocean and then dropped, as snow and rime, on the lands, the sealevel was lowered everywhere. As already noted, the lowering was about Ioo meters or 330 feet in maximum. From the amount of work done by the last set of ice-caps, it appears that sealevel was nearly as low during a period of the order of 50,000 years. During three long intervals of still earlier Pleistocene time, ice-caps had slowly grown to comparable size and then melted away more or less completely. The second glaciation seems to 
have lowered sealevel a little more than 330 feet. During tens of millennia each set of ice-caps grew in bulk; during other tens of millennia each set had maximum total volume; and during still other tens of millennia each set was slowly melting. From beginning to end of each of the four Glacial states-chaptered as growth, culmination and waning-the wind waves and tidal waves were breaking on the continental shelves, far from the existing shorelines. Thus, for a time totalling more than a quarter of a million years, the waves were pounding the old embankments of clay, mud, and sand. Along the temporary, slowly migrating shores, storm wave and turbulent tide were muddied to a degree far beyond that represented in the 'longshore water of the present day. While so charged with particles of solid rock, the silty water was effectively denser than clean sea water, and as a temporary suspension, sank bodily to the bottom, that is, to the surface of the continental terrace. There the weighted water flowed slowly down the gently sloping continental shelf, to run much faster after it had passed the fall-off at the top of the continental slope. Such accelerated density-currents along the sea floor were, according to the hypothesis now to be discussed, the chief excavators of our submarine valleys.

A bottom current of the kind and on the scale described is, perhaps, not easily pictured. However, here as so often with Nature's hidden processes, the imagination can be guided by analogy. Figure 72 is a photograph of a sandstorm, sweeping over North Khartoum in Nubia. We see how the suspension composed of air and sand hugs the ground, keeping its individuality, as its sinister front moves on. Note, too, that this layer, effectively more dense-heavier volume for volume-than the clear air above and in front of it, keeps pushing its toes out over the plain, as would be expected because of the superior density of the sand-laden mass of air. Of course, the motion 
across the flat plain was not caused by the excess of density but by unbalanced pressure in the atmosphere as a whole. On the other hand, there can be little doubt that such a sandy cloud would tend to sweep bodily down along any steep slope upon which it might be pushed.

The compulsion on the silt-laden water to dive and slide along the sea bottom was, of course, lessened in proportion to any settling-out of solid particles. However, such loss of excess density took time. Observation shows that shore waters, agitated by a storm, remain murky with sediment for many hours after the storm has spent its fury. We may therefore assume that a bottom current of Pleistocene time could run many hours. Over the gently sloping shelf its velocity was comparatively small, and over this region some of the coarser detritus must have settled out. But, during the long time when sealevel was lowered nearly to maximum, the zone of agitating waves was long situated at or close to the fall-off to the continental slope. Without much delay the silty water would then have been precipitated down the continental slope, with a velocity much greater than any possible on the adjacent shelf. With only moderate velocity the silty current would cross the whole slope in some hours. If, during those hours, the speed were enough to cause turbulent erosion of the slope sediment, the settling-out would be delayed and new solid particles added to the soup-like suspension. Nowadays the zone of intense agitation by the breakers is 50 to 150 miles from the outer edge of the flat shelf; hence, now, during the long, slow journey to the fall-off, a bottom current loses much of its operating load by settling-out and cannot attain great speed down the continental slope. Is it not clear that the silty currents of each Glacial stage should have been incomparably more energetic on the slope than any current developed by storms in postGlacial time? 
Quantitative testing of this Glacial-control hypothesis is not easy. Essential facts are buried in both space and time-under the ocean and under the obscuring blanket of post-Glacial and Glacial time. Yet there are already in sight valuable tests which, taken together, encourage faith in the root idea as the most promising of all those reported in print. These tests are based on illuminating analogies in Nature, on laboratory experiments, and on an engineer's formula relating to the flow of liquids under gravity.

An obvious analogy is that of the ordinary river, which also flows along the bottom of an ocean-an ocean of air. One condition for its descent is its possession of density greater than the density of the covering air. Similarly, the silty submarine current runs down the continental slope because of density greater than that of the covering clean water. The mechanical likeness to the rain-made streamlets that gully steep subaerial slopes is particularly striking. The items of this comparison are worth noting.

First: The gullying, subaerial stream is intermittent, with full momentum at times of heavy rainfall, and feeble or nonexistent at other times; the submarine silty currents had full momentum at times of strong agitation of shelf sediments by wind waves and tidal waves, and were feeble or non-existent at other times.

Second: Because the initial slope is steep, the main subaerial gullies and generating currents are directed, in roughly parallel lines, down the slope. The prevailing "drainage" pattern is not of the sprawled-out variety belonging to dissected plains of low slope. So it is with the rugged topography of the relatively steep continental slope.

Third: The subaerial stream represents concentration of rain-water along lines of initial depression across the escarpment and in channels dug along those lines. By hypothesis, 
the submarine stream represents the concentration of silty water along initial depressions with axes across the continental slope and along channels dug along those lines.

Fourth: Each subaerial stream preserves its individuality to receiving basin, whether this be lake, ocean, or desert sink. Our hypothesis assumes preservation of the individuality of each submarine silt current on the way out to the receiving basin-that occupied by the deep ocean.

Fifth: The velocity and erosive power of the subaerial stream grows with increase of gradient and with increase of the depth of water, either by lateral inflow or by deepening of the channel. We are to learn that similar laws must have been obeyed by the silty currents.

Sixth: The subaerial stream becomes turbulent, and therefore a more efficient excavator, when the velocity of flow surpasses a critical value. Again both theory and experiment show similarity with the silty currents of the sea bottom.

Seventh: The effective density of the running, subaerial water and its eroding power are somewhat increased by the addition of a load of silt, taken into suspension during the erosive attack on the valley sides. Experiments have proved that the same principle applied in the case of silty currents at the floor of a body of cleaner water.

Eighth: Each subaerial gully tends to become well graded from end to end; any side stream generally enters the main stream "at grade," that is, with no systematic break of gradient at the junction. The maps of Veatch and Smith demonstrate a similar condition ruling the "drainage" pattern of the continental slope.

Ninth: The deepening of the subaerial gully is not continuous, but is locally interrupted by temporary deposition of sediment, fallen from the sides of the gully to the floor. The channeling process has a kind of rhythm, being alternately 
positive and negative. We have already learned that the canyon floors off the eastern United States are veneered with fine mud, deposited since the excavation of those canyons. And, by hypothesis, that excavation was the product of a rhythmical change of conditions, due to the alternation of Glacial and Interglacial stages of the Pleistocene.

Tenth: The deepening and widening of a subaerial gully may be effectively stopped by climatic change, that is, by continued drought and absence of sufficient rainfall. The preferred explanation of submarine canyon and furrow implies cessation, or at least great weakening, of the submarine erosion when the water which had been temporarily bound up in the ice-caps was returned to the ocean.

While emphasizing the many parallels between subaerial and submarine gullying, it is well to remember a fundamental difference between ordinary river and silty bottom current. R. T. Knapp and H. S. Bell of the California Institute of Technology have recently described this contrast in graphic words: In the case of the river "the water transports the sediment" of the channel; in the case of the silty current "the sediment transports the water."

River water is about 800 times more dense than the overlying air. A thick silty current on the sea floor is likely to be no more than one or two per cent denser than the overlying clean water. These conditions for flow are quantitatively so different that one might doubt that any silty current running down a continental slope can have velocity enough to enforce erosion. Such antecedent doubt is relieved when analogy with another sort of bottom current in the ocean is recalled. This second kind of current is also denser, "heavier," than the overlying water, not because of suspended silt but because the bottom current is richer in dissolved salts than the water above. Such so-called salinity currents were long ago demonstrated at 
the Dardanelles, where the denser, more saline Mediterranean water keeps running along the bottom, through the strait, the Sea of Marmora, and the Bosporus, into the basin of the Black Sea. Overhead the less dense Black Sea water runs steadily in the opposite direction, ultimately mixing with the water of the Aegean Sea. A double salinity current on a much larger scale persists at the Strait of Gibraltar, where a layer of Mediterranean water, hundreds of feet thick, runs westward, while above it a thick return stream of the less dense Atlantic water flows into the basin of the Mediterranean Sea. Each of the currents at the Strait of Gibraltar has measured velocity reaching two to three miles per hour, although the difference of density is only about $I / 500$ of the density of either Atlantic or Mediterranean water. We note at once that the velocity of this density current along the sea floor suffices to move even gravel, and a fortiori to channel loose sands and muds. The lower current at Gibraltar is warmer than the Atlantic water, under which it glides, and, with the deep-sea thermometer, the current has been followed for hundreds of miles out under the open Atlantic. Because of the fact that the density-raising salts are in complete solution, and also because of the slowness of diffusion, it is not surprising that the lower current preserves its individuality to a great distance. The endurance of a silty current running down a continental slope represents a more difficult problem. For, as already remarked, the current must lose velocity as the weighting particles of rock, originally suspended in the current, obey an inevitable tendency and gradually settle out of the water. For this reason particular interest attaches to observations made by Forel on the Swiss lakes. More than half a century ago he studied the behavior of the Rhone River, where its water, milky with suspended rock-flour brought from the high glaciers, enters Lake Geneva. ${ }^{13}$

Any summer visitor on the heights above Montreux can see 
the whitish, silt-laden water of the river deployed on the lake for some distance; he can also see that this water is sharply bounded against the blue water of the lake. With simple apparatus Forel proved the sharpness of contact to be due to an almost vertical plunge of the silty water to the bottom of the lake. He therewith showed that a silty current does for a time preserve its individuality under the lake water. To what distance? Forel found an answer to this query also. The Swiss hydrographers had made a second important discovery: the surface of the sub-lacustrine delta of the Rhone is interrupted by a channel-like furrow, extending six miles down the delta, from the line where the silty water makes its initial plunge. See Figure 73. This occurs just outside the jetties at the mouth



FIGURE 73. MAP OF THE RHONE DELTA IN LAKE GENEVA. LAND OF THE CHABLAIS ALPS (LOWER LEFT) SHOWN BY SHADING. AXIS OF TRENCH IN DELTA (CONTOURED) INDICATED BY THE BROKEN LINE. SUB-LACUSTRINE CONTOUR INTERVAL FIVE METERS.

of the Rhone, seen in the southeast corner of the map. The path of the bottom current is represented by the broken line. The depth of the channel below its rim is considerable, with 
maximum of nearly 200 feet. Forel imagined two possibilities: first, that the channel was dug by bottom currents; second, that it is the result of preferential deposition of the silt where the current loses velocity by friction against the quiet water on each side of the current. The latter process would be analogous to the levee-building along the lower Mississippi River. Forel ultimately came to favor the second explanation of the trench. On the other hand, a mich later study led Dr. J. Romieux to credit erosion of the channel by silty underflows and also upbuilding of the channel's rim in the form of a sub-lacustrine levee. ${ }^{14}$ In any case the Swiss limnologists have agreed that the bottom current persists to a distance of six miles from the mouth of the Rhone. Their conclusion deserves strong emphasis in the discussion of submarine valleys.

And Switzerland has a parallel case. The contoured map of the Rhine delta under the surface of Lake Constance portrays a trench across the delta, with dimensions much like those of the Lake Geneva channel. Be it noted, too, that each of the Swiss channels has a slope which is less than one two-hundredth of the average slope down the flank of a continent.

For our problem, analogy becomes still more illuminating when we watch the course of a muddy river that enters a long reservoir, created by an artificial dam at the opposite end.

An ideal case is represented where the Colorado River penetrates Lake Mead, a reservoir with a length of about I20 miles, measured from the celebrated Boulder Dam that holds up the water level. See Figure 74. Since progressive silting and shallowing of the reservoir are inevitable, the Government engineers are systematically measuring the proportion of solid matter suspended in the water at the intake (point where the river enters the reservoir), and as systematically tracing the course of this weighted water after entry into the reservoir. Cloudbursts upstream from the lake suddenly increase the 


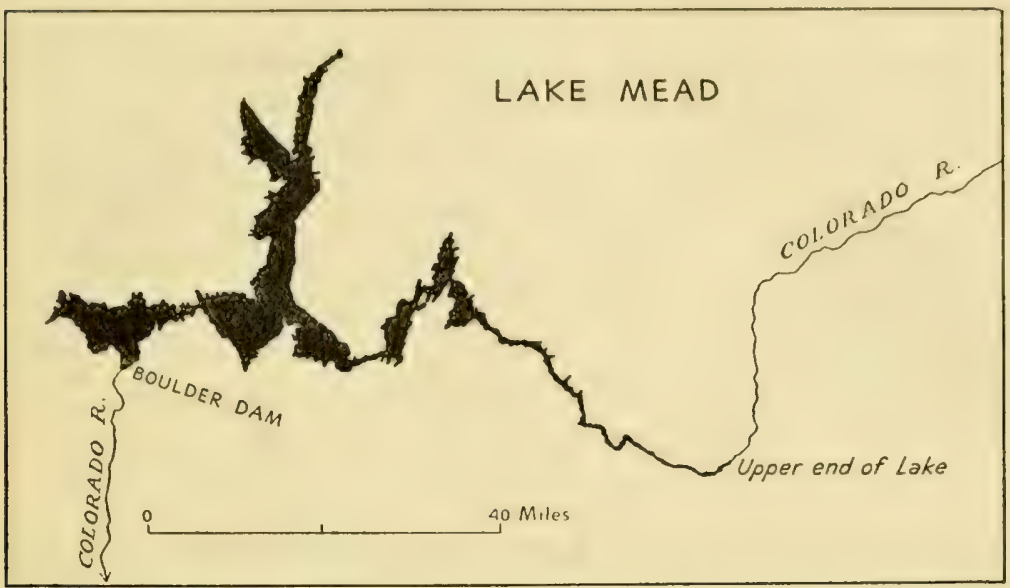

FIGURE 74. MAP OF LAKE MEAD (SUPPLIED BY H. T. KELCH OF THE SOIL CONSERVATION SERVICE, WASHINGTON).

volume, velocity, and silt-content of the torrential river. At the intake the time of arrival of water with maximum muddiness is noted. Some days thereafter the same water, still charged with a load of suspended silt, appears at the dam, I20 miles downstream from the intake. That the muddy current hugs the gently sloping bottom of the lake has been proved by sampling the water from surface to bottom and at various vertical sections between intake and dam. The thickness of the silty current running along the bottom is variable, as shown by Table VII, taken from a publication of Mr. H. N. Eaton. ${ }^{15}$

We note that a silty current along the bottom, measured on July 20 and 21 of the year I937, was 20 feet at Virgin Canyon near the upper end of Lake Mead and 37 feet at Boulder Canyon, farther down the Colorado River valley. The greatest thickness found was II feet, this time at Boulder Dam, the outlet of the lake.

Above each muddy sheet the reservoir water, hundreds of feet thick, was almost entirely free from suspended particles 
TABLE VII

THICKNESS OF SILTY LAYER, MEASURED AT FOUR STATIONS ALONG THE LENGTH OF LAKE MEAD (FEET)

\begin{tabular}{|c|c|c|c|c|}
\hline $\begin{array}{c}\text { Date of } \\
\text { measurement }\end{array}$ & $\begin{array}{c}\text { Virgin Canyon } \\
\text { (upper end of } \\
\text { lake) }\end{array}$ & $\begin{array}{l}\text { Boulder } \\
\text { Canyon }\end{array}$ & $\begin{array}{l}\text { Cape } \\
\text { Horn }\end{array}$ & $\begin{array}{l}\text { Boulder Dam } \\
\text { (lower end of } \\
\text { lake) }\end{array}$ \\
\hline 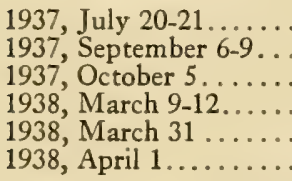 & $\begin{array}{l}20 \\
18 \\
3 \dot{3} \\
\cdots \\
\cdots\end{array}$ & $\begin{array}{l}37 \\
25 \\
\ddot{4} \dot{5} \\
\cdots \\
\cdots\end{array}$ & $\begin{array}{l}\ddot{4} \\
\ddot{49} \\
\ddot{50}\end{array}$ & $\begin{array}{r}\cdots \\
46 \\
117 \\
101 \\
\cdots\end{array}$ \\
\hline
\end{tabular}

of rock. Here, then, we have another clear proof that a silty current does not lose its individuality by mixing with the overlying clear water or by the settling-out of the silt. In the case of Lake Mead the bottom current persists for as much as 150 hours, one of the measured times for the traverse of 100 miles in the lake.

By identifying individual influxes of muddy water, the engineers have been able to measure the average velocity of the current between intake and dam. In one instance the rate was found to be half a mile per hour-a notable speed for a current following the average gradient of the floor of the reservoir, namely, a gradient of only 7 in 10,000 or less than $\mathrm{r}$ in $1000 .{ }^{16}$

The Elephant Butte Reservoir, in the New Mexican part of the Rio Grande Valley, receives the inflow of the Puerco River, which in flood is charged with fine sand and mud to an extraordinary degree. Here too the muddy water is seen to dive along a sharp line of demarcation at the surface and then follow the gently sloping bottom of the reservoir to the retaining dam, the surface water remaining "perfectly clear." The sub-lacustrine journey is about 35 miles in length. Although the measured thickness of the silty current is comparatively small-only five feet in one reported case, and, although the bottom gradient 

averages only I to 1000, the velocity of the bottom current has registered as much as 1.5 miles per hour. The high speed is explained by the unusual muddiness of the Puerco River at time of flood. After the entry of its water into the reservoir, a cubic foot of this water weighs two to three pounds more than a cubic foot of clear water at the same temperature. Another important observation: the bottom current was actually six degrees Fahrenheit warmer than the overlying water, so that there can be no thought of explaining the flow by lower temperature and resulting smaller degree of thermal expansion. ${ }^{17}$

Bottom currents, similarly motivated by suspended silt, have been demonstrated in four other American reservoirs: Lake Lee (North Carolina), Lake Murray and Saluda Reservoir (South Carolina), and San Carlos Reservoir (Arizona). The Government engineers have thus good ground for the conclusion that underflow of the kind described is a "general phenomenon in reservoirs" subject to inflow of muddy water on the grand scale. The silty water slides down the floor of a reservoir "much as water itself flows under air."

The studies at Lake Geneva, Lake Constance, and the six artificial lakes in the United States have established two fundamental facts: first, a silty underflow persists, keeping much of its initial velocity for many hours and even as much as seven days; second, the speed of flow can exceed one mile an hour although the slope traversed is only I to I000, and although the thickness of the bottom current is only a few feet. Since the continental slope is about I to 15 , and since the thickness of the silty current of Glacial times must have been at least 100 feet and probably more, we already have from analogies in Nature some good quantitative support for the preferred explanation of the submarine canyons and furrows. But other quantitative criteria as to the worth of the explanation should be found if properly controlled experiments are made in the 
laboratory. Knowing that experiment is the principal tool of science, Dr. P. H. Kuenen of Holland has called on the resources of the laboratory. He had three objectives: to devise a visual test of the possibility that silty currents can long preserve their individuality even though the motivating silt tends to settle out; second, to measure the velocities under controlled conditions regarding current density and slope of channel; and, third, to determine whether a current, flowing fast, will add to the suspended load and therefore run still faster. Kuenen succeeded with all three problems, and not the least significant of his conclusions is that a strong bottom current running down a continental slope may readily become selfaccelerating and thus endowed with new, self-generated power to erode. Some of his experiments will be briefiy described. ${ }^{18}$

In a glass-walled tank, 15 feet long and 2 feet deep, a model of a "continental terrace" was built of sand surfaced with hard gypsum. The "shelf" had a gentle slope as far as the fall-off to the "continental slope," which had a gradient of about I in ro or one typical of the upper part of the average continental slope in Nature. Water was poured into the tank until it topped the "shelf" by a few millimeters or centimeters. Just above the fall. off a strip of wood with a rubber flange at the bottom was placed all across the tank. Back of this bar, water with various proportions of solid particles in suspension was gently poured on the "shelf." The bar was then removed. The silty water at once began to flow down the "continental slope" in the form of a lively bottom current. These initial steps in experimentation are represented in the three cross-sections of Kuenen's diagram, Figure 75 . Figure 76 is a photograph of the tank, whose scale can be gaged by the width of each pane of glass, namely, about three feet; the terrace is shown in profile.

It was found that any slight crease or depression directed down the "continental slope" tended to draw the silty water 


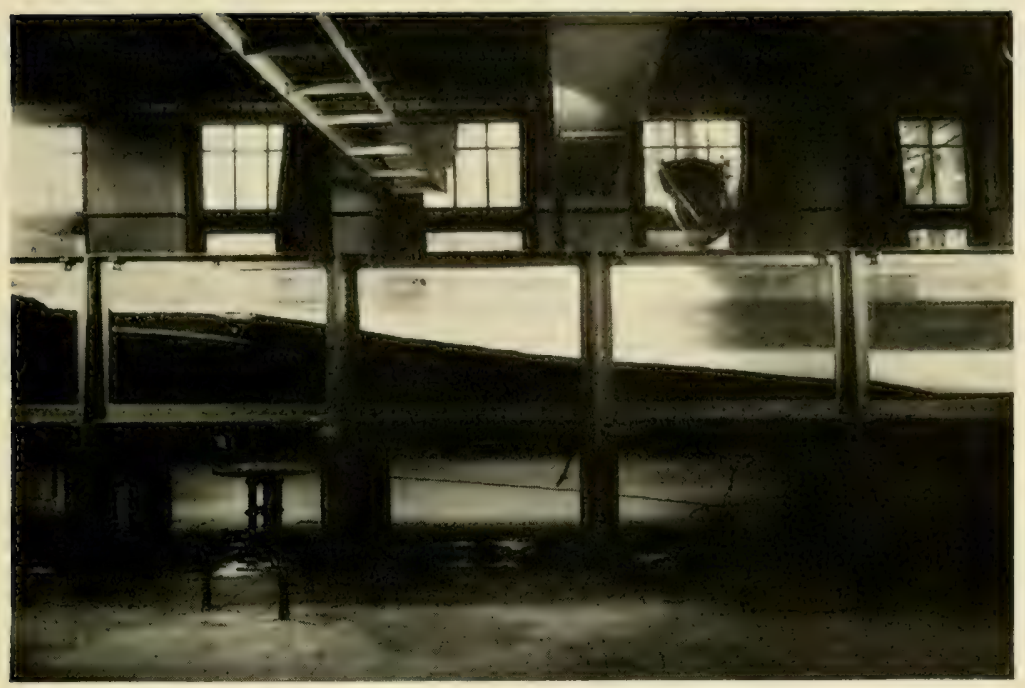

FIGURE 76. PHOTOGRAPH OF THE TANK USED BY KUENEN IN HIS EXPERIMENTS.

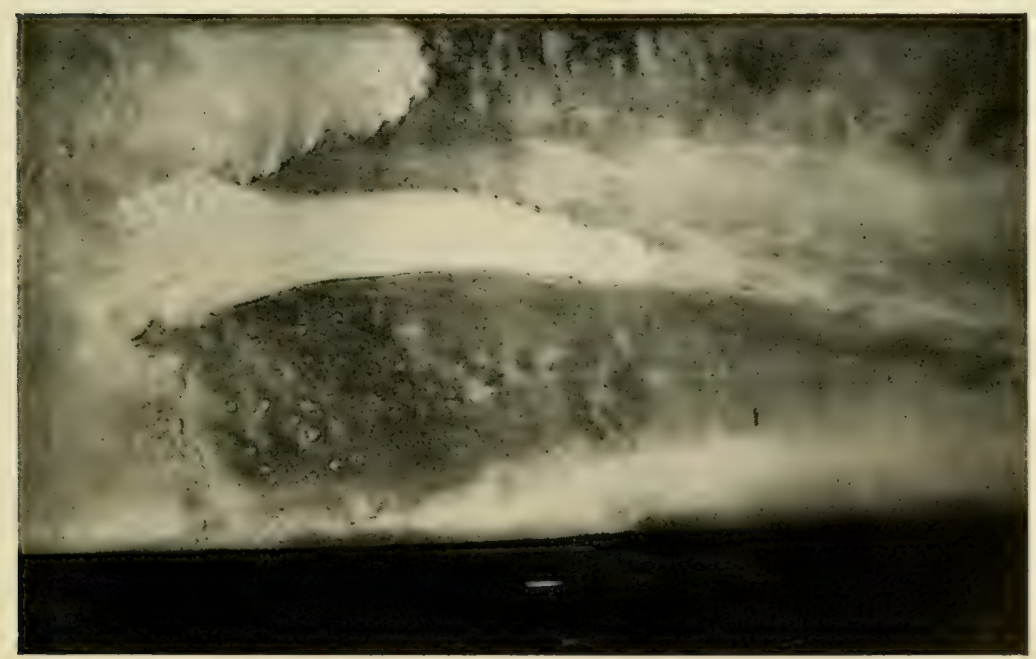

FIGURE 77. SUSPENSION-CURRENT SEEN FROM ABOVE: KUENEN EXPERIMLNT. 


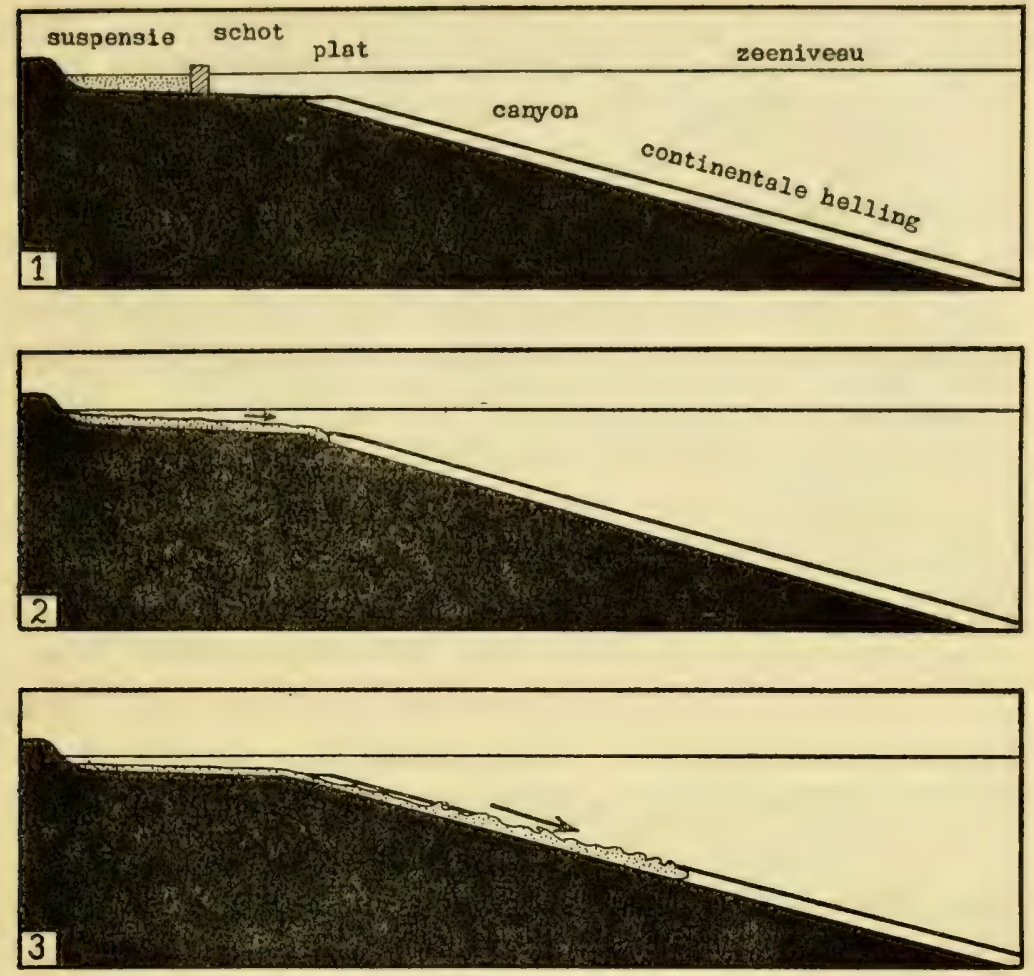

FIGURE 75. DIAGRAM ILLUSTRATING THE KUENEN EXPERIMENT ON SILTY CURRENTS.

from the right and left, thickening the current and correspondingly increasing its velocity. A tongue of the silty water ran down ahead of the more slowly flowing suspension on each side of the tongue. One of these tongues was photographed from above and through the clear overlying water, with the result shown in Figure 77, where faint lines of flow can be discerned.

Similar suspensions were released after the hard surface of the model was covered with thin layers of clay. When only moderately charged with "silt," the density current became 
turbulent soon after passing the fall-off, as illustrated by the mottled appearance of the dark tongue, photographed from above (again through the clear overlying water) and appearing in Figure 78. With the onset of turbulence the current began to deepen the initial depression directed down the "continental slope," making this into a "canyon" or "furrow." With the erosion went a gain in load for the current and also measurable acceleration of its velocity. Thus Kuenen proved once more that "to him that hath shall be given."

In order to make more vivid the evidence for erosion and self-acceleration of current, both to the eye and to the camera, clear solutions of salt in water were released on the "shelf," this time covered with a thin layer of white mud. As shown in Figure 79, this denser, saline water did rush down the "slope" and tore up and incorporated some of the bottom mud. Note that the photograph was taken looking into the side of the tank; and that the lower section is a continuation of the upper section. Figure 80 depicts on a somewhat larger scale the turbulent mass, clouded with the new load of suspended, solid matter.

Kuenen measured the velocities of flow and was able to estimate the average thicknesses of the moving sheets of "heavy" water, as seen through the glass walls of the tank. Knowing also the slope of the bottom, he had the data for applying an engineer's formula, which with proper precautions can be used to calculate the velocity expected for a current flowing steadily down a continental slope. This formula reads: $v=c \sqrt{m . s . d}$, where $c$ is a constant; $v$ represents the velocity; $m$, the so-called hydraulic mean depth (the cross-section of the current divided by its wetted perimeter); $s$, the slope down which the current runs; $d$, the effective density of the flowing mixture of water and silt.

From the measured values of $v, m, s$, and $d$ in the case of a 


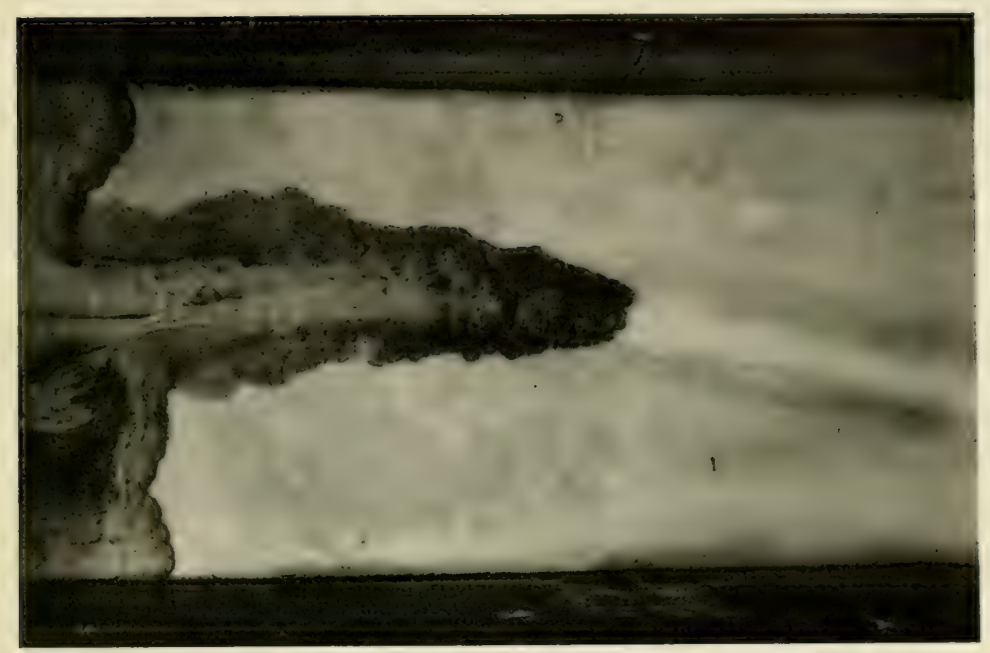

FIGURE 78. TURBULENCE IN SILTY UNDERFLOW DEVELOPED IN KUENEN TANK. VIEIV OF CURRENT FROM ABOVE.
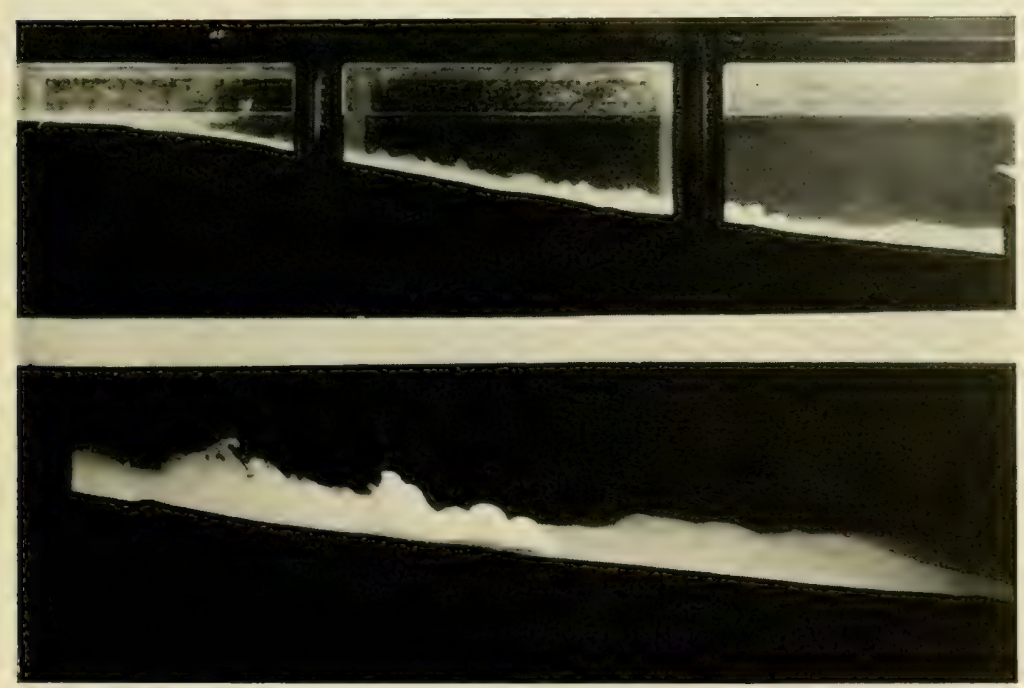

FIGURE 79. SIDE VIEIVS OF DENSITY CURRENT IN KUENEN TANK. 


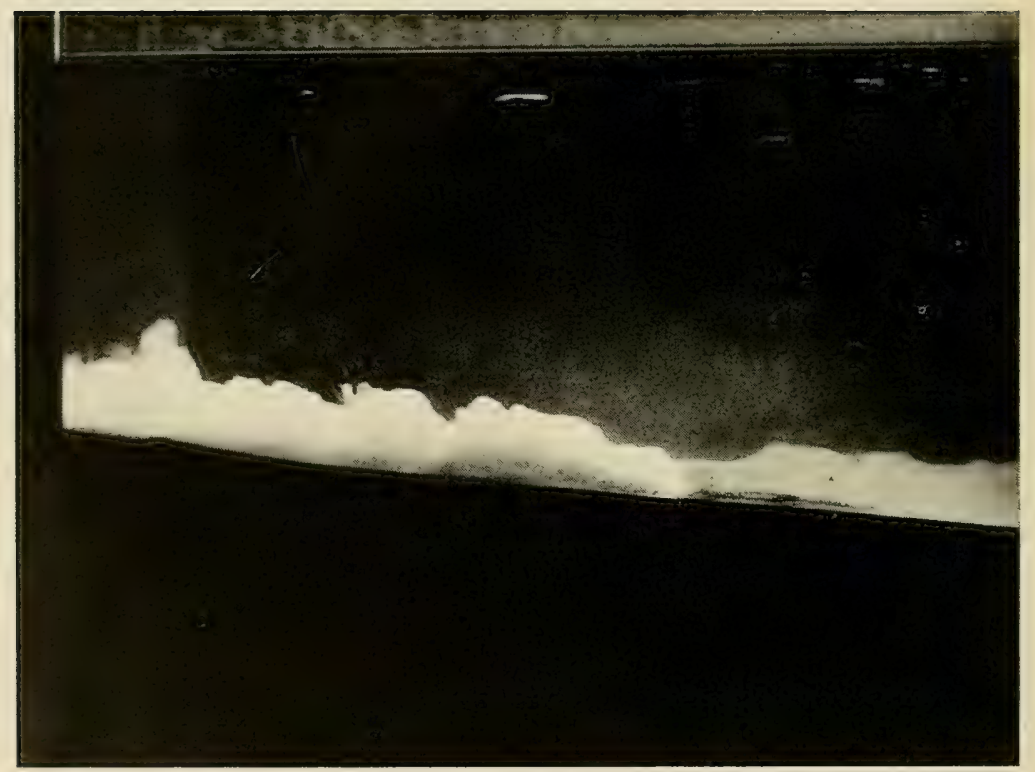

FIGURE 8O. CLOSER VIEW OF DENSITY CURRENT IN KUENEN TANK. 
bottom current at Lake Mead, Dr. Kuenen deduced an approximate value for $c$ that would match the conditions for erosive furrowing of the continental slope. In the centimetergram-second system of units the value for $c$ came out at 400 . For our problem let us assume $m$ to be 50 meters or 5000 centimeters ( 165 feet), a moderate estimate for the thickness of silty water when transferred into a canyon by a first-class storm. Let $s$, the mean slope, be taken at $\mathrm{I}$ in 15 ; and $d$ at only .0005. With corresponding substitutions in the formula, the velocity is found to be about 160 centimeters per second or 5.75 kilometers per hour or 4 miles per hour-a velocity sufficient to sweep along coarse gravel and to cause the tearing up of silt and sand. Many silty currents of Glacial times must have had initial effective densities higher than .0005; along the shore-belts of the present day, which in general are less muddy, the wave-stirred water has measured excess density at least twice as great.

The Kuenen experiments are particularly eloquent in showing that, if the current running down the muddy continental slope reaches a velocity of only two miles an hour, it should take up a new, additional supply of mud and should, therefore, run all the faster and erode still more efficiently. This new power would, of course, be lost again when the current reaches the lower, flatter part of the continental slope. Kuenen's own graphic account may be quoted: "The part played by the shelf is now thought to be that of the ringing voice loosening an avalanche. If the density of a comparatively small volume of water is once raised above that of the deeper strata, the flow is set off. It gathers volume and speed on the way down and takes up more and more silt. Given a little time the canyon erodes itself." This conclusion is all the more acceptable when it is remembered that the terrace sediments are water-soaked, hence highly mobile, and deposited near the angle of rest. 
Such material at the angle of rest will yield rapidly if its back is even gently brushed by a down-hill current.

Now, let us leave the laboratory and go outdoors again, to find other facts and potential tests relating to the Glacialcontrol hypothesis.

In Figure 8I, a map of Georges Bank, the submarine con-

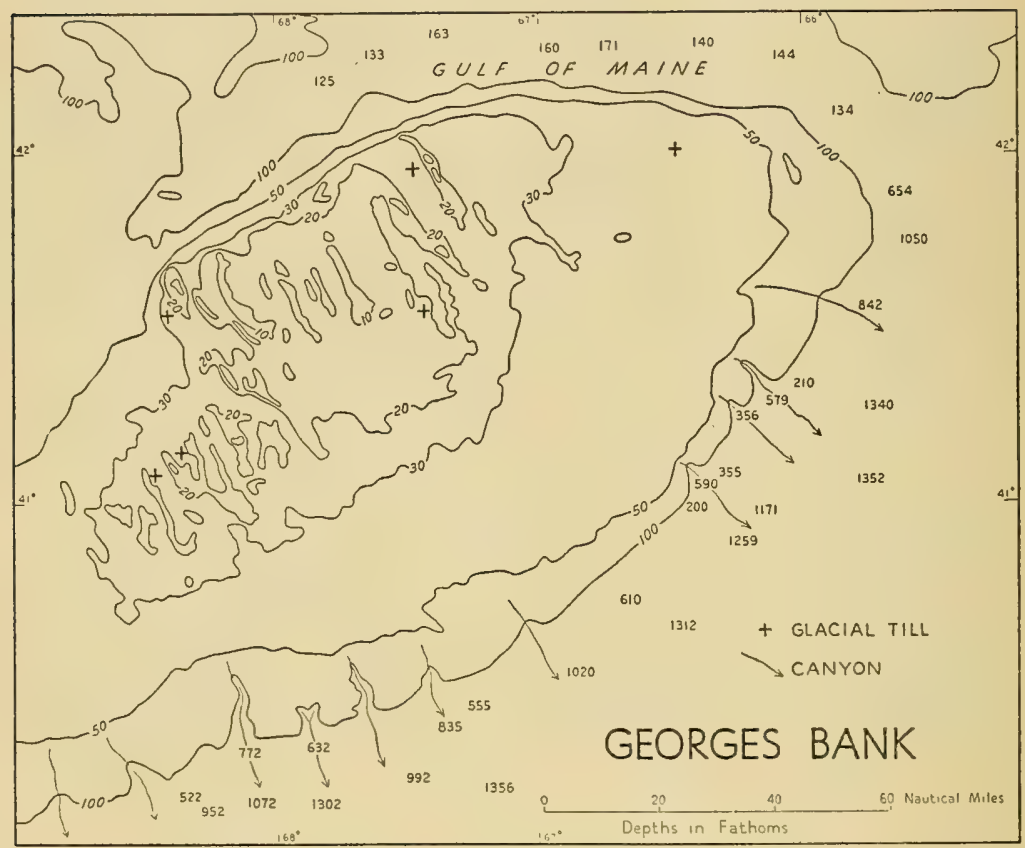

FIGURE 8I. MAP OF GEORGES BANK, SHOWING LOCATION OF GLACIAL TILL (CROSSES) AND OF SUBMARINE CANYONS (AT BARBED ARROWS).

tours or isobaths are drawn at intervals of ten fathoms. Over the southern half of the bank Professor Shepard has dredged up gravels like those just outside glacial moraines. ${ }^{19}$ At six points, marked with crosses, he found boulder-clay or till, a characteristic subglacial deposit. These facts suggest that the terminal moraine of the North American ice-cap lay across the middle of the bank, along a roughly east-west line; and that 
the fall-off to the Gulf of Maine was completely smothered under the ice. There, according to the Glacial-control hypothesis, no canyons or furrows should be discovered, and there the relative smoothness of the isobaths confirms the deduction. On the other hand, the many re-entrants of the isobaths along the southern fall-off of the bank represent canyons. Figure 67 shows part of the sculptured belt of this south side in some detail. Is it too much to argue that Georges Bank testifies to a Glacial date for the excavation of at least a large majority of the submarine valleys?

Again, the hypothesis is supported by a fact stated on page I00: in average the continental shelf lies several fathoms deeper than it should if this gentle slope had a profile of equilibrium. In concrete illustration: at the fall-off or outer limit of the shelf the water is something like Io or 15 fathoms deeper than it will be when the shape of the terrace has been stabilized by waves and currents of the future. As Dr. Kuenen has pointed out, the present departure from the profile of equilibrium is of the magnitude expected to result from wave erosion of the terrace sediments during the time of glacially lowered sealevel. Furthermore, his calculations show that the layer of sediment thus removed contained enough silt and sand to supply the gullying bottom currents that operated during the long period of glaciation.

An observation by Dr. Stetson is significant in this same connection. The Glacial-control hypothesis implies that along the outer part of the continental shelf the mud and finer sand should have been specially liable to be caught up and removed by the turbulent waves at the lowered sealevel; hence the superficial sediment of that outer belt should by sampling be found to be coarser than the average sediment now being deposited on the shelf. According to Dr. Stetson's researches in field and laboratory such is the fact. 
The preferred explanation of canyon and furrow accounts for another evident fact: a number of the canyons so far discovered are en axe with master rivers respectively draining adjacent continents. Examples are the intaglio trenches cut in the submarine deltas of the Hudson, Congo, Niger, Indus, and Ganges rivers. That the effect of each digging was at maximum would be a natural result of prolonged delta-building in pre-Glacial time. For each of the deltas means a strong concentration of silt and therefore a special condition favoring the development of silty bottom currents.

Again, we note that, with the Glacial lowering of sealevel, the master rivers of the continent were extended oceanward and compelled to excavate "channels" across the continental shelves. Some of them, with the anticipated maximum depth of 300 feet, still exist in spite of the effort of wave and current to fill the "channel" with sediment. That any of these channels still remains open at all is testimony to the comparative recency of origin.

Finally, it may be remarked that emphasis on the special conditions of the Glacial Period does not imply that some furrowing of the continental slopes may not be continued to the present day. Future investigations with the current-meter may prove that silty currents, now being produced by great storms and lashing their way across narrow continental shelves, may run with eroding velocity. A case in point is represented in Figure 82, which shows the continental terrace off California to be only a few miles wide, and also portrays five canyons that head close to shore. Here mud suspensions have to travel only a short distance before they begin to rush down the steep canyon floors, and can thus keep their individuality and perhaps even pick up new, accelerating load of sediment. Thus, along exceptionally narrow terraces submarine valleys may 


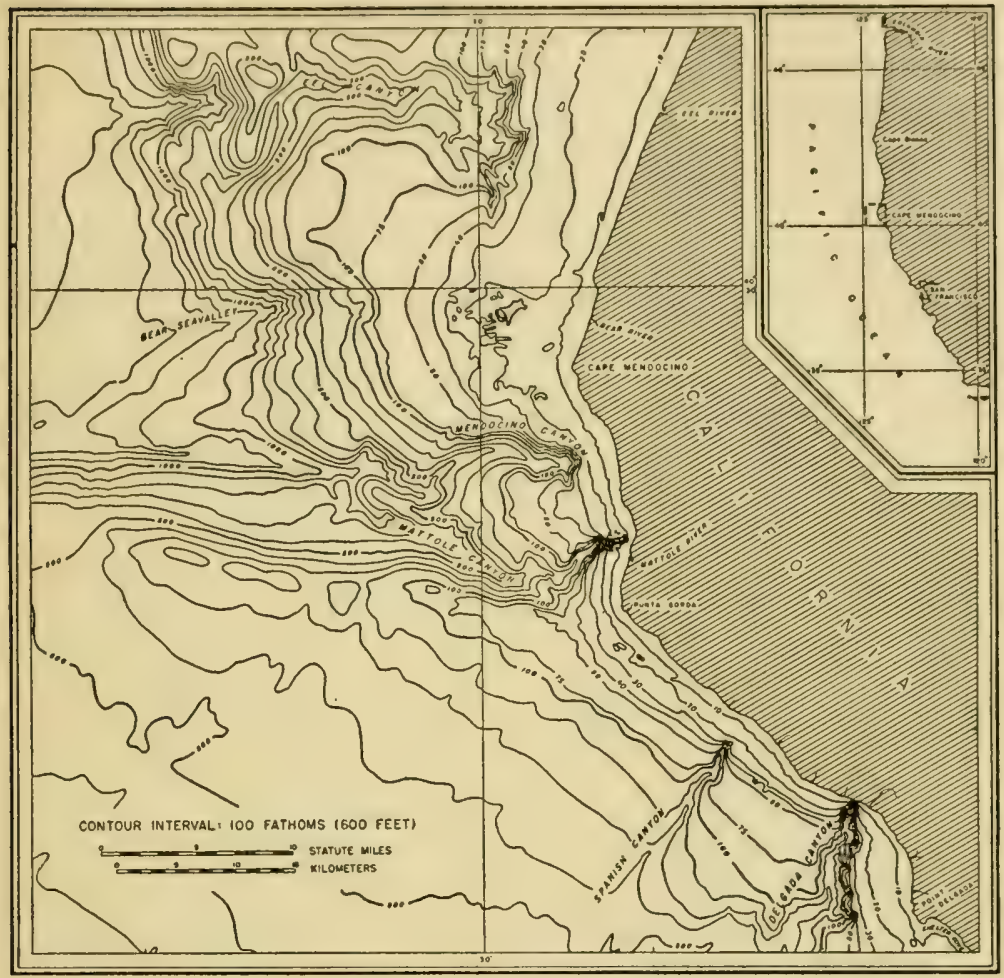

FIGURE 82. MAP OF SUBMARINE CANYONS OFF CALIFORNIA. AFTER H. W. MURRAY AND THE UNITED STATES COAST AND GEODETIC SURVEY.

now be kept open and not slowly filled with sand and mud as in the case of the canyons off the east coast of the United States.

\section{Summary}

Looking back, we see that the Glacial-control hypothesis covers the essential facts, which may be listed as follows: (I) the comparative youth of the topography; (2) its worldwide planetary distribution; (3) the similarity of the continental slopes to the gullied hill-sides on land; 4 ) the evidence 
that canyons are now being slowly filled with mud; (5) the discovery of cold-water shells (foraminifera) in the clay that underlies the new muddy layer of incipient filling; and (6) the departure of the existing continental shell from a profile of equilibrium.

Incidentally our study of silty currents has indicated a mechanism for the transport of shore sediment to water depths of 2000 fathoms and as far as 100 to 200 miles from the land where the sediment had been manufactured..$^{20}$ This long travel of sand and mud has long been a puzzle for geologists.

We have seen that the silty-current hypothesis is favored by the weakness of the terrace material, by the steepness of the continental slope, by the visible proof that shore waters are muddied through agitation by storms and tides, by laboratory tests, by the teaching of Nature in the Swiss lakes and in artificial reservoirs, and by the failure of all other hypotheses yet offered to account for the submarine valleys.

Perhaps a hypothesis with so many supporting advantages can qualify as a theory. It cannot represent demonstration. In the geological workshop, chips and shavings of uncertainty still lie around. They show that the carving of a complete image of truth about the submarine valleys must be regarded as unfinished business.

And a word about the workshop itself: it is that of Louis Agassiz, enlarged by his son Alexander, and by his grandchildren. The great Swiss master came to Harvard's center of scientific research soon after he had proved the former, wholesale glaciation of northern Europe and North America.

The epoch-making discovery of Louis Agassiz has been confirmed by a small army of enthusiastic geologists who, in its testing, have traversed the earth from pole to pole, across every continent and across islands in every ocean. After much patient labor they have mapped the glaciated tracts. Moreover, 
they demonstrated that there was a rhythmical waxing and waning of the ice-caps through at least half a million years; five million square miles of ice still remain. So vast were the dimensions of the vanished ice-caps that the shape of the whole planet was affected. Under the heavy masses of ice the earth's crust was basined, slowly to recoil with each slow melting. From observations on the recoil, as set forth in the first chapter, we learned about the exceeding weakness of the earth-shell immediately beneath the crust. In the second chapter we studied a second consequence of the glaciations-the world-wide lowering of sealevel, which had drastic effects on marine organisms, particularly the reef-building corals. In this final chapter we have traced still another glacial control-the prolonged muddying of shore waters, with the development of bottom currents in the ocean and the world-wide furrowing of the submerged continental slopes. While man and animals were driven to and fro by the climatic changes on land, while in the struggle for life man was mentally quickened into firemaker, tool-maker, and artist, and while the sealevel was swinging down and up over broad regions that were alternately dry land and drowned land, the shallow-water organisms were fighting with mud baths, and shoals and continental flanks were remodelled on a grand scale. The biologists and geologists of the future will be more and more impressed with the power of glacial controls in the later stages of organic and planetary evolution. 

LECTURES DELIVERED AT THE UNIVERSITY OF VIRGINIA ON THE PAGE-BARBOUR FOUNDATION, I907-I94I

1907-08 S. Weir Mitchell, Some Literary Reminiscences. (Not published.)

1908-09 Basil L. Gildersleeve, Hellas and Hesperia; or, The Vitality of Greek Studies in America. New York, Henry Holt \& Company, rgog.

rgog-io Charles William Eliot, The Conflict between Individualism and Collectivism in a Democracy. New York, Charles Scribner's Sons, rgro.

IgIO-II Thomas Raynesford Lounsbury, The Early Literary Career of Robert Browning. New York, Charles Scribner's Sons, IgII.

I9II-I2 William Henry Welch, The Development of Medicine as a Science. (Not published.)

I9I2-I3 James Bryce, Ancient Democracy. (Not published.) I9I3-I4 Arthur Twining Hadley, Undercurrents in American Politics. New Haven, Yale University Press, I9I5.

I9I4-I5 William Howard Taft, The Presidency, Its Duties, Its Powers, Its Opportunities, and Its Limitations. New York, Charles Scribner's Sons, I9ı6.

I9I5-I6 Archibald Cary Coolidge, The Origins of the Triple Alliance. New York, Charles Scribner's Sons, 1917.

igi6-i7 John Henry Wigmore, Poblems of Law, Its Past, Present, and Future. New York, Charles Scribner's Sons, 1920. 
I60 LECTURES ON THE PAGE-BARBOUR FOUNDATION

igrg-20 William Roscoe Thayer, The Art of Biography.

New York, Charles Scribner's Sons, 1920.

1921-22 Thomas Nelson Page, Dante and His Influence.

New York, Charles Scribner's Sons, I923.

1923-24 John Huston Finlex, The Making and the Mission of America. (Not published.)

1924-25 James Thomson Shotwell, The Security of Nations. (Not published.)

1925-26 Alexander Frederick Whyte, Asia in the Twentieth Century. New York and London, Charles Scribner's Sons, 1926.

I926-27 Alfred North Whitehead, Symbolism, Its Meaning and Effect. New York, The Macmillan Company, I927.

i927-28 Walter Lippmann, American Inquisitors; a Commentary on Dayton and Chicago. New York, The Macmillan Company, $\mathbf{1 9 2 8 .}$

1928-29 William Edward Dodd, The Statecraft of Woodrow Wilson. (Not published.)

1929-30 Frederick Paul Keppel, The Foundation, Its Place in American Life. New York, The Macmillan Company, I930.

1930-3I AlberT Jay Nock, The Theory of Education in the United States. New York, Harcourt, Brace and Company, 1932.

1931-32 Lindsay Rogers, Crisis Government. New York, W. W. Norton \& Company, Inc., I934.

I932-33 Thomas Stearns Eliot, After Strange Gods, a Primer of Modern Heresy. London, Faber and Faber, 1934; New York, Harcourt, Brace and Company, I934. 
LECTURES ON THE PAGE-BARBOUR FOUNDATION I6r 1933-34 Henry Norris Russell, The Solar System and Its Origin. New York, The Macmillan Company, I935.

1934-35 John Dewey, Liberalism and Social Action. New York, G. P. Putnam's Sons, I935.

I935-36 Robert A. Millikan, The Cosmic Rays. (Not published.)

1936-37 Thomas JefFerson Wertenbaker, The Beginnings of American Civilization. (Not published.)

1937-38 Wolfgang KöHler, Dynamics in Psychology. New York, Liveright Publishing Company, I940.

I938-39 Heinrich Bruning, The Changing Background of Democracy. (Not published.)

1939-40 Carl Lotus Becker, Modern Democracy. New Haven, Yale University Press, I94I.

I940-4I Reginald Aldworth Daly, The Floor of the Ocean: New Light on Old Mysteries. Chapel Hill, The University of North Carolina Press, 1942. 

NOTES

INDEX 



\section{NOTES}

\section{Chapter I: Foundations of the Great Deep}

I. For a description of modern methods of marine surveying and submarine contouring, see P. A. Smith, Bulletin Geological Society of America, Special Paper No. 7 , 1939, pp. $49 \mathrm{ff}$.

2. Sir John Murray, The Ocean (Home University Library), New York, p. 201.

3. C. S. Piggot, Scientific Monthly, XXXVI (1938), $20 \mathrm{r}$.

4. For a fuller account of the seismological method of diagnosis see R. A. Daly, Our Mobile Earth (New York, 1926), pp. 83, 122; Architecture of the Earth (New York, 1938), p. 42 .

5. See summary by J. B. Macelwane in Chapter $\mathrm{X}$ of Internal Constitution of the Earth, ed. by B. Gutenberg, New York, 1939. This technical book is one of the best works of reference on the physical nature of the earth's interior.

6. J. T. Wilson, Bulletin Seismological Society of America, XXX (1940), 273.

7. A summary of the contributions by the geodesists is to be found in R. A. Daly, Strength and Structure of the Earth, New York, 1940.

8. More details about the upheaval of the formerly glaciated tracts are given in R. A. Daly, The Changing World of the Ice Age, New Haven, Conn., 1934. Of special importance is a recent memoir by B. Gutenberg, in the Bulletin Geological Society of America, LII (194I), 721.

9. See R. A. Daly, Strength and Structure of the Earth, where are references to the work of and publications of T. J. Kukkamäki and E. Niskanen.

10. See A. H. Miller, Publications of the Dominion Observatory, Ottawa, XI, No. $5,1940$.

\section{Chapter II: Submarine Mountains}

I. See R. A. Daly, American Journal of Science, XLI (I9I6), I53.

2. Summaries and abundant references to original sources of information are to be found in R. A. Daly, Our Mobile Earth, New York, 1926; Igneous Rocks and the Depths of the Earth. New York, 1933; and Architecture of the Earth, New York, 1938.

3. See F. A. Vening Meinesz, Gravity at Sea, Vol. II (Delft, I934), for a wealth of details about this general subject.

4. A more elaborate statement is given in R. A. Daly, The Changing World of the Ice Age, Chapter VI.

5. H. H. Hess, Proceedings American Philosophical Society, LXXIX (1938), 71. [ 165 ] 


\section{Chapter III: Contunental Terraces and Submarine Valleys}

1. R. J. Russell, Bulletin Geological Society of America, LI (1940), I199.

2. C. Abbe, Jr., Proceedings Boston Society of Natural History, XXVI (1895), 489.

3. M. Ewing, A. P. Crary, and H. M. Rutherford, Bulletin Geological Society of America, XLVIII (1937), 755 ff.

4. E. C. Bullard and T. F. Gaskell, Nature, Vol. CXLII, Nov. 19, 1938.

5. A. C. Veatch and P. A. Smith, Bulletin Geological Society of America, Special Paper No. 7, 1939.

6. F. P. Shepard and C. N. Beard, Geographical Review, XXVIII (1938), 439.

7. H. C. Stetson, Transactions of the American Geophysical Union, I6th Meeting, 1935, Part I, p. 226; 17th Meeting, 1936, Part I, p. 223; Bulletin Geological Society of America, XLVII (1936), 339.

8. F. A. Forel, Bulletin société Vaudoise des sciences naturelles, XXIII (1887), I8; Le Léman (3 vols. Lausanne, 1892-1904), I, 65, 385.

9. F. P. Shepard, Proceedings National Academy of Sciences, XXII (1936), 496.

10. D. W. Johnson, The Origin of Submarine Canyons, New York, I939.

11. W. H. Bucher, Bulletin Geological Society of America, LI (I940), 489.

12. See R. A. Daly, American Journal of Science, XXXI (1936), 401.

13. F. A. Forel, Comptes Rendus Académie Française, October 19, 1885.

Contrast of temperature alone can produce a density current in water that is clean or is uniformly charged with suspended silt. A striking example is described in the recent (mimeographed) Report on Density Currents Investigations by the United States Bureau of Reclamation. See the section of Lake Mead (at Boulder Dam) in Figure 88 of the Report. The figure represents a case where a current of relatively cool and therefore contracted water of the Colorado River entered the lake in January, 1939. This current, with average thickness of about roo feet (one third of the average depth of the lake along the section), was found: ( 1 ) to keep its individuality for the IIo-mile traverse of the lake; (2) to plunge toward the bottom of the lake; and (3) to flow, for the week taken to make the journey, at the rate of about 2100 feet or 0.4 mile per hour. Here the excess of density above that of the zdjacent lake water was only 0.0003 (that of pure water at $4^{\circ} \mathrm{C}$. being $\mathrm{r.0}$ ), and the ilope on which the current moved was only about $\mathrm{I}$ in 860 or 0.00116.

14. J. Romieux, Les carbonates dans les sédiments du Lac de Genève (Thèse, Université de Genève), 1930.

15. Report presented at Annual Meeting of the Division of Geology and Geography, National Research Council, April 27, I940.

16. Compare N. C. Grover and C. S. Howard, Proceedings American Society of Civil Engineers, April, 1937.

17. H. M. Eakin, Technical Bulletin No. 524, U. S: Department of Agriculture, Soil Conservation Service, 1936.

18. P. H. Kuenen, Leidsche Geologische Mededeelingen, Deel VIII, Aflevering 2, 1937, p. 327; Tijdschrift van het Koninklijk Nederlandsche Aardrijkskundig Genootschap, Deel LV, Aflevering 6, Leiden, 1938; Geological Magazine, LXXV (1938), 24I.

19. F. P. Shepard, Bulletin Geological Society of America, XLV (1934), 292.

20. Sec H. C. Stetson and J. F. Smith, American Journal of Science, XXXV (1938), 12. 


\section{N D E X}

Abbe, c., 104, 162

Africa, submarine canyons off the west coast of, 134

Agassiz, A., 156

Agassiz, L., demonstrator of ice-caps, 156

Airy, G. B., 32, 8x

Alps, origin of root of, 86

Angle of rest for marine deposits, I22, I 5 I

Angenheister, G., investigator of the subPacific crust, I 8

Anomalies of gravity, 62

Airy, 32, 8I

Bouguer, 29, 30, 32

Free-air, 42, 43, 63, 64, 8I

Hayford, 32, 8I

Heiskanen, 32, 8I

Isostatic, 30, 31, 63, 82

Regional-isostatic, $8 \mathbf{r}$

Antarctica, 82, 130

Apia, Samoa, seismographic station at, 18

Aquifers, defined, 132

Archipelagoes, 80, 95

Arctic Ocean, wave-velocities in crust under, 45

Aristotle, 4

Ascension Island, 23, 50, 63

Asia, horizontal movement of, 85

Asiatic chains of mountains, 88

Asymmetry of river deltas, ror ff

Atlantic Ocean, velocities of surface waves in crust under, $21,22,45$ sialic rock under the, 23,45
Atolls

capping beveled mountains, $66 \mathrm{ff}, 68$

lagoons of, tests of crustal stability, 69 , 74

Australian continental shelf, 10, 74

Azores Islands, continental rocks in, 23

Back-deeps, origin of, 9I

Baltic Sea, 8, 34, 37

Baltimore Canyon, I 16

Banda Sea, deep basin of, 8o, 9 I

Banggai Island, deformed rocks in, 89

Banks, marine, 9, 72

Barbados Island, uplift of, 95

Barrier-reef lagoons, tests of crustal stability, $67 \mathrm{ff}, 74$

"Basal wrecks," 53

Basalt, the most abundant lava, 18,48 , 57

Basaltic glass, elasticity of, 46

Basaltic layers of the earth's crust, 2 I. See Substratum

Basaltic substratum of earlier epochs, $5^{8}$

Basement Complex, structure and history of, 3

Basining of the earth's crust, under icecaps, 34, 35, 44, I 57

Baton Rouge, Louisiana, IoI

Beaches of Fennoscandia, tilted, 35, 37, 40

Beard, C. N., I62

Bell, H. S., I 4 I

Bering Sea, 8

Berkey, C. P., 88 
Bermuda Island, a truncated and veneered volcanic pile, 65,66 gravity on, 63

Bora Bora Island, submergence of, 75

Bore-holes

in Bermuda, 65

in the continental crust, 78

in the Gulf Coast sediments, III

in Heron Island, 73

in Michaelmas Cay, 73

Bosporus, double marine current at the, I 42

Bottom currents. See Density currents

Bottom deposits, I2

Bouguer anomalies of gravity

defined, 29

negative in the United States and other continental areas, 30

positive in areas of deep ocean, 30

Bouguer reduction of gravity, 28

Boulder Dam, I44, 166

Boulder Canyon, 145

Boulder clay on Georges Bank, 152

Box-head canyons and gorges, 133

Brazil, continental terrace off, 8

Breakers, migrating zone of the, 137 , I38, I53

British Isles, continental terrace off, 8

Bucher, W. $H_{\text {,, }}$ on origin of submarine valleys, I34, I62

Bullard, E. C., investigator of the British continental terrace, I06, II0, I66

Buoy-control, 7

Calderas, 5I

California

abnormal submarine canyons off, $\mathrm{I} 26$, I34, 154

continental terrace off, I06

Canada, gravity in southern, 44

Canary Islands, sialic rocks in, 50

"Canyon erodes itself," I5I

Canyons, submarine

compared with subaerial, I12, I20 ff, 123, 126

dimensions of, II $3 \mathrm{ff}$, II7, I 22

distinguished from furrows, I I5

en axe with land rivers, II 4, II9, 154

gradients of, $120,123,127$

known number of, II 5 origin of, $112 \mathrm{ff}, 124,127,153,155$ post-Glacial sedimentation of floors of, 124

simultaneous development of, 127

world-wide development of, I I2, 127 youthful features of the terrestrial topography, I26, 127

Cape Canaveral, 103

Cape Fear, ro3

Cape Hatteras, 103

Cape Henry, I08, I15

Cape Lookout, I03

Cape May, I19, I33

Cape Romain, I06

Cape Verde Islands, sialic rocks in, 50

Caroline Islands, coral reefs of, 67

Catastrophic changes of volcanic islands, $52 \mathrm{ff}$

Celebes Island, deformed rocks in, 89

Celebes Sea, deep basin of, 80

Cenozoic Era, 88

Ceram Island, deformed rocks in, 89

"Challenger" Expedition, 12

Channeling, rhythm in, 139, I40

"Channels" in continental shelves, II3, II 8

related to submarine canyons, 131,154

Chemical reactions in volcanic gas, a cause of heat, 56

China Sea, 8, 75

Clay, a material of low solubility, 134

Cliff-and-talus topography, I26

Coastal plain of eastern United States. 133

Cold-water fossils in canyon sediments. See Fossils

Colorado River Canyon compared with submarine canyons, II3, I 26

Compensation for terrestrial relief, 27 , $31,32,81$

Concentration of "heavy" water running on continental terrace, 140,148

Congo River, relation to Congo canyon, I24, I 54

Constance, bottom current of Lake, I 44, 147

Contamination of primary lava, 48

Continental plateaus, flooding of, 8

Continental rocks, 44,59

in oceanic islands, 23,49 
Continental shelf, "channels" of, II3 defined, 9 , xoo

outer sediments of relatively coarse, 153

Continental slopes, 10, 100 canyons of. See Canyons, submarine furrows of. See Furrowing of continental slopes

gradient of, 101, 127, 156

inadequate sounding of, 122

ridges of, 115

ruggedness of, 99 , III

valley systems of, 5. See Canyons; Furrowing

Continental terraces, 9 ff, 99 ff break of slope (fall-off) of, 100, I53 composition of, 10, 11, 99, 106, 109, 127,156

dimensions of, 99, I I0

discontinuities in, 109

furrowed by currents of the Glacial Period, II3, $136 \mathrm{ff}$

migration of shorelines on, 137,138 , 153

post-Glacial sedimentation on, 124

profile of equilibrium for, I0o

relative homogeneity of sediments in, I 26

slow development of, I29

total length of, I0, II i

Continents

distribution of isostasy in, 32

mean heights of, 7,26

origin of, 3,47

rock-layers under, 18

support of, 28, 3I

Cook Islands, 66

Co-operation among specialists needed, 49

Coral larvae, colonizers of reef platforms, 68, 7I

Coral reefs (atolls and barriers), 10, 157

inhibition of growth of, 70

lagoons of, $67 \mathrm{ff}$

relation to banks, yo

tests of crustal stability, $67 \mathrm{ff}, 69,74$

uplifted, 92

veneers on beveled mountains, 67,68

wall-like, 69, 72, 73

Cordilleras, characteristics of, $3 \mathrm{r}, 86 \mathrm{ff}$
Core of the earth, iron, 46 not solidified, 47

Cores of deep-sea deposits, 13, 124

Crary, A. P., 106, 166

Crust of the earth, 5, 11, 17, 21, 27

definition of, 32,33

distortion of, $77,85 \mathrm{ff}, 88$

strength of, $62 \mathrm{ff}, 65 \mathrm{ff}, 78,79,97,130$

sub-oceanic, I9

thickness of, $31,32,33,57,61,97$

Crust-substratum hypothesis, 60

Cuba, uplift of, 95

Current upwarping, of Fennoscandia, 38 of northeastern North America, 44

Cusps (cuspate forelands) of the eastern coast of the United States, I04

Daly, R. A. See bibliographical references, p. 165

Damping of earthquake waves, 16

Dana, J. D.

on coral reefs, 73

on the Hudson Canyon, 128, 130

Dardanelles, double density-current at the, 142

Darwin, C.

on coral reefs, 73

on the rocks of Ascension Island, 23

Dead Sea, below sealevel, 4

Death Valley, below sealevel, 4

Deep, ocean, 7, 9, 97

Japan, 7

Java, 82,91

Mindanao, 7

Nero, $7,78 \mathrm{ff}$

origin of, 77

Porto Rico, 82

tests of crustal strength, 78

Deflection of the plumb-line, 23,26

Delaware River, relation to shelf "channel," 119

Deltas, asymmetry of, I0I ff

Density

of continental rock, mean, 30, 6r, 85

of sea water, mean, 26

of sub-oceanic rock, mean, 30, 61, 85

Density currents, $112,129,136,145$ ff acceleration of, $137,140,148,151$ analogies of submarine, 137 
compared with subaerial rivers, $139 \mathrm{ff}$ concentration of water of, 139,148 controlling slopes of, $137 \mathrm{ff}, 146 \mathrm{ff}$, I5I

duration of, 140, 143, 146, 147, 148, 162

erosion by, 143, 150

of the Glacial Period, $137,138,147$

graded floors of, 140

mud suspensions causing, 129

plunging of, $138,143,166$

of the present time, I $43 \mathrm{ff}, 154$

salinity one cause of, I4I ff, 150

speeds of, 138, 140, 146, 147, 148, I50, 166

temperature one cause of, $\mathbf{I} 66$

turbulence of, 138,150

Deposits, marine, II ff

Depth of isostatic compensation, 31, 32, $8 \mathrm{r}$

Depth of ocean, mean, 26

Diagnosis, methods of, $4,13,18,27,34$, 45

Discontinuities in sediments of continental terraces, 109

Donaldsonville, Louisiana, ror

Downwarping, in relation to the continental terrace, to

under ice-caps. See Basining

Dredge, deep-sea, II

"Drowned" atolls, 75

Dry land, conditions for, 6

Eakin, H. M., 166

Earth

cooling of, 58

dimensions of, 7

figure of, $24 \mathrm{ff}$

plasticity of, 4,45

pressures in, 16

Earthquake in Turkey, 15

Earthquake waves in the earth's core, 16 in the mantle overlying the core, $13 \mathrm{ff}$, 58

Earthquake waves in the ocean, 134 comparative rarity and inefficiency of, I35

Earth-shells, 33, 46, 57, 59, 96

Easter Island, 50
East Indian archipelago

exploration of, 49

intensity of gravity in, $80,82 \mathrm{ff}$

mountain-chain of, $80,82 \mathrm{ff}, 90,94$, 98

submarine shelves of, 8

Eaton, H. N., on silty bottom currents in Lake Mead, 145

Ebro River delta, asymmetry of, 103

Echo-sounding, 6, 7, 99

Elastic waves. See Earthquake waves; Waves

Elephant Butte Reservoir, silty bottom currents in, 146

Ellipsoid, standard, 25

Erosion of continental slopes. See Canyons; Furrowing

Erosion of continents, disturbing isostasy, 32

Eruptibility of vitreous basalt, 60

Escher, B. G., 54

Etna, lava column of Mount, 6 I

Eustatic (world-wide) shifts of sealevel, 128, 131, 136

Everest, Mount, explanation of height of, 93

Evisceration of volcanic islands in the ocean, 53

Ewing, M., 106, 166

Experiments

Nature's, with ice-caps, 34, 43, 44

of P. H. Kuenen on density currents, I $48 \mathrm{ff}$

Explosions, at oceanic islands, 51, 52

Fall-off of the continental terrace, 9, 100

Faults, and the continental terrace, ro

Fennoscandia

gravity anomalies in, 42

upwarping of, after deglaciation, 35 , $37 \mathrm{ff}, 4 \mathrm{I}$

Fennoscandian ice-cap

area of, 34

basining of the earth's crust by, 35

center of, 35,38

current upheaval of, $4 \mathrm{I}$

flow-lines of, 36

future upheaval of, 4 I

thickness of, 40 
Figure of the earth, $24,45,80$

Figure of fluid equilibrium, 25

Fiji Islands, continental rocks in, 23

Finland

current upheaval of, 39,40

deficient mass under, 41,42

geodetic investigations in, 39

gravity anomalies in, 42

ice-cap on, 34

upwarping in the future, $40,4 \mathrm{I}$

Flores Island, 89

Flow of material in isostatic adjustment, 40

Folding of strata, 87

Foraminifera shells

in mud of canyon floors, 124

indicating change of ocean temperature, 124,128

Fore-deeps, 82, 88, 9 I

Forel, F. A., investigator of the silty bottom current in Lake Geneva, 129, 142, 166

Formula for speed of a density current, 150

Fort Monroe, Virginia, 108

Fossils, in sediments of continental terrace, 128

Funafuti atoll, test of prolonged crustal stability, 68

Furnace-effect of chemical reactions, 56 of radioactivity, 33, 45

Furrowing of continental slopes, I I5, 155

analogies to, $\mathbf{I} 23$

explanation of, I I I ff, I5 I

of Glacial date, $136 \mathrm{ff}$, I 5 I

largely arrested in post-Glacial time, I38, I 4 I, I 54

not correctly represented by existing maps, 122

probably world-wide, 124, 157

resulting in youthful topography, $\mathbf{2} 26$, 127,153

rhythm in, 139

Gabbro, 18

Gabbroic shell of the earth, 17, 18

Ganges River, relation to Ganges canyon, I24, 154
Gaskell, T. F., 106, 110, 166

Geneva, Lake, bottom silty current in, I 42-43, I 47

Geodesy an aid to the geologist, 24

Geoid

defined, 25, 27

relation to standard spheroid, 26

Geophysical methods of investigation, 8 , $13,24,45,50$

Georges Bank, I 15, I 17, 120, 134, 152

Germany, glacial moraines in, 34

Gibraltar, double density-current at, 142

Glacial controls, 34, 72, I13, I39, 153 , 155, 157

Glacial Period, 34, 128, 131

stages of, $36,70,136,157$

Glaciated tracts, $34,44,45$, I 56

Gradients (slopes)

of Atlantic submarine canyons, 122

of Colorado River, 122

of continental shelf, I00

of continental slope, 9, ror

of Snake River, 122

of submarine canyons, longitudinal, $122 \mathrm{ff}$

of submarine canyons, lateral, 122

Graham Land, Antarctica, relation to mountain-arc, $8 \mathbf{2}$

Grand Canyon of Arizona

cliff-and-talus topography of, 126

compared with submarine canyons, I 13,126

"Granitic" layer of the earth's crust, I7, I 9

Gravels, washed, on Georges Bank, I52

Gravimeter, a diagnostic instrument, I I, 23,28

Gravitational attraction of land masses, 27,80

Gravity

deficient in Finland, $4 \mathrm{I}$

deficient in ocean deeps, 78

deficient in southern Canada, 44 in excess in volcanic islands, $63 \mathrm{ff}$ reduction of observed, $28,31,62,81$

Great Barrier Reef of Australia, 10, 73

Great Lakes, water-gages of the, 44

Griggs, D., investigator of rock strength, 78

Ground-water as feeder of aquifers, 132 
Grover, N. C., I66

Guam Island, 77

Gulf of Bothnia, 34, 39, 40, 42, 44

Gulf of Finland, 39

Gulf of Maine, 153

Gulf of Mexico

thickness of shelf sediments under, II I weak tides of, 103

Gulf Stream, cause of giant eddies, I04

"Gun," invented by C. S. Piggot, I2

Gutenberg, B., 20, 21, 22, I65

$\mathrm{H}_{\text {awaii Island, } 52}$ gravity anomalies in, $63 \mathrm{ff}$

Hawaiian Islands, map of, $18,19,50$

Hayford, J. F., investigator of the earth's figure, $32,8 \mathrm{I}$

Heat of the earth

inherited, 45

radioactive, 45

volcanic, 56

"Heavy water," I37, I4I

Heiskanen, W., investigator of the earth's figure, $32,8 \mathrm{r}$

Helsinki (Helsingfors), 39

Heron Island, bore-hole at, 66

Hess, H. H., on geology of the West Indies, $84,95,99,165$

Himalayas date of formation of, 92

in isostatic balance, 93

origin of, 88

structure of, 92

upheaval of, $92 \mathrm{ff}$

Hirvonen, R. A., on gravity in Finland, 42

Horizontal displacement of the sialic crust, $47,92,97$

Howard, C. S., 166

Hudson Bay, 8, 44

Hudson Canyon, II 4, II 6 ff

Hudson River, relation of to "Channel" and Canyon, II, 154

Hudson (shelf) "Channel," II 4

Hydraulic head, 133

Hydraulic mean depth, I50

Ice-caps, Canadian, 44

connected with eustatic shifts of sealevel, 70

dimensions of, $34,13 \mathrm{I}$
Ice-caps, Fennoscandian, $34 \mathrm{ff}$

flexing (basining) the earth's crust, $34 \mathrm{ff}$

melting of, $34,37,136$

times of duration, 137

India, submarine canyons off coast of, I34

Indian Ocean, 2I, 45

sialic rock under, 23

Individuality of density-current preserved, I $40,143,146 \mathrm{ff}, 162$

Indus River, relation to Indus canyon, I24, 154

Interglacial stages, 70,72

"Intermediate" layer of the earth's crust, I7, 23

Iron core of the earth, $\mathrm{x} 6$

Island belts, 80

Islands, thalassic or deep-sea, $9,48,50 \mathrm{ff}$

Isobases, 37,39

Isobath, 9, II 5

Isostatic adjustment (flow in depth), 32

Isostatic anomalies. See Anomalies of gravity

Isostasy, $27,3 \mathrm{I}, 45,8 \mathrm{I}$

Jaggar, T. A. See Figure 23

Jaluit atoll, a test of prolonged crustal stability, 66

Japan, Sea of, 9r

Japan Deep, 7

Japanese mountain-arc, 9I

Java Deep, 82, 9 I

Java Island, 89

Johnson, D. W., explanation of submarine valleys by, $\mathrm{I}_{3} \mathrm{I} \mathrm{ff}, \mathrm{I} 66$

Jungfrau Mountain, 92

Kei Island, deformed rocks in, 89

Kelch, H. T., I 45

Kerguelen Island, 50

Kilauea, volcanic vent at, 56

Knapp, R. T., I 4 I

Kolumadulu atoll, test of prolonged crustal stability, 68

Krakatoa Island, eviscerated, 53, 54

Kuenen, P. H., experiments by, $148 \mathrm{ff}$, I 53, I 66

Kukkamäki, T. J., on changes of leve! in Finland, 39 
Labrador, obscrvations in, 44

Lagoons inside coral reefs, II

depths of, 68

flatness of floors of, 67

testimony regarding strength of the earth's crust, $67 \mathrm{ff}$

Lake Constance. See Constance, Lake

Lake Geneva. See Geneva, Lake

Lake Lee, 147

Lake Mead. See Mead, Lake

Lake Murray, 147

Landsliding, in volcanic islands, 53

Lava

cause of ascent from depth, 51

cascade, 56

fountains, 56

lakes, 56

liquidity of, $50,58,60$

origin of, $56 \mathrm{ff}, 60$

temperature of, 56

Leet, L. D., 15

Level, changes of shown by water-gage, 38

shown by the spirit-level, 39

Lindenkohl, A., on the Hudson Canyon, I 28

Lizard, The, continental terrace off, IIo

Long Island, New York, furrowed slope off, I 6,133

Loo Choo mountain-arc, $9 \mathrm{r}$

Louisiade archipelago, 68

Louisiana, continental terrace off, III

Love, A. E. H., I6

Love seismic waves defined, 16 velocities of, I9, 2 I

Loyalty Islands, 66

Macclesfield Bank, test of prolonged crustal stability, 67

Macelwane, J. B., I65

McLaughlin, D. H. See Figure 7I

Madeira Island, test of crustal strength, 63

Maldive archipelago, 50

Mangaia Island, test of prolonged crustal stability, 66

Mango Island, test of prolonged crustal stability, 66
Marine currents

affecting symmetry of deltas, 102

in Gulf of Mexico, 102

in the Mediterranean Sea, 103

Marmora Sea, double density-current in, 142

Marshall Islands, 66

Massachusetts, continental shelf off, I00

Matterhorn, 92

Mauna Loa, lava lake of, 61

Mead, Lake

density currents in, I $44 \mathrm{ff}$

gradient of floor of, 146

velocity of density currents in, 146

Mediterranean sea-basins, origin of, 4

Michaelmas Cay, bore-hole at, 66

Mid-Atlantic Swell, 9, 23

Miladummadulu Bank, test of prolonged crustal stability, 72

Mille (Mulgrave) atoll, test of prolonged crustal stability, 67

Miller, A. H., on gravity in southern Canada, 44, I65

Milligal, defined, 30, 64

Mindanao Island, 7

Miocene sediments in canyon walls, 128

Mississippi Delta, asymmetry of, IOI

Mississippi River

deflection of, ror

trenching its own alluvium, r 30

"Mixed" paths of Surface earthquake waves, 21,22

Montreux, Switzerland, I 42

Morris, F. K., 88

Mount Etna, lava column of, 6 I

Mount Everest, cause of height of, 93

Mountain chains arcuate ground-plans of, 88, 9I, 95, 97

delayed uplift of, 89,93

folding of bedded rocks in, 88

origin of, $3,47,86$

overthrusts in, 87,89

peridotite in roots of, 95

structure of, 86

submarine, $5,48 \mathrm{ff}, 79$

Mountain structures of the sea floor, $48 \mathrm{ff}$

Mud-suspensions affecting density of sea water, I I 2, 136, I 47

Murilo atoll, map of, 67

Murray, H. W., 155 
Murray, Sir John, investigator of deepsea sediments, 12, 165

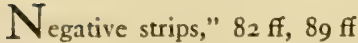

Nero Deep, gravity over the, $77 \mathrm{ff}$

Netherlands Geodetic Commission, 28

New Orleans, Ior

Newton, Sir Isaac, 4

Niger River, relation to Niger canyon, 154

Niaufou Island, 51

Niskanen, E., on upheaval of Finland, $40,4 \pi, 165$

Nomwin atoll, 67

Non-basaltic lavas, origin of, 48,58

Norfolk, Virginia, II 6

Norfolk Canyon, II6, I 20

North Khartoum, sandstorm at, 137

North Sea, 8

Northwest Territories, observations in, 44

Nubia, sandstorm in, 137

Oahu Island, a test of crustal strength, 63

\section{Ocean}

dimensions of, 6,7

floor of, 8 , II ff

mean density of, 25

mean depth of, 7,25

Ofu Island, origin of, 55

Olosega Island, origin of, 55

Ontario, observations in, 44

Ooze, deep-sea, 13

Pacific Ocean

islands of, 50

wave-velocities under, 20, 45

Palawan Bank, "drowned" atolls on, 76

Paleontological proof of crustal stability, 65

Patagonia, 8

Penck, A., 38

Pendulum, gravity-measuring, 27

Peridot, 58

Peridotite, 58, 95

vitreous, 59

Peridotitic earth-shell, 58, 96

Peros Banhos Bank, 68
Peru, observations on gravity in, 28

Philippine group, "drowned" atolls of, 75

Piggot, C. S., investigator of deep-sea deposits, 12, 165

Plasticity, of the earth's body, 2, 46

"Plateaus"

continental, 5

submarine, 9

Pleistocene Period, canyon-cutting during, 128

Plumb-line, deflection of the, 23,26

Porto Rico Deep, 82

Position at sea, fixing, 6

Post-Glacial time definition of, $35,40,136$ marine conditions of, I $4 \mathrm{I}, \mathrm{I} 54$

Pressure, all-sided, increasing strength of rock, 78

Pressures in the earth, 16

Profile of equilibrium of continental terrace, 100, 153

Pseudo-Rayleigh (seismic) waves, 16, I9, 20

Puerco River, silt suspended in, 146

Push waves, I 4,18

Radio-acoustic ranging, 7

Radioactive furnace, 33

Radioactivity of rocks, 33,44

Rayleigh, Lord, 16

Rayleigh (seismic) waves, I6

Recoil of the earth's crust after deglaciation, $36,44,157$

Reefs, coral. See Coral reefs

Reflection (seismic) method of finding discontinuities, 107

Reflux currents in relation to submarine valleys, I34

Refraction (seismic) method in geophysical research, 107

Relief of the sea floor, 8, I22

Renner, F. G. See Figures 68 and 69

Reservoirs with density currents, I44, $146,147,151,166$

Rhine River delta, in Lake Constance, I 44

Rhone River delta of Lake Geneva, I42 ff of the Mediterranean Sea, ro3 
Richter, C. F., 20, 22

"Ridges" of the continental slope, I15

Rio Grande Valley, 146

Romicux, J., I 44, I 66

Roots of mountain chains, 85,96 melting of, 93 thermal expansion of, 92

Roti Island, 95

Russell, R. J., I01, 166

Russia, glacial moraines in, 34

Rutherford, H. M., I06, 166

Saint Helena Island, 50, 63

Salinity, excess, a cause of density currents, I4I ff, 150

Saluda Reservoir, 147

Samoa, 50, 55

Sampling the sea floor, 8, II, I2

San Carlos Reservoir, 147

Sandstorm near Khartoum, 137

Sao Miguel Island, a test of crustal strength, 63

Saumlaki Island, deformed rocks in, 89

Sea bottom, varied relief of, 48

Sea of Japan, 9I

Sealevel, eustatic (world-wide) shifts of, I28, 131, 136

Sediment, mechanism for transport of, to deep water, 156

"Sediment transports water," I4I

Seismogram, II, 13, 2 I

Seismogram of the recent earthquake in Turkey, 15

Seismograph, detection with the, 13,18 , 2I, 106

Self-acceleration of bottom currents, 138 , 150

Seychelles Bank, 67

Seychelles Islands, 23

Seychelles Plateau, 23, 24

Shake waves, $14,18,47$

Shepard, F. P., on submarine valleys, $124 \mathrm{ff}, 128,131,152,166$

Shoals, 9, 48, 50, 97

development of, $5 \mathrm{x}, 65,70$

Sial

defined, $17,18,33,46,49$

of Atlantic and Indian Ocean basins, 21,22 original thickness in East Indian region, 94

thickened in belts of mountain-building, 88,89

Siberoet Island, deformed rocks in, 89

Sicily, thickness of the crust under, $6 \mathbf{I}$

Silty currents. See Density currents

Sima, defined, 17,18

Simatic crust, $33,46,49,59$

Sipoera Island, deformed rocks in, 89

Slopes. See Gradients

Smith, J. F., I62

Smith, P. A., investigator of submarine valleys, II5, 122, 140, 161, I66

Snake River Canyon, compared with submarine canyons, 122, 123

Society Islands, 50

Soembawa Island, 89

Sonic sounding, 6

South Africa, 8

South Georgia, relation to mountain-arc, 82

South Sandwich Islands, relation to mountain-arc, 82

Southwest Pacific, velocities of earthquake waves under, 18,20

Spheroid, oblate, 25

Spheroid, standard, 25

Spirit-level, showing recent changes of level, 39

"Spring-sapping," a suggested origin of submarine valleys, 132,134

Stability of volcanic islands, $65 \mathrm{ff}, 67$

Stereogram of earth-shells, 46

Stetson, H. C., investigator of continental terrace, 100, 124, 128, 153, 66

Stevenson, R. L., 5 I

Strength

of crust, $33,62,74,77$

of earth-shells under Fennoscandia, 43 of earth-shells under Hudson Bay, 44 of rock in relation to pressure, 62,78 ,

97

Stress

caused by deglaciation, 40, 42

causing isostatic adjustment, 32, 42

"Strips" of deficient mass (negative anomalies of gravity), 82

origin of, 86,95

Subaerial and submarine bottom currents compared, 139 ff 
176

Subcrustal weakness, 43

Submarine canyons. See Canyons

Submarine mountains, 5, 48

Alpine type, 98

volcanic. See Volcanic islands

Submarine valleys See Canyons; Furrowing

Sub-oceanic crust

largely simatic, I9, 27, 6I

strength of, $62 \mathrm{ff}$

structure of, 2 I

thickness of, 33,78

Subsidence of volcanic piles, 75

Substratum

density of, 85

secular change of, 58

simatic nature of, 17

source of volcanism, $57 \mathrm{ff}, 97$

viscosity of, 59

vitreous or glassy, 57

weakness of, $57,97,98,157$

world-circling, 57

Sumatra Island, 89

Super-elevation of continents in relation to submarine canyons, 129

Surface (seismic) waves, velocities of, 20,21

Surface-shear waves, I7, 20

Susquehanna River, in relation to shelf "channel," I 99

Suva Diva atoll, map of, 67

"Swells," submarine, 9

Synthesis, a tool of science, 2

Tagula Island, 68

Tahiti Island, relation to Bora Bora Island, 75

Tanimbar Island, deformed rocks in, 89

Taut-wire control, 7

Temperature

a cause of weakness in rocks, 32,44 , 45,78

initial, of lava, 56

origin of volcanic, 56

Tertiary Era, 88

Tests of isostasy

in Fennoscandia, $34 \mathrm{ff}$

in northeastern North America, 44

Tests of theory of submarine valleys, $138 \mathrm{ff}, 147 \mathrm{ff}$
INDEX

Texas, continental terrace off, ir I

Thalassic islands, 9,48

Tide-gages, showing recent changes of level, 39, 44

Tiladummati Bank, test of prolonged crustal stability, 72

Till on Georges Bank, 152

Timor Island, 89, 92, 95

Tonga Islands, continental rocks in, 23

Trinidad Island, deformed rocks in, 95

Truk Islands, 67

Turbulence of silty currents, 138,150

Turkey, recent earthquake in, 15

Typhoons in relation to "drowned" atolls, 75

Underflow, silty. See Density currents

United States, continental terraces off, 8, II 6, I36

United States Coast and Geodetic Survey, I1 5,155

United States Soil Conservation Service. See Figure 74

Upheaval

in Canada after removal of ice load, 44

future, in Fennoscandia, $4 \mathrm{I}$

in Fennoscandia, 35, 37, 38

of mountain chains, delayed, 94

Uplift hypothesis to explain submarine valleys, 128

Underflows. See Density currents

Upolu Island, I 8, 5 I

Uvea Island, a test of prolonged crustal stability, 66

$\mathrm{V}_{\text {alley systems of continental slope, }}$ III ff origin of, $127 \mathrm{ff}$ pattern of, 139

Van Bemmelen, R. W., 83

Vancouver, British Columbia, 136

Veatch, A. C., investigator of submarine valleys, II $6,120,122,140,166$

Velocity of bottom density current, formula for, 150

Vening Meinesz, F. A., investigator of sub-oceanic structures, $28,63,77,80$, $85,90,95,98,165$ 
Virginia

coastal plain of, 108

continental terrace off, 103,116

submarine canyons off coast of, I 16

Viscosity of the substratum, 33

Vitreous earth-shell, 33, 46

Volcanic heat, origin of, $56 \mathrm{ff}$

Volcanic islands of sea floor, 50 catastrophic changes of, $52 \mathrm{ff}$ loads on the earth's crust, $60,62 \mathrm{ff}$, $65,67,97$

tests of crustal strength, $60,62 \mathrm{ff}$

upbuilding of, 50

Volcanism, in relation to substratum, 57 ,

97

$W_{\text {arping of the geoid, 25, } 27}$

Washington Canyon, II6, I 19

Water-gages of the Great Lakes, 44

Wave-base, defined, 52, 69, 100

Waves, elastic, seismic

body, 15 compressional, longitudinal, or push, I4

Love, 17

Main or Long, I4

pseudo-Rayleigh，I6，19, 20

Rayleigh, 16

Surface, 15

Surface-shear, I7

Transverse, Shear, or Shake, 14, 18, 47

West Indian archipelago

gravity in, $95 \mathrm{ff}$

mountain chain of, $80,82,95,98$

Wilmington Canyon, 116,118

Wilson, J. T., investigator of the suboceanic crust, 21, 165

Wisconsin stage of the Glacial Period, 128

Woods Hole, Massachusetts, I08, II0

Wüst, G. See Figure I

$Y_{\text {oldia Sea, } 39}$

Yucatan, continental terrace off, 8 







Reprinted from Rep. Challenger Society, 3, No, XIX, 1967

SPECIAL LECTURE

21.7 .66

Studies of the Atlantic Deep-Sea Floor:

The State of the Art

DR. D. H. MATTHEWS 
STUDIES OF THE ATLANTIC DEEP-SEA FLOOR:

THE STATE OF THE ART

Dr. D. H. MatTheWS

(Department of Geodesy and Geophysics, Cambridge)

THE "HEROIC AGE": 1945-55

The growth of submarine geophysics is closely bound up with the development of new techniques. It has recently been said that the first decade after World War II was the heroic age of marine geophysics: the techniques available at the time were echo sounding, seismic refraction (which enab!es one to determine the thickness and velocity of sound in layers of rock below the sea floor), measurement of gravity at discrete points by swinging pendulums in a submerged submarine, and bottom sampling by coring for soft sediment and dredging for hard rocks. During the period it became possible to measure the rate of efflux of heat through the sea floor, and the accuracy and convenience of echo sounding was greatly improved with the advent of better timing and straight-scale recording. Echo sounding is the most revealing of all single techniques and the results of many years of work were summarised by Heezen and Tharp in 1957 with the first publication of a chart showing the physiography of the North Atlantic Ocean and the definition of distinct physiographic provinces (Fig. 1): the continental margin (shelf, slope and rise), the ocean basin floor (abyssal plains with slopes of less than 1:1000 and areas of abyssal hills), and the Mid-Ocean Ridge (Heezen, Tharp and Ewing, 1959).

Towards the end of that first decade, in 1954, two symposia were held. The first, with the avowed intention of crystallizing present knowledge of the earth's crust, was held at Columbia University (Poldervaart, 1955). The papers concerned with the crust beneath the deep ocean, by Ewing and Press, Gutenberg, and Worzel and Shurbet were primarily concerned to drive home the difference between continent and ocean-the vital discovery that the Moho (the abrupt discontinuity between less dense crust and denser mantle rock) is shallower under the oceans which accounts for the general equality of gravity measured at sea level over continents and oceans. This discovery is certainly the greatest single achievement of submarine geology.

In the same year there was a one-day discussion on the floor of the Atlantic held at the Royal Society (Bullard 1954). The essential difference between continent and ocean was summarised by Hess (Fig. 2). The evidence for it, presented by Hill, Laughton and Gaskell, was primarily from explosion seismology. Browne and Bullard examined its consequence, that the oceans must be 

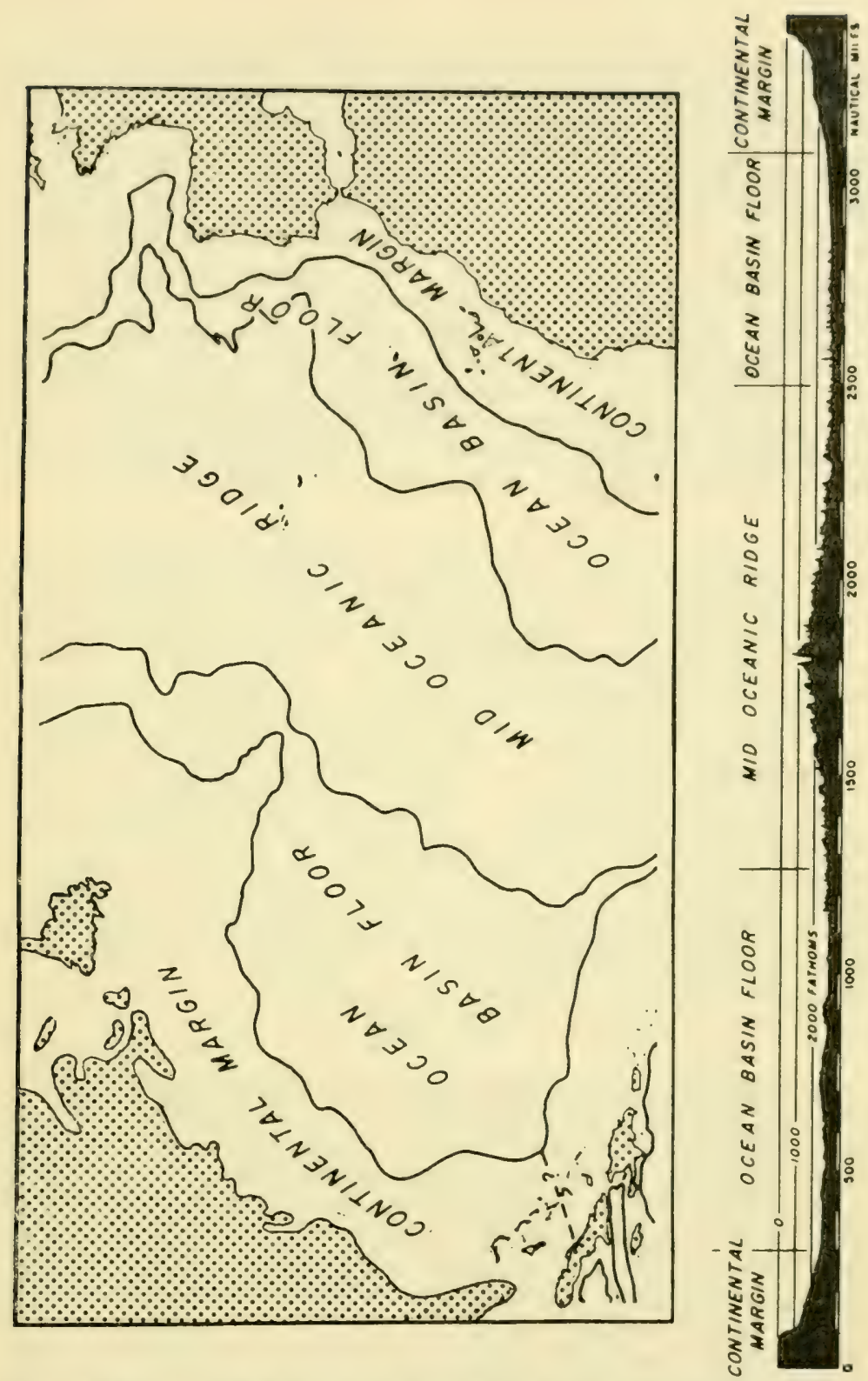

Fig. 1. Major morphologic divisions of the North Atlantic Ocean. The profile is a representative profile from New England to the Sahara Coast. (Heezen, Tharp and Ewing, 1959). 
permanent (a view which Lees opposed vigorously on the grounds that geological structures can be seen that strike out towards the sea and must be supposed to cross the boundary). At that time continental drift was a theory out of favour with geophysicists and the new seismic evidence showed beyond doubt that the Atlantic could contain no sunken continents such as those proposed by geologists to have provided the sediments found in the marginal geosynclines of America and Britain. Likewise, the presence of vesicles in fragments of basalts dredged from the Mid-Atlantic Ridge and the existence of coarse detrital sands dredged by the CHALLENGER from the abyssal plains could no longer be argued as evidence of a one time wholesale emergence of the seafloor, as they had been by Gregory (1929). An alternative explanation of the deep-sea sands was discussed at the Royal Society by Kuenen, and by Shepherd, in terms of transport by turbidity currents.

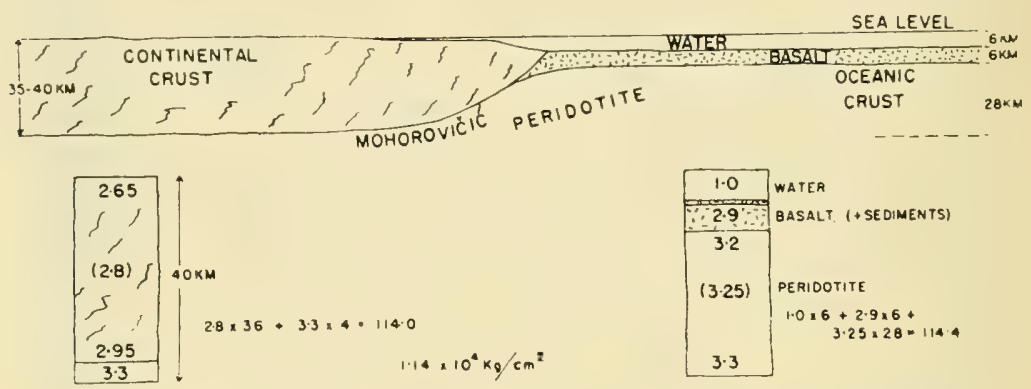

Fig. 2. Diagram to show typical continental and oceanic sectors of the earth's crust. (Hess, in Bullard 1954).

\section{$1955-1959$}

By the first International Oceanographic Congress, held in New York in 1959, it was generally agreed that turbidity currents could transport material of shallow water origin down the continental slope and deposit them many hundreds of miles from land in graded beds which formed the abyssal plains. The question of whether these currents eroded or merely kept clear the submarine canyons on the continental margin was not (and still is not) settled, but Laughton (1960) provided very convincing evidence of erosion by rejuvenated turbidity currents at the S.W. corner of the Biscay abyssal plain. There the turbidity currents, already some 400 miles from their source on the continental slope, had gathered speed and flowed down through a gap in the confining hills to spread out again on the Iberia abyssal plain $100 \mathrm{fm}$. deeper, cutting on their 
way a meandering gorge through the hills and ponded sediments.

The permanence of the ocean basins, at that time presumed to have been there for at least 1,000 million years, posed the important question: where have all the sediments gone? In the five years batween 1954 and 1959 the seismic layering beneath the ocean basins had been worked out and was summarised by Hill (1957) for the Atlantic:

\section{Layer}

\section{Sea water}

1. (unconsolidated sediments)

2. (volcanics or consolidated sediments?)

3. basic igneous

4. peridotite

$\begin{array}{cc}\begin{array}{c}\text { Sound Velocity } \\ V_{p} \mathrm{~km} / \mathrm{sec} .\end{array} & \begin{array}{c}\text { Thickness } \\ 1.5\end{array} \\ 2 & 4.5 \\ 2 & 0.45 \\ 4-6 & 4.75 \\ 6.71 & 4.7 \\ 8.09 & -\end{array}$

A new technique had emerged in the shape of the towed proton magnetometer; on many crossings of the Mid-Atlantic Ridge Ewing and Heezen had discovered the existence of a median magnetic anomaly associated with a median valley. The existence of high heat flow on the Mid. Ocean Ridge had become established and the ships of the Lamont Observatory had demontrated that the position of the Mid-Ocean Ridge system could be predicted from its association with a world-encircling system of earthquake epicentres, as Rothé had suggested at the Royal Society in 1954. Earthquake seismologists working on surface waves had demonstrated that the low velocity channel in the upper mantle predicted by Gutenberg was shallower under the oceans than under the continents. All these advances were reviewed by M. Ewing (Ewing and Landisman in Sears, 1961) at the first International Congress. Bullard, in Sears, 1961, significantly, drew attention again to the problem raised by Lees, of geologic structures which transect the continental margin, and discussed the possibility of continental drift.

However, one of the main problems was the question of where the sediments had gone, and this reduced to determining the nature of the rocks of layer 2: if layer 2 were compacted sediment it was just possible that the oceanic floor could be permanent, but if it was lava it could not be. The case for believing the seismic second layer to be consolidated sediment was put by E. L. Hamilton (1959; also Sears, 1961) but it has not prevailed. The only abyssal hill yet sampled proved to be of weathered basalt having just the right seismic velocity (Matthews, 1961) and subsequent calculations to explain magnetic anomalies observed at sea have required strongly magnetised rocks in layer 2 . Current opinion regards layer 2 as being volcanic though with sediments intermingled. If this is the case then the ocean floors cannot be old- 


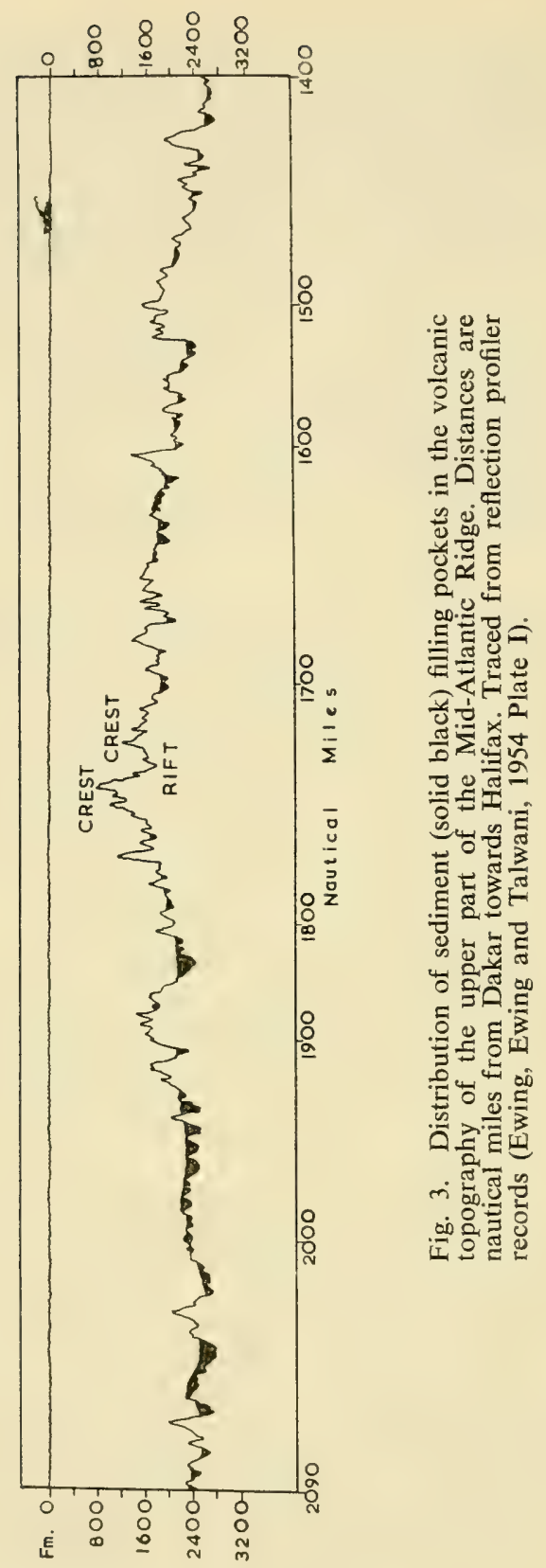


probably not very much more than 100 m.y. old, the age of the oldest rocks yet dredged-and the theory of continental drift, already strongly argued on palaeomagnetic grounds, begins to look more plausible. Only drilling through the sedimentary layers at several points in the deep ocean can finally solve this problem.

\section{NEW YORK 1959 TO MOSCOW 1966}

During the seven years between the First International Oceanographic Congress in New York in 1959 and the second in Moscow in 1966 the subject came of age. Existing techniques were used especially to study the structure of the atypical areas, particularly the mid-ocean ridges. New techniques included the development of safe and reasonably cheap devices for continuous reflection profiling (sparkers and air guns) with a resulting huge increase in knowledge of structure within the sediments and of the relief of the top of layer 2, the volcanic layer (Fig. 3). Also, it became possible to measure gravity continuously from a surface ship. Towards the end of the period the first deep offshore holes were drilled to explore the geological structure of the Blake Plateau, the deepest in more than $500 \mathrm{fm}$. of water. The Blake Plateau, an area of deep continental shelf separated from the rest of the shelf off Florida by a $400 \mathrm{fm}$. scarp, was found to have been formed not by faulting but by the non-deposition of the Tertiary strata due to the erosional effects of the Gulf Stream; the Cretaceous rocks beneath the scarp pass under it without disruption.

Other advances during these seven years inc'uded the discovery by Raff and Mason of the great pattern of magnetic anomaly lineations running north-south off the west coast of the U.S.A. and the recognition by Vacquier and others (see Bullard and Mason in Hill, 1963) that this pattern has been displaced sideways by distances as much as 600 miles along great transcurrent faults like the Mendocino Escarpment which has been traced out almost one third of the way across the Pacific. The publication of the third volume of The Sea (Hill, 1963) summarising almost all our knowledge of the sea floor up to that time, of Menard's (1964) Marine Geology of the Pacific, and of the Royal Society's discussion meetings on Continental Drift (Blackett, Bullard and Runcorn, 1965) and on the geological results of the International Indian Ocean Expedition (Hill, 1966) also marked the consolidation of knowledge.

\section{THE STATE OF THE ART}

It became clear, during the years between the two International Oceanographic Congresses, that the upper mantle is the key to the geological process that affects the crust of the earth. At present 


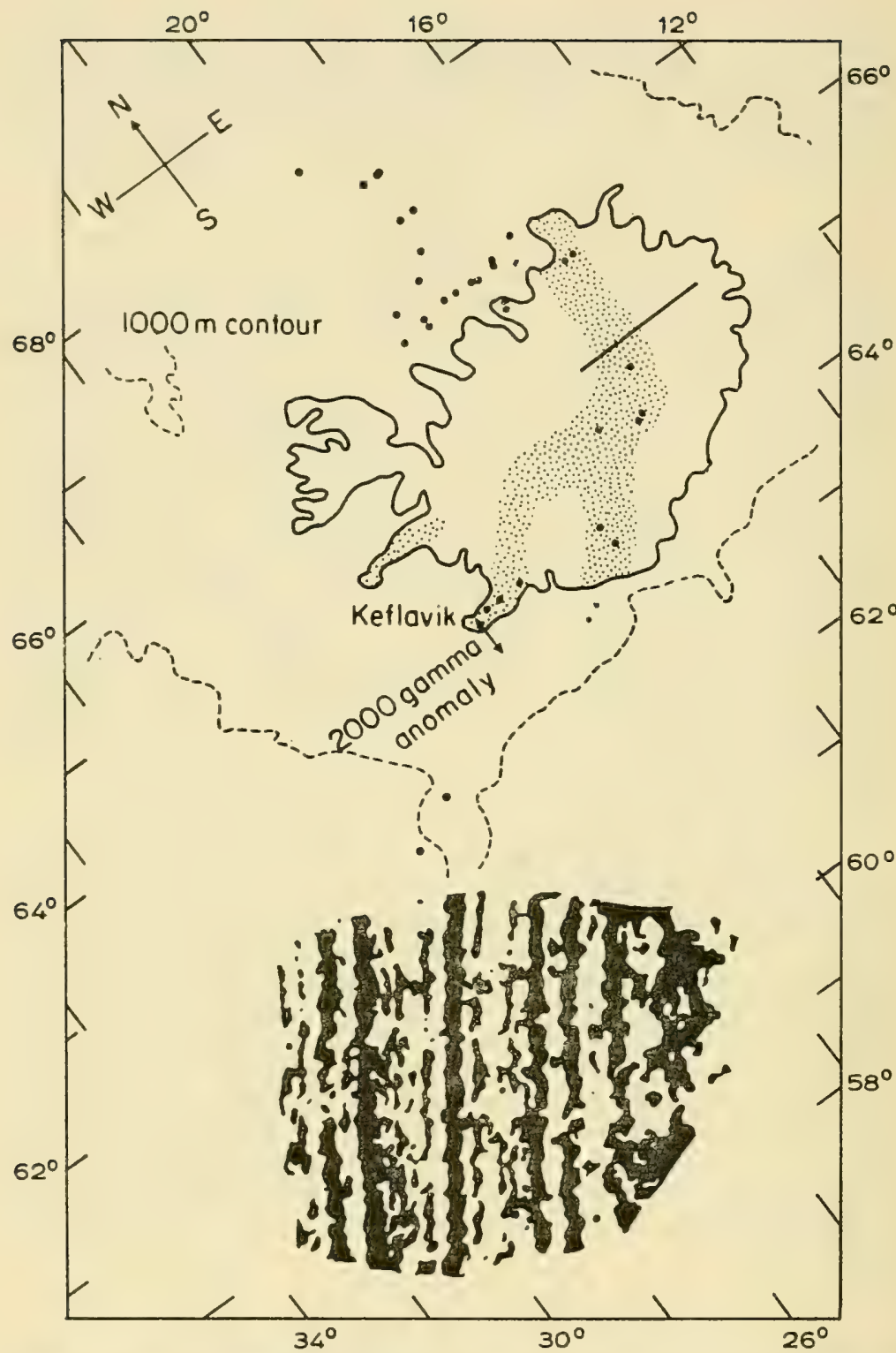

Fig. 4. Area of magnetic survey southwest of Iceland. Positive anomalies are shown in solid black. Belts of Quaternary volcanics in Iceland are shaded. Dots mark earthquake epicentres. (From Heirtzler, Le Pichon and Baron, 1966). 
the search for a mechanism in the mantle that could account for continental drift and for the youth of the ocean floor has lead to study of the mid-ocean ridge, of magnetic lineations in the deep ocean, of the age and geologic history of rocks from the occan floor, and of the continental margin; and it will lead very soon to more direct study of the upper mantle at sea.

\section{THE MID-OCEAN RIDGE}

Reflection profiles across the Mid-Atlantic Ridge reveal it as an uplifted welt of the sea floor some $2 \mathrm{~km}$. high and $2000 \mathrm{~km}$. wide. The edges are buried in sediment, and the amount of sediment decreases, and the relief increases, towards the crest. The crest is marked by a line of earthquake epicentres, is frequently marked by a median "rift" valley, is displaced by transcurrent faults, and near it high heat flow values are frequently measured (though low ones occur as well). Gravity values measured at sea level show no progressive change, so the uplifted welt must be compensated by less dense material beneath. Seismic refraction results indicate that the mantle beneath the crest of the ridge has unduly low velocity $(7.5 \mathrm{~km} / \mathrm{sec}$. instead of the usual 8.1$)$ and the corresponding decrease in density must provide the compensation required by the gravity results. Where the ridge comes to land in Iceland it is clearly an active volcanic structure, and the presence of large volcanic seamounts like the Azores, and the dredging of basalts from innumerable places along the ridge confirm its volcanicity. This is all consistent with the idea of convection in the mantle bringing heat up and causing melting in the upper mantle.

The pattern of magnetic anomalies observed over the crest of the ridge is very striking: three detailed surveys of the crest of the Mid-Atlantic Ridge, all reported during the past year, have shown a pattern of linear anomalies running parallel with the axis of the ridge. An example is shown in Fig. 4. To explain a similar pattern observed during a survey of the Carlsberg Ridge made in 1962, Vine and Matthews (1963) proposed the hypothesis that dykes were being injected into the crust near the crest of the ridge. As each dyke cooled it became magnetised in the direction of the earth's magnetic field and was progressively shouldered aside by younger dykes. It was known that the polarity of the earth's field has reversed every million years or so during the past few million years, so that the result of this process would be the formation of strips of the earth's crust alternately normally and reversely magnetised-just the structure needed to explain the linear pattern of anomalies. This "fruitful Vine" hypothesis has recently received additional support when it was found able to deduce a sequence of reversals for the past 10 million years from profiles of the mid-ocean ridge in the East Pacific and to use these correctly 
to predict the pattern of anomalies observed off Iceland (Pitman and Heirtzler, 1966). The rates of expansion of the ridge deduced by this method are in very good agreement with those (1 to 2 $\mathrm{cm} / \mathrm{yr}$.) suggested by the time scale of continental drift.

\section{LINEATIONS}

The only adequate way to check how much of the ocean basin floor shows these strongly linear magnetic structures would be to survey a trans-Atlantic strip in detail. In the absence of such a survey, one may compare the existing magnetometer profiles. So far the results are not too encouraging: correlation between adjacent tracks are unimpressive once the immediate vicinity of the ridge crest has been left, but the tracks are too far apart and often too poorly navigated for this to be certain. This method has however revealed a pattern of broad magnetic lineations in the Bay of Biscay, surveyed this summer by R.R.S. DISCOVERY which is at least consistent with the idea that the Bay was formed by the anti-clockwise rotation of Spain as Girdler had suggested on palaeomagnetic grounds.

\section{ROCKS FROM THE OCEAN FLOOR}

Fairly numerous hauls of lava from the ocean floor have been described during the past few years and at the International Oceanographic Congress in Moscow there was, at last, some discussion of their petrology. On a recent cruise of DISCOVERY several days were spent surveying and dredging a small area on the flanks of the Mid-Atlantic Ridge (at $43^{\circ} \mathrm{N}$., $20^{\circ} \mathrm{W}$.) where we thought that a section through the oceanic crust had been exposed by faulting. Here a succession of sedimentary pelagic limestones going back to Eocene in age was found overlying a basement of metamorphosed basalts and gabbros. $\mathrm{K}^{40}: \mathrm{A}^{40}$ age determinations put the age of the metamorphism at 55 m.y. ago. This is all consistent with the metamorphism and faulting of the crust having occurred near the crest of the Mid-Ocean Ridge at that time (Cann and Funnell, 1966). Studies of this kind could disprove the idea that the ocean floor is growing from the middle if unequivocally old sediments were found close to the ridge axis. Such specimens have been reported recently by Ewing, Le Pichon and Ewing (1966).

\section{THE CONTINENTAL MARGIN}

On the American side of the Atlantic the Appalachian structures run parallel to the continental margin, but on the European side they run perpendicularly across it, out to sea. If the idea of continental drift is true they must be truncated and continued on the other side (Fig. 5).

We know remarkably little about the structure under the edge of the continent off the mouth of the English Channel and this is an obvious challenge. 


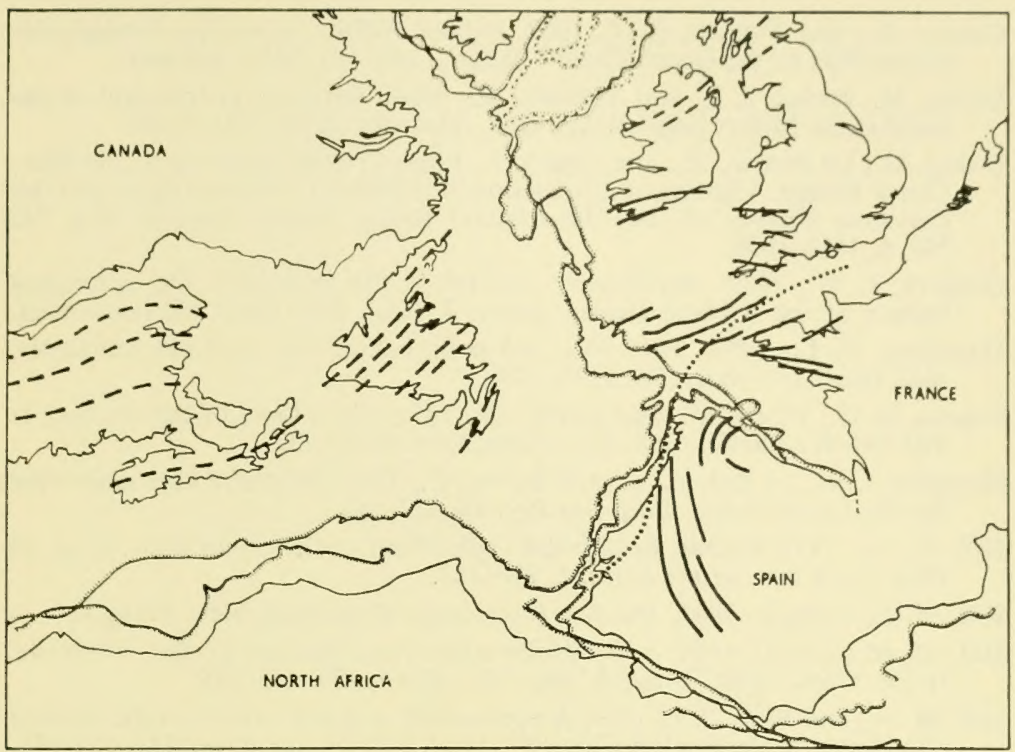

Fig. 5. Fit of the North Atlantic continents after Bullard et al. Structural trends on land: broken lines Appalachian-Caledonian, solid lines Hercynian. Solid lines in mouth of English Channel are magnetic anomaly lineations (Hill and Vine, 1965).

\section{THE FUTURE}

In the future, during the next few years, there is bound to be great expansion of our attempts to make direct studies of the upper mantle, taking to sea the techniques, such as large arrays of seismometers or strain and tilt measuring devices, that have revolutionised seismology on land during the past decade. We need to be able to map the shape of the Moho by reflection techniques and to be able to study the anisotropy and non-uniformity of the properties of the rocks beneath it.

It is because the oceanic crust is relatively thin and simple compared to the continents, so that it reflects the recent history of the mantle better than the continental crust does, that geology must go on at sea if we are to understand the development of the crust and its structure and resources.

\section{REFERENCES}

Blackett, P. M. S., Bullard, E. C., and Runcorn, S. K. (Editors), 1965, A Symposium on Continental Drift. Phil. Trans. A. Roy. Soc. Lond. 258, 1-323.

Bullard, E. C. (Editor), 1954, A discussion on the floor of the Atlantic Ocean. Proc. Roy. Soc. A. 222, 287-407. 
Cann J. R., and Funnell, B.M., 1967, Palmer Ridge : a Section through the Upper Part of the Ocean Crust? Nature, 213, No. 5077, 661-664.

Ewing, M., Ewing, J. I., and Talwani, M., 1964, Sediment distribution in the oceans: the Mid-Atlantic Ridge. Bull. Geol. Soc. Amer. 75, 17-36.

Ewing, M., Le Pichon, X., and Ewing, J., 1966, Crustal Structure of the MidOcean Ridges. 4 Sediment distribution in the South Atlantic Ocean and the Cenozoic History of the Mid-Atlantic Ridge. Journ. Geophys. Res. 71, No. 6, 1611-1636.

Gregory, J. W., 1929, Anniversary address of the President: The geological history of the Atlantic Ocean. Quart. J. Geol. Soc. Lond. 85, 1xviii-cxxii.

Hamilton, E. L., 1959, Thickness and consolidation of deep-sea sediments. Bull. Geol. Soc. Amer. 70, 1399-1424.

Heezen, B. C., Tharp, M., and Ewing, M., 1959, The Floors of the Oceans: 1 . The North Atlantic. Geol. Soc. Amer. Spec. Paper 65.

Heirtzler, J. R., Le Pichon, X., and Baron, G., 1966, Magnetic anomalies over the Reykjanes Ridge. Deep-Sea Res. 13, 427-443.

Hill, M. N., 1957, Recent geophysical exploration of the ocean floor. Prog. in Phys. and Chem. of the Earth. 2, 129-163.

Hill, M. N. (Editor), 1963, The Sea, Interscience Publishers, New York, 3.

Hill, M. N. (Editor), 1966, A discussion concerning the floor of the Northwest Indian Ocean. Phil. Trans. A. Roy. Soc. Lond., 259, 133-298.

Hill, M. N., and Vine, F. J., 1965, A preliminary magnetic survey of the western approaches to the English Channel. Quart. J. Geol. Soc. Lond. 121, 463-475.

Laughton, A. S., 1960, An interplain deep-sea channel system. Deep-sea Res. 7, 76-88.

Matthews, D. H., 1961, Lavas from an abyssal hill on the floor of the North Atlantic Ocean. Nature, 190, No. 4771, 158-159.

Menard, H. W., 1964, Marine Geology of the Pacific. McGraw-Hill.

Pitman III, W. C., and Heirtzler, J. R., 1966, Magnetic anomalies over the Pacific-Antarctic Ridge. Science 154, 1164-1171.

Poldervaart, A. (Editor), 1955, The Crust of the Earth. Geol. Soc. Amer. Special Paper 62.

Sears, M. (Editor), 1961, Oceanography: invited lectures presented at the International Oceanographic Congress held in New York, 31st August-12th September, 1959. Amer. Assoc. Adv. Sci. No. 67.

Vine, F. J., and Matthews, D. H., 1963, Magnetic anomalies over oceanic ridges. Nature, 199, No. 4897, 947-949. 


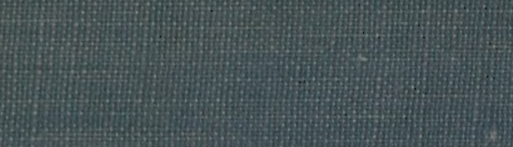

